\title{
USING BAYESIAN NETWORK TO DEVELOP DRILLING EXPERT SYSTEMS
}

\author{
A Dissertation \\ By \\ ABDULLAH SALEH H. ALYAMI \\ Submitted to the Office of Graduate Studies of \\ Texas A\&M University \\ in partial fulfillment of the requirements for the degree of \\ DOCTOR OF PHILOSOPHY
}

August 2012

Major Subject: Petroleum Engineering 


\section{USING BAYESIAN NETWORK TO DEVELOP DRILLING EXPERT SYSTEMS}

Copyright 2012 Abdullah Saleh H. Alyami 


\title{
USING BAYESIAN NETWORK TO DEVELOP DRILLING EXPERT SYSTEMS
}

\author{
A Dissertation \\ by \\ ABDULLAH SALEH H. ALYAMI
}

\author{
Submitted to the Office of Graduate Studies of \\ Texas A\&M University \\ in partial fulfillment of the requirements for the degree of \\ DOCTOR OF PHILOSOPHY
}

\begin{abstract}
Approved by:
Chair of Committee, Jerome J. Schubert

Committee Members, Hans C. Juvkam-Wold

Gene Beck

Yuefeng Sun

Head of Department, A. Daniel Hill
\end{abstract}

August 2012

Major Subject: Petroleum Engineering 


\author{
ABSTRACT \\ Using Bayesian Network to Develop Drilling Expert Systems. \\ (August 2012) \\ Abdullah Saleh H. Alyami, B.S., Florida Institute of Technology; M.S., King Fahd \\ University of Petroleum and Minerals \\ Chair of Advisory Committee: Dr. Jerome J. Schubert
}

Long years of experience in the field and sometimes in the lab are required to develop consultants. Texas A\&M University recently has established a new method to develop a drilling expert system that can be used as a training tool for young engineers or as a consultation system in various drilling engineering concepts such as drilling fluids, cementing, completion, well control, and underbalanced drilling practices.

This method is done by proposing a set of guidelines for the optimal drilling operations in different focus areas, by integrating current best practices through a decision-making system based on Artificial Bayesian Intelligence. Optimum practices collected from literature review and experts' opinions, are integrated into a Bayesian Network BN to simulate likely scenarios of its use that will honor efficient practices when dictated by varying certain parameters.

The advantage of the Artificial Bayesian Intelligence method is that it can be updated easily when dealing with different opinions. To the best of our knowledge, this study is the first to show a flexible systematic method to design drilling expert systems. 
We used these best practices to build decision trees that allow the user to take an elementary data set and end up with a decision that honors the best practices. 


\section{DEDICATION}

To my parents- thank you for your prayers, support and the values that you have taught me in my life.

To my wife and children- none of this would have been possible without your love and support. 


\section{ACKNOWLEDGEMENTS}

I would like to thank Dr. Jerome Schubert for serving as my advisor and a good friend. Your support and teaching has been invaluable during my studies at the Petroleum Department.

I would like to thank Dr. Hans Juvkam-Wold, Dr. Gene Beck and Dr. Yuefeng Sun for their encouragement and support in my PhD research.

I would like to thank Mr. Bill Rehm for many useful comments and discussion related to underbalance drilling operations.

Thanks also go to my friends and colleagues and the department faculty and staff

for making my time at Texas A\&M University a great experience. I also want to extend my gratitude to Saudi ARAMCO Company for sponsoring my PhD study at Texas A\&M University.

Finally, thanks to my mother and father for their prayers and to my wife and children for their patience and love. 


\section{NOMENCLATURE}

\begin{tabular}{ll} 
BHST & Bottom hole static temperature \\
BOP & Blow out preventer \\
BWOC & By weight of cement \\
Gps & Gallons per sack \\
Hp & Horse power \\
Ibpg & Bounds per gallon \\
PPA & Pound of proppant added per gallon of clean fluid \\
RIH & Run in hole \\
ROP & Rate of penetration \\
TD & Total depth \\
UB & Underbalanced \\
UBD & Underbalanced drilling \\
UBCT & Underbalanced coiled tube \\
UBCTD & Underbalanced coiled tube drilling \\
UBLD & Underbalanced liner drilling \\
\hline
\end{tabular}


TABLE OF CONTENTS

Page

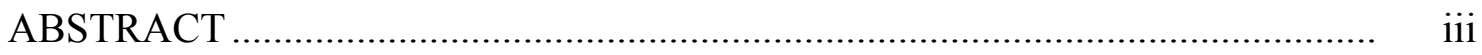

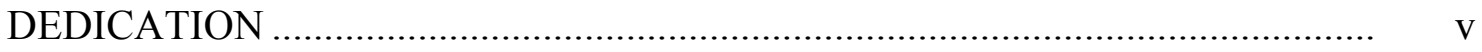

ACKNOWLEDGEMENTS ………............................................................. vi

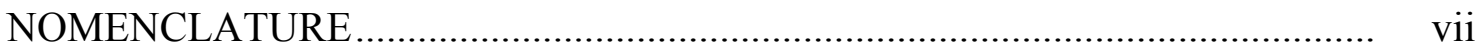

TABLE OF CONTENTS ……............................................................................ viii

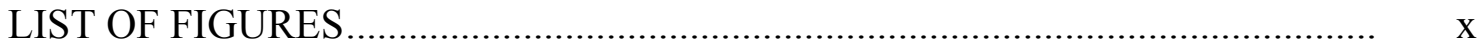

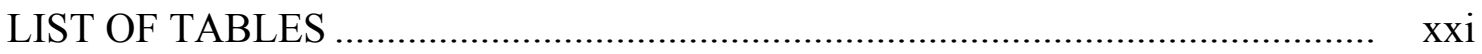

CHAPTER

I INTRODUCTION AND LITERATURE REVIEW ............................ 1

II MODEL FOR THE PROOF OF THE CONCEPT................................ 18

III WELL COMPLETION EXPERT SYSTEM........................................ 28

3.1 Junction classification decision ................................................. 29

3.2 Treatment fluid ............................................................... 32

3.3 Lateral completion.............................................................. 33

3.4 Perforating....................................................................... 34

3.5 Openhole gravel packing......................................................... 37

3.6 Packer selection.................................................................. 40

3.7 Final consequences................................................................ 42

3.8 Completion expert system utility node..................................... 42

IV DRILLING FLUIDS MODEL...........................................................

V WELL CONTROL MODEL .............................................................. 48

VI CEMENTING MODEL_............................................................. 59

VII UNDERBALANCED DRILLING MODELS....................................... 63 
7.1 General approach to underbalanced drilling model ................. 64

7.2 Flow underbalanced drilling model........................................... 69

7.3 Gaseated underbalanced drilling model .................................... 78

7.4 Foam underbalanced drilling model........................................ 81

7.5 Air and gas underbalanced drilling model .............................. 83

7.6 Mud cap model ................................................................... 87

7.7 Underbalanced liner drilling model......................................... 90

7.8 Underbalanced coil tube model................................................ 92

7.9 Snubbing and stripping model.................................................. 94

VIII RESULTS AND DISCUSSION.................................................... 98

8.1 Well completion model ........................................................ 99

8.2 Drilling fluids model ............................................................... 111

8.3 Well control model.............................................................. 124

8.4 Cementing model .............................................................. 138

8.5 Underbalanced drilling models ............................................. 149

8.5.1 General approach to underbalanced drilling model ........ 149

8.5.2 Flow underbalanced drilling model................................ 150

8.5.3 Gaseated underbalanced drilling model ......................... 155

8.5.4 Foam underbalanced drilling model............................... 160

8.5.5 Air and gas underbalanced drilling model .................... 162

8.5.6 Mud cap model ............................................................. 169

8.5.7 Underbalanced liner drilling model............................... 173

8.5.8 Underbalanced coil tube model...................................... 179

8.5.9 Snubbing and stripping model........................................ 181

IX CONCLUSIONS AND SUGGESTION FOR FUTURE WORK ....... 188

9.1 Suggestion for future work........................................................ 193

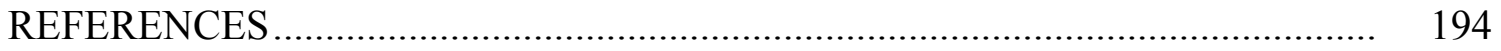

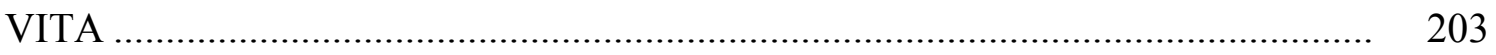




\section{LIST OF FIGURES}

FIGURE Page

1 An example of a bayesian network............................................... 8

2 A graphical design of bayesian network ......................................... 11

3 Assigning conditional probabilities distribution for each node ............... 12

$4 \quad$ An example of a decision tree ............................................................ 13

$5 \quad$ A simple problem example ............................................................ 14

$6 \quad$ BDN model for the proof of the concept........................................... 18

$7 \quad$ Model for the proof of concept (first approach)................................ 26

$8 \quad$ Model for the proof of concept (second approach) .............................. 26

$9 \quad$ Completion expert model .............................................................. $\quad 30$

10 Part of consequences for junction classification selection ..................... 32

11 Part of consequences for completion (treatment) fluid selection............. 33

12 Part of consequences for completion selection ................................ 34

13 Part of consequences for perforation selection.................................... 37

14 Part of consequences for openhole gravel pack selection ...................... 39

15 Part of consequences for packer selection........................................ 41

16 Part of consequences for the final consequences node........................... 42

17 Overall model of drilling fluids expert system................................... 44

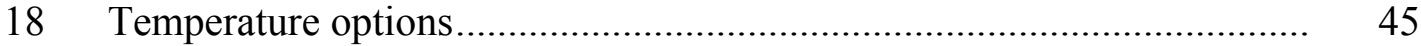

19 A list of possible potential hole problems ........................................... 46 
20 Formations' names in Saudi Arabia ................................................... 47

$21 \quad$ Well control expert model ................................................................ 49

22 Kick indicators …................................................................... 50

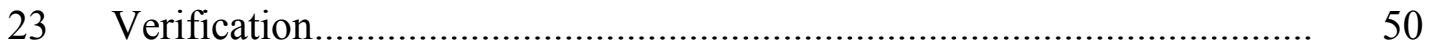

$24 \quad$ Possible kick details .................................................................. 51

$25 \quad$ Proposed circulation method .......................................................... 51

26 Part of consequences for optimum method of circulation method........... 52

27 Possible scenarios in well control .................................................... 53

$28 \quad$ Part of possible operations …............................................................. 53

29 A list of recommended practices ....................................................... 54

30 Part of consequences of proper well control practices .......................... 54

31 Check list for possible trouble shooting .......................................... 55

32 A list of possible actions and results .............................................. 56

33 A list of possible problems ............................................................... 57

$34 \quad$ Part of possible solutions................................................................. 57

35 Part of consequences of trouble shooting ........................................... 58

36 Final consequences.................................................................... 58

37 Cementing expert model based on bayesian network ............................ 62

38 General approach to underbalanced drilling ...................................... 65

39 Formations indicators list that need to be considered ........................... 65

40 A list of considerations for the different formations indicators available......................................................................... 66

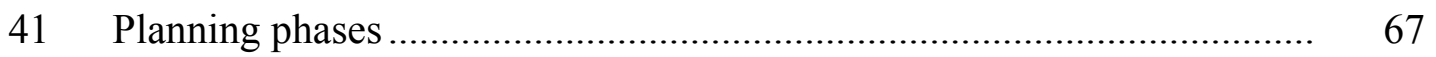


42 Planning phases recommendations.................................................... 67

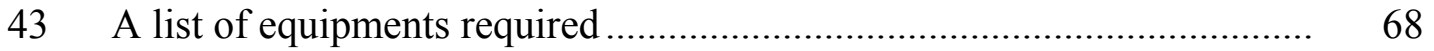

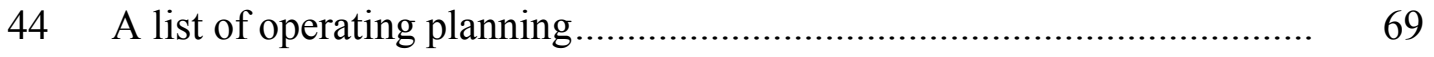

45 Overall model of flow UBD ........................................................ $\quad 70$

46 Tripping options in flow UBD .................................................. 71

47 Permeability level options in flow UBD ........................................ 71

$48 \quad$ A list of tripping recommendations..................................................... 72

49 Connection options................................................................... 73

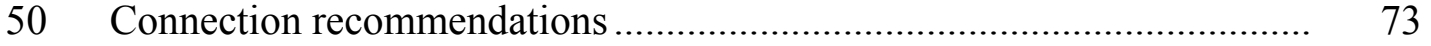

51 Flow drilling options ...................................................................

52 The user selects RIH option ........................................................... 74

53 The user selects high permeability option ....................................... 75

54 Tripping recommendation for low permeability formation during RIH operation ................................................................... $\quad 75$

55 The user selects on connection option............................................. 76

56 Connection recommendation.......................................................... 76

57 The user selects flow drilling takes place in formation with gas or fluid returns ................................................................................ $\quad 77$

58 The recommended flow drilling with formation gas or fluid returns........ 77

59 Overall model for gaseated UBD ...................................................... $\quad 78$

$60 \quad$ A list of gaseated methods ............................................................. 79

61 Possible general limits of gas and fluid volume................................... 79

62 Possible operational concerns and challenges................................... 80 
63 Possible kick types ......................................................................... 80

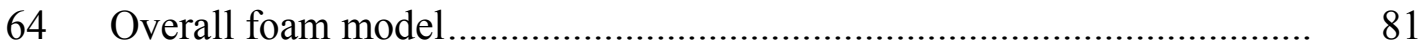

65 Possible challenges and technical limits of foam UBD ............................ 82

66 A list of basic designing steps in foam UBD .......................................... 82

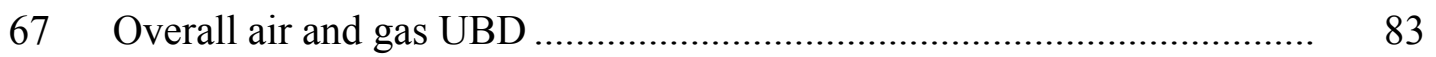

68 Rotary and hammer drilling options...................................................... 84

69 A list of limits and challenges for air and gas UBD................................. 85

$70 \quad$ A list of possible gas drilling operations ................................................. 86

71 A list of possible rig equipment for gas drilling....................................... 87

$72 \quad$ Mud cap overall model.................................................................... 88

73 A list of background mud cap drilling ..................................................... 88

$74 \quad$ A list of mud cap drilling problems ......................................................... 89

$75 \quad$ Floating mud cap drilling options …………………………………….... 89

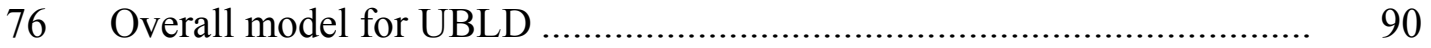

$77 \quad$ A list of problems that can be solved by UBLD ....................................... 91

$78 \quad$ Limits and challenges with UBLD ........................................................ 91

79 Basic planning for UBLD options.......................................................... 92

$80 \quad$ Overall model for UBCT .................................................................. 92

81 A list of pre-planning possibilities......................................................... 93

82 A list drilling challenges with UBCTD ..................................................... 94

83 Overall model for snubbing and stripping............................................... 95

$84 \quad$ A list of basic snubbing options........................................................... 96 
85 A list of snubbing unit................................................................ 96

$86 \quad$ A list of possible stripping procedure ................................................... 97

$87 \quad$ A list of possible snubbing operations ............................................. 97

88 Selection of considerations of designing a multilateral junction ............. 100

89 Selection of considerations of type of drilling fluid............................. 101

$90 \quad$ Selection of well type .................................................................... 102

91 Selection of completion fluids............................................................ 103

92 Selection of oil and gas characteristics............................................ 104

93 Selection of wellbore fluids........................................................... 105

94 Optimum selection of junction classification...................................... 105

95 Optimum selection of completion (treatment) fluid............................ 106

96 Optimum selection of completion selection..................................... 106

97 Optimum selection of perforation selection........................................ 106

98 Optimum selection of openhole gravel packs details........................... 107

99 Optimum selection of packers.................................................... 107

100 Optimum selection of completion (openhole gravel pack) selection for different conditions........................................................... 107

101 Selection of fluid loss formation ........................................................ 108

102 Selection of required slurry density from designing details....

103 Part of consequences of openhole gravel packs showing optimum slurry density

104 Selecting formation damage as a potential hole problem (example 1) ..... 112

105 Selecting temperature range (example 1)......................................... 112 
106 Some possible drilling fluids recommendation

for the conditions user selected (example 1)

107 More some possible drilling fluids recommendation

for the conditions user selected (example 1)

108 Selecting temperature range (example 2)

114

109 Selecting loss of circulation and water flows

as a potential hole problem (example 2)

110 Formulation 7 is an example of a drilling fluid that will work in the selected conditions (example 2).

111 Selecting temperature range (example 3)

112 Selecting loss of circulation and water flows as a potential hole problem (example 3 )

113 Formulation 24 is an example of a drilling fluid that will work in the selected work in the selected in the selected conditions (example 3 )

114 Formulation 47 is another example of a drilling fluid that will work in the selected conditions (example 3)

115 Selecting temperature range (example 4)

116 Selecting Saudi Arabia formation (example 4) .....

117 Showing resultant potential hole problems in Arab D formation as selected before (example 4)

118 Drilling fluid 23 is the optimum fluid in this case (example 4)

119 Selecting temperature range (example 5)

120 Selecting Saudi Arabia formation (example 5).

121 Showing resultant potential hole problems in Wasia and Shuaiba formations as selected (example 5)

122 Showing some recommended drilling fluids for the above conditions (example 5) 
123 Showing some recommended drilling fluids for the above conditions (example 5)

124 Selecting temperature range (example 6)

125 Selecting potential hole problem (example 6)

126 Showing the recommended drilling fluids for the above conditions (example 6)

127 Kick indicator example

128 Verification of the kick

125

129 The kick is from a horizontal or deviated well

130 The recommended circulation method of driller method

131 The user is controlling the well using driller method.....

132 The user is entering his pipe, casing and pump operational conditions....

133 The optimum practice of proper well control is shown.

134 The user shows his problem by selecting drill pipe and casing pressure response

135 Possible probabilities due to the selection from the check list for trouble shooting node are shown

136 The user then selects an action and its corresponding result in an attempt to identify the problem

137 The problem is identified

138 A recommendation is given to solve this problem

139 The user is controlling the well without any prerecorded data

140 The user is entering his observations

141 The recommended proper well control practice is shown.

142 The user is controlling the well and he has pump 
troubles during a kick

143 The user is entering his observations during

the pump trouble

144 The recommended proper well control practice is shown for the conditions for the pump trouble during a kick

145 The user is facing a kick in deep water

146 The user is entering his observations for the deep water kick

147 The recommendation for the kick in deep water.

148 Selection of well type

149 Selection of bottom hole static temperature

150 Selection of well objective

151 Selection of drilling fluid

152 The cementing expert system recommends formulation 13, operational note 5 and spacer 2 to be used in this application

153 The model showing more details for this application (Example 1)

154 The model showing more details for this application (Example 2) ..........

155 The user selects that he has naturally fractured and vugular formation

156 The consideration decision

157 The user selects RIH option

158 The user selects high permeability option

159 Tripping recommendation for low permeability formation during RIH operations

160 The user selects on connection option.

161 Connection recommendation 
162 The user selects flow drilling takes place in formation with gas or fluid returns

163 The recommended flow drilling with formation gas or fluid returns.

164 The user selects gaseated UBD method (dual casing string)

165 The recommendation for dual casing string is shown.

166 The user selects general limit of gas and fluid volume (back pressure)

167 Back pressure recommendation

168 The user selects operational concern (pressure surges).

169 Pressure surges recommendation

170 Selecting kick type (gas flow)

171 Recommendation for kick type (gas flow)

172 The user selects hot holes as a challenge

173 Hot holes recommendation.

174 Selecting basic designing in making a connection in foam UBD

175 Recommendation for making a connection in foam UBD.

176 Selecting horizontal drilling with air hammers.

177 Recommendation for horizontal drilling with air hammers

178 Selection of water or wet holes as a challenge

179 Water or wet holes recommendation................................................... 165

180 Selection of mist pumps ................................................................ 166

181 Recommendation for mist pump ................................................... 167

182 Selection of gas drilling operations

(well kicks detection and solution). 
183 Well kicks detection and solution recommendation

184 Selecting trips with pressurized mud caps

185 Recommendation for trips with pressurized mud caps

186 Selection of drilling ahead with mud losses.

187 Recommendation for drilling ahead with mud losses.....

188 Selection of water sensitive formation exposed while floating mud cap drilling depleted reservoirs

189 Recommendation for water sensitive formation exposed while floating mud cap drilling depleted reservoirs

190 Selection of basic planning of the bit

191 Recommendation for the bit used in UBLD

192 Selection of the potential problem (hole ballooning)

193 Showing how UBLD can solve the potential problem (hole ballooning)

194 Selecting liner hanger as a challenge for UBLD.

195 Recommendation for the liner hanger in UBLD....

196 Selecting drilling fluids as a challenge for UBLD

197 Recommendation for drilling fluids in UBLD ...

198 Selecting pre-planning option of BOP stack requirement.....

199 Recommendation of pre-planning option of BOP stack requirement.

201 Recommendation for ROP reduction challenge in UBCTD

202 Selecting stripping with annular preventer or stripping rubber

182

203 Recommendation for stripping with annular preventer or stripping 


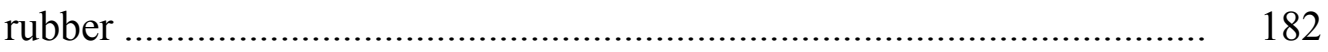

204 Selection of auxiliary equipment from snubbing unit options ................... 183

205 Recommendation for auxiliary equipment from snubbing

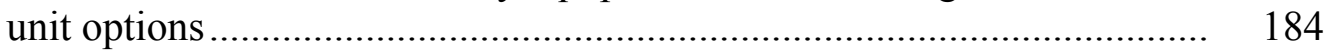

206 Selection of ram to ram stripping procedure ……………………............ 185

207 Recommendation for ram to ram stripping procedure ……...................... 186

208 Selection of a snubbing operation (temporary securing of the well) ........ 187

209 Recommendation for a snubbing operation (temporary securing of the well). 


\section{LIST OF TABLES}

TABLE

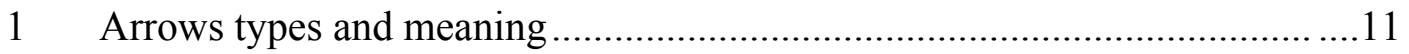

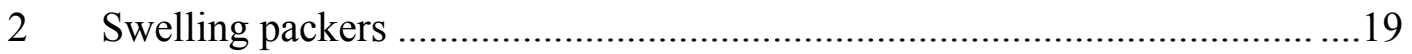

3 Probability states of treating fluids based on swelling packers....................20

$4 \quad$ Probability states of type of drilling fluids based on swelling packers

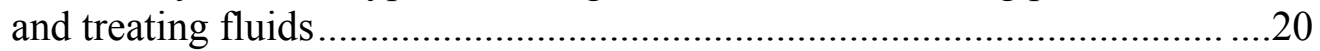

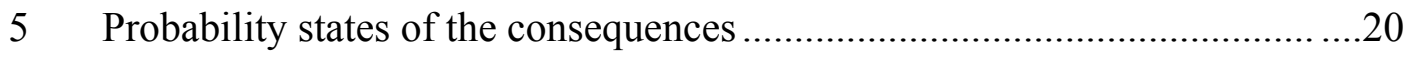

$6 \quad$ Input utility values associated with the consequences .............................20

$7 \quad$ Total probability for type of drilling fluid............................................. 21

8 Using bayesian equation for the proposed model.........................23

9 Consequences when selecting $\mathrm{CaCO}_{3}$ drilling fluid (from table 7) and table 4 ................................................................. 24

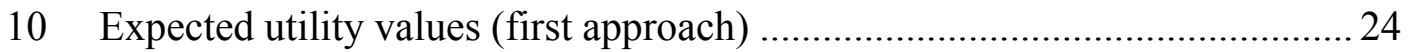

11 Consequences when selecting formate drilling fluid and lactic acid (from table 5)

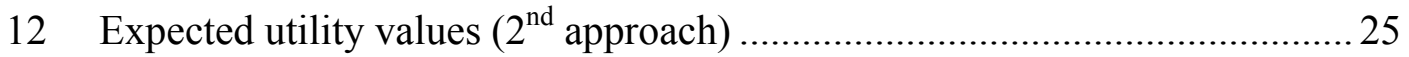

13 Probability states of considerations in designing multilateral junctions' node.

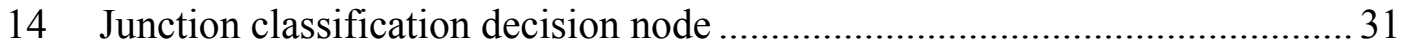

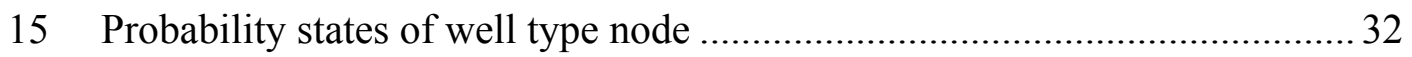

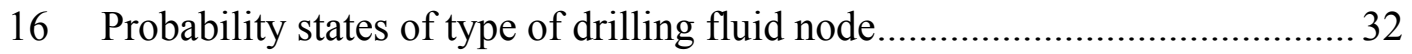

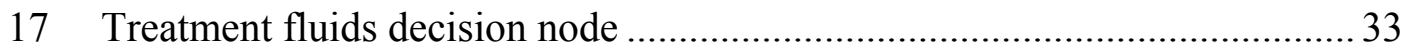

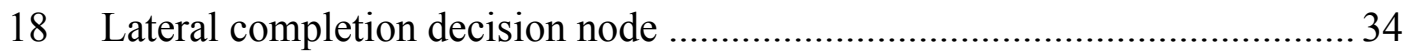




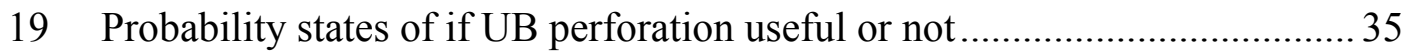

20 Probability states of fluid damage and temperature effect ...........................35

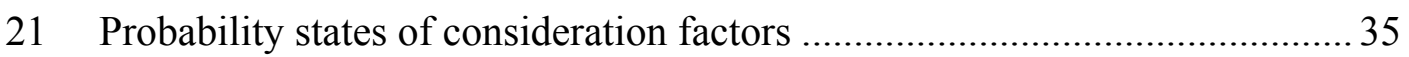

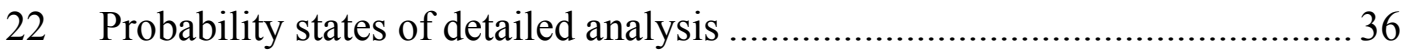

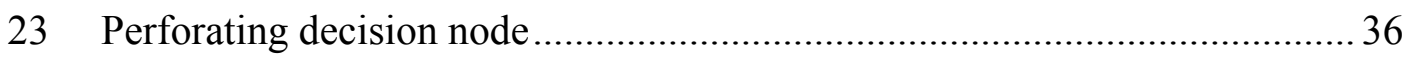

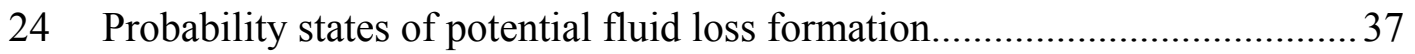

25 Probability states of type of openhole gravel packing .................................38

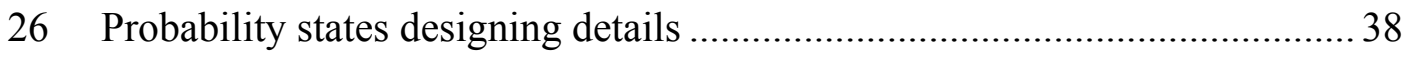

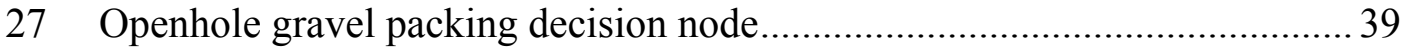

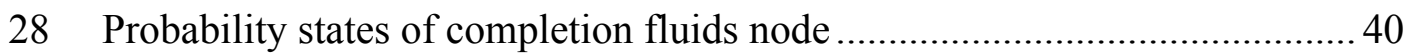

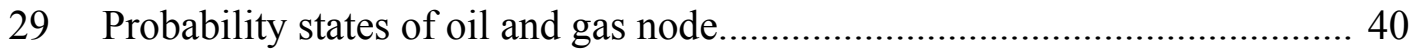

30 Probability states of wellbore fluids node ............................................. 41

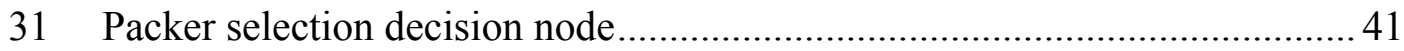

32 Expected utility values for the final consequences node............................ 42 
CHAPTER I

INTRODUCTION AND

LITERATURE REVIEW

Expert systems are knowledge processing which enable computers to do certain tasks similar to humans or some times better than human experts. The real motive of such type of research is the shortage of expertise, Hayes-Roth (1987).

Expert system can be defined as "An interactive computer-based decision tool that simulates the thought process of a human expert to solve complex problems in a specific domain." We need experts system because of limitations in expertise, working memory, insufficient maintenance of significant data and biased opinions, (Pandey and Osisanya 2001).

The design of drilling expert systems depends mainly on previous experience and knowledge to successfully complete with a degree of confidence. Effective communication is also an important factor for successful operations. Good coordination is required between the engineer, the service company and the rig foreman. Knowledge transfer in drilling operations is therefore fundamental for the optimal design of the job, Shadravan et al. (2010). Literature review, drilling programs and experts' opinions were used to build up the expert systems in this research in drilling fluids, underbalanced drilling, cementing, well completion and well control, after Al-Yami et al. (2012b).

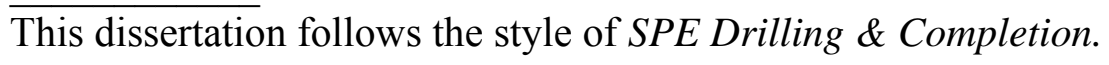


(McCaskill \& Bradford 1997) mentioned the factors that we need to consider when designing drill-in fluids. For example, formation permeability determines filtration characteristics. Temperature or water sensitive formation determines the type of polymer and type of drill-in fluids needed. The authors also suggested that there are goals in designing drill-in fluids that we need to consider such as rheological properties to provide good carrying capacity and minimum filtration control loss.

Samuel et al. (2003) explained polymers function in providing filtration and viscosity to drill-in fluids are affected at high temperature because of the degradation of polymers or reduced molecular interactions. An expert system was developed to control solids in drilling fluids using flow charts, (Pandey and Osisanya 2004).

An underbalanced drilling expert system based on fuzzy logic was developed to perform screening decisions. These decisions include whether to use underbalanced drilling or not. A list of underbalanced drilling was also included such as liquid drilling, dry air drilling, and mist drilling, (Garrouch and Haitham 2003). However, no detailed expert system for underbalanced drilling was developed to aid engineers and scientists in selecting optimum detailed practices.

Typically, designing cement slurries depend on setting rules of thumbs and years of experience. A service company has developed a detailed cementing expert system utilizing service company chemicals such as fluid loss additives, retarders and accelerators. Expert's opinions were used to build this expert system, Kulakofsky et al. (1993). However updating this expert system or using it by another service companies will require reprogramming the whole software. 
Different types of cements are used in drilling and completion operations to:

- Isolate zones by preventing fluids immigration between formations

- Support and bond casings

- Protect casing from corrosive environments

- Seal and hold back formation pressures

- Protect casing from drilling operations such as shock loads

- Seal loss circulation zones

Cement costs can be minimized by eliminating expensive and unnecessary additives required in certain operations. From common practice it is known that cementing slurries should be tested in advance, since each particular well has distinctive characteristics. Therefore, it is not possible to define a general guideline for all situations for the concentration of additives required for the cementing job (Sauer and Landrun, 1985).

Effective communication is also an important factor for successful cementing jobs. Good coordination is required between the drilling engineer, the service company and the rig foreman. Applying quality control is critical for avoiding cement-related failures in the field. Knowledge transfer in cementing operations is therefore fundamental for the optimal design of the cementing job, Smith (1984).

Multilateral completion expert system based on Fuzzy logic was developed. The expert system included a screening process for planning multilateral well candidates, lateral completion and junction level. Flow charts were linked to a computer program, Garrouch et al. (2004). 
The purpose of development of well control procedure is to prevent catastrophes that could result from blowouts. The development of up to date source of proper well control practices is a challenging task. Using current methods of flow charts in decision making does not allow enough room for different or changing well control practices to be included, Al-Yami et al. (2012c).

There are different methods that companies have approached to make guidelines for their engineers to save on operations cost and time. However, these methods cannot be used by other companies or experts with different opinions or with different field conditions Al-Yami et al. (2012a).

Texas A\&M University recently has established a new method to develop a drilling expert system that can be used as a training tool for young engineers or as a consultation system in various drilling engineering concepts such as drilling fluids, cementing, completion, well control, and underbalanced drilling practices.

This method is done by proposing a set of guidelines for the optimal drilling operations in different focus areas, by integrating current best practices through a decision-making system based on Artificial Bayesian Intelligence. Optimum practices collected from literature review and experts' opinions, are integrated into a Bayesian Network BN to simulate likely scenarios of its use that will honor efficient practices when dictated by varying certain parameters.

The term Bayesian derives from Thomas Bayes (1702-1761), who was a British mathematician Bayes introduced Bayes' theorem, which was used in this research. Differences between Frequents statistics and Bayesian statistics are: 
- Frequents statistics: The uncertainty here is investigated by finding out how estimates change in repeated sampling from the same population.

- Bayesian statistics: Uncertainty is investigated by finding out how much prior opinion about parameter values change in light of the observed data.

To a Bayesian, only observed data sets are relevant in making inferences. In contrast, in the frequents way, data that might be observed but are not are considered in determining uncertainty, Gelman et al. (2003).

The advantage of the artificial Bayesian intelligence method is that it can be updated easily when dealing with different opinions. To the best of our knowledge, this study is the first to show a flexible systematic method to design drilling expert systems.

Best practices were gathered to build decision trees that allow the user to take an elementary data set and end up with a decision that honors the best practices.

The Bayesian paradigm can be defined as:

$p($ hypothesis $\mid$ evidence $)=\left(\frac{p(\text { evidence } \mid \text { hypothesis })}{p(\text { hypothesis })}\right)$

Representing the probability of a hypothesis conditioned upon the availability of evidence to confirm it. This means that it is required to combine the degree to plausibility of the evidence given the hypothesis or likelihood p(evidence|hypothesis), and the degree of certainty of the hypothesis or $\mathrm{p}$ (hypothesis) called prior. The intersection between these two probabilities is then normalized by $\mathrm{p}$ (evidence) so the conditional probabilities of all hypotheses can sum up to 1 . 
This work introduces the use of Bayesian Networks as a way to provide reasoning under uncertainty, using nodes representing variables either discrete or continuous. Arcs are used to show the influences among the variables (nodes). Thus, Bayesian Networks can be used to predict the effect of interventions, immediate changes, and to update inferences according to new evidences.

Bayesian Networks are known as directed acyclic graphs because generating cycles are not allowed. The terminology for describing a Bayesian Network follows a hierarchical parenting scheme. A node is named a parent of another node named child if we have an arc from the former to the later. The arcs will represent direct dependencies. Evidence can be introduced to the Bayesian Network at any node, which is also known as probability propagation or belief updating. It is important to define the conditional probability distributions to each node (Korb and Nicholson, 2004).

Bayesian Network was used to evaluate several parameters to enhance well quality in deepwater environment such as caliper desirability, trajectory, skin factor and average drilling speed. Sorted well data from a global drilling database and drilling experience were gathered to develop a set of well quality metrics to evaluate the performance of drilling and completion in a certain field. A software tool was developed that can perform the following:

- Evaluate well quality expected by using information related to caliper, skin factor, trajectory, ROP, and lost rig time,

- Estimate risk and cost related to designing complex trajectory wells,

- Recognize attributes that affect quality of the well. 
The software included probabilistic networks and was used to gather expert knowledge and data to forecast well quality. The software used networks that can update prior knowledge in the light of new data which cannot be done by conventional risk assessments. In addition, these networks can be used in case of incomplete data, Kravis et al. (2002).

Once the Bayesian Network is defined and the states of nodes have been determined, probability tables with each node (parent or child) must be specified. Next joint distribution is calculated.

Bayesian Networks models have been constructed for Greater Bangkok North to detect probable water production. Bayesian probability theory allowed to model uncertainty by using common-sense knowledge and observational evidence. A Bayesian Network has the following:

- A set of variables (uncertainties),

- Graphical design connecting these variables, and

- Conditional distributions to define the relationship between the variable values.

An example of a Bayesian Network is shown in Fig.1. 


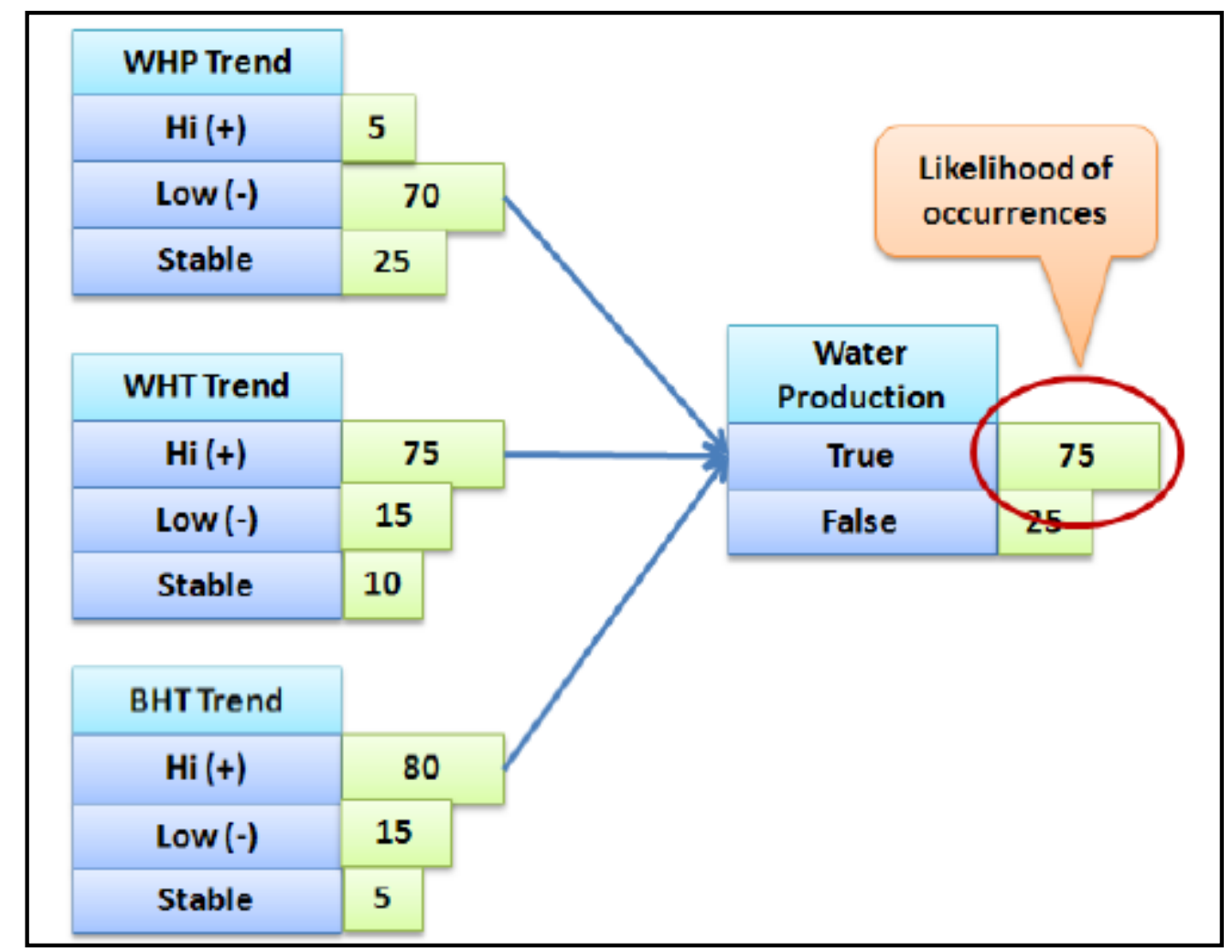

Fig.1: An example of a bayesian network

To design a Bayesian Network the following guidelines should be observed:

- All variables that are important in the modeling should be included,

- Causal knowledge should be used to link between the variables to lead to "causes" to "effects,

- Prior knowledge should be used to specify the conditional distributions (elicitation).

Decision variables were assigned and defined by the decision maker opinions. The objective of this work was to choose an optimize decision that was quantified by a 
utility node. Utility nodes represent the variables that contain information and show the decision maker goals and objectives, Ronald et al. (2011).

Generalized statistical methods or numerical simulation were used to evaluate the performance for infill wells. The generalized statistical methods are quick but lack in accuracy. The numerical simulation is accurate but requires complex steps and computations. The objective of this paper was to select the optimum infill locations using an integrated data mining charts by looking into past production performance and trying to predict future performance of current wells, Al-Kinani et al. (2009).

A Bayesian Network is a probabilistic model that shows a set of variables and their probabilistic interdependencies. These interdependencies or evidence can be entered by an expert as used in expert or trouble shooting system or can be a learning algorithm that can quantify the interdependencies from a training data set. Experts can reproduce their reasoning in Bayesian Network under different aspects of their decisions such as economic, logistic and reservoir considerations. A score between 0 and 100 can describe the outcome. A value of 100 means the best producer well and 0 means the worse, Al-Kinani et al. (2009).

The Bayesian Network uses both causal and probabilistic semantics which makes it suitable for gathering prior knowledge and data. Bayesian Network has one technical limitation which is filling long tables with hand. Bayesian model was used in Heidrun field in the Norwegian Sea. The objective was to utilize all information provided by the experts and combine it with spatial distance between the well to build up the Bayesian Network, (Rasheva and Bratvold 2011). 
One of the main challenges with the Bayesian Network approach is the assigning of evidences. The following are some proposed methods that were used in this paper:

- Obtaining Geologist opinions about the reservoirs and spatial distances between wells,

- Using knowledge of local geology to obtain strongest correlations between wells,

- Building Bayesian Network.

Bayesian Network is practical and flexible approach to evaluate prospect dependencies to find optimal method that exploits the information provided by early drilling wells, (Rasheva and Bratvold 2011).

Expert opinions and real-time data were used to construct Bayesian Network for optimal placement of horizontal wells. The well placement decision making process requires opinions from different backgrounds. Bayesian Network was used to design, evaluate and support real time drilling processes. The graphical design shows joint probability distribution in decisions, uncertainties, and values. A decision node is shown as rectangle and a chance node as oval. The value node is shown as hexagons as shown in Fig.2, (Rasheva and Bratvold 2011). 


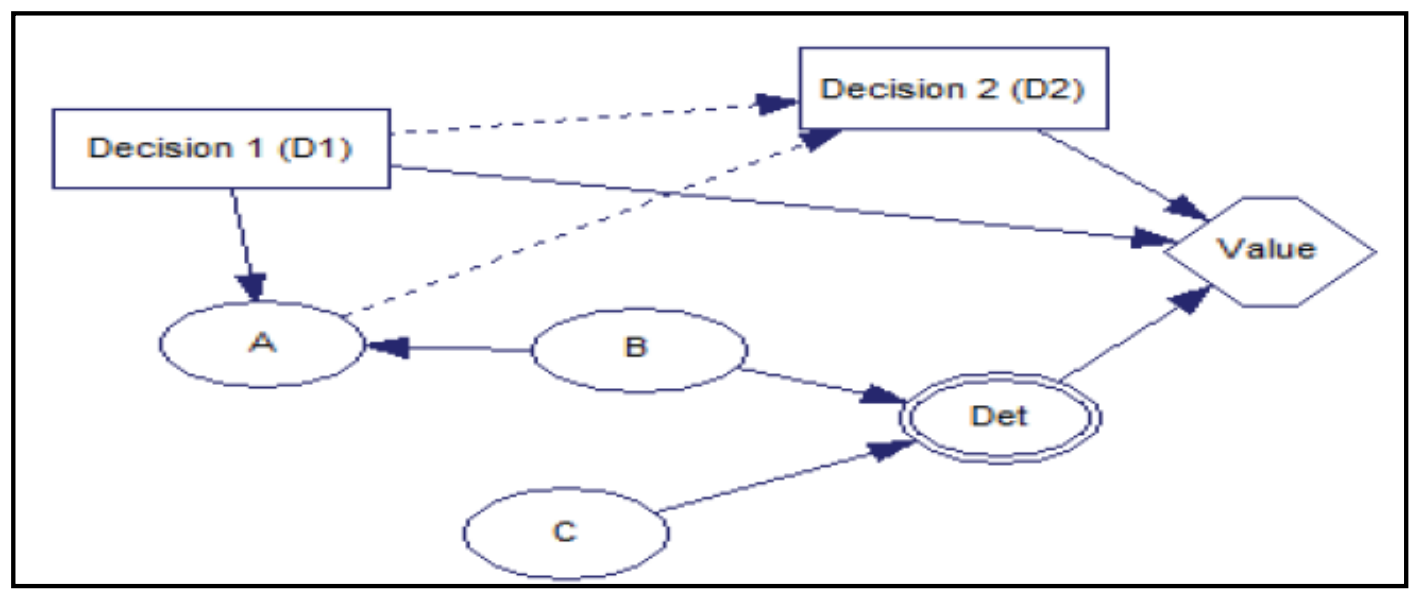

Fig.2: A graphical design of bayesian network

The arrow types and measuring depend on the node information as shown in the

Table 1, (Rasheva and Bratvold 2011).

Table 1: Arrows types and meaning

\begin{tabular}{|c|c|c|c|}
\hline $\begin{array}{c}\text { Arrow } \\
\text { Information }\end{array}$ & Parent Node & Child Node & Arrow Meaning \\
\hline Information & Decision & Decision & \multirow{2}{*}{$\begin{array}{c}\text { The outcome of the parent node is } \\
\text { known before the decision is } \\
\text { made }\end{array}$} \\
\hline Information & Chance & Decision & \\
\hline Influence & Decision & Chance & \multirow{2}{*}{$\begin{array}{l}\text { The probability distribution of the } \\
\text { child node depends on its parent's } \\
\text { outcome }\end{array}$} \\
\hline Relevance & Chance & Chance & \\
\hline Function & $\begin{array}{l}\text { Decision or } \\
\text { chance }\end{array}$ & Deterministic & \multirow{2}{*}{$\begin{array}{l}\text { The child's value is a function of } \\
\text { the parent node }\end{array}$} \\
\hline Function & $\begin{array}{l}\text { Chance, } \\
\text { deterministic, } \\
\text { or decision }\end{array}$ & Value & \\
\hline
\end{tabular}


Bayesian Network was used to aid in setting casing depth in North Sea. Probabilities can be extracted from data or simulation outputs or be elicited (from subject experts). Elicited probabilities should have reflective accuracy. The derived distribution should represent expert's knowledge. For the probability distributions of the nodes, first the unconditional marginal probability distribution of root nodes (without parents) is assigned by the experts. After that, the conditional probability distribution for each node is assigned. These assigned values can be continuous or discrete, Fig.3, (Rajaieyamchee and Bratvold 2009).

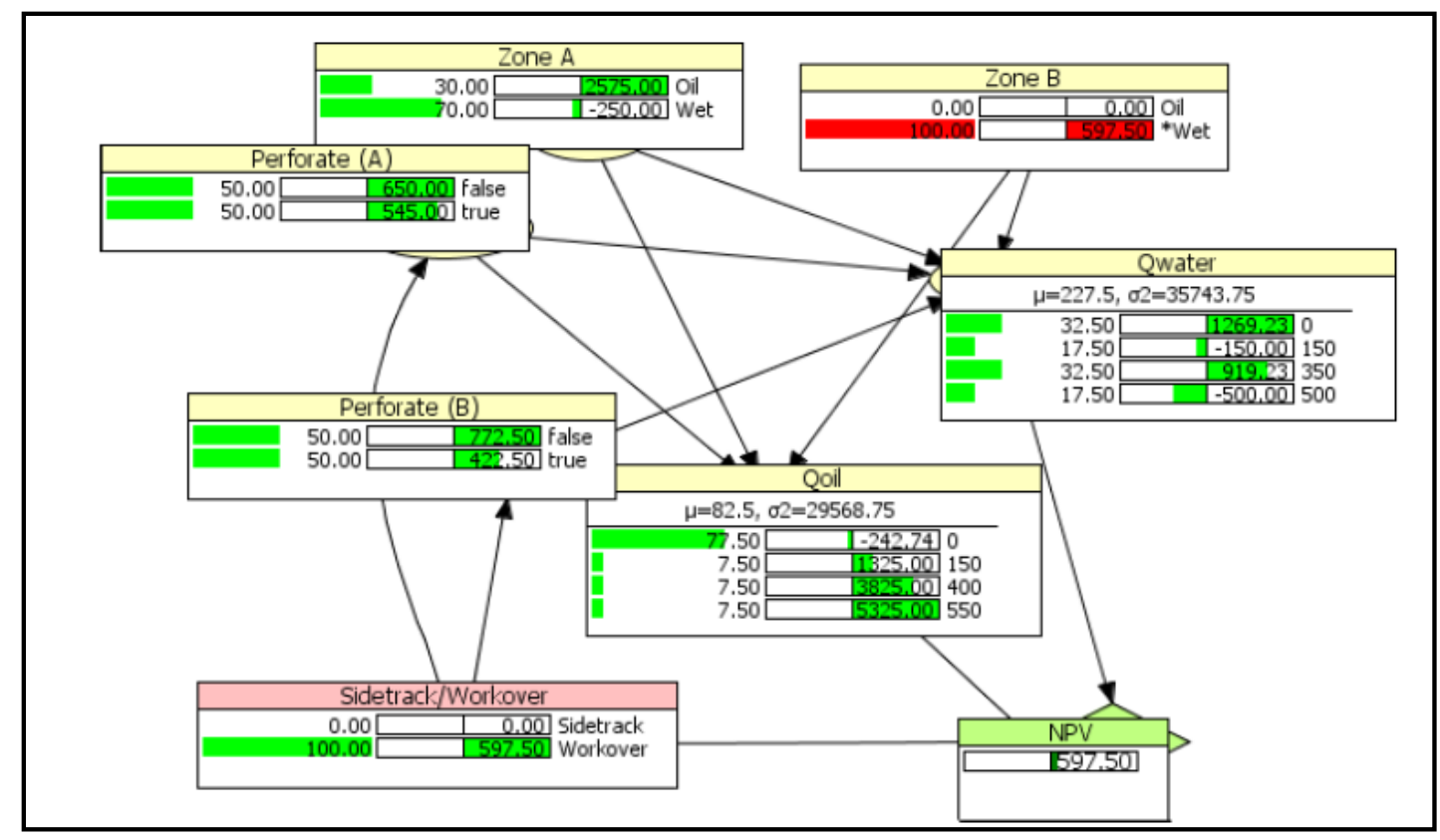

Fig.3: Assigning conditional probabilities distribution for each node 
Decision trees are graphical structures that show the order of variables in decision problems. Influence diagrams are developed to automate decision trees. The decision tree can grow exponentially with more variables in the decision. This can make the decision tree too big to track. In addition, conditional probabilistic independences cannot be conveyed in decision trees (Fig.4), (Rajaieyamchee and Bratvold 2009).

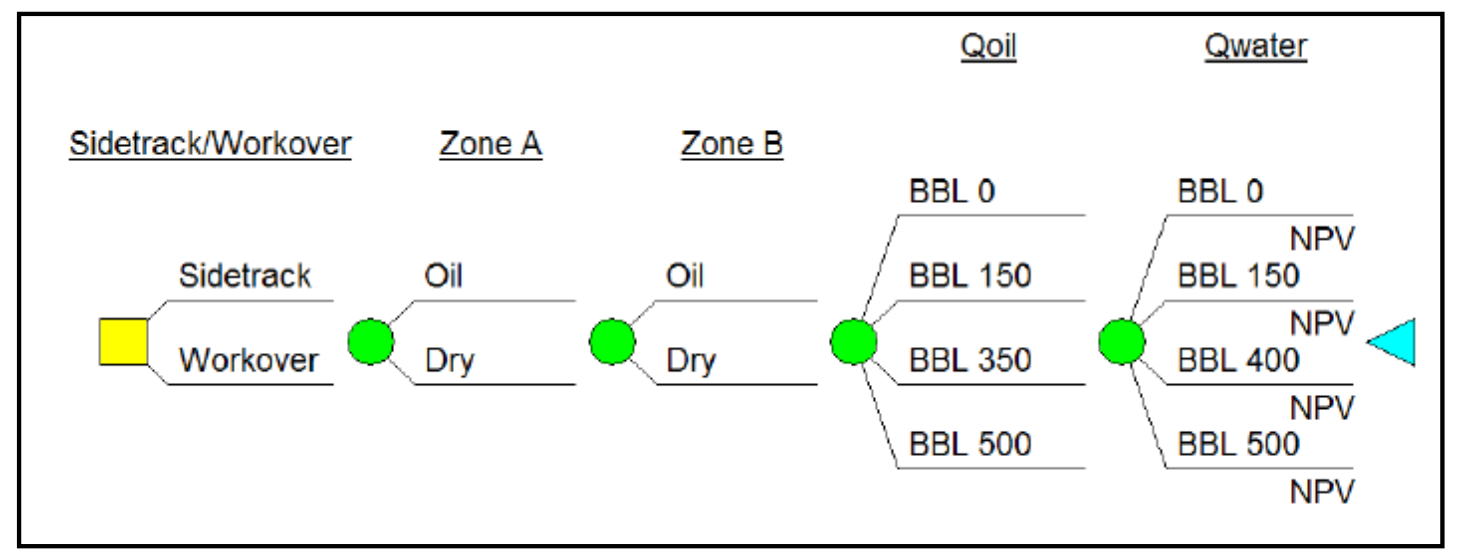

Fig.4: An example of a decision tree

Bayesian Network was used to aid drilling engineers to decide whether to circulate, increase mud weight, set a casing, plug back, etc. while drilling near high pressure formation and when gas influx is observed, (Giese and Bratvold 2010).

Decision trees are used widely in the petroleum industry. The decision trees will provide graphical illustration of uncertainties and decisions. For simple decision problems, decision trees can be intuitive. However, for complex decisions, decision trees grow exponentially with the increase in number of variables involved which make their 
use impractical. Bayesian Network can be used when dealing with complex decision problems easily compared to decision trees, (Giese and Bratvold 2010).

Wright $(1921,1934)$ and Good $(1961 \mathrm{a}, \mathrm{b})$ used graphical structure for illustrating joint probability distributions. (Howard and Matheson 1981) explained this illustration in more details. (Kim and Pearl 1983), (Lauritzen and Spiegelthaler 1988) and Pearl (1988) have introduced computer science and statistics into the graphical representation of joint probability distributions.

A simple problem example is shown in Fig.5. The following observation can explain the model, (Giese and Bratvold 2010):

- There is pore pressure that depends on depth and well geology,

- Measurement of depth is shown in the model,

- Equivalent circulating density (ECD) downhole is also shown and can be estimated using flow and mud weight,

- Gas will flow into the wellbore if the pore pressure is greater than ECD.

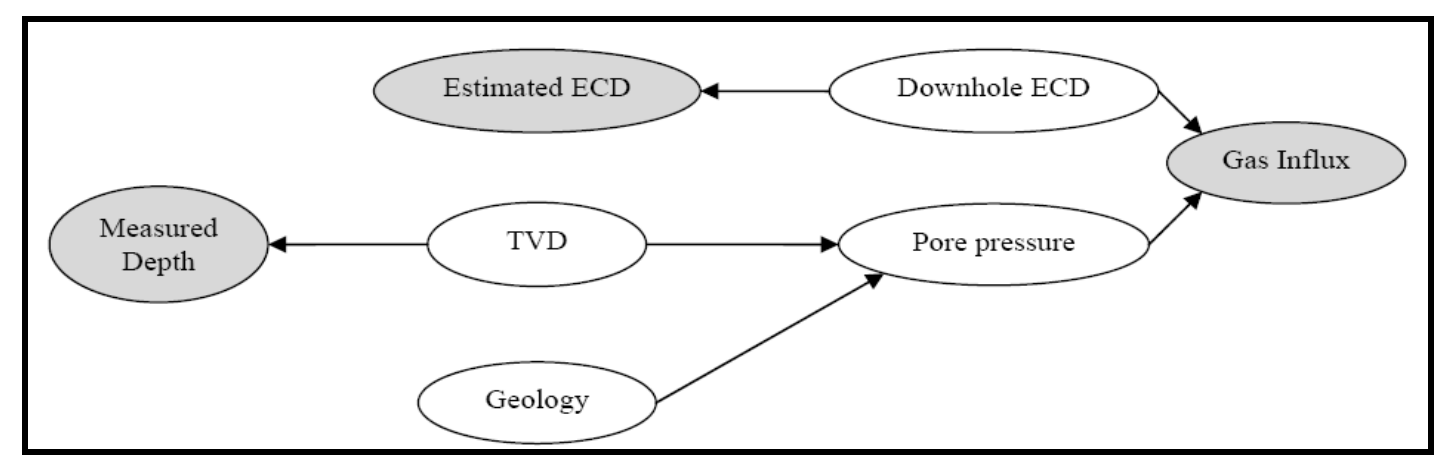

Fig.5: A simple problem example 
Expert system based on Bayesian Network was used for selection of proper EOR techniques. The expert system was applied to 10 Iranian southwest reservoirs. $\mathrm{CO}_{2}$ flooding showed to be the most practical method for EOR in these 10 wells, Zerafat et al. (2011).

A Bayesian Network can behave similarly to human begins when dealing with uncertainties to predict the likelihood of future operations from given prior trials. Subjectivity is a limitation of Bayesian method when handling prior belief, Zerafat et al. (2011).

Bayesian Network was performed to assess the risk from nuclear waste disposal, Lee et al. (2005). Bayesian Network was also used to model flow to select the model with greatest uncertainty at the boundaries, Abbaspour et al. (2000). Hydrodynamic behavior characterization was also done by Bayesian Network, Ferraresi et al. (1996). Most probable areas of salinity sources distribution in the Gaza aquifer were done using Bayesian Network, Ghabayen et al. (2006).

Existing systems cannot deal with certain geotechnical risks for example excessive deformation or rock falls. The reason behind that is the need to capture expert knowledge. To achieve this, Bayesian Network was used to model these uncertainties. Using fault tree analysis for encoding uncertain expert knowledge can result in significant complications, (Sousa and Einstein 2007).

Bayesian Network was used for pipeline leak detection. Prior probabilities were integrated to detect leaks, Carpenter et al. (2003). Bayesian network was used to design models to support geosteering decisions. Using Bayesian Network can lead to reduction 
of required number of operators on rig sites. Previous systems were built using fuzzy logic and neural networks, Lloyed et al. (1990), Dashevski et al. (1999), and Stoner (2003). The limitations of these approaches are:

- The knowledge database and inference algorithms are inseparable. Thus adding new rules or changes require programming again. This makes updating the expert system difficult and challenging.

- The previous approaches are limited in their ability to make decisions under uncertainty.

Bayesian Network was used to analyze and support geosteering decisions. Drillers' opinions were considered under conditions of uncertainty. Drillers were also able to update the model with the arrival of new data, (Rajaieyamchee and Bratvold 2010).

Decisions must be made without elimination of uncertainty. The use of Bayesian Network supported the real time decision making. The reason behind this is the ability to update the probabilistic information embedded in the network with new data arrival, Fjellheim et al. (2011).

The objective of this research is to propose models to serve as training tools or a guide to aid drilling engineers and scientists in field operations in five areas:

1. Cementing Operations

2. Completion Operations

3. Drilling Fluids Operations

4. Underbalanced Drilling Operations 


\section{Well Control Operations}

In order to prove the concept and the benefits of using this approach, one simple BDN model simulating the decision-making process of the selection of swelling packer is introduced in Chapter II. 


\section{CHAPTER II}

\section{MODEL FOR THE PROOF OF THE CONCEPT*}

In order to prove the concept and the benefits of using this approach, one simple BDN model simulating the decision-making process of the selection of swelling packer is introduced in Fig.6. This model contains one decision node (swelling packer), three uncertainty nodes (treating fluid, type of drilling fluid, and Consequences), and one value node (Completion Expert System).

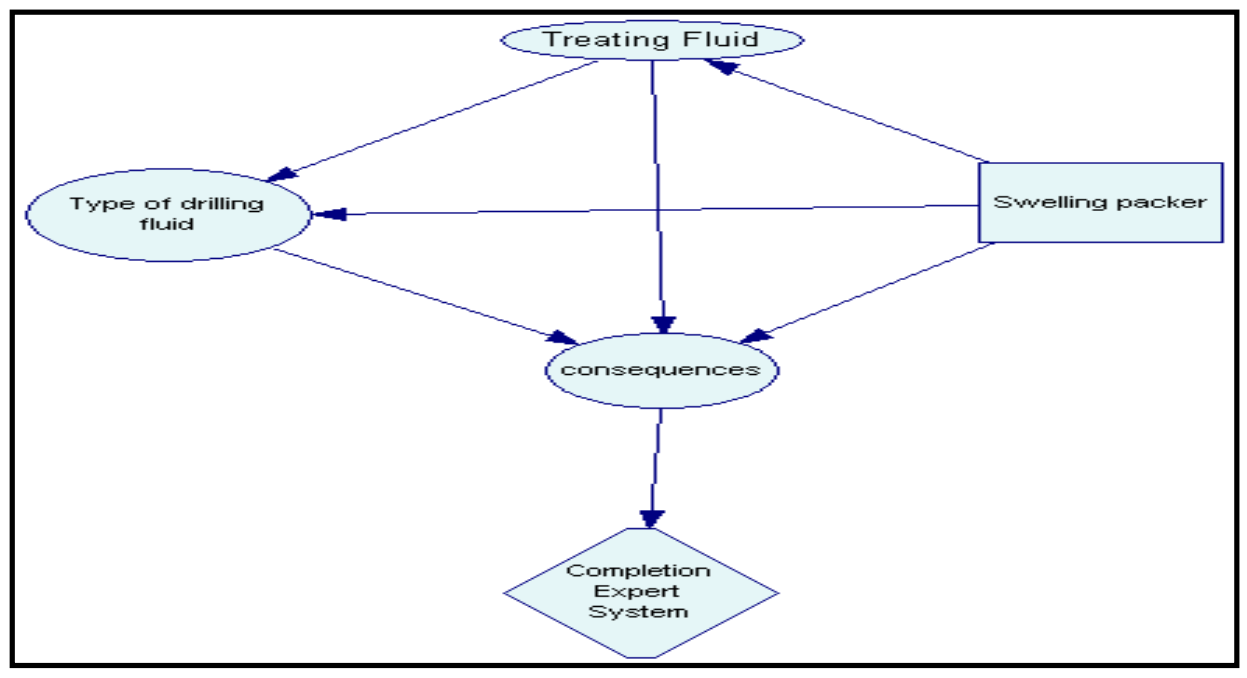

Fig.6: BDN model for the proof of the concept

*Reprinted with permission from "Expert System for the Optimal Design and Execution of Successful Completion Practices Using Artificial Bayesian Intelligence," by Al-Yami, A.S., Schubert, J., and Beck, G., 2011, SPE 143826, Copyright (C) 2012, Society of Petroleum Engineers. 
In this model, our selections for swelling packers are affected by our selection of treating fluid and drilling fluids. Once the structure of the BDN is defined, it is required to define the probability states associated with each node. These are given in Table 2 through Table 6. The model is designed in a way that the engineer will select his uncertainty nodes (treating fluid and/or type of drilling fluid) to select the recommended type of swelling packer (oil swelling or water swelling packer, Table 2). Table 3 shows the probability states of treating fluids based on swelling packers. Lactic acid has a probability of 0.9 for success when using water swelling packers but only 0.1 chance of success when using lactic acid. Table 4 shows the probability states of type of drilling fluids based on swelling packers and treating fluids. Table 5 defines the extent of the probability states of the consequences, which are defined as recommended and not recommended. The input utility value associated with the consequences is given in Table 6. The expected utility outcomes considering all possible cases of evidence set a minimum value of zero, which is the "not recommended" case, and a maximum value of one, which assumed to be the "recommended" case.

Table 2: Swelling packers

Water swelling packer

Oil swelling packer 
Table 3: Probability states of treating fluids based on swelling packers

\begin{tabular}{|c|c|c|}
\hline Swelling packer & Water swelling packer & Oil swelling packer \\
\hline Lactic acid & 0.9 & 0.5 \\
\hline $\mathrm{HCl}$ acid & 0.1 & 0.5 \\
\hline
\end{tabular}

Table 4: Probability states of type of drilling fluids based on swelling packers and treating fluids

\begin{tabular}{|l|c|c|c|c|}
\hline Swelling packer & \multicolumn{2}{|c|}{ Water swelling } & \multicolumn{2}{c|}{ Oil swelling } \\
\hline Treating Fluid & Lactic acid & $\mathrm{HCl}$ acid & Lactic acid & $\mathrm{HCl}$ acid \\
\hline $\begin{array}{l}\text { Formate } \\
\text { drilling fluid }\end{array}$ & 0.8 & 0.2 & 0.8 & 0.2 \\
\hline $\begin{array}{l}\text { CaCO3 drilling } \\
\text { fluid }\end{array}$ & 0.2 & 0.8 & 0.2 & 0.8 \\
\hline
\end{tabular}

Table 5: Probability states of the consequences

\begin{tabular}{|c|c|c|c|c|c|c|c|c|}
\hline Swelling & \multicolumn{4}{|c|}{ Water swelling packer } & \multicolumn{4}{|c|}{ Oil swelling packer } \\
\hline $\begin{array}{l}\text { Type of drilling } \\
\text { fluid }\end{array}$ & \multicolumn{2}{|c|}{$\begin{array}{l}\text { Formate drilling } \\
\text { fluid }\end{array}$} & \multicolumn{2}{|c|}{$\begin{array}{c}\mathrm{CaCO} 3 \\
\text { drilling fluid }\end{array}$} & \multicolumn{2}{|c|}{$\begin{array}{c}\text { Formate } \\
\text { drilling fluid }\end{array}$} & \multicolumn{2}{|c|}{$\begin{array}{c}\mathrm{CaCO} 3 \\
\text { drilling } \\
\text { fluid }\end{array}$} \\
\hline Treating fluid & Lactic acid & $\begin{array}{l}\mathrm{HCl} \\
\text { acid }\end{array}$ & $\begin{array}{l}\text { lactic } \\
\text { acid }\end{array}$ & $\begin{array}{l}\mathrm{HCl} \\
\text { acid }\end{array}$ & $\begin{array}{l}\text { lactic } \\
\text { acid }\end{array}$ & $\begin{array}{l}\mathrm{HCl} \\
\text { acid }\end{array}$ & $\begin{array}{c}\text { lactic } \\
\text { acid }\end{array}$ & $\begin{array}{l}\mathrm{HCl} \\
\text { acid } \\
\end{array}$ \\
\hline Recommended & 0 & 0 & 1 & 0 & 1 & 0 & 0 & 1 \\
\hline $\begin{array}{l}\text { Not } \\
\text { recommended }\end{array}$ & 1 & 1 & 0 & 1 & 0 & 1 & 1 & 0 \\
\hline
\end{tabular}

Table 6: Input utility values associated with the consequences

\begin{tabular}{|c|c|c|}
\hline Consequences & Recommended & Not recommended \\
\hline Value & 1 & 0 \\
\hline
\end{tabular}


The main goal after the required inputs are entered into the model is to simulate the uncertainty propagation from the existing sources of evidence, which means moving the information forward starting from the swelling packers node. First the total probability is calculated for the type of drilling fluid. The above model shows that our selection of drilling fluid will affect the treating fluid and our swelling packers.

The below equation is used:

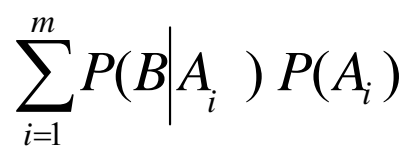

The results are shown in Table 7. Tables $\mathbf{3} \mathbf{4} \mathbf{4}$ are used for this calculation for example:

$$
\sum_{i=1}^{m} P\left(\text { formate drilling fluid | } \text { lactic acid }_{i}\right) P(\text { lactic acid })=(0.9 \times 0.8)+(0.1 \times 0.2)=0.74
$$

Table 7: Total probability for type of drilling fluid

\begin{tabular}{|c|c|c|}
\hline Swelling packer & $\begin{array}{c}\text { Water swelling } \\
\text { packer }\end{array}$ & $\begin{array}{c}\text { Oil swelling } \\
\text { packer }\end{array}$ \\
\hline $\begin{array}{c}\text { Formate drilling } \\
\text { fluid }\end{array}$ & 0.74 & 0.5 \\
\hline $\begin{array}{c}\text { CaCO3 drilling } \\
\text { fluid }\end{array}$ & 0.26 & 0.5 \\
\hline
\end{tabular}

Then Bayesian equation can be used as shown below:

$p($ hypothesis $\mid$ evidence $)=\left(\frac{p(\text { evidence } \mid \text { hypothesis })}{p(\text { hypothesis })}\right)$ 
Which is the same thing as:

$$
P\left(A_{j} \mid B\right)=\frac{P\left(B \mid A_{j}\right) P\left(A_{j}\right)}{\sum_{i=1}^{m} P\left(B \mid A_{i}\right) P\left(A_{i}\right)}
$$

The results are shown in Table 8. Tables 3, 4 and 7 are used for this calculation. The calculation shows the probabilities of selecting treating fluids (lactic acid or $\mathrm{HCl}$ acid) when the engineer wants to use a certain drilling fluid (formate or $\mathrm{CaCO}_{3}$ ) for a particular swelling packer (oil or water swelling). The detailed calculations for water swelling packer are shown below:

$$
\begin{aligned}
& p(\text { lactic acid } \mid \text { formate })=\left(\frac{p(\text { formate } \mid \text { lactic acid }) p(\text { lactic acid })}{p(\text { formate })}\right)=\frac{0.8 \times 0.9}{0.74}=0.9729 \\
& p(\text { HCl acid } \mid \text { formate })=\left(\frac{p(\text { formate } \mid \text { HCl acid }) p(\text { HCl acid })}{p(\text { formate })}\right)=\frac{0.2 \times 0.1}{0.74}=0.0270 \\
& p\left(\text { lactic acid } \mid \mathrm{CaCO}_{3}\right)=\left(\frac{p\left(\mathrm{CaCO}_{3} \mid \text { lactic acid }\right) \text { p }(\text { lactic acid })}{p\left(\mathrm{CaCO}_{3}\right)}\right)=\frac{0.2 \times 0.9}{0.26}=0.6923 \\
& p\left(\mathrm{HCl} \text { acid } \mid \mathrm{CaCO}_{3}\right)=\left(\frac{p\left(\mathrm{CaCO}_{3} \mid \mathrm{HClacid}\right) p(\text { HCl acid })}{p\left(\mathrm{CaCO}_{3}\right)}\right)=\frac{0.8 \times 0.1}{0.26}=0.3076
\end{aligned}
$$

For oil swelling packer, the calculations are:

$$
\begin{aligned}
& p(\text { lactic acid } \mid \text { formate })=\left(\frac{p(\text { formate } \mid \text { lactic acid }) p(\text { lactic acid })}{p(\text { formate })}\right)=\frac{0.8 \times 0.5}{0.5}=0.8 \\
& p(\text { HCl acid } \mid \text { formate })=\left(\frac{p(\text { formate } \mid \text { HClacid }) p(\text { HCl acid })}{p(\text { formate })}\right)=\frac{0.2 \times 0.5}{0.5}=0.2 \\
& p\left(\text { lactic acid } \mid \mathrm{CaCO}_{3}\right)=\left(\frac{p\left(\mathrm{CaCO}_{3} \mid \text { lactic acid }\right) p(\text { lactic acid })}{p\left(\mathrm{CaCO}_{3}\right)}\right)=\frac{0.8 \times 0.5}{0.5}=0.8
\end{aligned}
$$




$$
p\left(\mathrm{HCl} \text { acid } \mid \mathrm{CaCO}_{3}\right)=\left(\frac{p\left(\mathrm{CaCO}_{3} \mid \mathrm{HCl} \text { acid }\right) p(\text { HCl acid })}{p\left(\mathrm{CaCO}_{3}\right)}\right)=\frac{0.2 \times 0.5}{0.5}=0.2
$$

Table 8: Using bayesian equation for the proposed model

\begin{tabular}{|c|c|c|c|c|}
\hline $\begin{array}{c}\text { Swelling } \\
\text { packer }\end{array}$ & \multicolumn{2}{|c|}{ Water swelling } & \multicolumn{2}{c|}{ Oil swelling } \\
\hline Treating Fluid & \multicolumn{2}{|c|}{ Updated values } & \multicolumn{2}{c|}{ Updated values } \\
\hline Lactic acid & 0.9729 & 0.6923 & 0.8 & 0.2 \\
\hline $\mathrm{HCl}$ acid & 0.027 & 0.3076 & \multicolumn{2}{c|}{ Updated values } \\
\hline $\begin{array}{c}\text { Type of } \\
\text { drilling fluid }\end{array}$ & \multicolumn{2}{|c|}{ Updated values } & Selected by user & 0.8 \\
\hline $\begin{array}{c}\text { Formate } \\
\text { drilling fluid }\end{array}$ & $\begin{array}{c}\text { Selected by } \\
\text { user }\end{array}$ & Selected by user & & $\begin{array}{c}\text { Selected } \\
\text { by user }\end{array}$ \\
\hline $\begin{array}{c}\text { CaCO } \\
\text { drilling fluid }\end{array}$ & & &
\end{tabular}

Now, once the Bayesian calculations are completed, there are two approaches for the engineers to use this model. The first approach is to specify the type of drilling fluid he wants to use to drill the well and this will determine the correct decision in this model which is the suitable swelling packer. For example if $\mathrm{CaCO}_{3}$ is required to drill the well, then the probabilities of using the packers (consequences) in Table 8 and probability states of the consequences in Table 5 are used. The results are shown in Table 9. Below is an example calculation when $\mathrm{CaCO}_{3}$ drilling fluid is selected:

Water swelling packers

$$
\begin{aligned}
& \text { Re commended } \\
& (1 \times 0.6923+0 \times 0.3076)=0.6923 \\
& \text { Not } \operatorname{Re} \text { commended } \\
& (0.6923 \times 0+1 \times 0.3076)=0.3076
\end{aligned}
$$

Oil swelling packers 
Re commended

$(0.2 \times 0+0.8 \times 1.0)=0.8$

Not Re commended

$(0.2 \times 1+0 \times 0.8)=0.2$

Table 9: Consequences when selecting $\mathrm{CaCO}_{3}$ drilling fluid (from table 7) and table 4

\begin{tabular}{|c|c|c|}
\hline Swelling Packers & Water swelling packers & Oil swelling packers \\
\hline Recommended & 0.6923 & 0.8 \\
\hline Not recommended & 0.3076 & 0.2 \\
\hline
\end{tabular}

The utility in Table 10 is finally calculated using below equation from Table 9 and Table 6:

For water swelling packer it is:

$$
\text { Expected utility }=\sum_{i} \text { consequence result } \times \text { input believe }=0.6923 \times 1+0.3076 \times 0=0.6923
$$

For oil swelling packer it is:

$$
\text { Expected utility }=\sum_{i} \text { consequence result } \times \text { input believe }=0.8 \times 1+0.2 \times 0=0.8
$$

Table 10: Expected utility values (first approach)

\begin{tabular}{|c|c|c|}
\hline Swelling packer & Water swelling & Oil swelling \\
\hline Expected utility & 0.6923 & 0.8 \\
\hline
\end{tabular}

The other option for the engineer to use this model is to specify all the uncertainties (drilling fluid and treating fluid) to determine the optimum selection of 
swelling packers. Table 5 can be used directly. For example selecting formate drilling fluid and lactic acid indicate that oil swelling packer is recommended, Table 11.

Table 11: Consequences when selecting formate drilling fluid and lactic acid (from table 5)

\begin{tabular}{|c|c|c|}
\hline Swelling Packers & $\begin{array}{c}\text { Water swelling } \\
\text { packers }\end{array}$ & Oil swelling packers \\
\hline Recommended & 0 & 1 \\
\hline Not recommended & 1 & 0 \\
\hline
\end{tabular}

The utility is calculated as mentioned above, Table 12.

Table 12: Expected utility values ( $2^{\text {nd }}$ approach)

\begin{tabular}{|c|c|c|}
\hline Swelling packer & water swelling & oil swelling \\
\hline Expected utility & 0 & 1 \\
\hline
\end{tabular}

For this study, Graphical Network Interface was used for calculations of the uncertainty propagation to build up the expert system. Fig.7 shows the results for the first approach example (selecting $\mathrm{CaCO}_{3}$ drilling fluid) which agrees with the calculation above. Fig.8 shows the results for the second approach example (selecting formate drilling fluid and lactic acid treating fluid) which also agrees with the calculation above. 


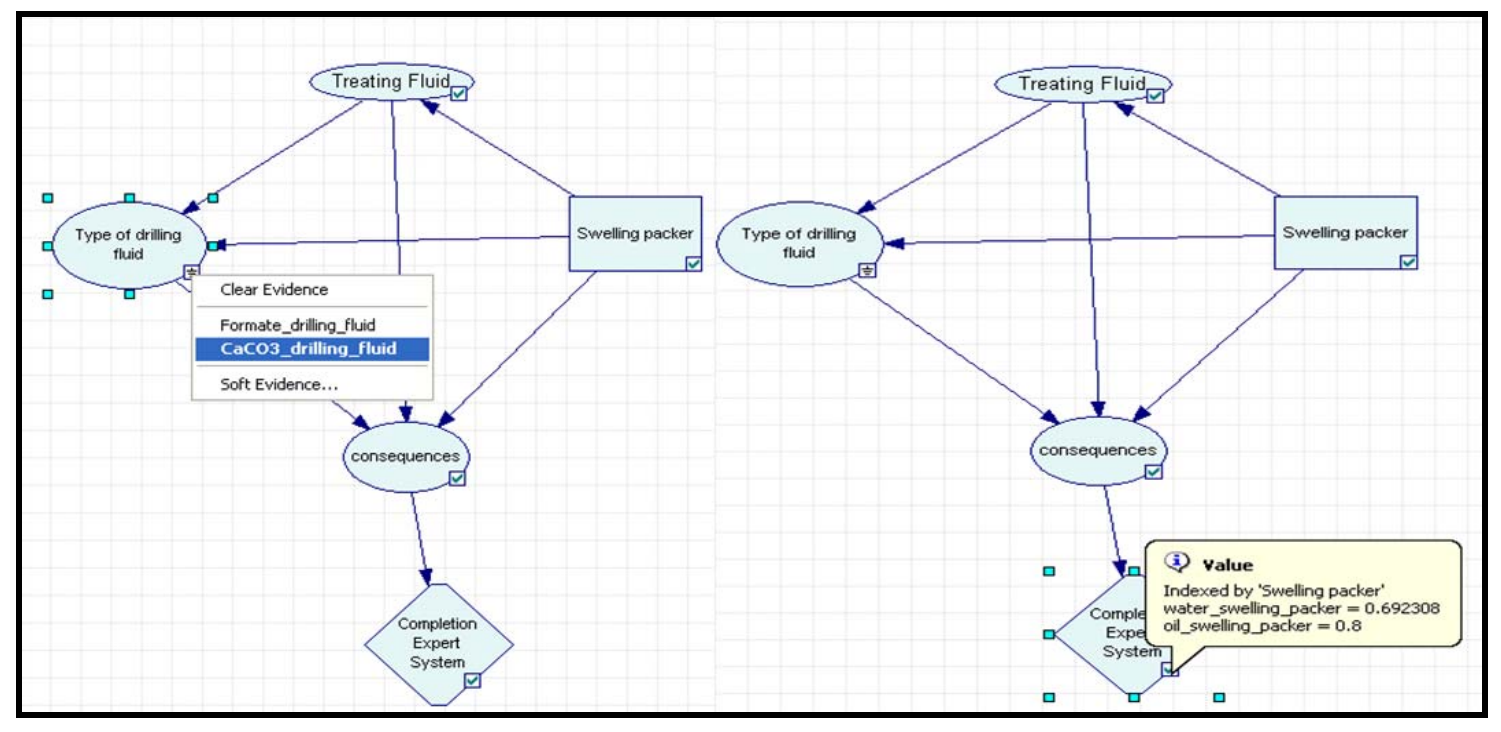

Fig.7: Model for the proof of concept (first approach)

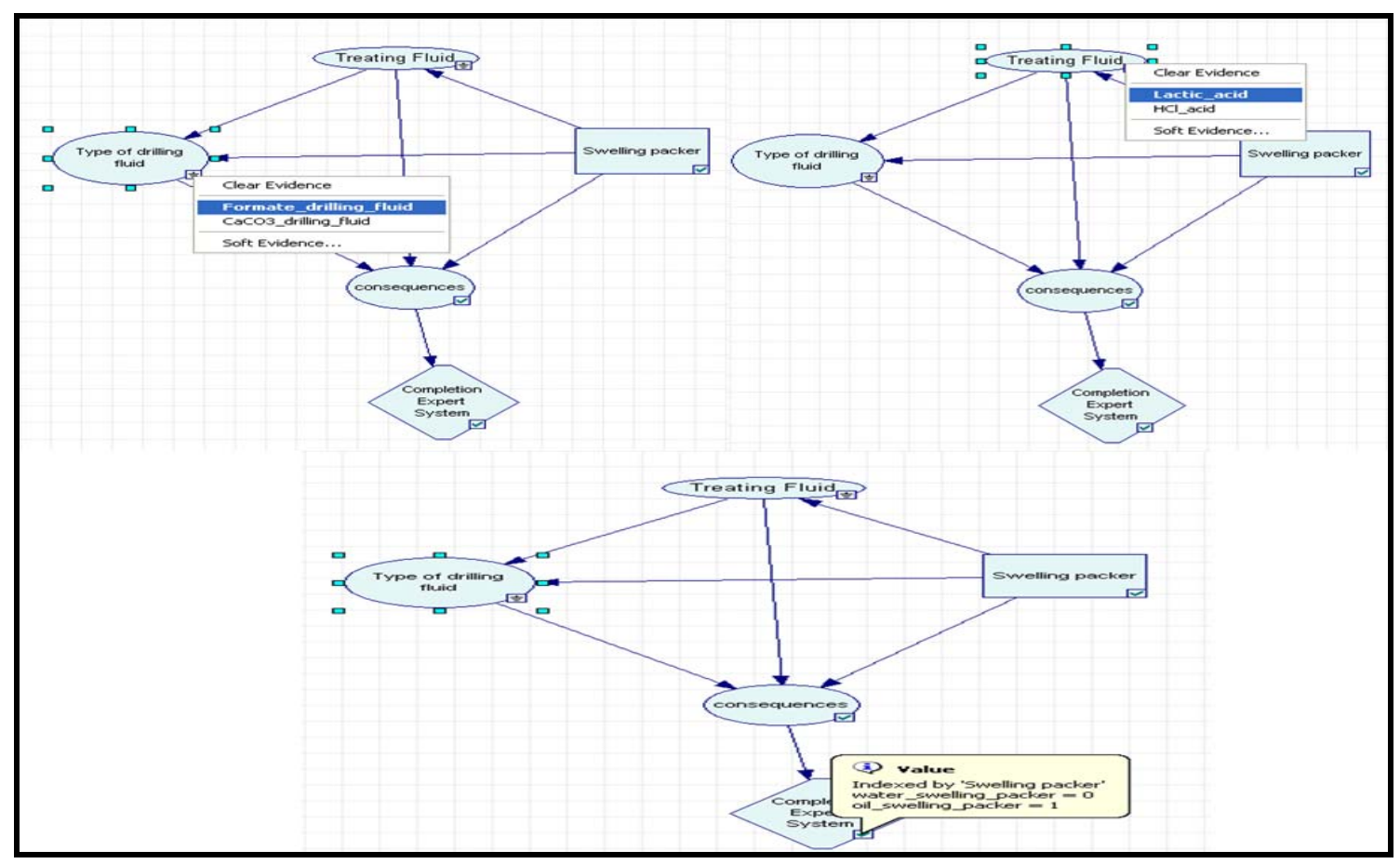

Fig.8: Model for the proof of concept (second approach) 
Using Bayesian Intelligence allows the design of drilling and completion expert systems that can be used in different fields and/or by different experts with different opinions. The system can be updated easily with the new opinions by changing the probability states shown above (Tables 3-5) and the model will update the calculation to show the recommended type of swelling packer. 


\section{CHAPTER III}

\section{WELL COMPLETION EXPERT SYSTEM*}

The objective of this chapter is to propose a set of guidelines for the optimal completion design, by integrating current best practices through a decision-making system based on Artificial Bayesian Intelligence. Best completion practices collected from data, models, and experts' opinions, are integrated into a Bayesian Network BN to simulate likely scenarios of its use, that will honor efficient designs when dictated by varying well objectives, well types, temperatures, pressures, rock and fluid properties.

The described decision-making model follows a causal and uncertainty-based approach capable of simulating realistic conditions on the use of completion operations. For instance, the use of water swelling packer dictates the use of organic acids instead of $\mathrm{HCl}$ acids. However, rock type and well geometry affect our selection of treatment fluids. Another example is selection of sand control method based on rock properties.

The chapter also outlines best operational practices in fracturing, sand control, perforation, treatment and completion fluids, multilateral junction level selection and lateral completion. Completion experts' opinions were considered in building the model in this paper.

*Reprinted with permission from "Expert System for the Optimal Design and Execution of Successful Completion Practices Using Artificial Bayesian Intelligence," by Al-Yami, A.S., Schubert, J., and Beck, G., 2011, SPE 143826, Copyright (C) 2012, Society of Petroleum Engineers. 
Fig.9 shows the completion expert model. Literature review and completion experts' opinions were used as evidence to build the model using the proposed Bayesian Network. Variable nodes allow the user to input desired well conditions that allows for generating the corresponding best completion practices. Eighteen uncertainty nodes are defined for this model to determine best practices in six decision nodes. The model is divided into six parts or decisions. Each decision has uncertainties and consequences nodes. The consequences node combines the uncertainty nodes where completion expert opinions were used to assign and define the conditional probability distribution. The model then calculates the optimum practices decision. Below are descriptions of each decision in the model.

\subsection{Junction classification decision}

The uncertainty node is named considerations in designing multilateral junctions. Table 13 shows its probability states. There are six levels in TAML classification as detailed below:

- Level 1: open unsupported junction.

- Level 2: Motherbore cased and cemented and lateral open.

- Level 3: Motherbore cased and cemented and lateral cased but not cemented.

- Level 4: Motherbore and lateral cased and cemented.

- Level 5: Pressure integrity is provided at the junction using straddle packers.

- Level 6: Pressure integrity is provided using integral mechanical seal that can include reformable junction or non-reformable and full diameter splitter. 


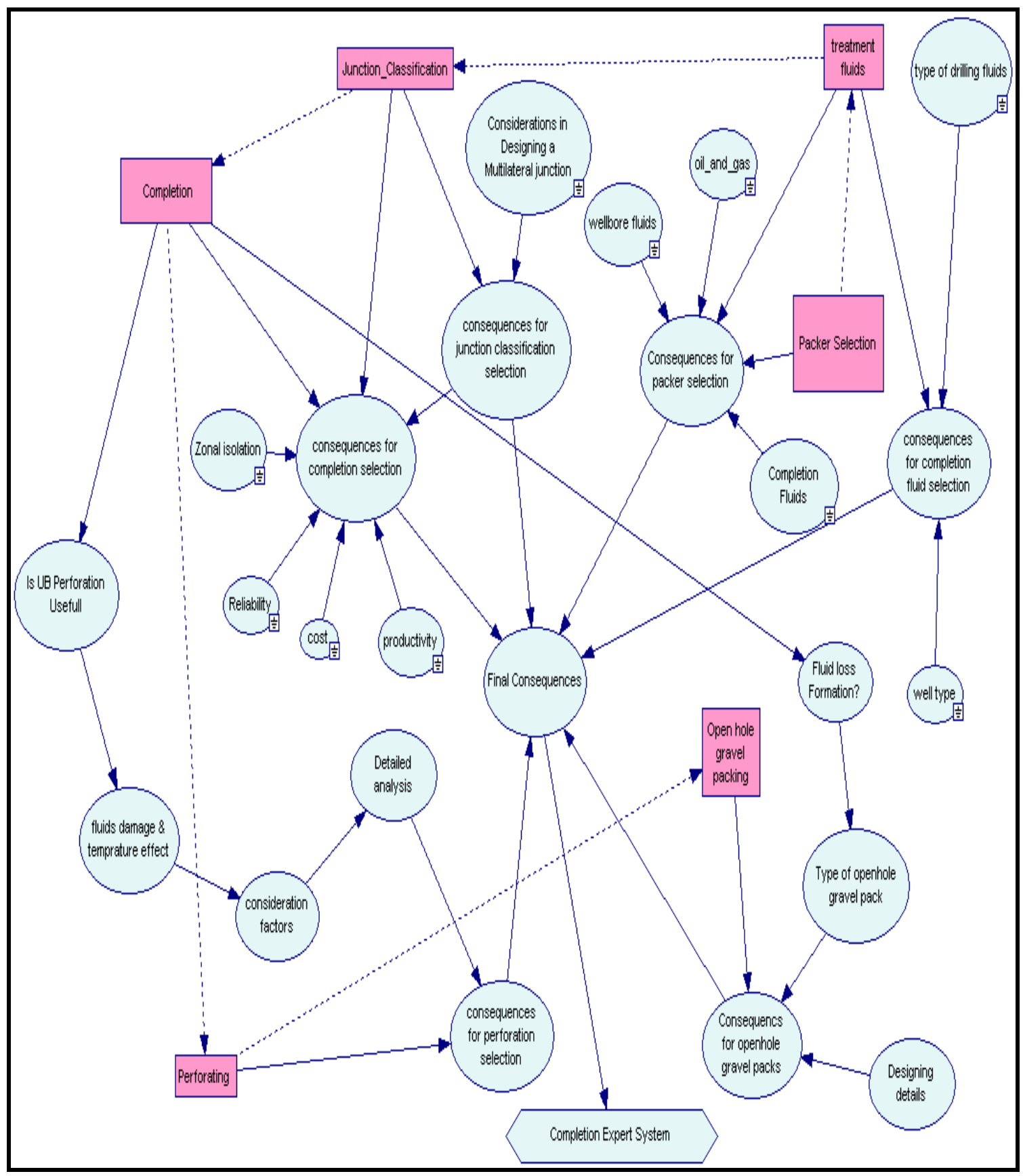

Fig.9: Completion expert model 
Table 13: Probability states of considerations in designing multilateral junctions' node

\begin{tabular}{|l|c|}
\hline Consolidated strong formation and zonal control is not critical & 0.15 \\
\hline Formation stability is required but not at the junction & 0.15 \\
\hline $\begin{array}{l}\text { Formation stability is required and mechanical isolation and limited } \\
\text { stability at the junction }\end{array}$ & 0.15 \\
\hline Re entry is possible & 0.15 \\
\hline $\begin{array}{l}\text { Formation stability is required and hydraulic isolation and stability at } \\
\text { the junction }\end{array}$ & 0.15 \\
\hline best completion for weak incompetent susceptible to wellbore collapse & 0.05 \\
\hline $\begin{array}{l}\text { single component completion hydraulic isolation is maximum and does } \\
\text { not } \\
\text { depend on cementing and continuous liner ID accessing both bores } \\
\text { increase well control capability }\end{array}$ & 0.05 \\
\hline kickoff point is not possible at strong formation & 0.15 \\
\hline
\end{tabular}

The decision node has six options, Table 14. Fig. 10 shows part of the consequences. For consolidated strong formation where zonal control is not required, level 1 is the optimum design. When formation stability is required but not at the junction then level 2 is the optimum practice. As mentioned above, different experts can update these numbers easily in case they do not agree with them.

Table 14: Junction classification decision node

\begin{tabular}{|l|}
\hline Level 1 \\
Level 2 \\
Level 3 \\
Level 4 \\
Level 5 \\
Level 6 \\
\hline
\end{tabular}




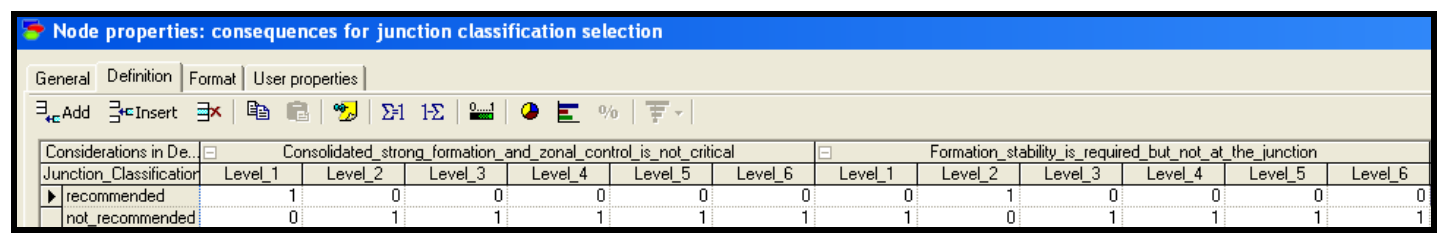

Fig.10: Part of consequences for junction classification selection

\subsection{Treatment fluid}

For the treatment fluid decision, there are two uncertainties (factors). The first one is the well type (short or long lateral), Table 15. The second uncertainty node is the type of drilling fluid used, Table 16. The treatment fluid decision is shown in Table 17. Fig. 11 shows part of the consequences input. In case of long horizontal lateral and when using $\mathrm{CaCO}_{3}$ drilling fluid, the optimum practice is either to use lactic acid or formic acid.

Table 15: Probability states of well type node

\begin{tabular}{|l|c|}
\hline $\begin{array}{l}\text { short horizontal } \\
\text { section }\end{array}$ & 0.5 \\
\hline $\begin{array}{l}\text { Long horizontal } \\
\text { section }\end{array}$ & 0.5 \\
\hline
\end{tabular}

Table 16: Probability states of type of drilling fluid node

\begin{tabular}{|l|c|}
\hline Water based mud with $\mathrm{CaCO}_{3}$ & 0.2 \\
\hline Water based mud with Barite & 0.2 \\
\hline Emulsion oil based mud & 0.2 \\
\hline All oil based mud & 0.2 \\
\hline Potassium formate mud & 0.1 \\
\hline Drilling fluid based with $\mathrm{Mn}_{3} \mathrm{O}_{4}$ & 0.1 \\
\hline
\end{tabular}


Table 17: Treatment fluids decision node

\begin{tabular}{|l|}
\hline Inhibitors Amines \\
\hline Alcohol methanol \\
\hline Acid less than $15 \mathrm{wt}$ percentage $\mathrm{HCl}$ acid \\
\hline Acid more than $15 \mathrm{wt}$ percentage $\mathrm{HCl}$ acid \\
\hline HF acid less than $65 \mathrm{wt}$ percentage \\
\hline Acetic acid \\
\hline Surfactants \\
\hline Citric \\
\hline Formic \\
\hline Lactic \\
\hline Potassium formate \\
\hline Enzymes \\
\hline Circulation of new volume of drilling fluid \\
\hline
\end{tabular}

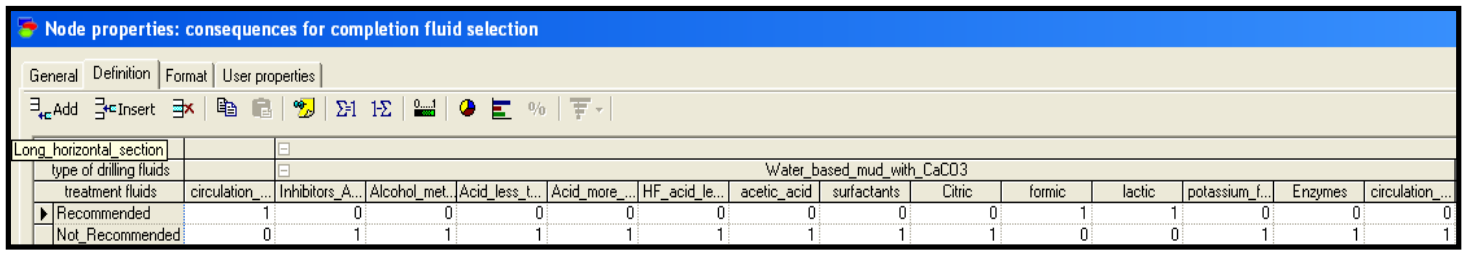

Fig.11: Part of consequences for completion (treatment) fluid selection

\subsection{Lateral completion}

The lateral completion decision has four uncertainties (cost, zonal isolation, reliability and productivity). Each one of them has three levels (high, medium and low). There is also an additional uncertainty which is potential of sand production. In the model we can see that our selection of junction classification decision affect the potential of sand production uncertainty. As known, level 1 and 2 do not have sand production potential. The lateral completion is shown in Table 18. Fig. 12 shows that for a formation that has 
sand production problem, and for good reliability, good productivity, good cost and good zonal isolation, the optimum practice is to use openhole expandable screen.

Table 18: Lateral completion decision node

Standalone screen

Open hole gravel pack

Cased hole gravel pack

Frac pack

Openhole expandable

screens

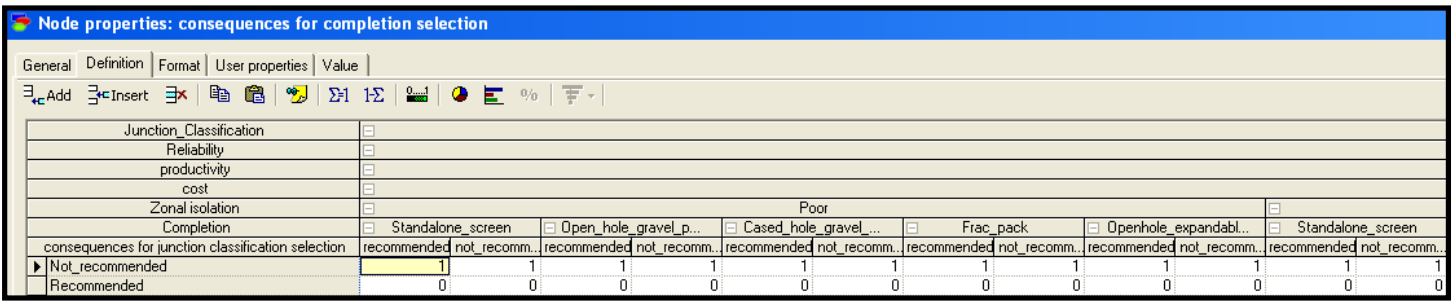

Fig.12: Part of consequences for completion selection

\subsection{Perforating}

The perforating part of the model outlines the decision into more steps compared to the other parts. The user will need to determine if underbalanced perforation is useful or not (Table 19) which will affect the decision of formulating non damaging fluids or temperature consideration, Table 20. Tables 21 and 22 give probability states that lead to detailed analysis that goes to the consequences node. Part of the consequences input, 
Fig. 13, shows that if we can formulate non-damaging fluid then the optimum practice is to design for overbalanced perforation using wire line conveyed casing guns. The perforating decision node details are shown in Table 23.

Table 19: Probability states of if UB perforation useful or not

\begin{tabular}{|l|c|c|c|c|c|}
\hline Completion & $\begin{array}{c}\text { Standalone } \\
\text { screen }\end{array}$ & $\begin{array}{c}\text { Openhole gravel } \\
\text { pack }\end{array}$ & $\begin{array}{c}\text { Cased } \\
\text { hole } \\
\text { gravel } \\
\text { pack }\end{array}$ & $\begin{array}{c}\text { Frack } \\
\text { pack }\end{array}$ & $\begin{array}{c}\text { Openhole } \\
\text { expandable } \\
\text { screen }\end{array}$ \\
\hline $\begin{array}{l}\text { Not } \\
\text { required }\end{array}$ & 1 & 1 & 0 & 1 & 1 \\
\hline Yes & 0 & 0 & 0.5 & 0 & 0 \\
\hline Not & 0 & 0 & 0.5 & 0 & 0 \\
\hline
\end{tabular}

Table 20: Probability states of fluid damage and temperature effect

\begin{tabular}{|l|c|c|}
\hline Is Underbalanced perforation useful & Yes & No \\
\hline can we formulate non damaging fluid & 0.2 & 0.8 \\
\hline Need to consider temperature & 0.8 & 0.2 \\
\hline
\end{tabular}

Table 21: Probability states of consideration factors

\begin{tabular}{|l|c|c|}
\hline $\begin{array}{l}\text { Fluid damage and } \\
\text { temperature effect }\end{array}$ & $\begin{array}{c}\text { can we formulate non damaging } \\
\text { fluid }\end{array}$ & $\begin{array}{c}\text { Need to consider } \\
\text { temperature }\end{array}$ \\
\hline Higher than $450^{\circ} \mathrm{F}$ & 0.1 & 0.4 \\
\hline Lower than $450^{\circ} \mathrm{F}$ & 0.1 & 0.4 \\
\hline $\begin{array}{l}\text { We can formulate non } \\
\text { damaging fluid }\end{array}$ & 0.4 & 0.1 \\
\hline $\begin{array}{l}\text { We cannot formulate } \\
\text { non damaging fluid }\end{array}$ & 0.4 & 0.1 \\
\hline
\end{tabular}


Table 22: Probability states of detailed analysis

\begin{tabular}{|l|c|c|c|c|}
\hline \multicolumn{1}{|c|}{ Consideration factors } & $\begin{array}{c}\text { Higher than } \\
450 \mathrm{~F}\end{array}$ & $\begin{array}{c}\text { Lower } \\
\text { than } \\
450 \mathrm{~F}\end{array}$ & $\begin{array}{c}\text { We can } \\
\text { formulate } \\
\text { Non- } \\
\text { damaging } \\
\text { fluid }\end{array}$ & $\begin{array}{c}\text { we cannot } \\
\text { formulate } \\
\text { non-damaging } \\
\text { fluid }\end{array}$ \\
\hline $\begin{array}{l}\text { multiple runs with } \\
\text { through tubing guns } \\
\text { cannot achieve } \\
\text { adequate well rates }\end{array}$ & 0.25 & 0.1 & 0.1 & 0.1 \\
\hline $\begin{array}{l}\text { multiple runs with } \\
\text { through tubing guns } \\
\text { can achieve adequate } \\
\text { well rates }\end{array}$ & 0.25 & 0.1 & 0.1 & 0.1 \\
\hline $\begin{array}{l}\text { through tubing guns } \\
\text { can be used }\end{array}$ & 0.1 & 0.25 & 0.1 & 0.1 \\
\hline $\begin{array}{l}\text { through tubing guns } \\
\text { cannot be used }\end{array}$ & 0.1 & 0.25 & 0.1 & 0.1 \\
\hline $\begin{array}{l}\text { can the damage be } \\
\text { removed by acidizing } \\
\text { in carbonate formation }\end{array}$ & 0.1 & 0.1 & 0.1 & 0.25 \\
\hline $\begin{array}{l}\text { can the damage be } \\
\text { removed by } \\
\text { fractured stimulation }\end{array}$ & 0.1 & 0.1 & 0.1 & 0.25 \\
\hline $\begin{array}{l}\text { we can formulate non } \\
\text { damaging fluid }\end{array}$ & 0.1 & 0.1 & 0.4 & 0.1 \\
\hline
\end{tabular}

Table 23: Perforating decision node

Multiple runs with through tubing guns

through tubing guns

Design for tubing conveyed perforation

Consider if underbalanced perforating with casing guns

is acceptable and evaluate fluid damage risks during completion running

if well will kill itself if perforated without tubing

Consider perforating overbalanced in acid with casing or through tubing guns

Review special perforation requirements for fracturing such as diversion and proppant placement

Design for overbalanced perforating using wire line conveyed casing guns 


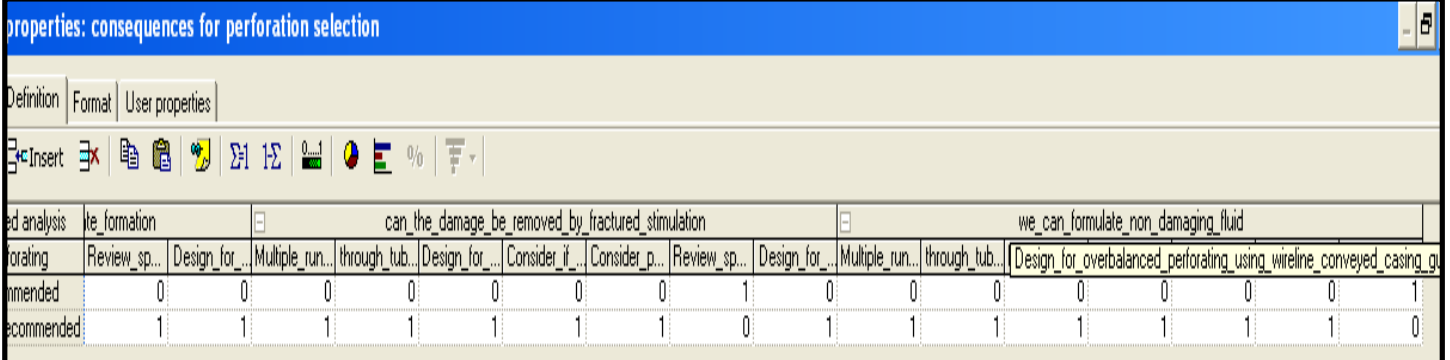

Fig.13: Part of consequences for perforation selection

\subsection{Openhole gravel packing}

The openhole gravel packing section shows two types of gravel packing methods (alternate path and circulating pack). The circulating pack is more suitable where there is no fluid loss while alternate path is applied when there is a potential for lost circulation as shown in the probability states in Tables 24 and 25. Table 26 shows the probability states for designing details such as slurry density and applied pressure. Table 27 shows the openhole gravel packing decision details for the treatment. Part of the consequences is shown in Fig. 14 where it shows that it is possible to exceed the fracturing pressure when following the alternate path.

Table 24: Probability states of potential fluid loss formation

\begin{tabular}{|c|c|c|c|c|c|}
\hline Completion & $\begin{array}{c}\text { Standalone } \\
\text { screen }\end{array}$ & $\begin{array}{c}\text { Openhole } \\
\text { gravel pack }\end{array}$ & $\begin{array}{c}\text { Cased hole } \\
\text { gravel pack }\end{array}$ & $\begin{array}{c}\text { Frack } \\
\text { pack }\end{array}$ & $\begin{array}{c}\text { Openhole } \\
\text { expandable } \\
\text { screen }\end{array}$ \\
\hline Not required & 1 & 0 & 1 & 1 & 1 \\
\hline Fluid loss & 0 & 0.5 & 0 & 0 & 0 \\
\hline No fluid loss & 0 & 0.5 & 0 & 0 & 0 \\
\hline
\end{tabular}


Table 25: Probability states of type of openhole gravel packing

\begin{tabular}{|l|c|c|}
\hline $\begin{array}{l}\text { Potential fluid loss } \\
\text { formation }\end{array}$ & $\begin{array}{c}\text { Fluid } \\
\text { loss }\end{array}$ & No fluid loss \\
\hline Alternate path & 1 & 0 \\
\hline Circulating pack & 0 & 1 \\
\hline
\end{tabular}

Table 26: Probability states designing details

\begin{tabular}{|l|c|}
\hline gravel pack fluids & 0.1 \\
\hline slurry density & 0.1 \\
\hline $\begin{array}{l}\text { Fluid volume and } \\
\text { time }\end{array}$ & 0.1 \\
\hline Fluid loss & 0.2 \\
\hline Pressure & 0.1 \\
\hline Hole condition & 0.1 \\
\hline Filter cake removal & 0.1 \\
\hline Screen size & 0.1 \\
\hline Cost & 0.1 \\
\hline
\end{tabular}


Table 27: Openhole gravel packing decision node

gravel pack fluid of water or oil with viscosifier

gravel pack fluid of water used with friction reducer

high slurry density of 8 ppa

low slurry density of up to $2 \mathrm{ppa}$

low fluid volume and reduced pumping time

large fluid volume

No need for complete returns

Complete returns is required

can exceed fracture pressure

cannot exceed fracture pressure

critical washout is not a problem

critical washout is a problem

filter cake need to be removed

filter cake does not have to be removed

small base pipe but larger overall diameter for

shunts

large base pipe screen

less time but more expensive chemicals

More rig time for pumping is required

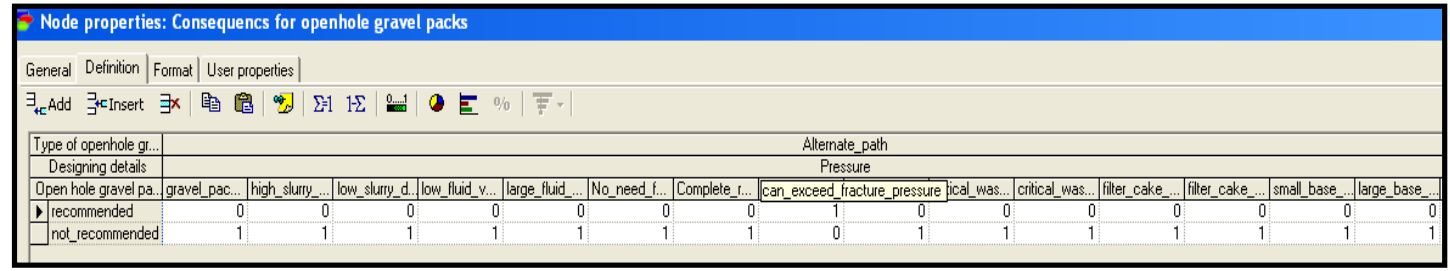

Fig.14: Part of consequences for openhole gravel pack selection 


\subsection{Packer selection}

The packer model part indicates that selection of packers depends on completion fluids (Table 28), oil and gas details (Table 29), wellbore fluids (Table 30), and treatment

fluids (Table 17). For example water swelling packers are damaged by $\mathrm{CaCl}_{2}$ brines and $\mathrm{HCl}$ acids. Table 31 shows the available packers for the user to select. Fig. 15 shows part of the consequences for the optimum conditions for the PVDF Coflon packer applications.

Table 28: Probability states of completion fluids node

\begin{tabular}{|l|l|}
\hline $\mathrm{CaCl}_{2} / \mathrm{CaBr}$ & 0.25 \\
\hline $\mathrm{ZnBr}$ & 0.25 \\
\hline $\mathrm{K}_{2} \mathrm{CO}_{3}$ & 0.25 \\
\hline $\begin{array}{l}\text { Brine } \\
\text { seawater }\end{array}$ & 0.25 \\
\hline
\end{tabular}

Table 29: Probability states of oil and gas node

\begin{tabular}{|l|r|}
\hline Aliphatic hydrocarbons & 0.1 \\
\hline Aromatic hydrocarbons & 0.1 \\
\hline Crude oil less than $250^{\circ} \mathrm{F}$ & 0.2 \\
\hline $\begin{array}{l}\text { Crude oil more than } 250 \\
\text { of }\end{array}$ & 0.2 \\
\hline Sour crude & 0.2 \\
\hline Gas sour natural gas & 0.2 \\
\hline
\end{tabular}


Table 30: Probability states of wellbore fluids node

\begin{tabular}{|l|l|}
\hline water & 0.2 \\
\hline steam & 0.2 \\
\hline methane & 0.2 \\
\hline $\mathrm{CO}_{2}$ & 0.2 \\
\hline $\mathrm{H}_{2} \mathrm{~S}$ & 0.2 \\
\hline
\end{tabular}

Table 31: Packer selection decision node

\begin{tabular}{|c|}
\hline CR Neoprene \\
\hline AE AU Urethane \\
\hline NBR Nitrile \\
\hline ECO Hydrin \\
\hline PVDF Coflon \\
\hline HNBR Therban \\
\hline FKM Viton \\
\hline ETFE Tefzel \\
\hline FCM Aflas \\
\hline PEEK Victrex \\
\hline FFKM Kalrez \\
\hline PTFE Teflon \\
\hline Oil swelling packer \\
\hline water swelling packer \\
\hline
\end{tabular}

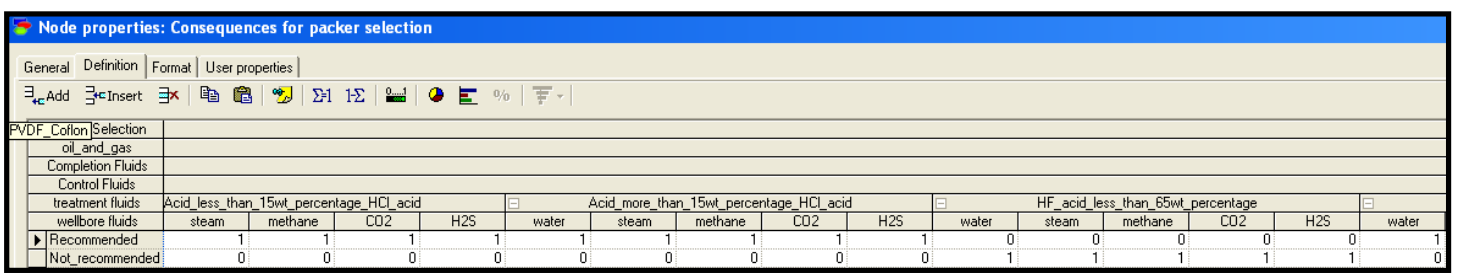

Fig.15: Part of consequences for packer selection 


\subsection{Final consequences}

All different parts of the big model consequences are gathered into one node named final consequences. The final consequences is used to select optimum practices from the whole model ( all decision nodes i.e. lateral junction, treating fluids, lateral completion, perforation, gravel packing, and packer selection). Fig. 16 shows part of the final consequences. A value of 1 is assigned to the recommended practices from each decision node in the model.

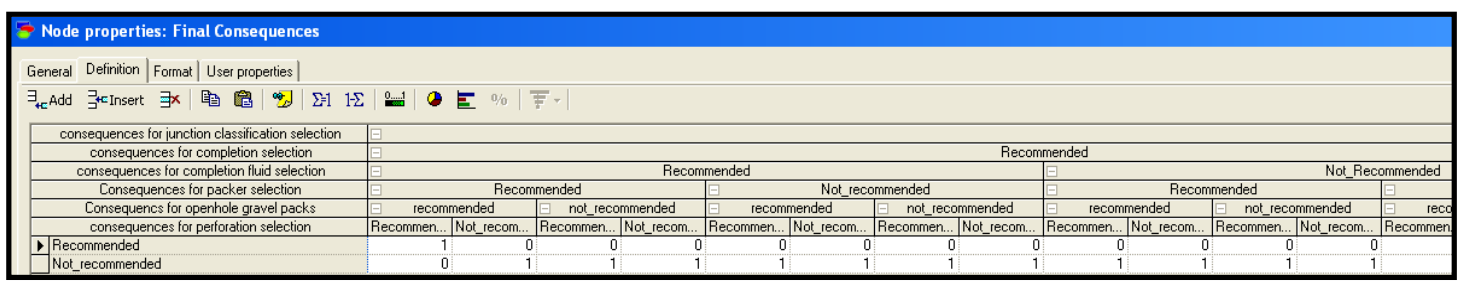

Fig.16: Part of consequences for the final consequences node

\subsection{Completion expert system utility node}

In the model, there is only one utility node to calculate the expected values from the final consequences node, Table 32.

Table 32: Expected utility values for the final consequences node

\begin{tabular}{|c|c|c|}
\hline $\begin{array}{c}\text { Final } \\
\text { Consequences }\end{array}$ & Recommended & $\begin{array}{c}\text { Not } \\
\text { recommended }\end{array}$ \\
\hline Value & 1 & 0 \\
\hline
\end{tabular}




\section{CHAPTER IV}

\section{DRILLING FLUIDS MODEL*}

Drilling fluids are important factor in drilling and completion operations. Designing drilling fluids depend on formation lithology, temperature and pressure. The objective of this chapter is to set a module that should aid drilling engineers when designing drilling fluids. A module was created based on several inputs. To create this module, we interviewed experts to gather the information required to determine best practices as a function of different probabilities. Drilling fluids formulations were gathered from Saudi Arabia fields to build up this model.

Fig.17 shows the drilling fluids model. Literature review and drilling fluids experts' opinions were used as evidence to build a model using the proposed Bayesian Network.

Variable nodes allow the user to input desired well conditions that allows for generating the corresponding best drilling fluids practices. Three uncertainty nodes are defined for this model to determine best practices in one decision node (recommended drilling fluids).

*Reprinted with permission from "Drilling Fluids Consultation System: Development and Field Applications," by Al-Yami, A.S. and Schubert, J., 2012a, SPE 152098, Copyright (C) 2012, Society of Petroleum Engineers. 
The model has one decision which has uncertainties and one consequence node. The consequence node combines the uncertainty nodes where drilling fluids' expert opinions were used to assign and define the conditional probability distribution. The model then calculates the recommended drilling fluids decision.

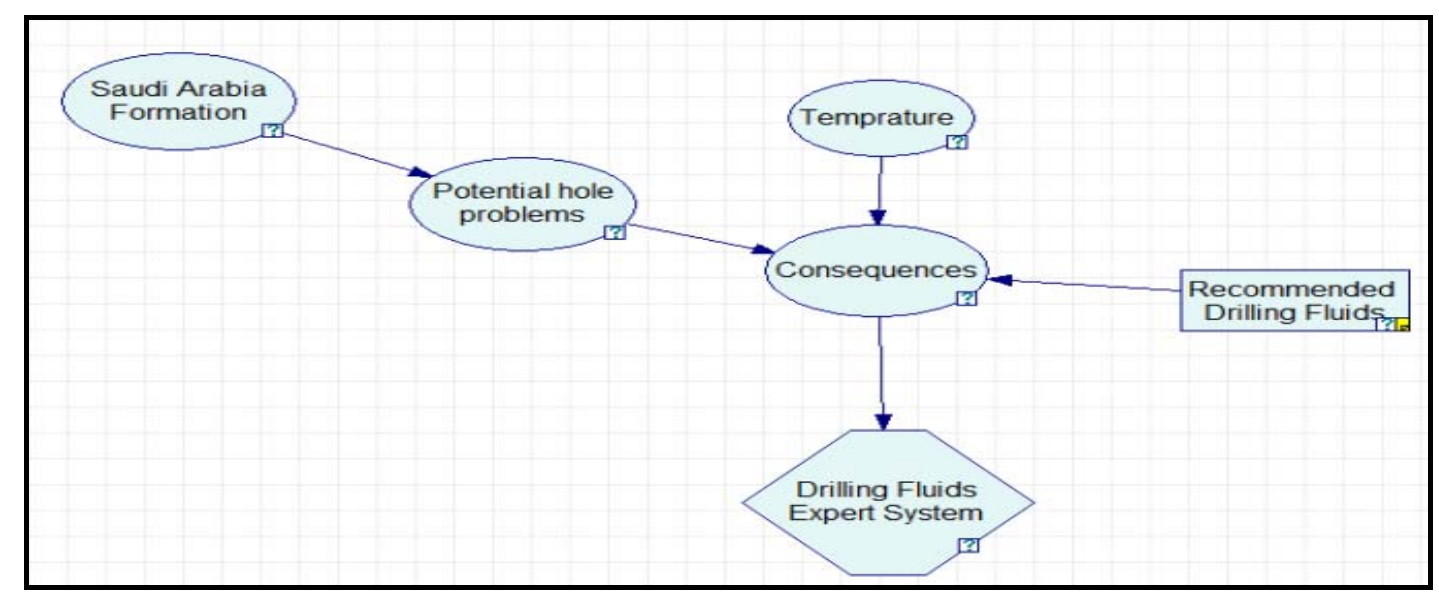

Fig.17: Overall model of drilling fluids expert system

The first uncertainty node is the temperature range, Fig.18. Temperature is divided into 4 ranges since different polymers used in drilling fluids are affected by temperature. 


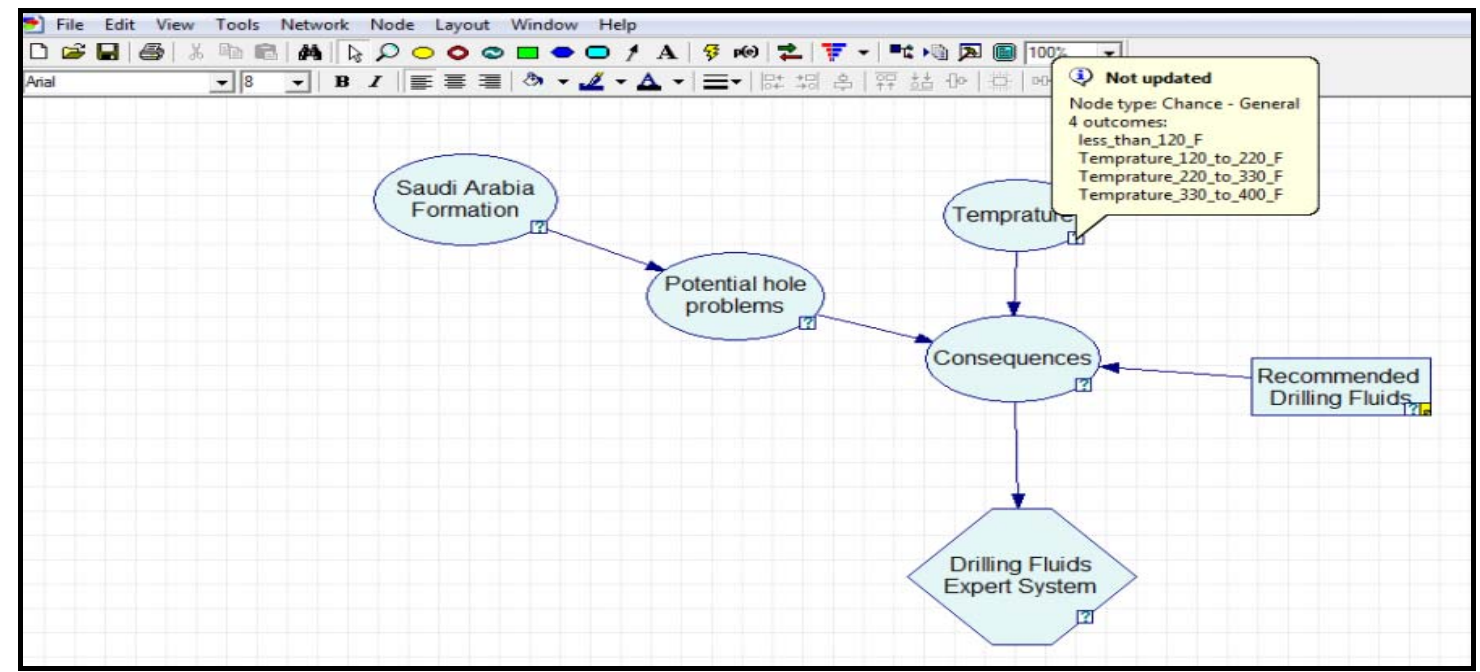

Fig.18: Temperature options

The second node is the potential hole problems uncertainty, Fig. 19. These problems are considered to be general problems that need to be considered when designing drilling fluids. The consequences node depends on the temperature range and potential hole problems probabilities selected. 


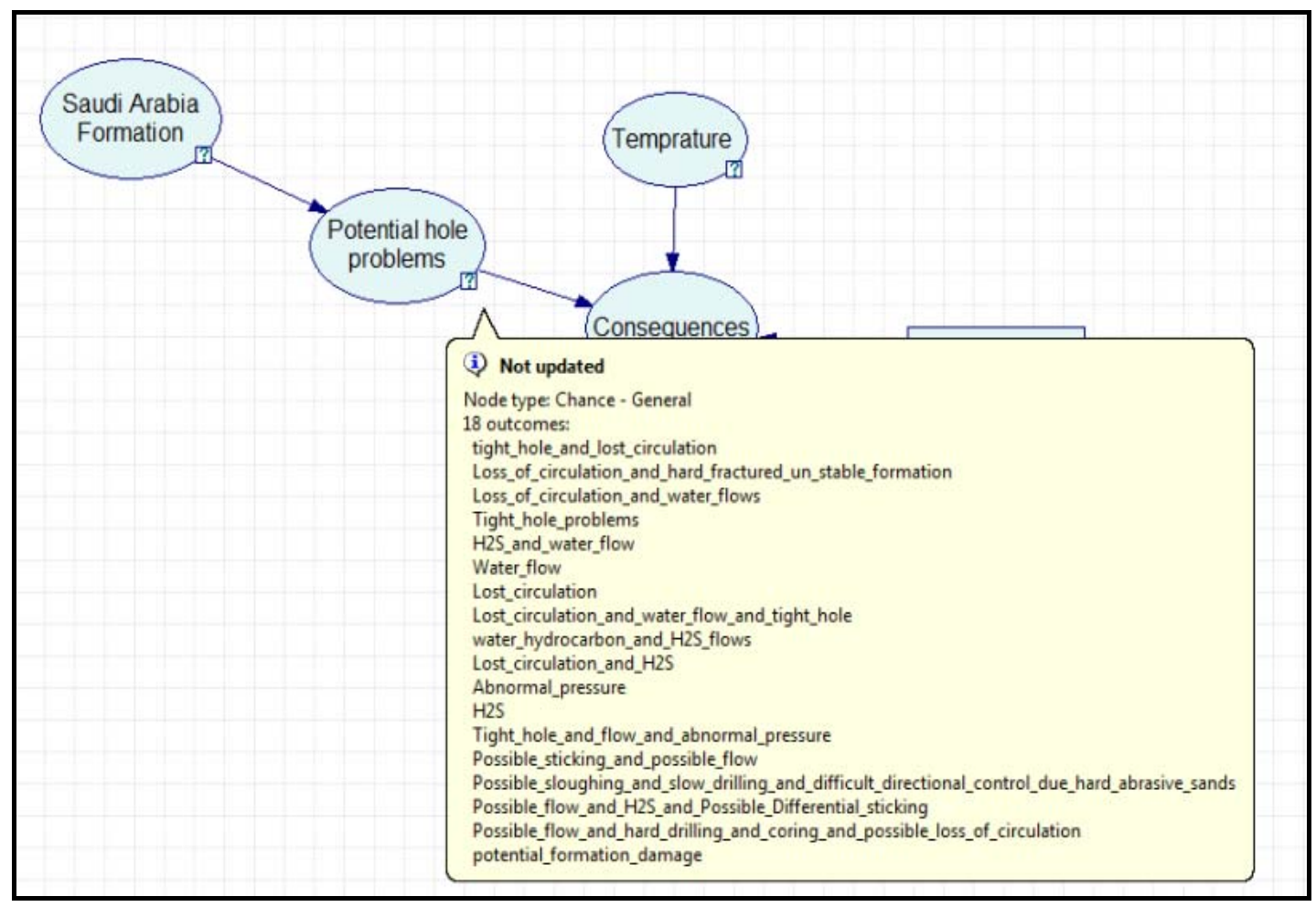

Fig.19: A list of potential hole problems

The last uncertainty node in the model is the Saudi Arabia formation, Fig.20. The objective of this node was to use this model in Saudi Arabia fields. 


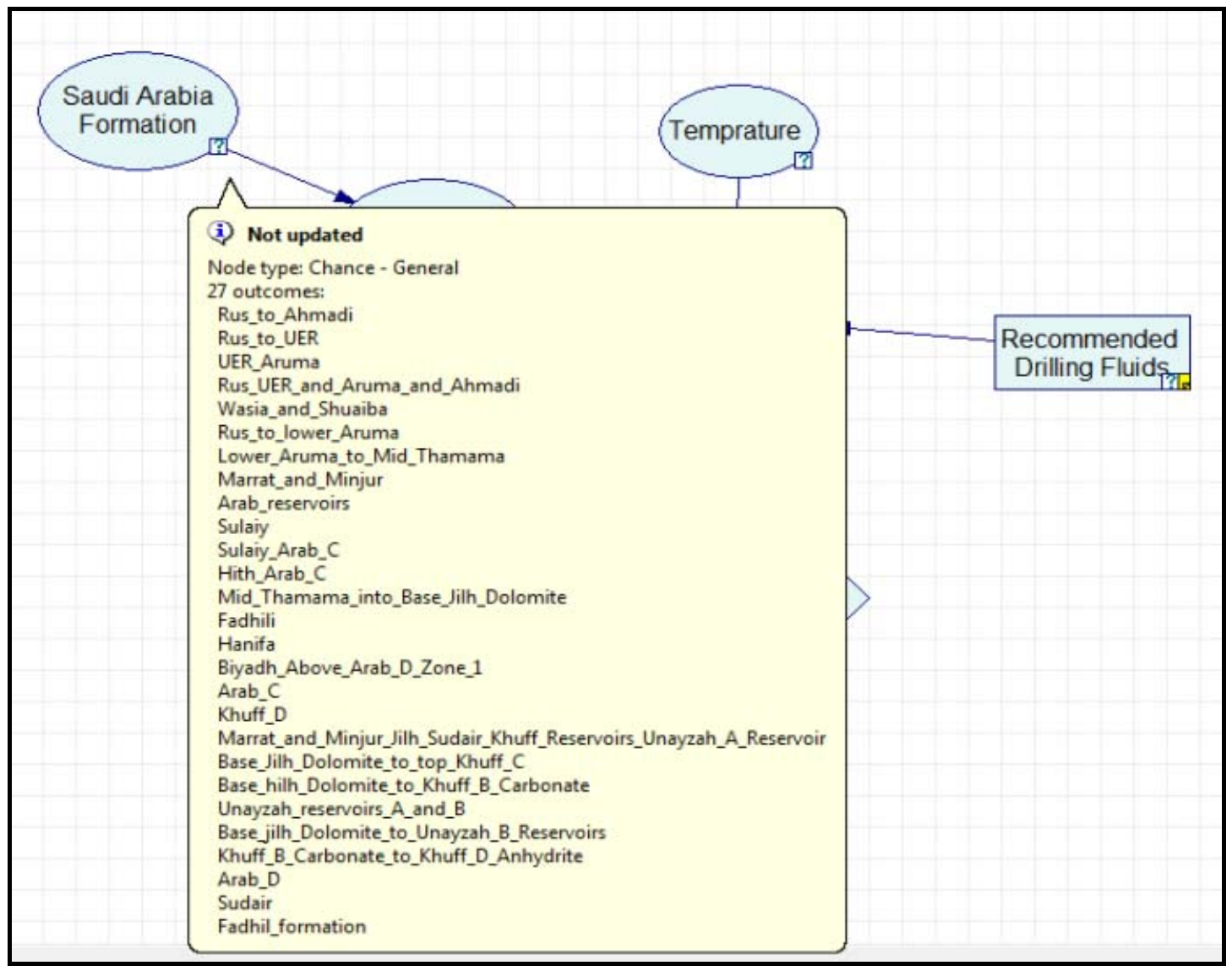

Fig.20: Formations' names in Saudi Arabia 


\section{CHAPTER V}

\section{WELL CONTROL MODEL*}

The objective of this chapter is to propose a set of guidelines for optimal well control operations, by integrating current best practices through a decision-making system based on Artificial Bayesian Intelligence.

The proposed decision-making model follows a causal and an uncertainty-based approach capable of simulating realistic conditions on the use of well control operations. For instance, as the user varies the operation, rig and crew capabilities, kick details (such as slim hole, deviated or horizontal well), the system will show the optimum practices for circulation method.

The advantage of the Artificial Bayesian Intelligence method is that it can be updated easily when dealing with different opinions. The outcome of this paper is userfriendly software, where you can easily find the specific subject of interest, and by the click of a button, get the related information you are seeking. The model is divided into three parts or decisions. Each decision has uncertainties and consequences nodes. The consequences node combines the uncertainty nodes where well control expert opinions were used to assign and define the conditional probability distribution. The model then calculates the optimum practices decision.

*Reprinted with permission from "Development of Optimum Well Control Practices Using Artificial Bayesian Intelligence," by Al-Yami, A.S. and Schubert, J., 2012c, OTC 22882, Copyright C 2012, Society of Petroleum Engineers. 
Fig.21 shows the model which is divided into three parts of uncertainty and decision nodes. The first provides the proposed circulation method decision based on the kick details provided. The second part provides the user the optimum recommended practice based on the possible scenarios and operations in well control. The third part provides the user with a quick check list for trouble shooting in case of problems while controlling the well.

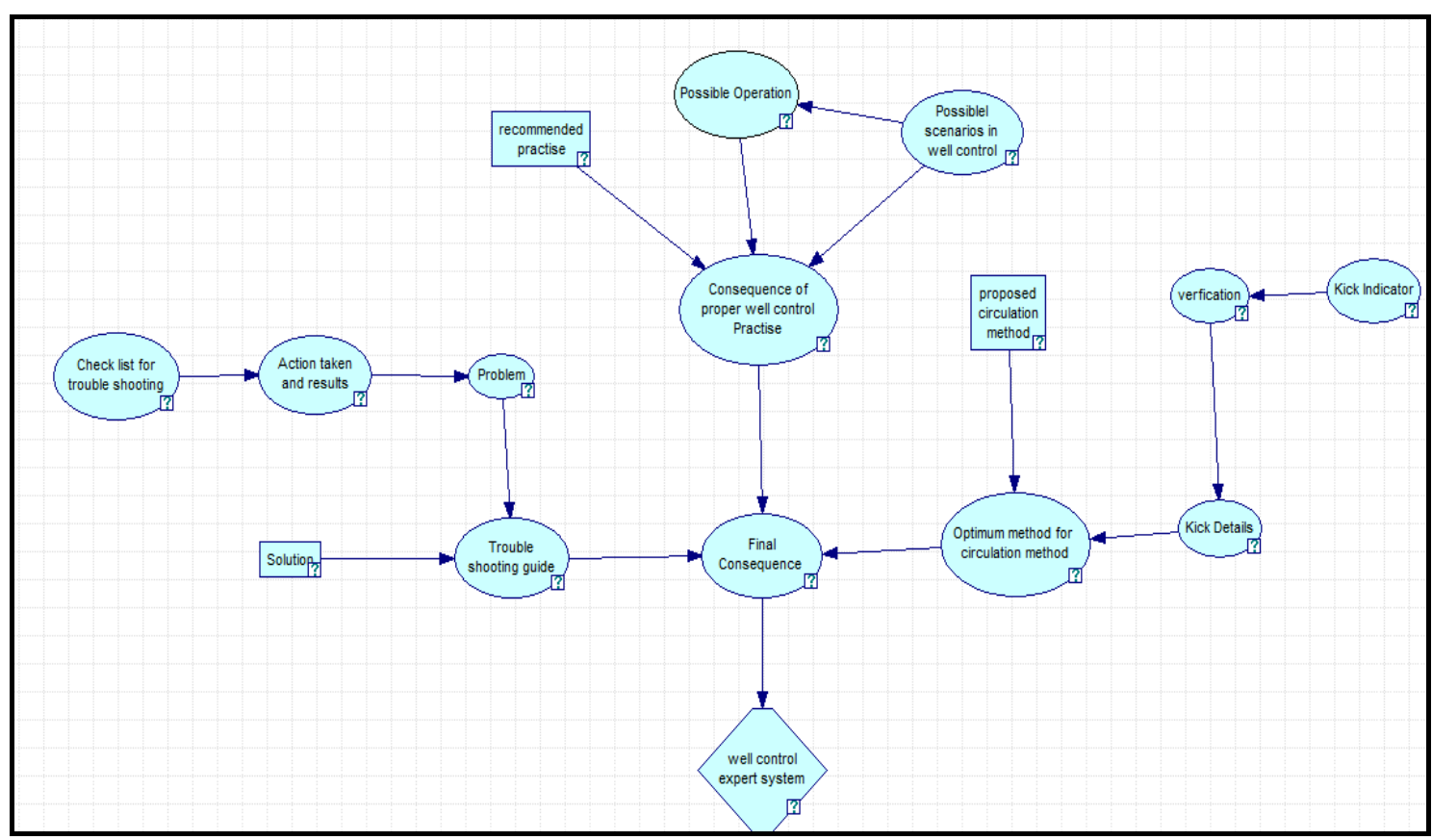

Fig.21: Well control expert model

Kick indicators' uncertainties are shown in Fig.22. The kick can be verified by checking the flow when pumps are off, Fig. 23. 


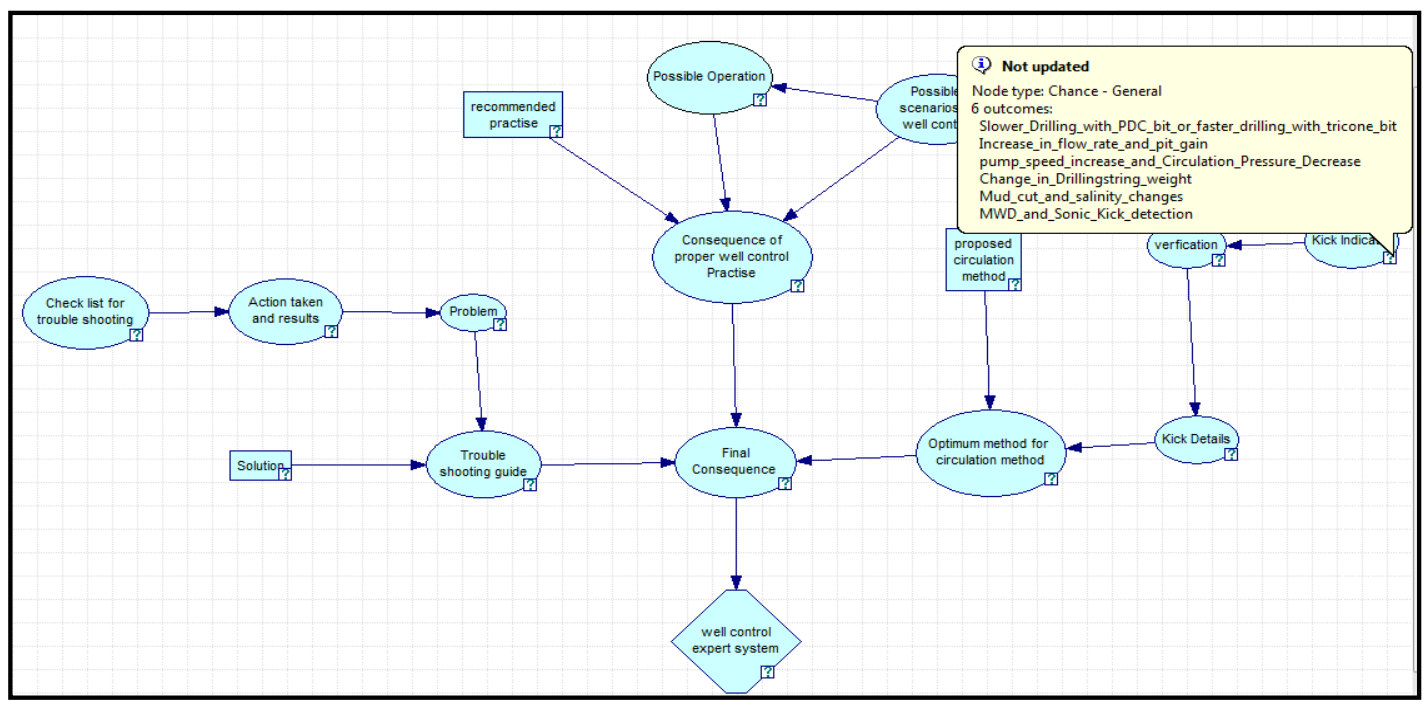

Fig.22: Kick indicators

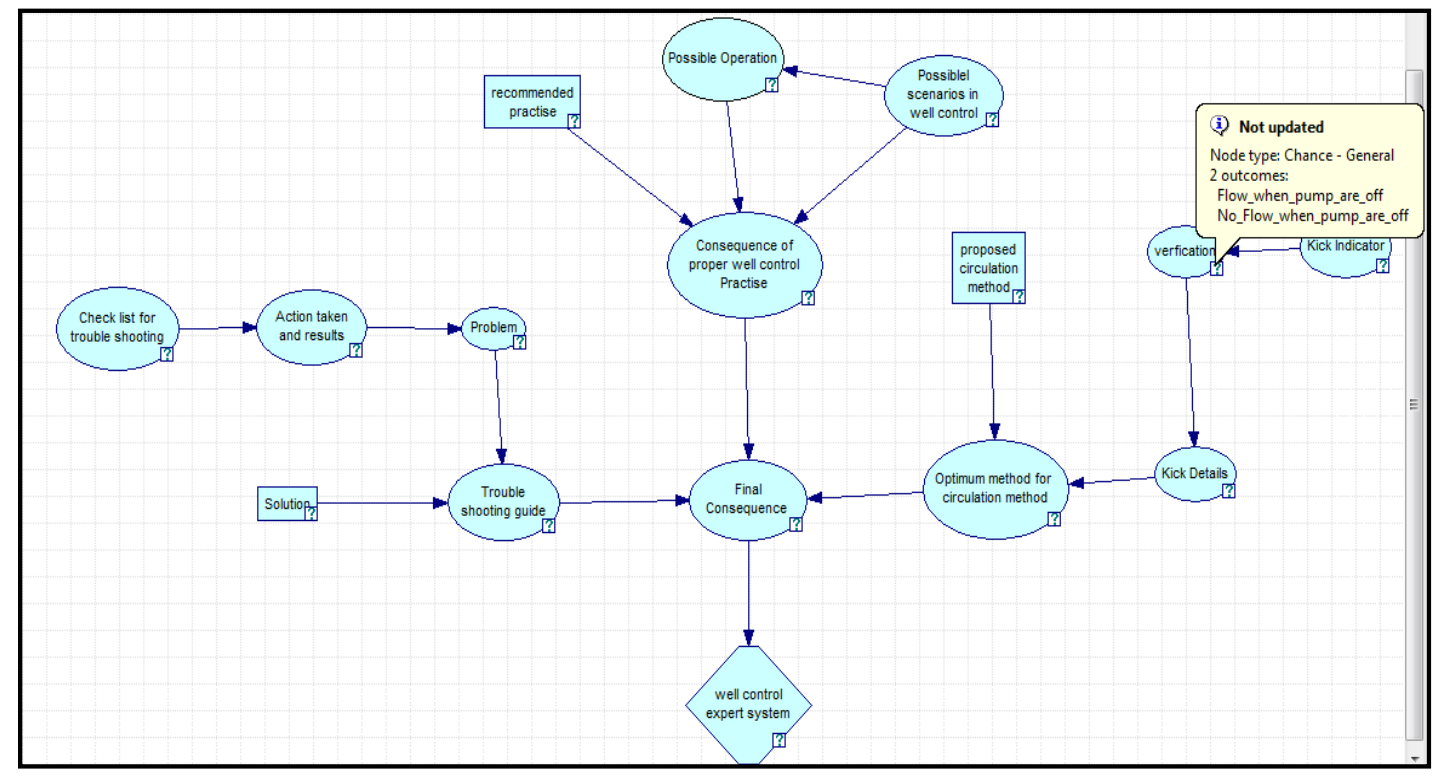

Fig.23: Verification 
The kick details' uncertainty (Fig.24) affects the user selection of proposed circulation methods shown in Fig.25.

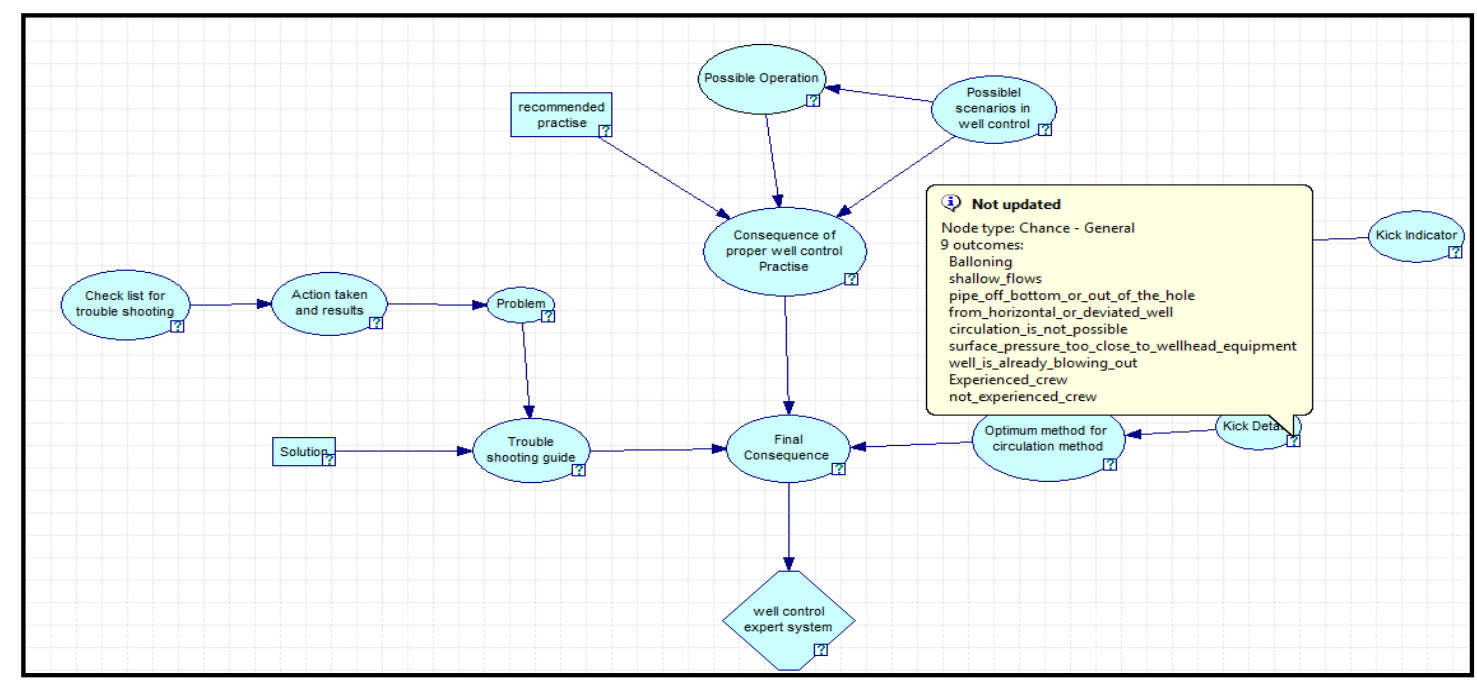

Fig.24: Possible kick details

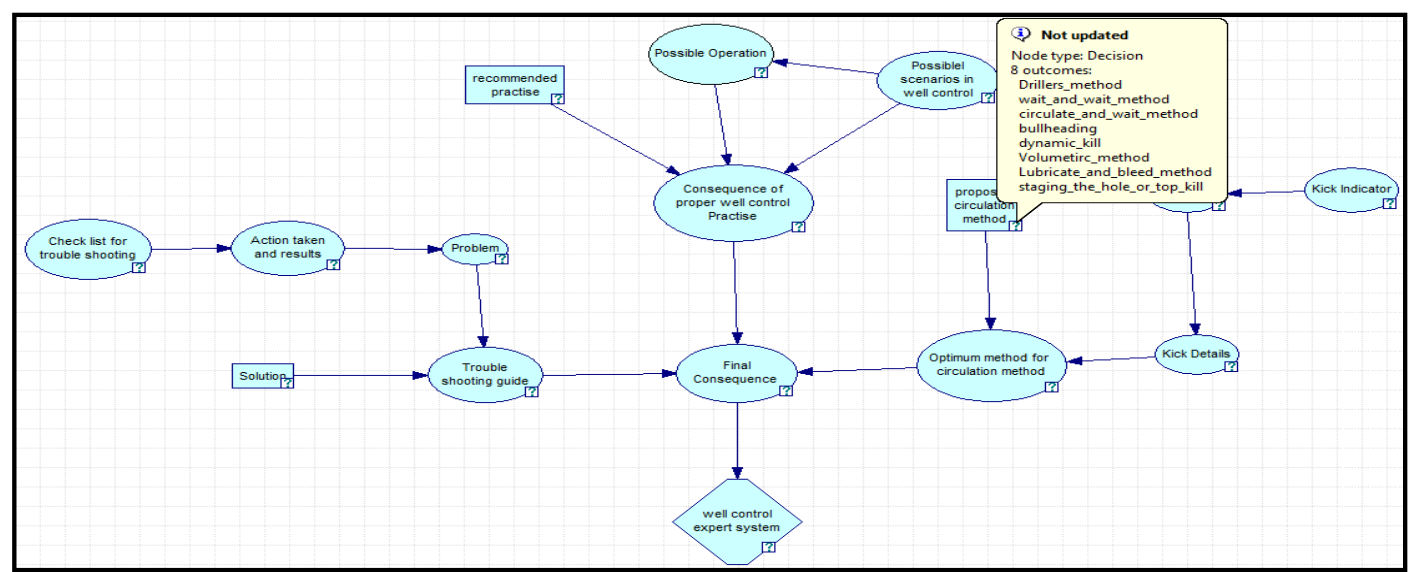

Fig.25: Proposed circulation method 
Experts' opinions were used to build up the node known as consequences for optimum method of circulation method, Fig.26 by assigning 1 to the optimum circulation method. This node can be updated easily when different opinions are presented.

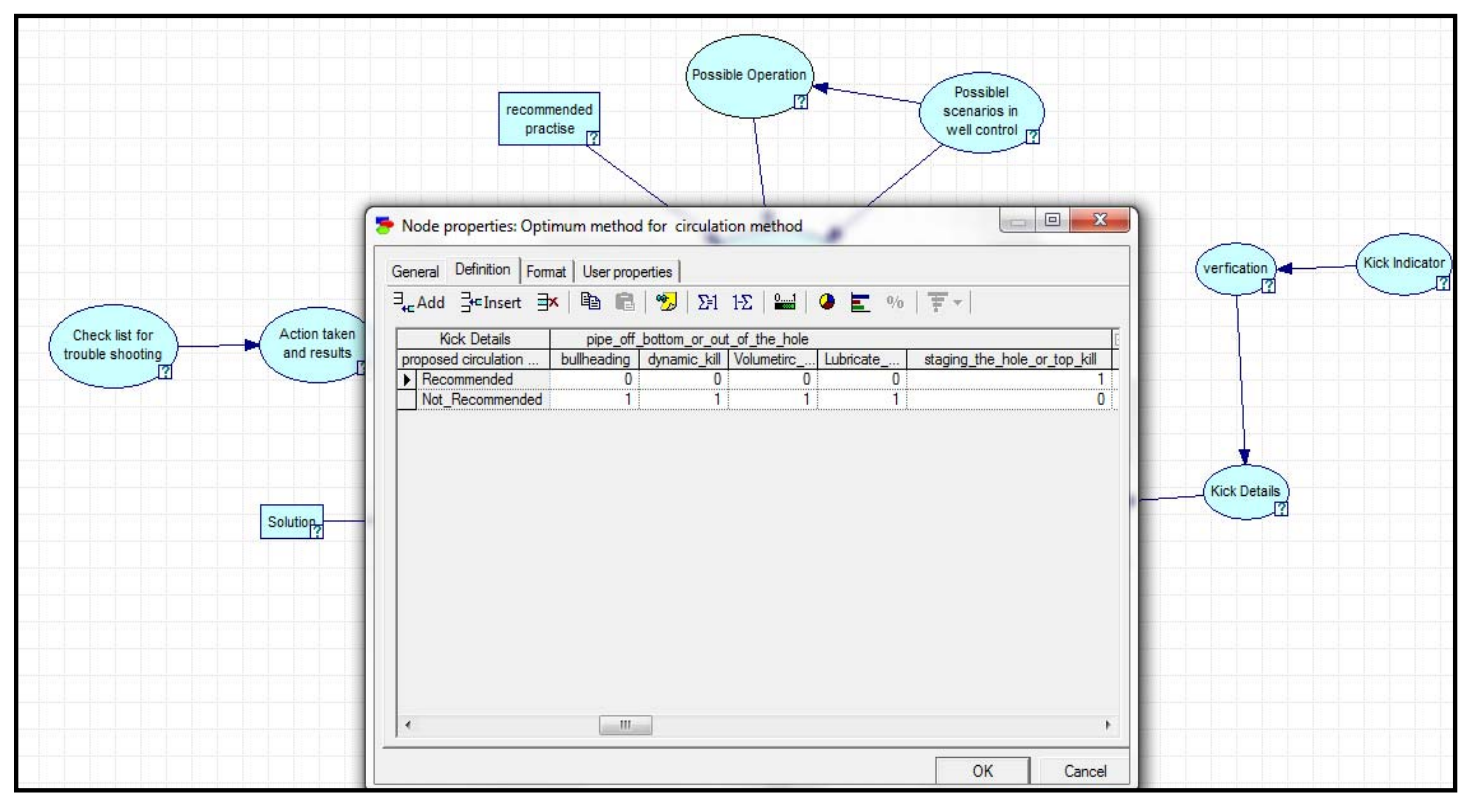

Fig.26: Part of consequences for optimum method of circulation method

The second part is related to proper well control practices under different scenarios such as driller method, killing deep wells, etc as shown in Fig.27. A long list of possible operations (probabilities) was assigned to the possible operation node as shown partially in Fig.28. 


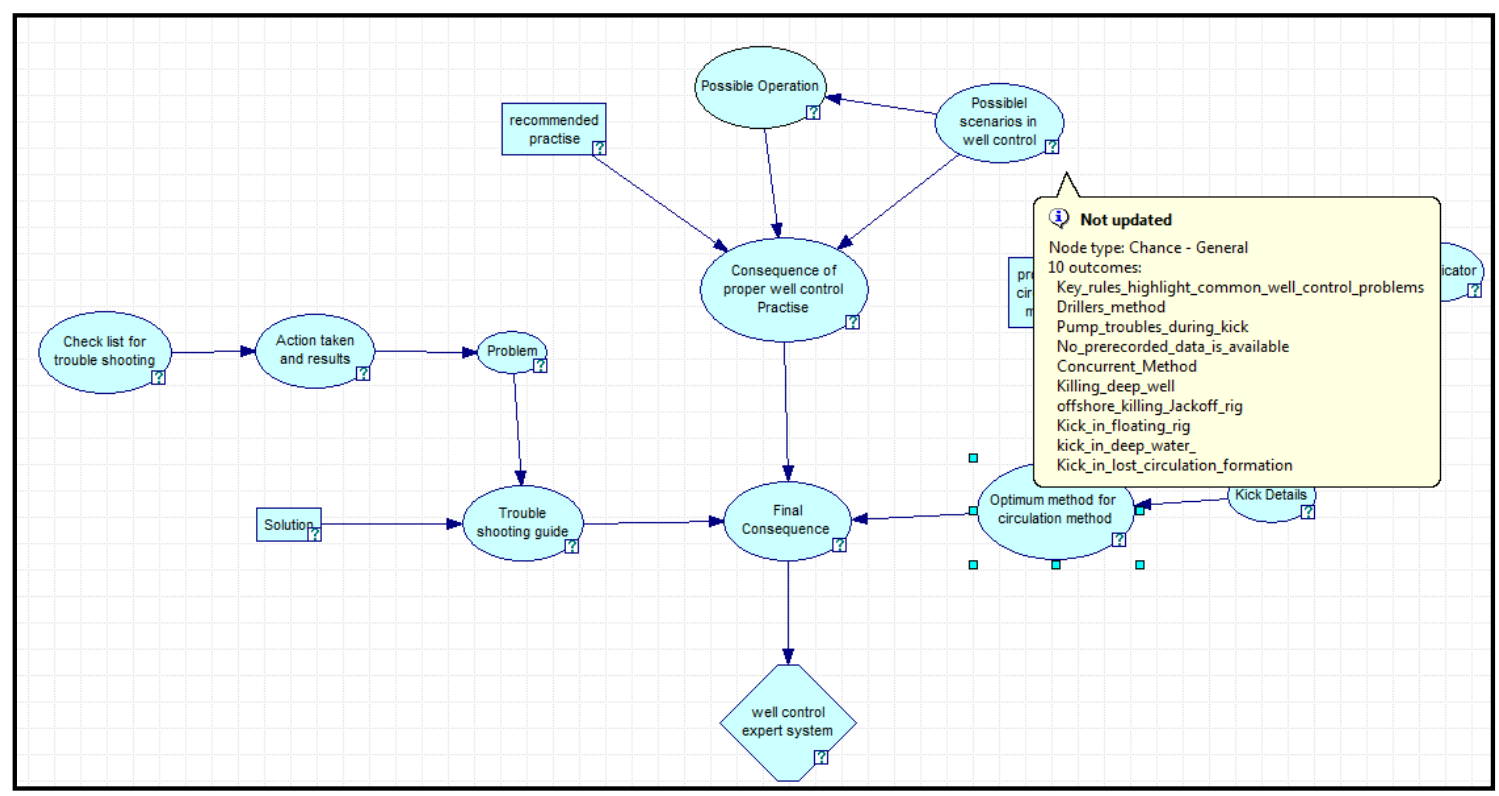

Fig.27: Possible scenarios in well control

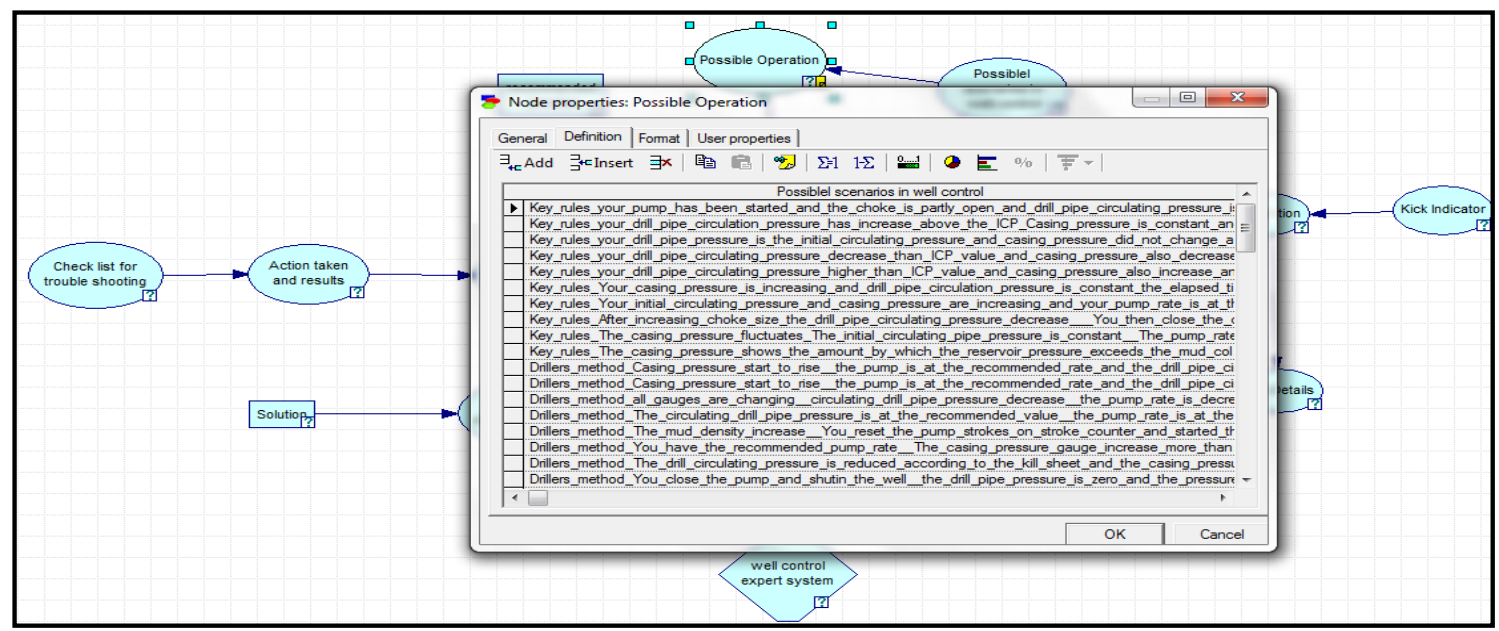

Fig.28: Part of possible operations 
The recommended practice probabilities for proper well control are shown in Fig.29. Experts' opinions were used to assign probability values in the consequence of proper well control practices. Part of the assigned values is shown in Fig.30. Again these probabilities can be updated easily by different experts or at different field conditions.

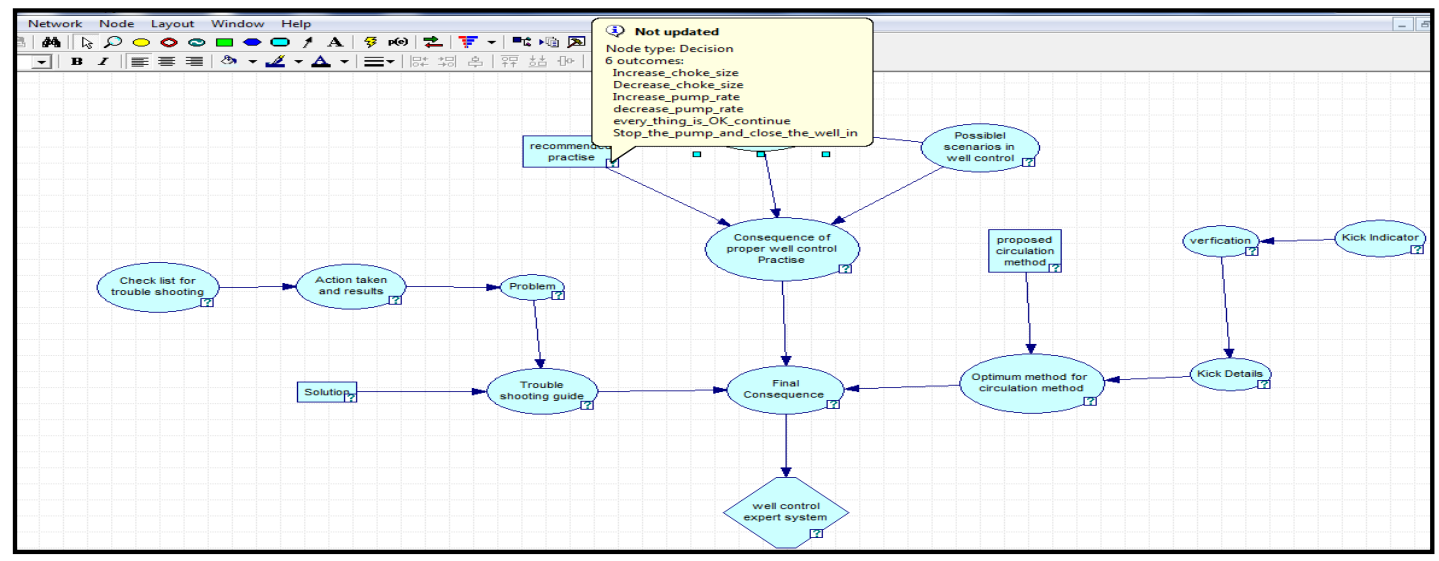

Fig.29: A list of recommended practices

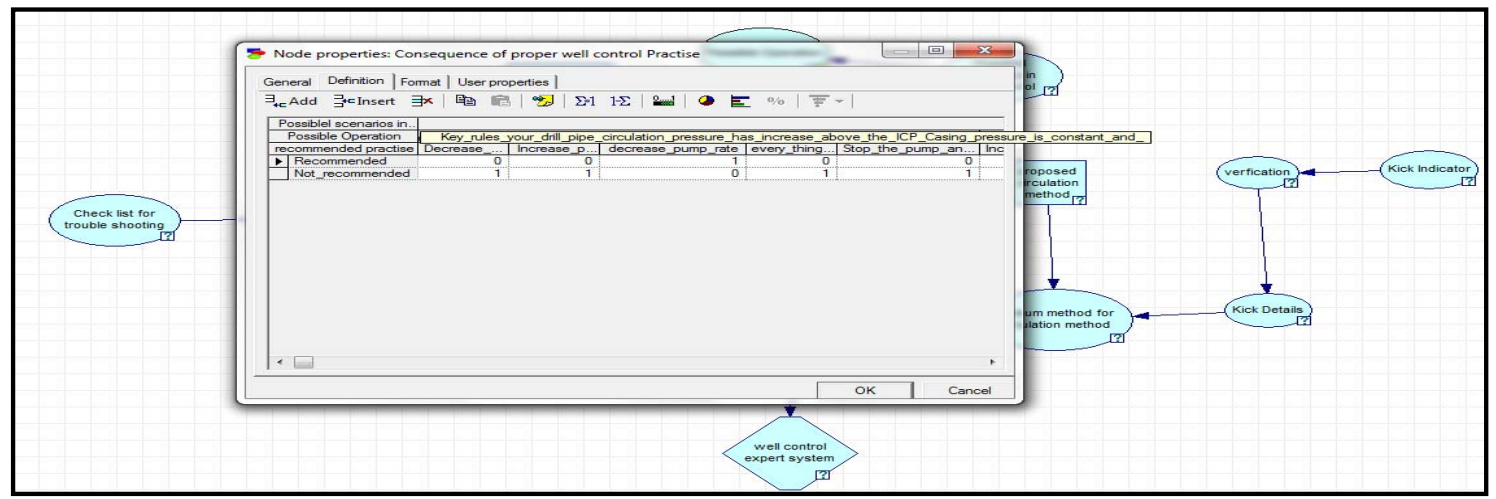

Fig.30: Part of consequences of proper well control practices 
The third part is designed to assist the user to find the optimum solution for a list of potential problems that can be faced during well control operations. A check list of trouble shooting is shown in Fig.31. The model also recommends a list of actions and observes their results by using the action and results node. This node is affected by the user selection from the check list for trouble shooting node. Part of actions and results are shown in Fig.32.

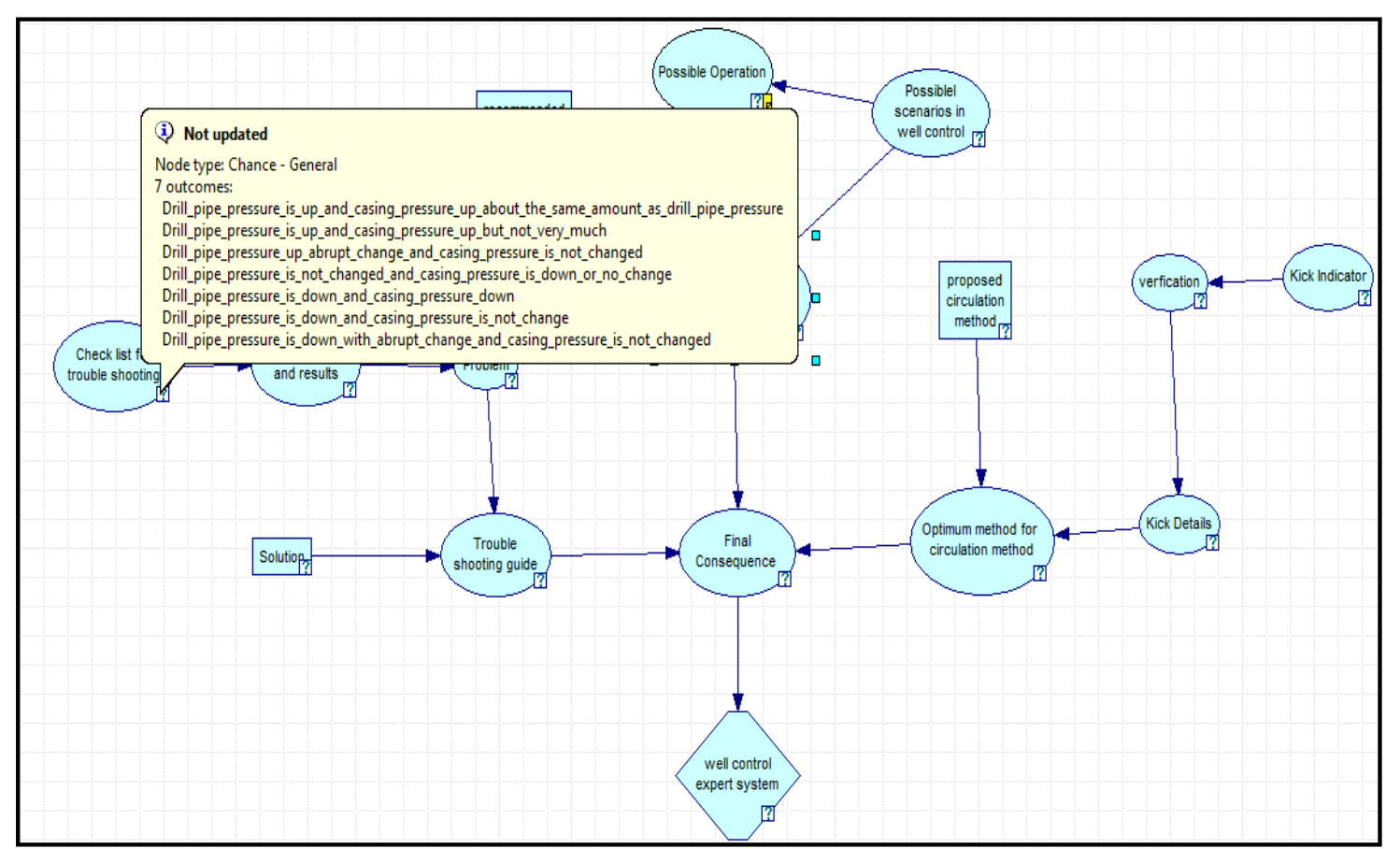

Fig.31: Check list for possible trouble shooting 


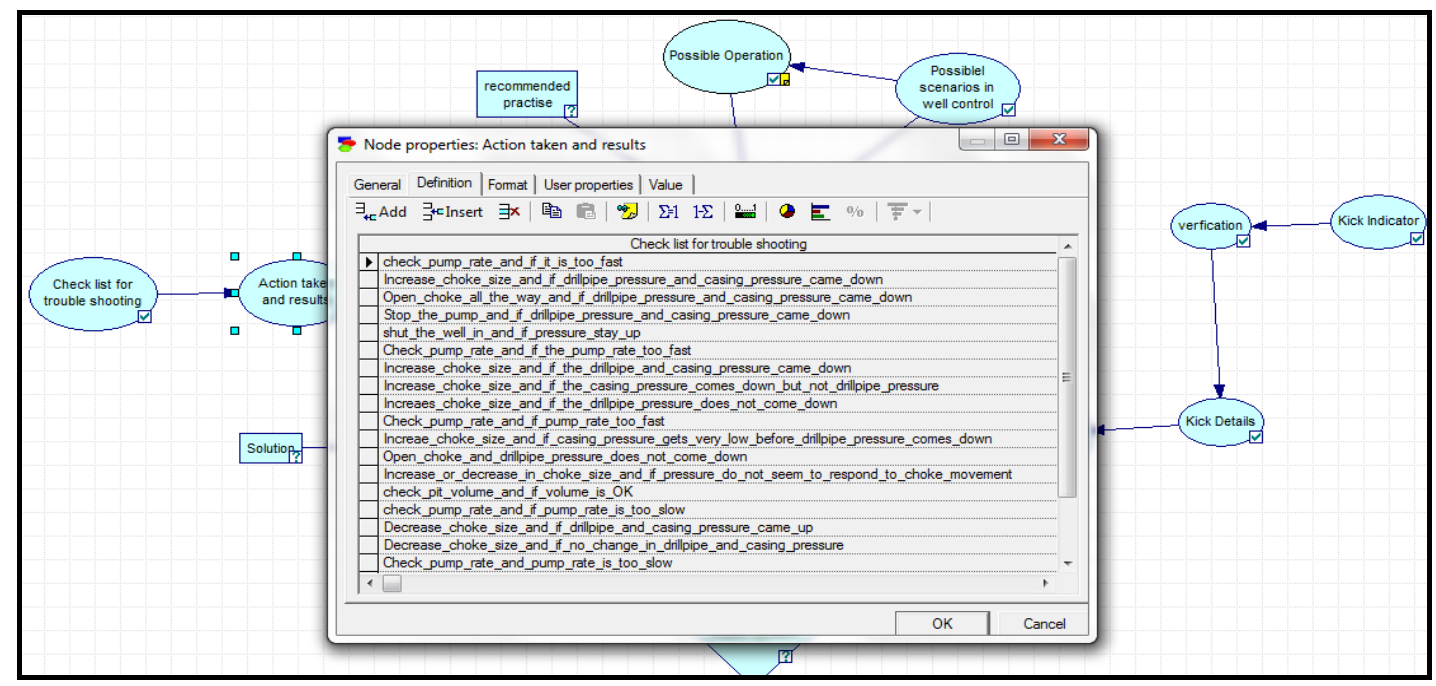

Fig.32: A list of possible actions and results

Based on the user selection of action taken and result node the problem can be identified. A list of problem probabilities is shown in Fig.33. Finally, once the problem is identified, an optimum solution from the solution decision can be recommended. Part of the solution is shown in Fig.34. Experts' opinions are used to assign probability values to the consequences of trouble shooting node. Part of these values is shown in Fig.35. 


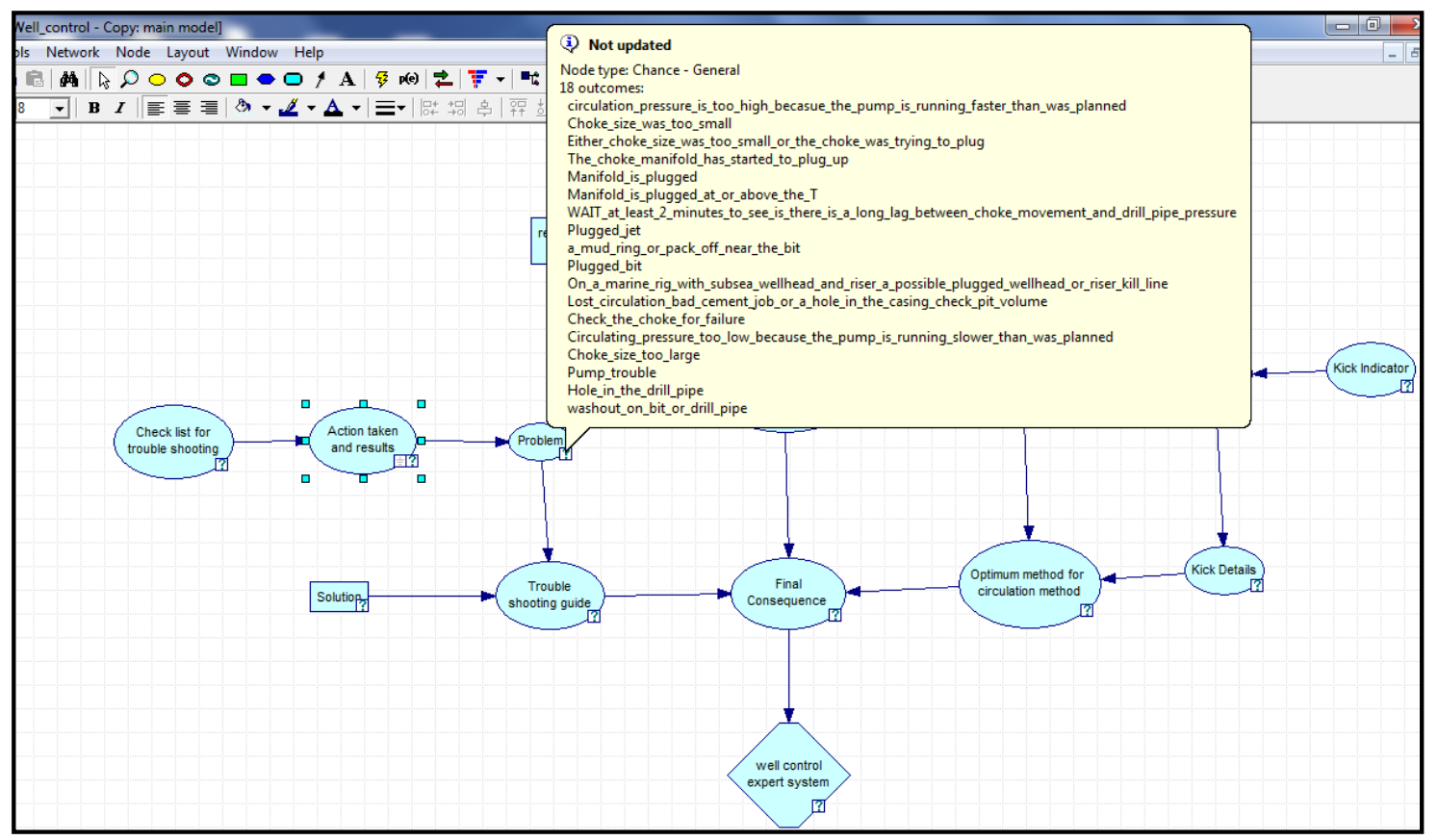

Fig.33: A list of possible problems

(i) Not updated

Node type: Decision

17 outcomes:

Slow_the_pump_rate_down_to_the_planned_rate_if_pressure_come_down_every_is_oK

If_the_pressure_come_down_when_the_choke__ize_was_increased_everything_is_ol

if_pressure_come_down_every_thing_is_OK
Switch_to_the_alternative_choke_line_and_clear_the_manifold

Switch_to_alternate_choke_line_if_pressure_come_down_go_back_to_well_killing

Close_the_master_valve_on_the_kill_line_release_the_pressure__from_the_manifold_and_clean_it_out

Allow_for_long_time_lag_with_big_gas_kicks

Raise_or__eciprocate_the_drill_pipe

Restore_casing_pressure_to_where_it_was_before_the_trouble_started_take_the_changed_drillpipe_pressure_as_the_new_constant_circulating_pressure_or_stop_the_pump_and_shut_in_the_well_and_bleed_the_pressure_off_the

Slow_the_pump_to_the_planned_rate Stop_the_pump_and__shut_the_well_in_try_rocking_the_pump_to_clear_the_bit_you_may_have_to_shoot_off_or_back_off_the_bit

Pick_a_new_slower_circulating_rate_then_add_lost_circulation_material_drop_a__barite_plug

Increase_pump_rate_to_the_planned_rate

Stop_the_pump_and_shut_the_well_in_you_may_have_strip_out_to_replace_a_joint_of_pipe

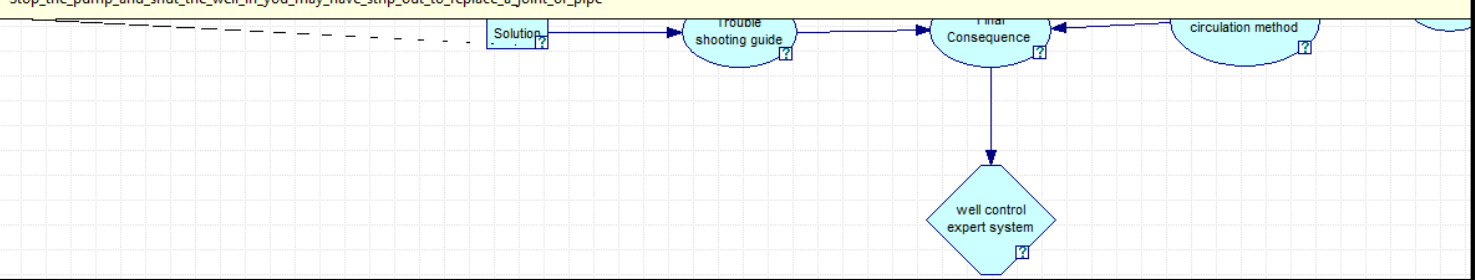

Fig.34: Part of possible solutions 


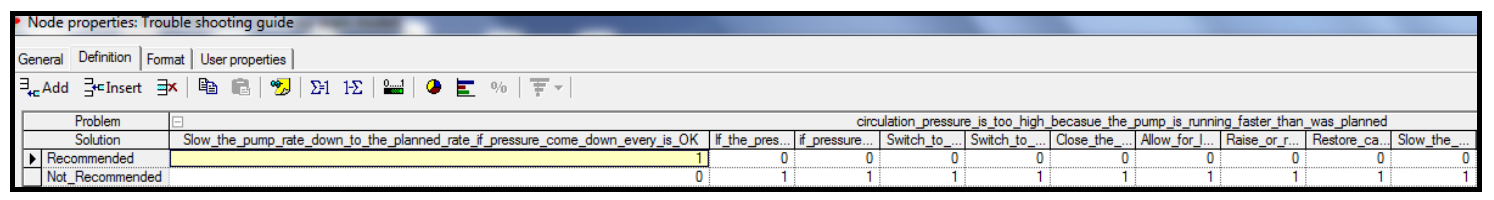

Fig.35: Part of consequences of trouble shooting

The user can select which part he needs individually or can use all parts together at the same time by selecting probability values from desired uncertainty nodes. The final sequence will select the optimum practice from each consequence (optimum method of circulation method consequence, trouble shooting guide consequence and consequence of proper well control practice); part of the final consequence is shown in

\section{Fig.36.}

\begin{tabular}{|c|c|c|c|c|c|c|c|c|c|}
\hline \multicolumn{10}{|c|}{$\exists_{* \subset}$ Add $\quad \exists_{\exists}$ Insert } \\
\hline \multicolumn{2}{|c|}{ Optimum method for } & \multicolumn{4}{|c|}{ Recommended } & \multicolumn{4}{|c|}{ Not_Recommended } \\
\hline \multicolumn{2}{|c|}{ Trouble shooting guide } & \multicolumn{2}{|c|}{ Recommended } & \multicolumn{2}{|c|}{$\exists$ Not_Recommended } & \multicolumn{2}{|c|}{ Recommended } & \multicolumn{2}{|c|}{ - Not_Recommended } \\
\hline$\nabla$ & Not_recommended & 0 & 1 & 1 & 1 & 1 & 1 & 1 & 1 \\
\hline
\end{tabular}

Fig.36: Final consequences 


\section{CHAPTER VI}

\section{CEMENTING MODEL*}

Cementing is an important factor in drilling and completion operations. Good cementing practices are required for a proper advancing in drilling and production operations. Successful cementing practices start with the design of effective cement slurries.

The objective of this chapter is to propose a set of guidelines for the optimal design of cement slurries, by integrating current best practices through a decisionmaking system based on Artificial Bayesian Intelligence. Best cementing practices collected from Saudi Arabia fields are integrated into a Bayesian Network BN to simulate likely scenarios of its use, which will honor efficient designs when dictated by varying well objectives, well types, temperatures, pressures, and drilling fluids.

The proposed decision-making model follows a causal and an uncertainty-based approach capable of simulating realistic conditions on the use of cement slurries during drilling and completion operations. For instance, well sections and drilling operations dictate the use of the proper cement design, which may include the use of specific additives according to the particular modeling scenarios.

*Reprinted with permission from "Drilling Expert System for the Optimal Design and Execution of Successful Cementing Practices," by Al-Yami, A.S., Schubert, J., Medina, C., and Ok-Youn, Y., 2010b, IADC/SPE 135183, Copyright (C) 2010, Society of Petroleum Engineers 
These include operations on surface casing, top jobs, intermediate casings, cementing in weak formations, squeeze treatment, kickoff and isolation plugs, horizontal, and vertical completions, among others.

Fig.37. shows the cementing expert model. Six uncertainty nodes are defined for this model (well type, objectives, bottom hole static temperature, pumping time, drilling fluids, and consequences). This considers three decision criteria. The three decisions are a) recommended cementing formulations, b) recommended spacers formulations and c) recommended operational practices.

The uncertainty node corresponding to the well type enables the drilling engineer to set his/her evidence (i.e. to select his well type) as oil well, or gas well. The bottom hole static temperature uncertainty node enables the selection of the temperature range. Temperature ranges were selected for oil and gas wells up to $400^{\circ} \mathrm{F}$. Bottom hole static temperature affects required pumping time. The user can either select a temperature or a suitable pumping time for the proposed well section. Pumping time ranges up to 8 hours in this model.

The Objective uncertainty node enables the user to select the objective of the operation. Different options are made available for the user. These include kickoff and isolation plugs; squeeze cementing, single stage cementing, conductor, surface, intermediate and production casings. In addition, the objective uncertainty node has cementing long liners, expandable casings, and cementing $\mathrm{CO}_{2}$ injection wells. The Drilling Fluid Type uncertainty node shows possible options such as water based, water 
based with high $\mathrm{Cl}^{-}$content, and oil based mud. The drilling fluid type mainly affects the spacer selection.

The recommended cement formulations decision node contains all possible cementing slurries that correspond to the different well type, objective nodes and bottom hole temperature. The recommended spacer decision node shows all possible spacer formulations (water, water based fluid, special spacer fluid with mutual solvent and water wetting additives). The recommended operational practices decision node shows required actions for each casing type such as multistage operation, optimum pump rate, surface shallow leaks and other best practices related to cementing such as top jobs and cementing plugs recommendations.

The consequences node combines the four uncertainty nodes (well type, required pumping time, objective and drilling fluid) and the three decision nodes (recommended cement formulations, recommended spacers and recommended operational practices). Cementing experts' opinions were used to assign and define the node conditional probability distribution.

The model is designed in a way to give the user options to design well cementing and best practices effectively. The user will select options that match his application from well type, bottom hole temperature or required pumping time, objective and drilling fluid. Then the model (cementing expert utility) will suggest optimum cement formulations, spacer formulations and operational practices that fit the given well conditions. 


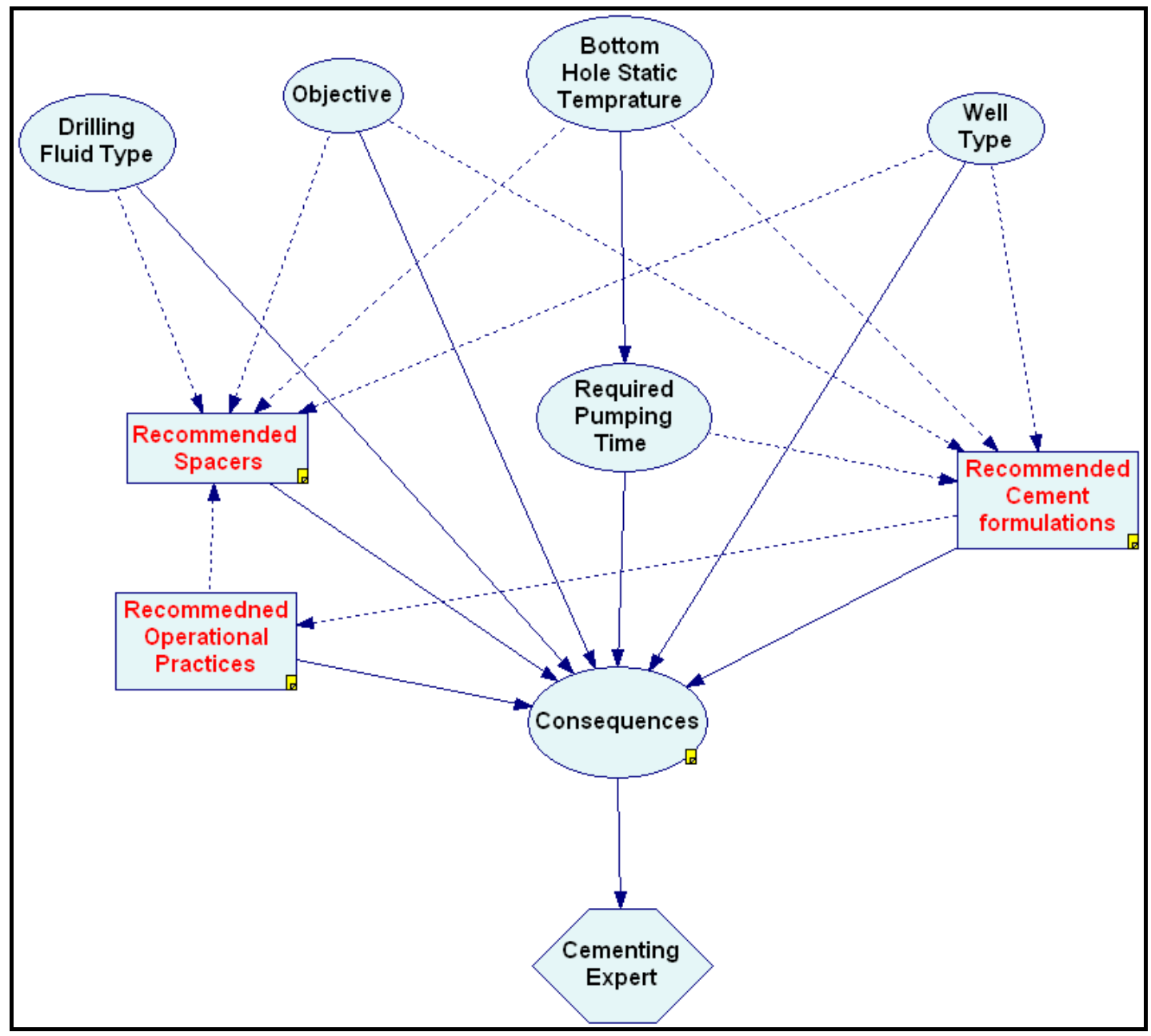

Fig.37: Cementing expert model based on bayesian network 


\section{CHAPTER VII}

\section{UNDERBALANCED DRILLING MODELS*}

The objective of this chapter is to propose a set of guidelines for the optimal underbalanced drilling operations, by integrating current best practices through a decision-making system based on Artificial Bayesian Intelligence.

The outcome of this chapter is user-friendly software, where you can easily find the specific subject of interest, and by the click of a button, get the related information you are seeking. Literature review and experts' opinions were used as evidence to build these models using the proposed Bayesian Network. Variable nodes allow the user to input desired conditions that allows for generating the corresponding best practices.

Underbalanced drilling expert system here is combined into nine models as follow:

- General approach to underbalanced drilling

- $\quad$ Flow underbalanced drilling

- $\quad$ Gaseated underbalanced drilling

- $\quad$ Foam underbalanced drilling

- $\quad$ Air and gas underbalanced drilling

*Reprinted with permission from "Guidelines for Optimum Underbalanced Drilling Practices Using Artificial Bayesian Intelligence," by Al-Yami, A.S. and Schubert, J., 2012d, OTC 22883, Copyright (C) 2012, Society of Petroleum Engineers. 
- $\quad$ Mud cap drilling

- Underbalanced Liner Drilling Model

- Underbalanced Coil tube Model

- $\quad$ Snubbing and Stripping Model

Uncertainty nodes are defined for each model to determine best practices decision nodes. The model is divided into several parts or decisions. Each decision has uncertainties and consequences nodes. The consequences node combines the uncertainty nodes where underbalanced drilling expert opinions were used to assign and define the conditional probability distribution. The model then calculates the optimum practices decision. Below are descriptions of the models.

7.1 General approach to underbalanced drilling model

Fig.38 shows the model which is divided into four parts of uncertainty and decision nodes. The first part describes the formation to be drilled underbalanced and the considerations required, Figs. 39 \& $\mathbf{4 0}$. 


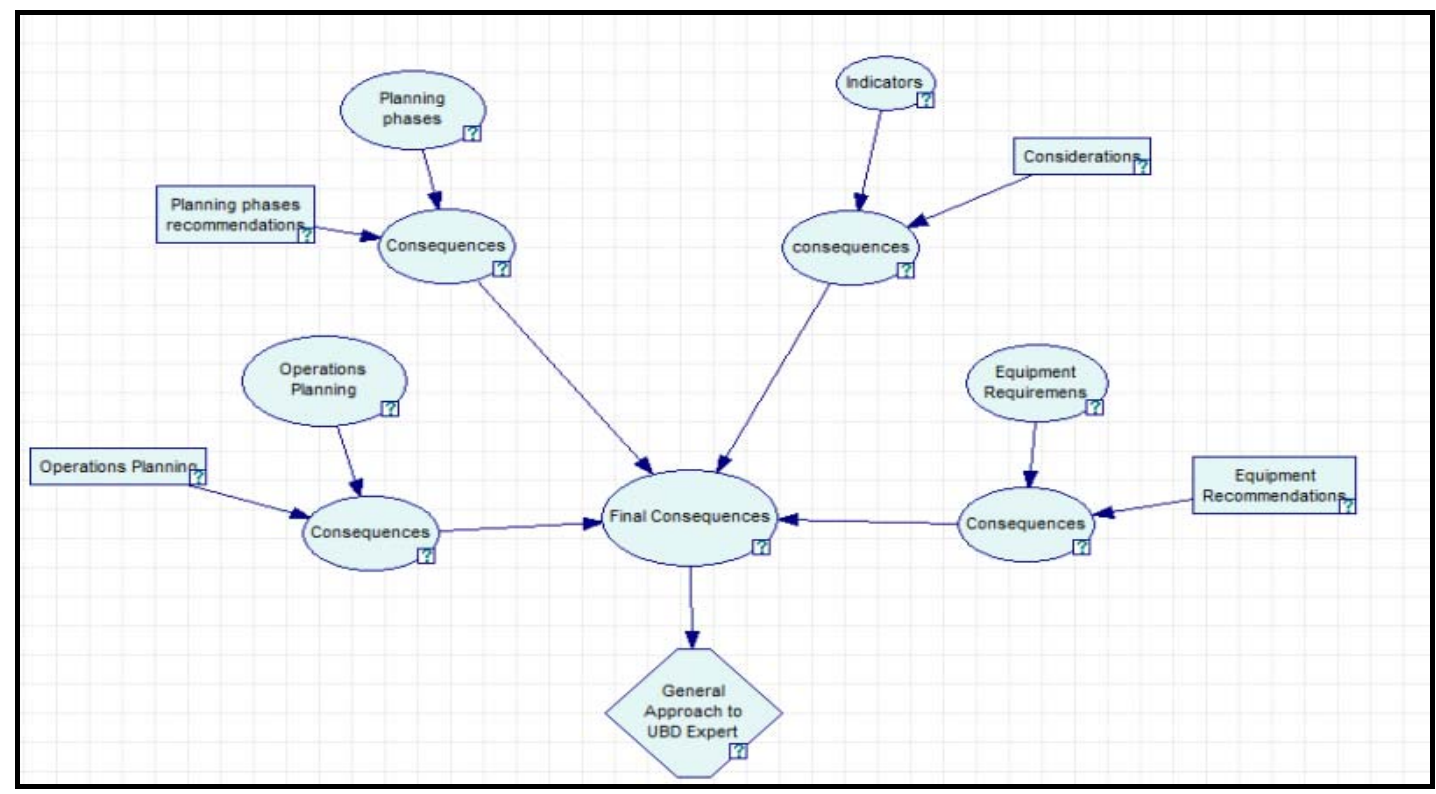

Fig.38: General approach to underbalanced drilling

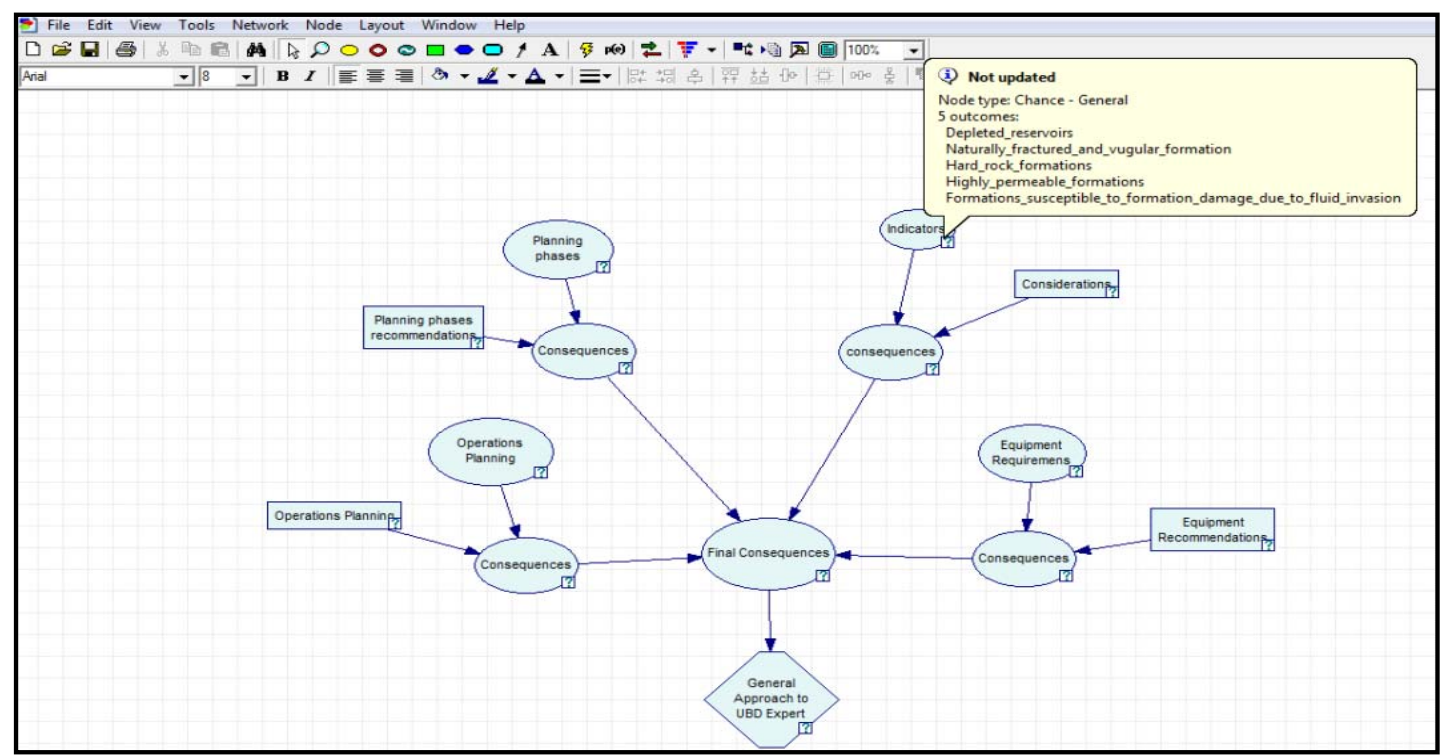

Fig.39: Formations indicators list that need to be considered 


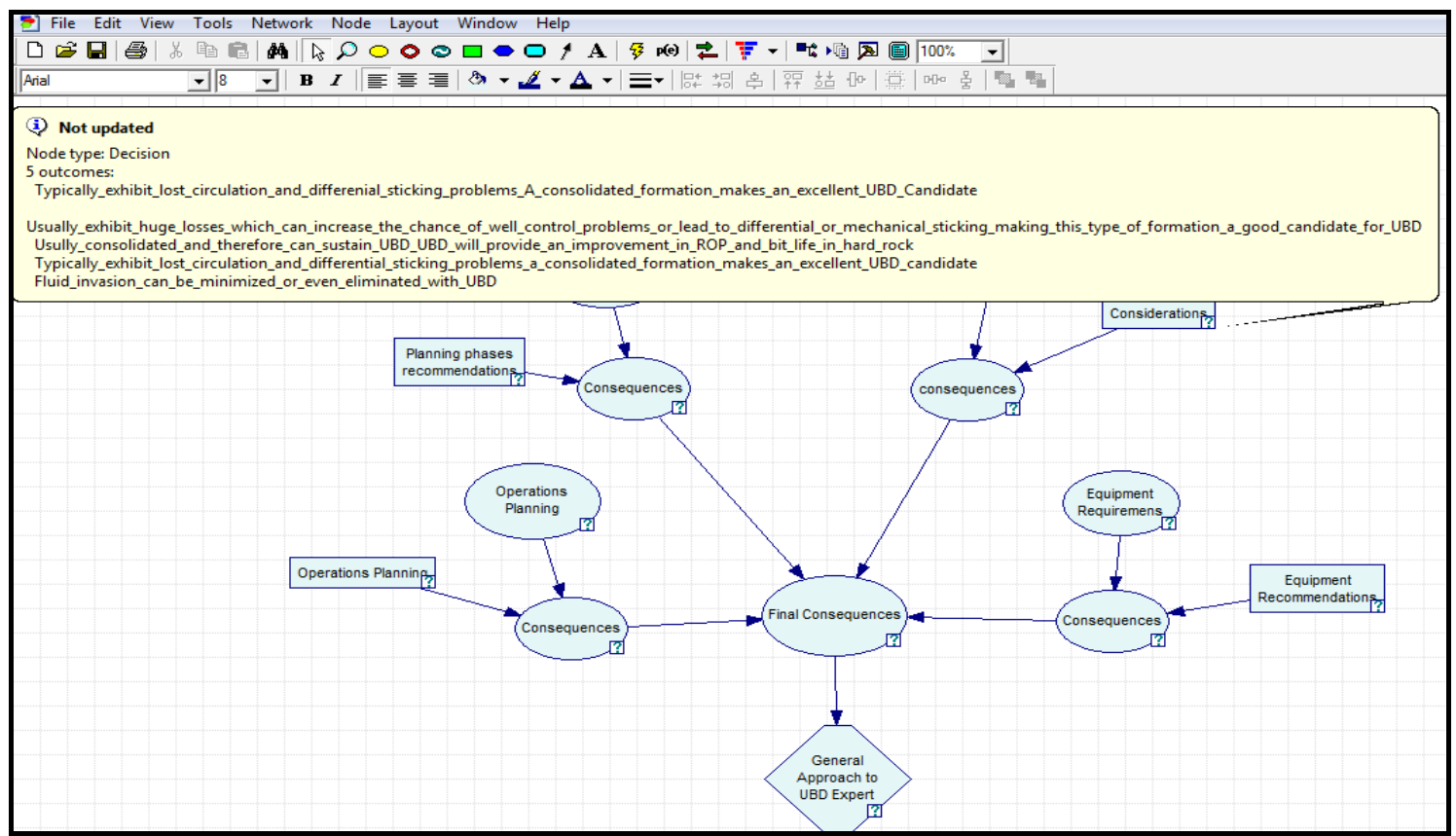

Fig.40: A list of considerations for the different formations indicators available

The second part shows the planning phases' uncertainty (Fig.41) and its corresponding recommendations, Fig.42. 


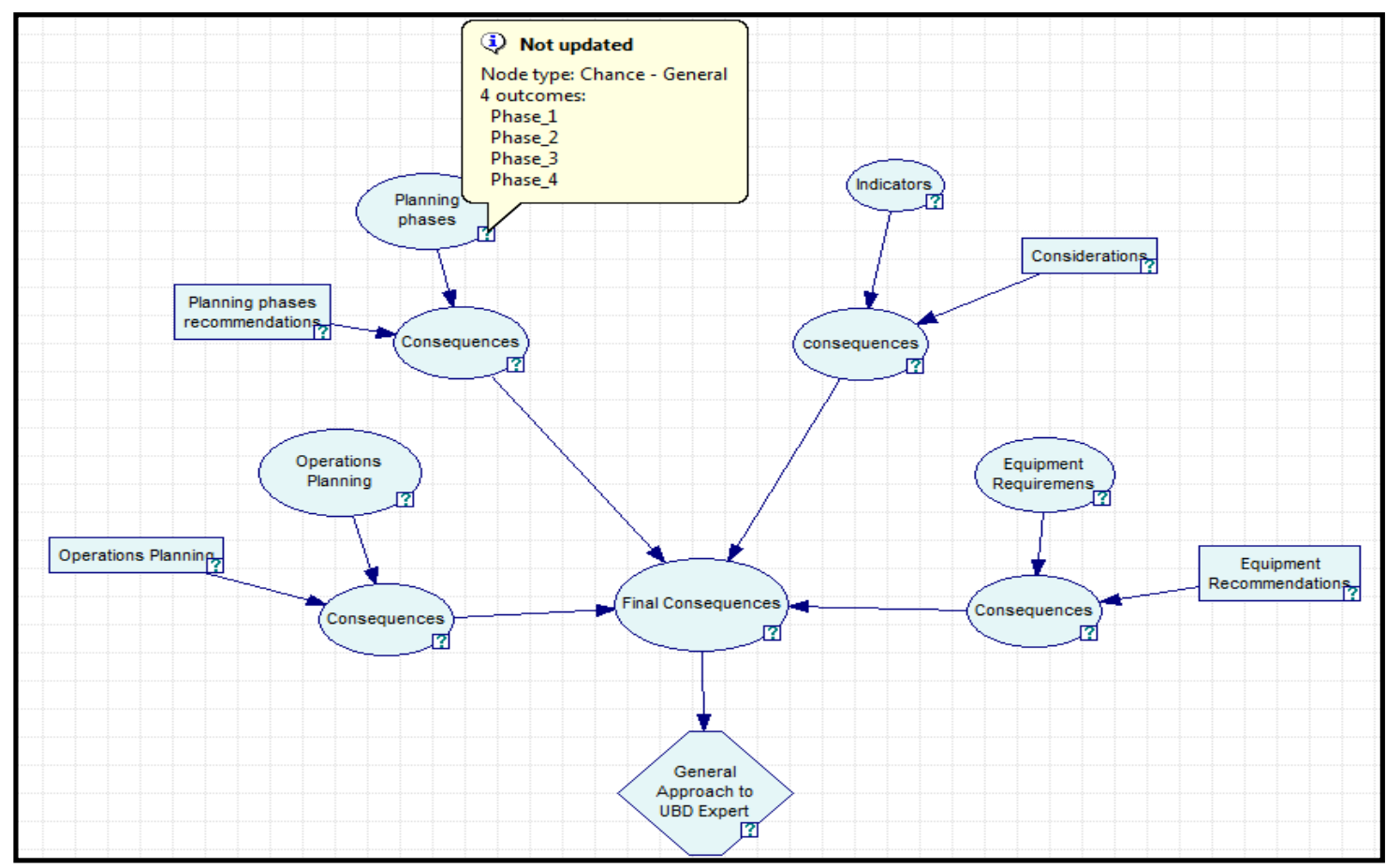

Fig.41: Planning phases

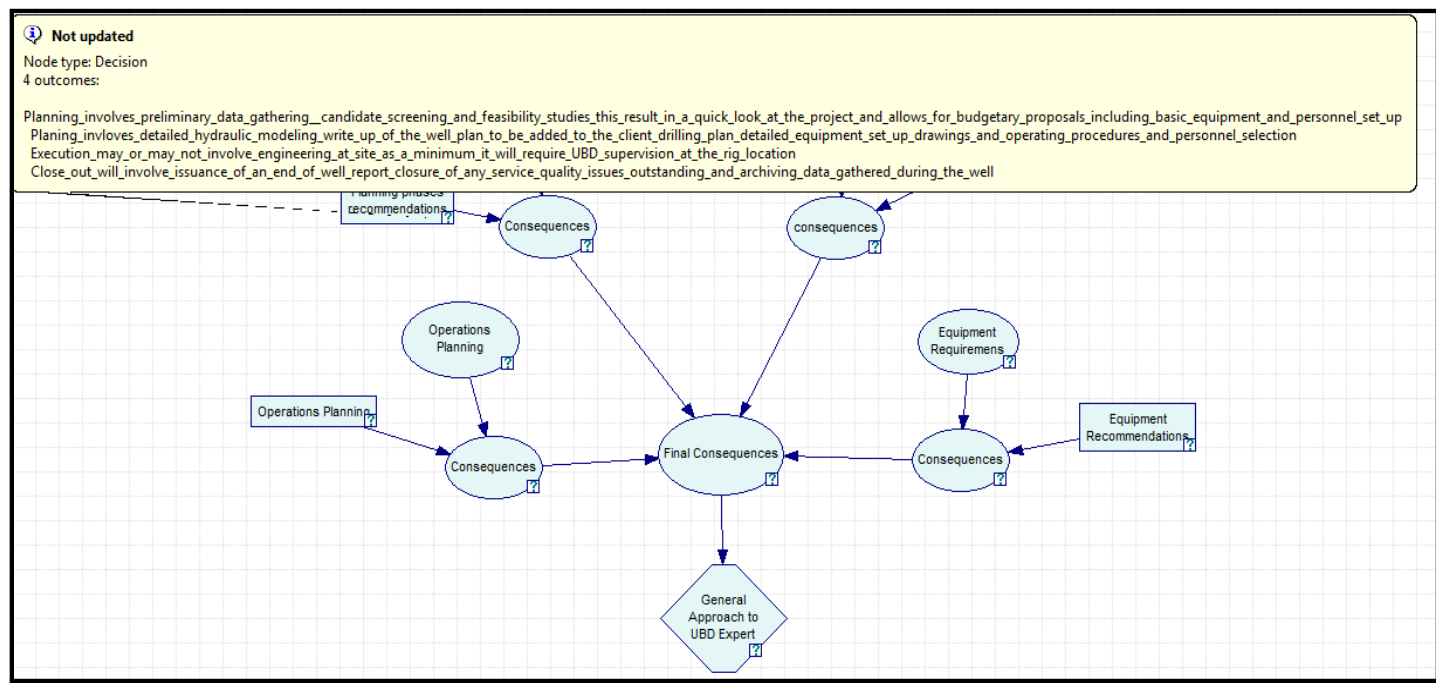

Fig.42: Planning phases recommendations 
The third part shows the equipments requirement uncertainty node or options (Fig.43) and its corresponding decision (equipment recommendations).

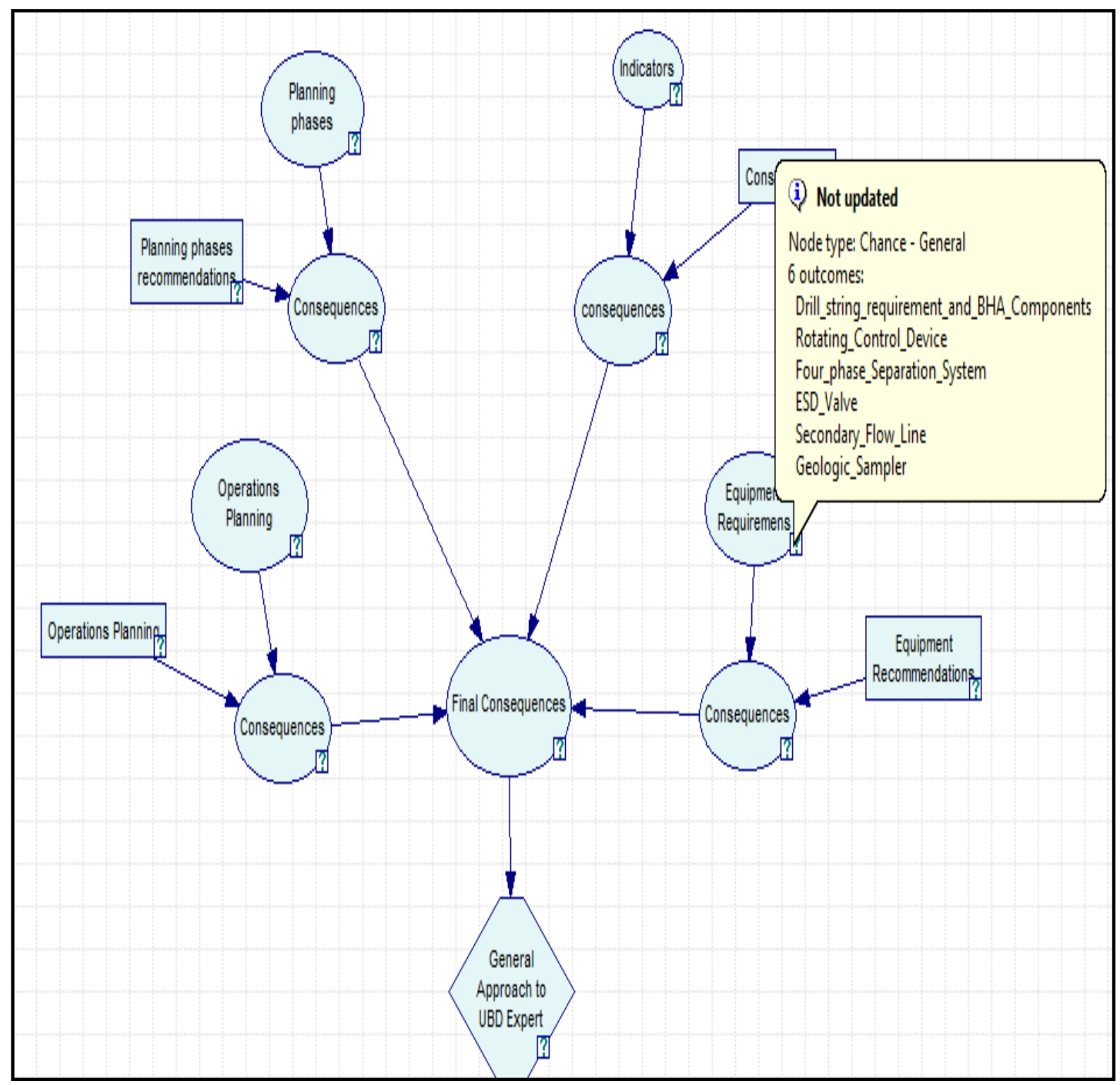

Fig.43: A list of equipments required 
The fourth part shows the operations planning probability and its corresponding decisions, Fig.44.

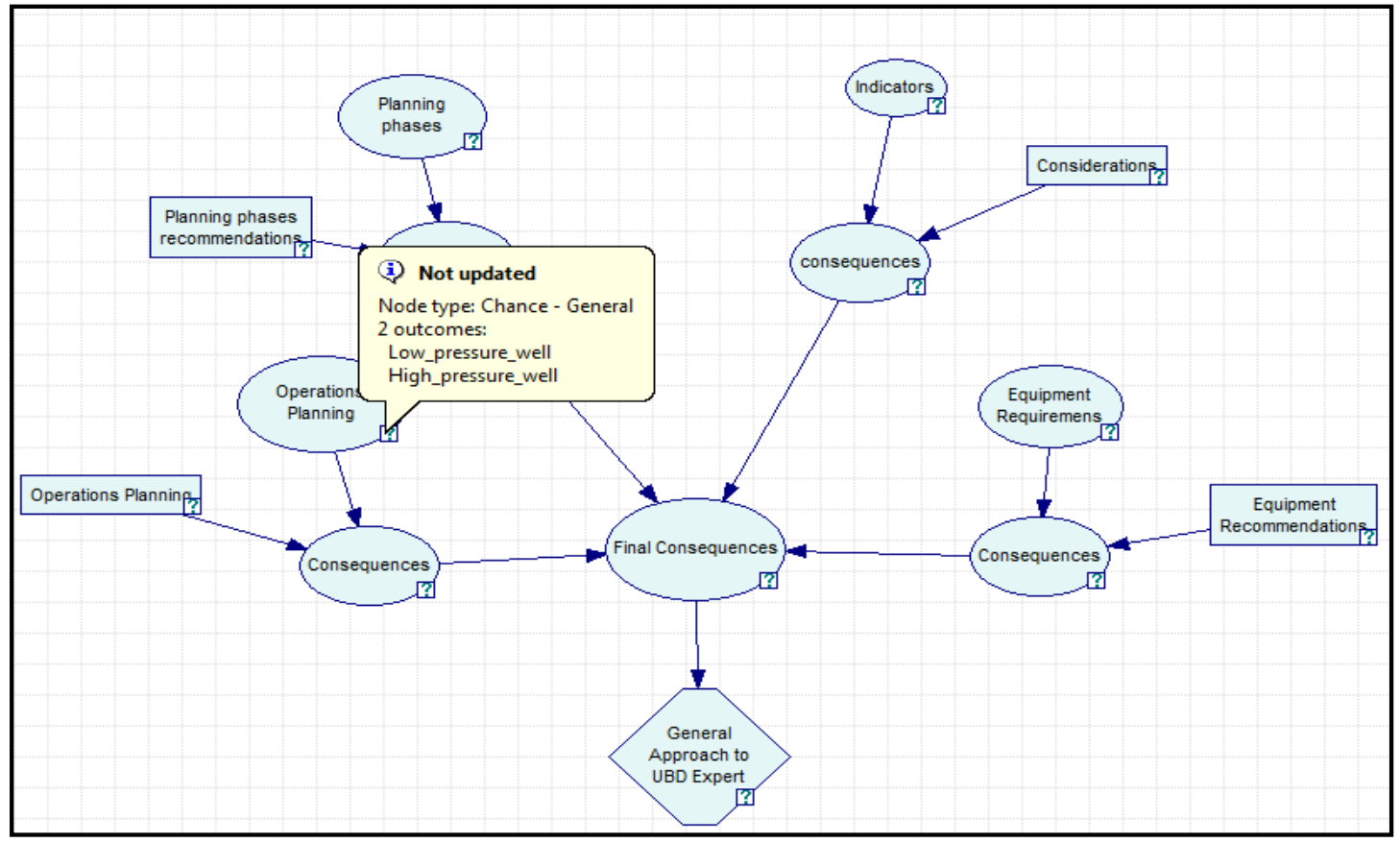

Fig.44: A list of operating planning

7.2 Flow underbalanced drilling model

Fig.45 shows the overall model of flow UBD. The model is divided into three parts (tripping, connection and flow drilling uncertainty and decision nodes). 


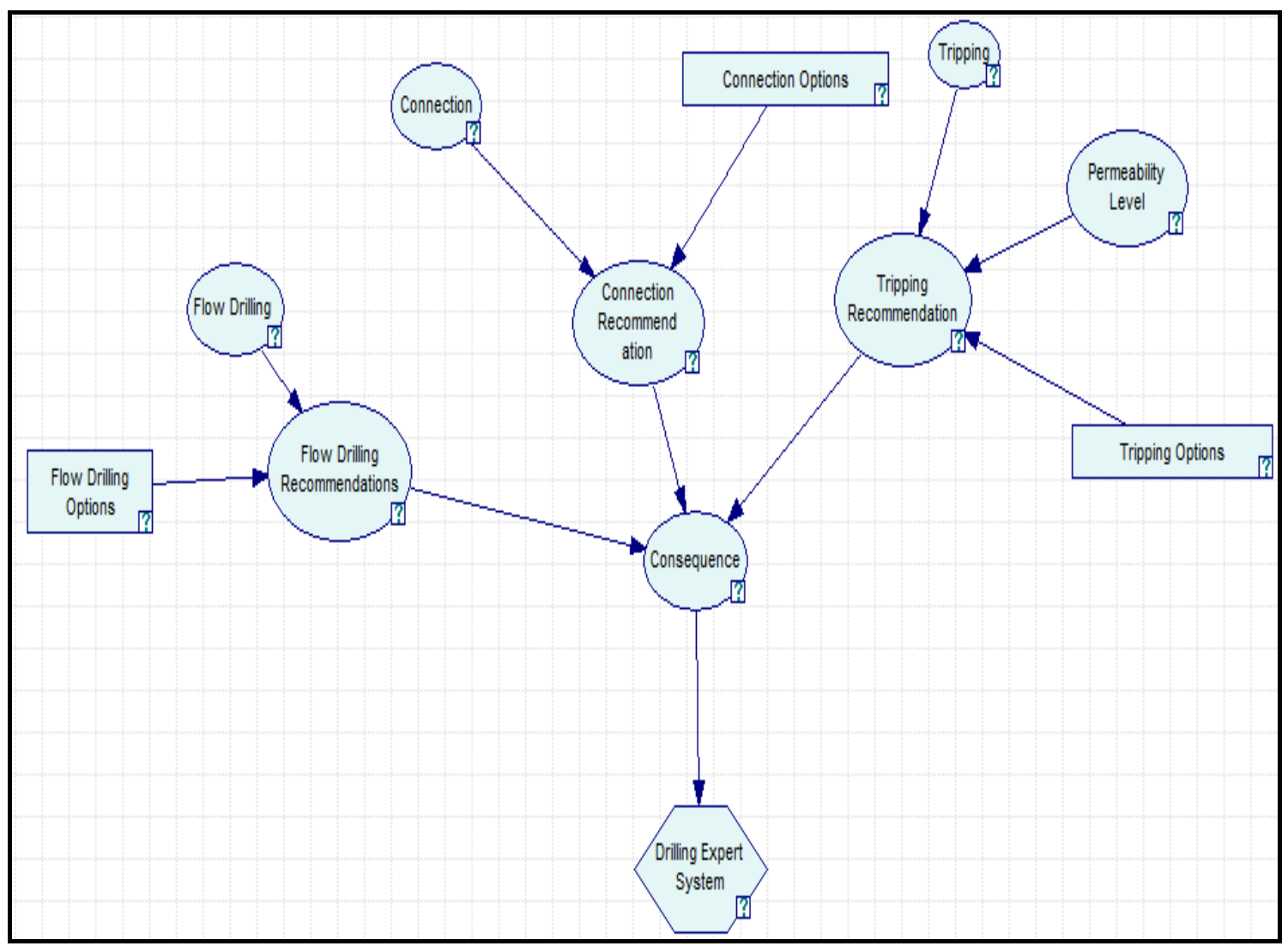

Fig.45: Overall model of flow UBD

Tripping probabilities (Fig.46) and permeability level probabilities (Fig.47) affect the tripping options, Fig.48. 


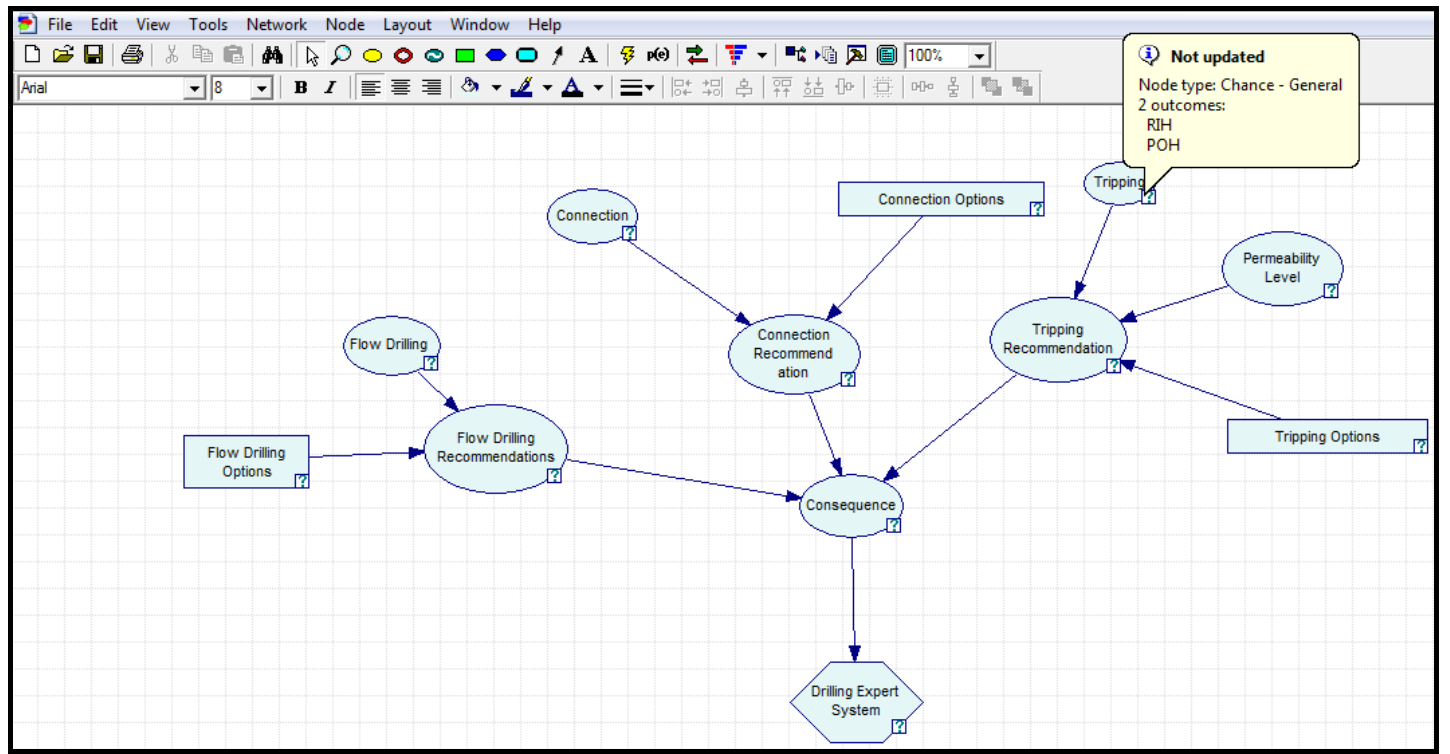

Fig.46: Tripping options in flow UBD

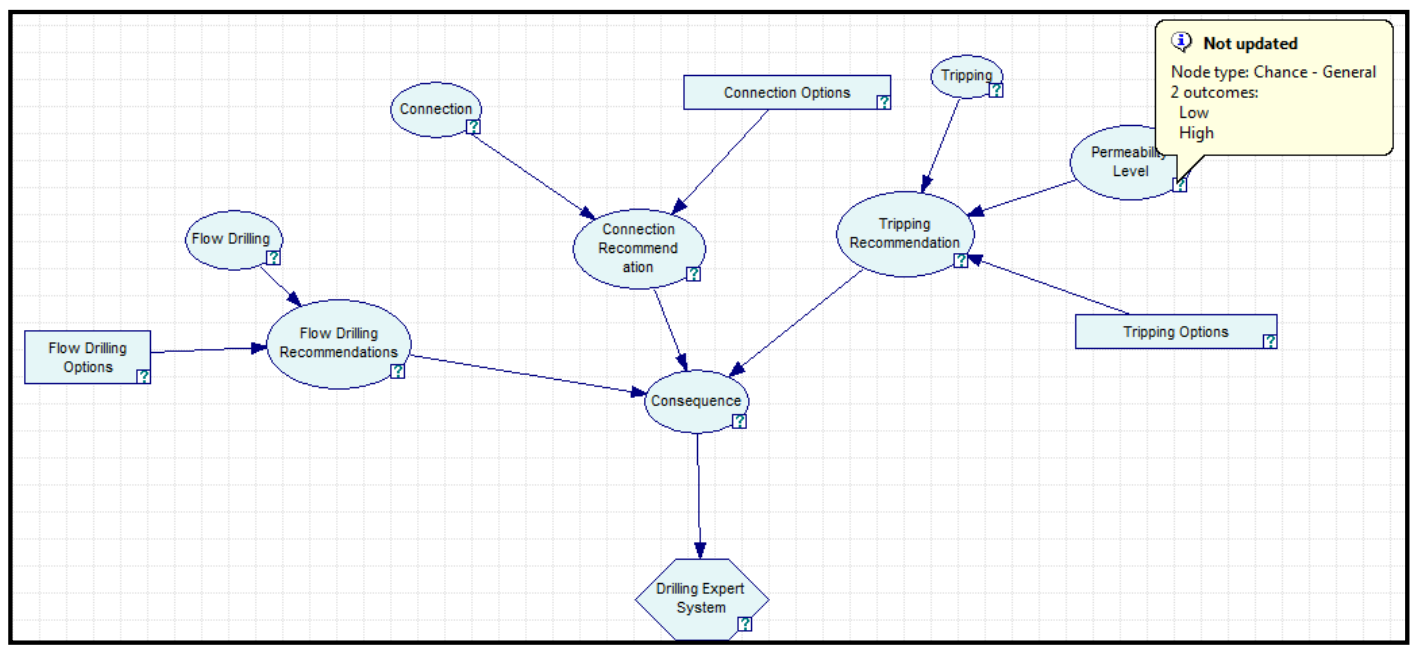

Fig.47: Permeability level options in flow UBD 


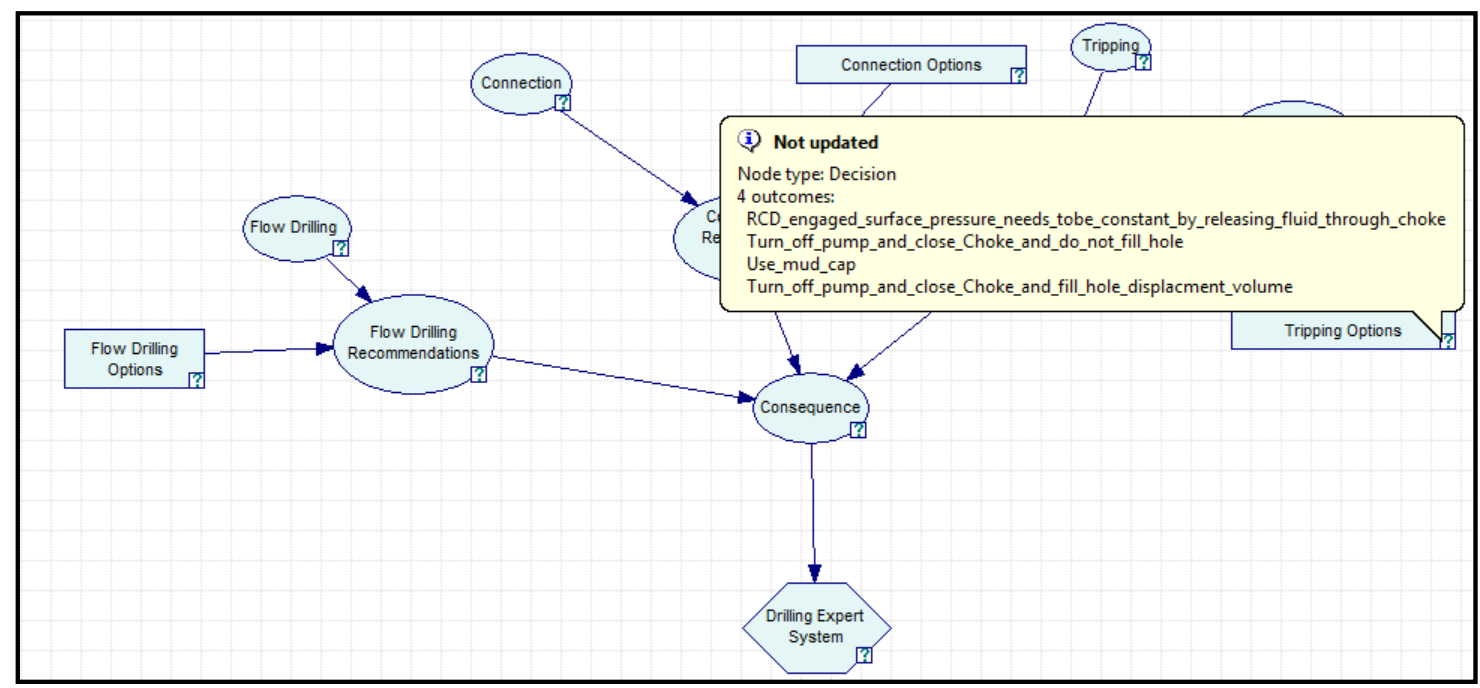

Fig.48: A list of tripping recommendations

The second part is the connection probabilities (Fig. 49) and connection options,

Fig. 50. The third part is related to flow drilling operations, Fig. 51. 


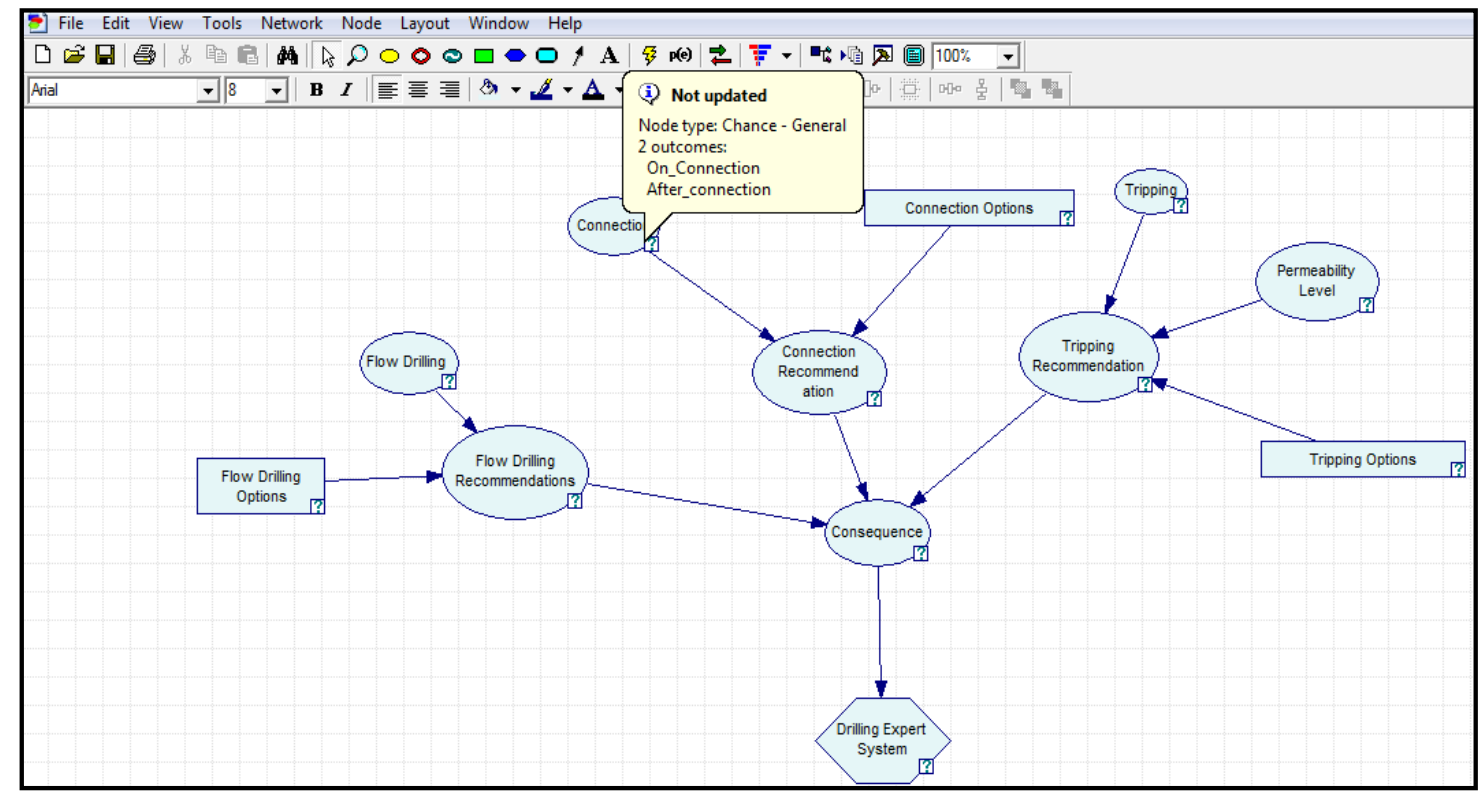

Fig.49: Connection options

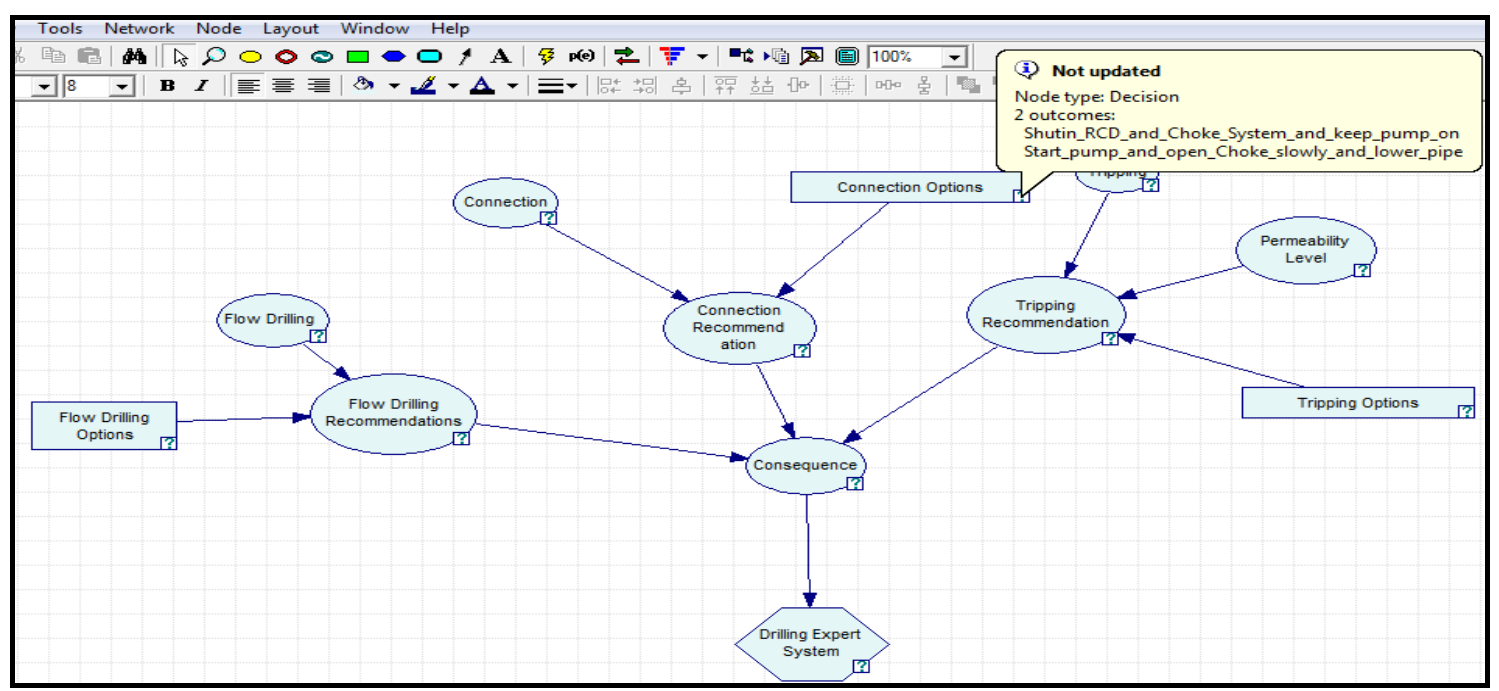

Fig.50: Connection recommendations 


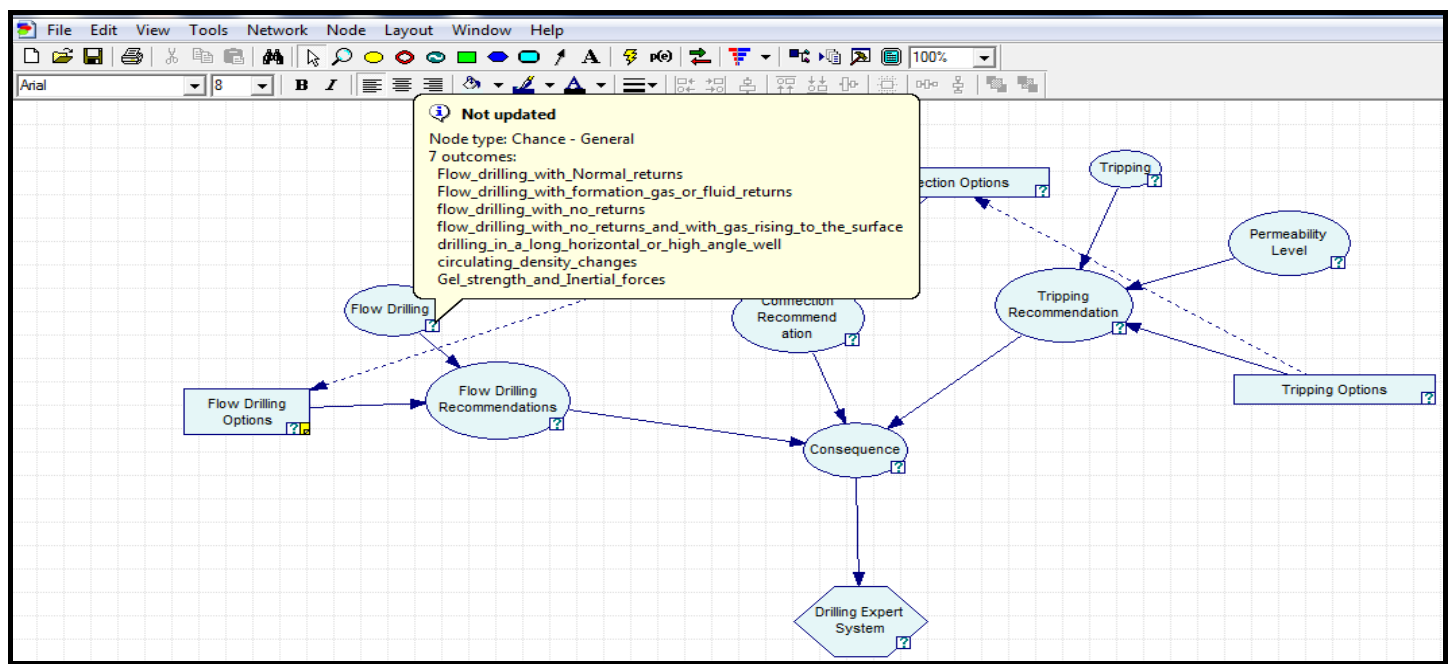

Fig.51: Flow drilling options

If the tripping probability is selected as RIH (Fig.52) and high permeability level (Fig.53) then the optimum tripping operation is to use mud cap, Fig. 54.

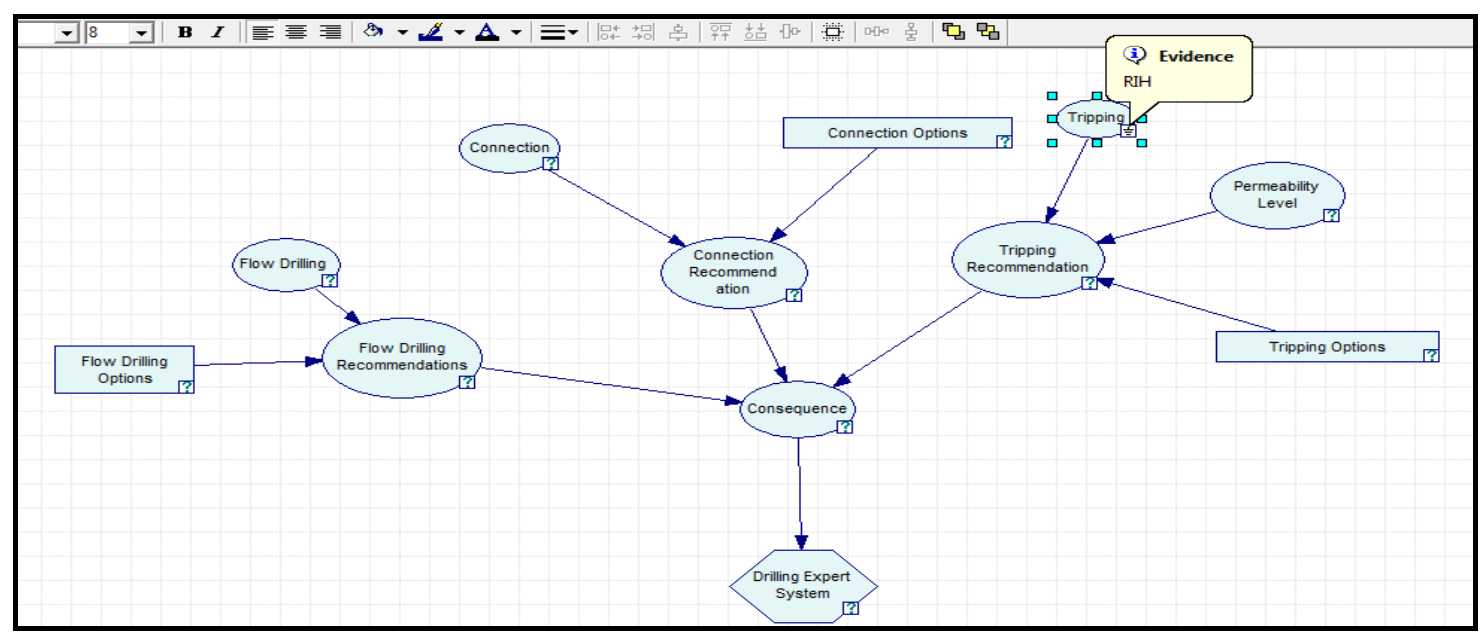

Fig.52: The user selects RIH option 


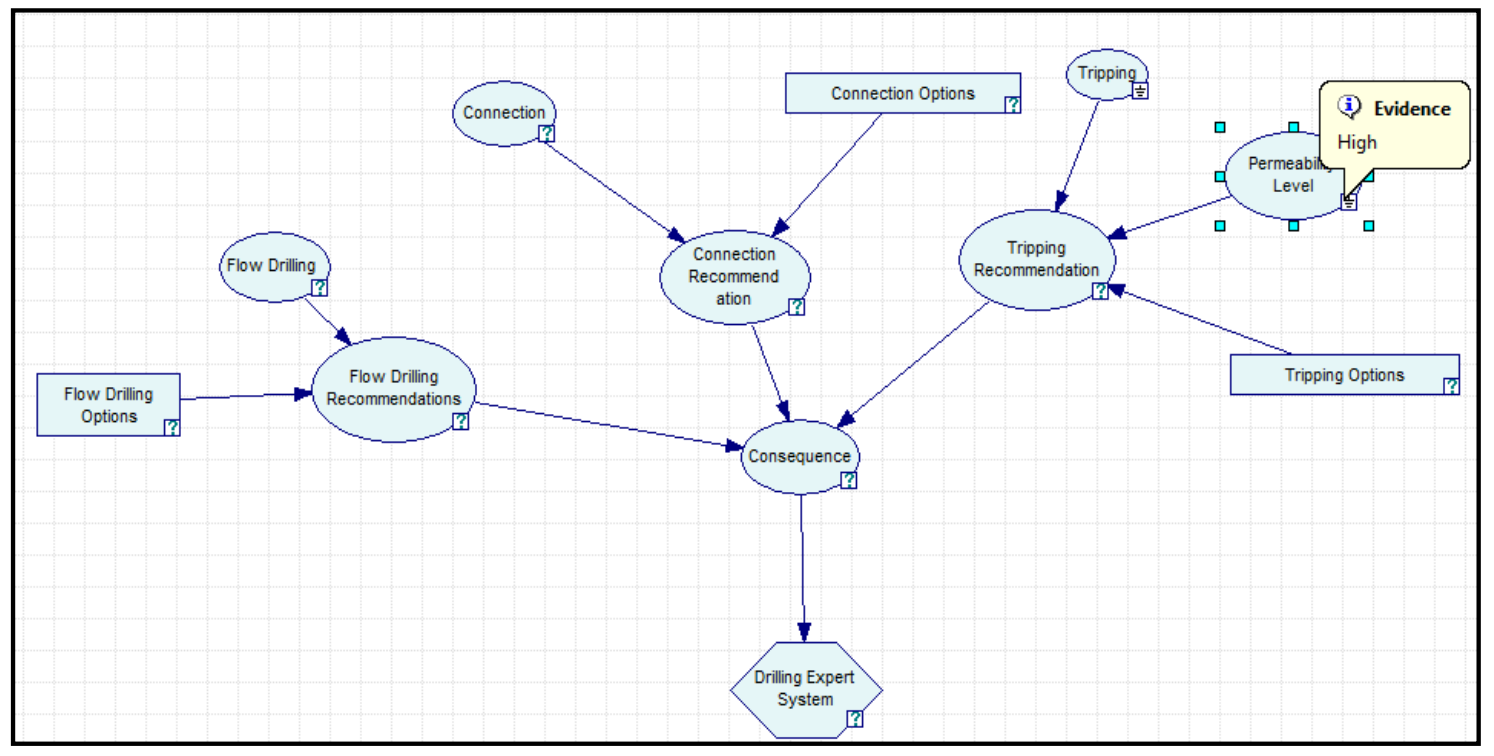

Fig.53: The user selects high permeability option

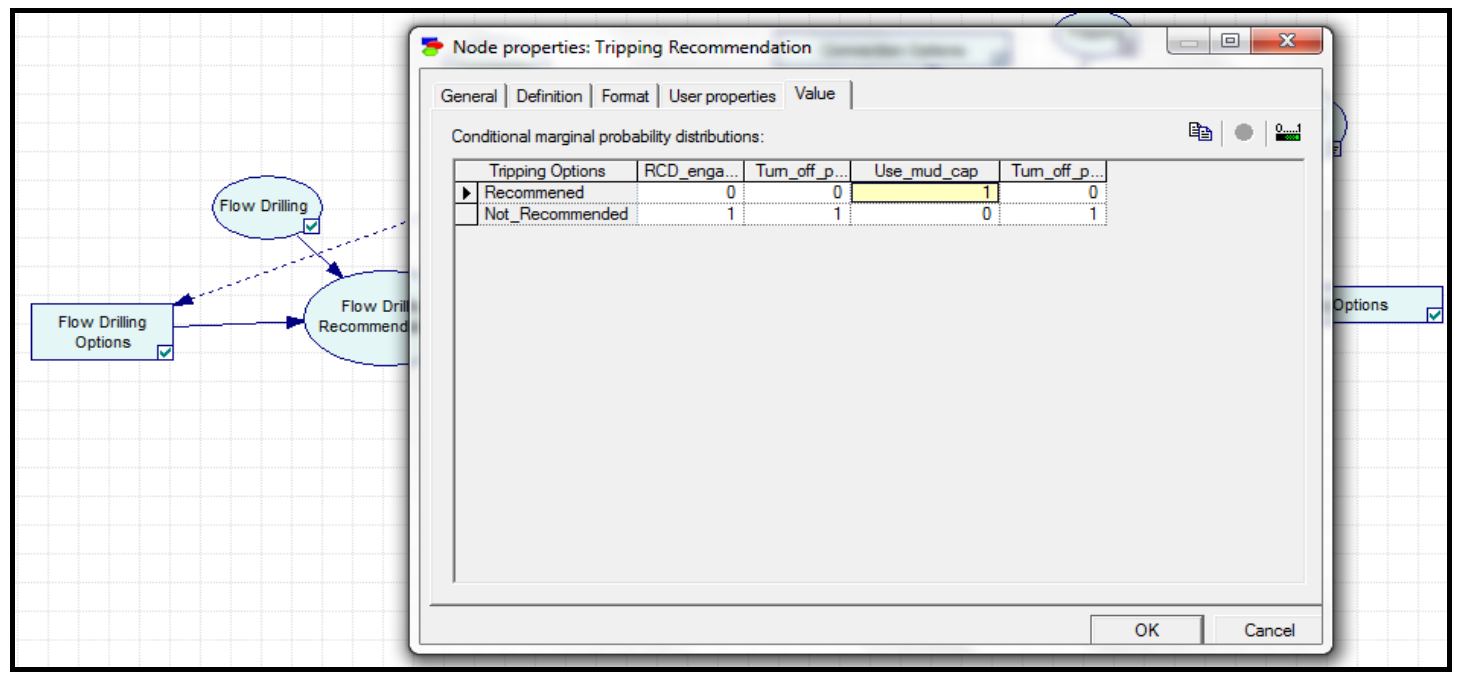

Fig.54: Tripping recommendation for low permeability formation during RIH operation 
Selection of on connection probability (Fig.55) leads to optimum connection option shown in Fig.56.

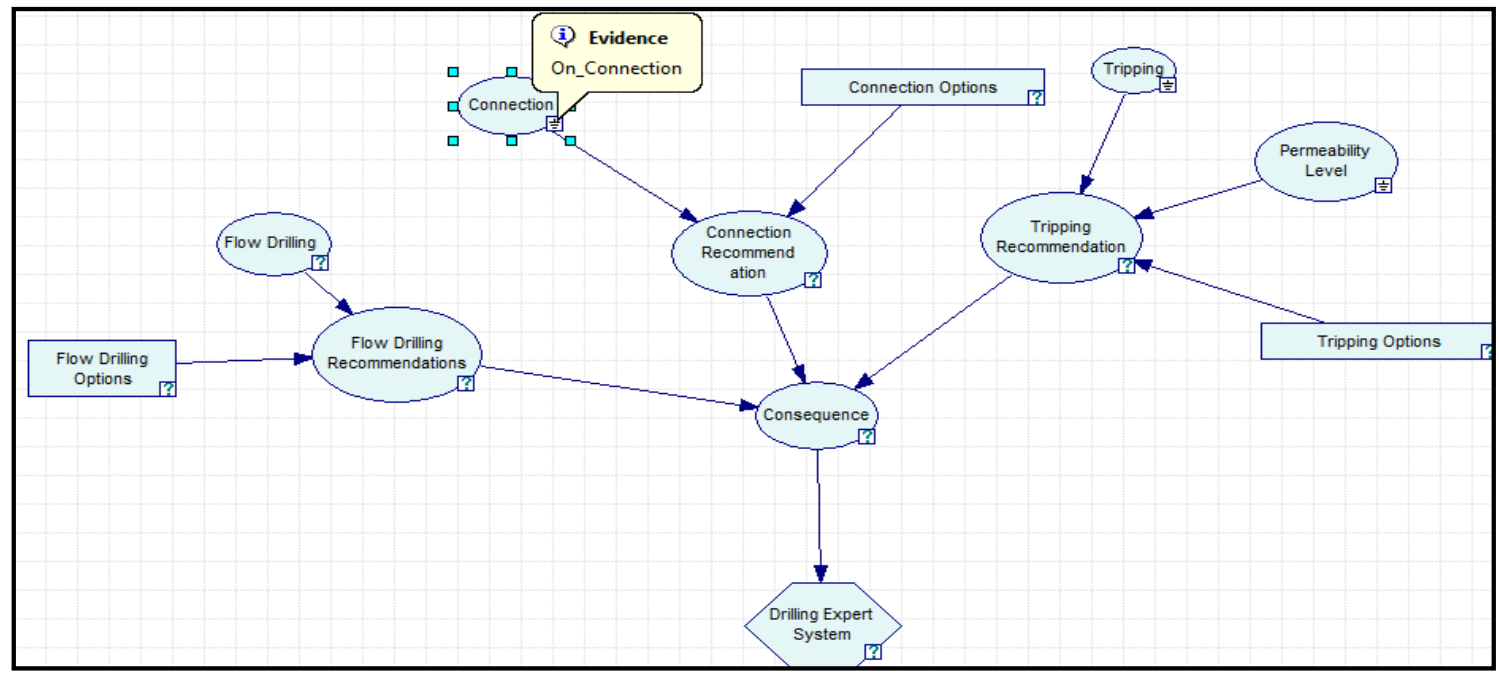

Fig.55: The user selects on connection option

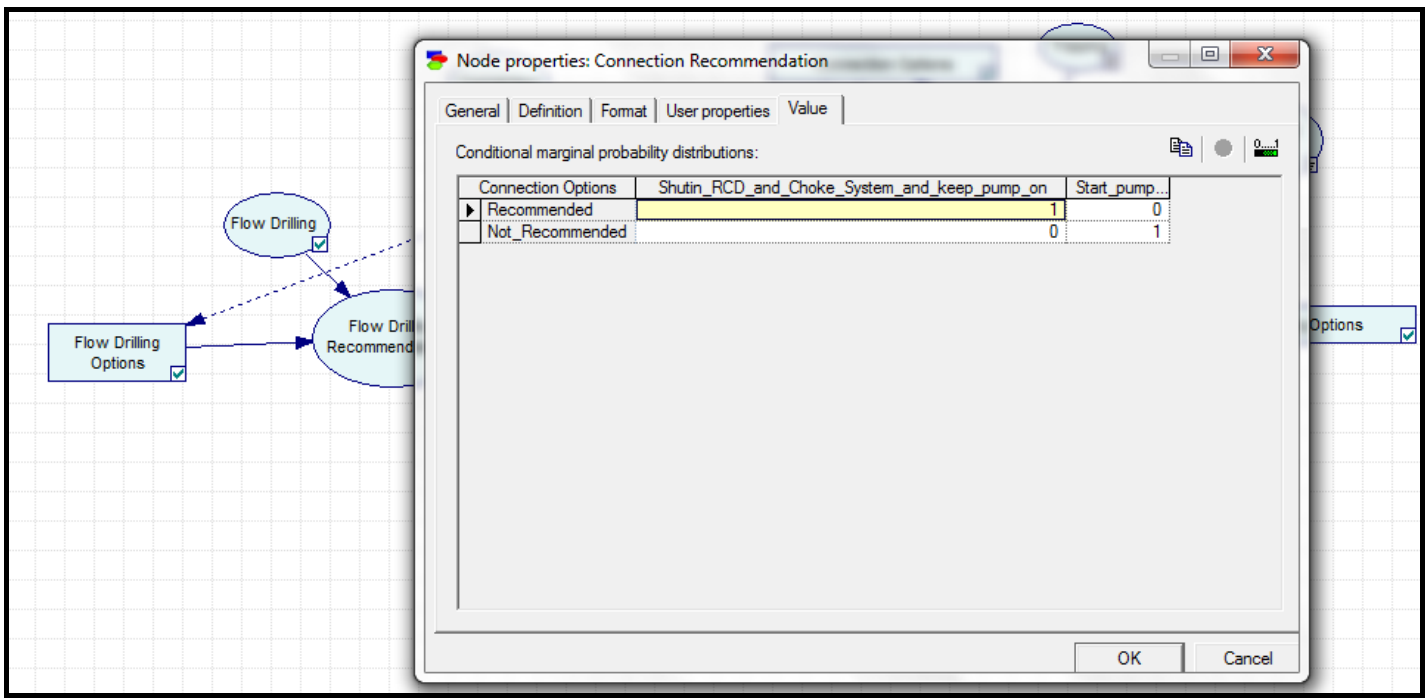

Fig.56: Connection recommendation 
Selection of flow drilling with formation gas or fluid returns (Fig. 57) leads to the optimum practice shown in Fig.58.

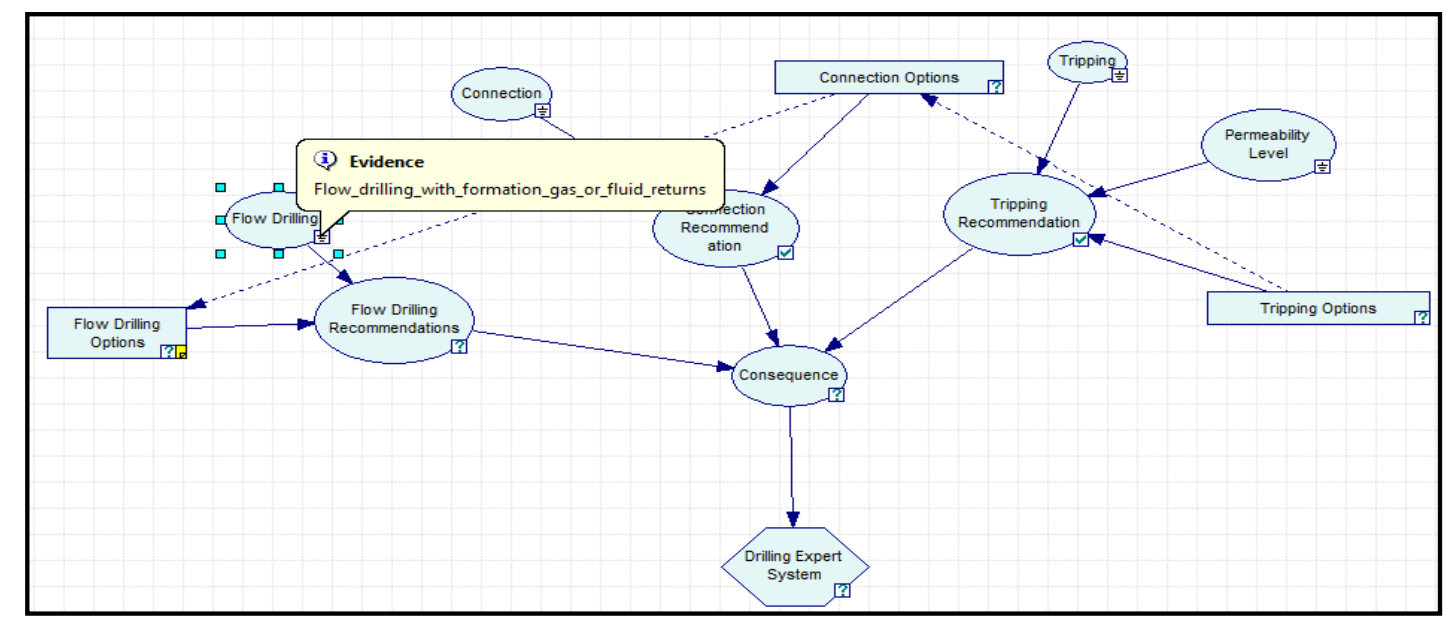

Fig.57: The user selects flow drilling takes place in formation with gas or fluid returns

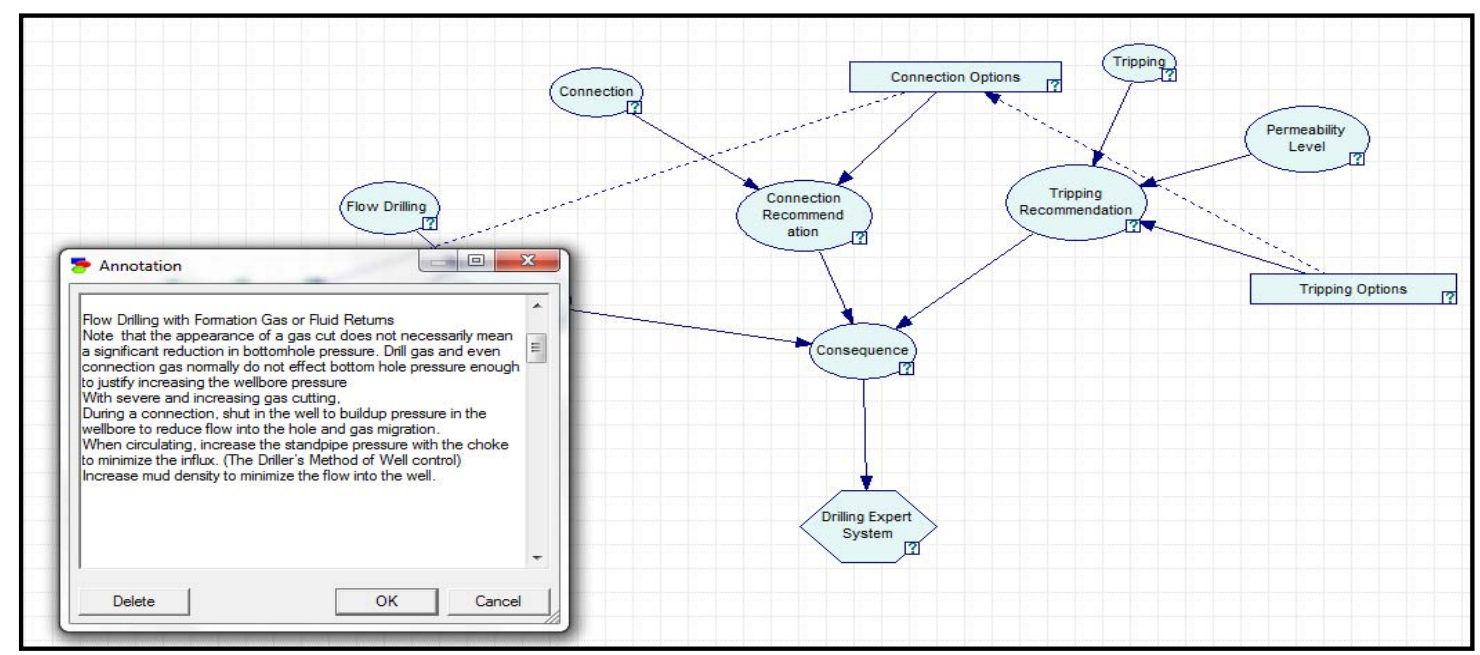

Fig.58: The recommended flow drilling with formation gas or fluid returns 
7.3 Gaseated underbalanced drilling model

Fig.59 shows the overall model of gaseated UBD. The model is divided into four parts (selection method benefits and challenges, requirements for general limits of gas and fluid volume, operational concerns and challenges recommendations, and well kicks recommendations.

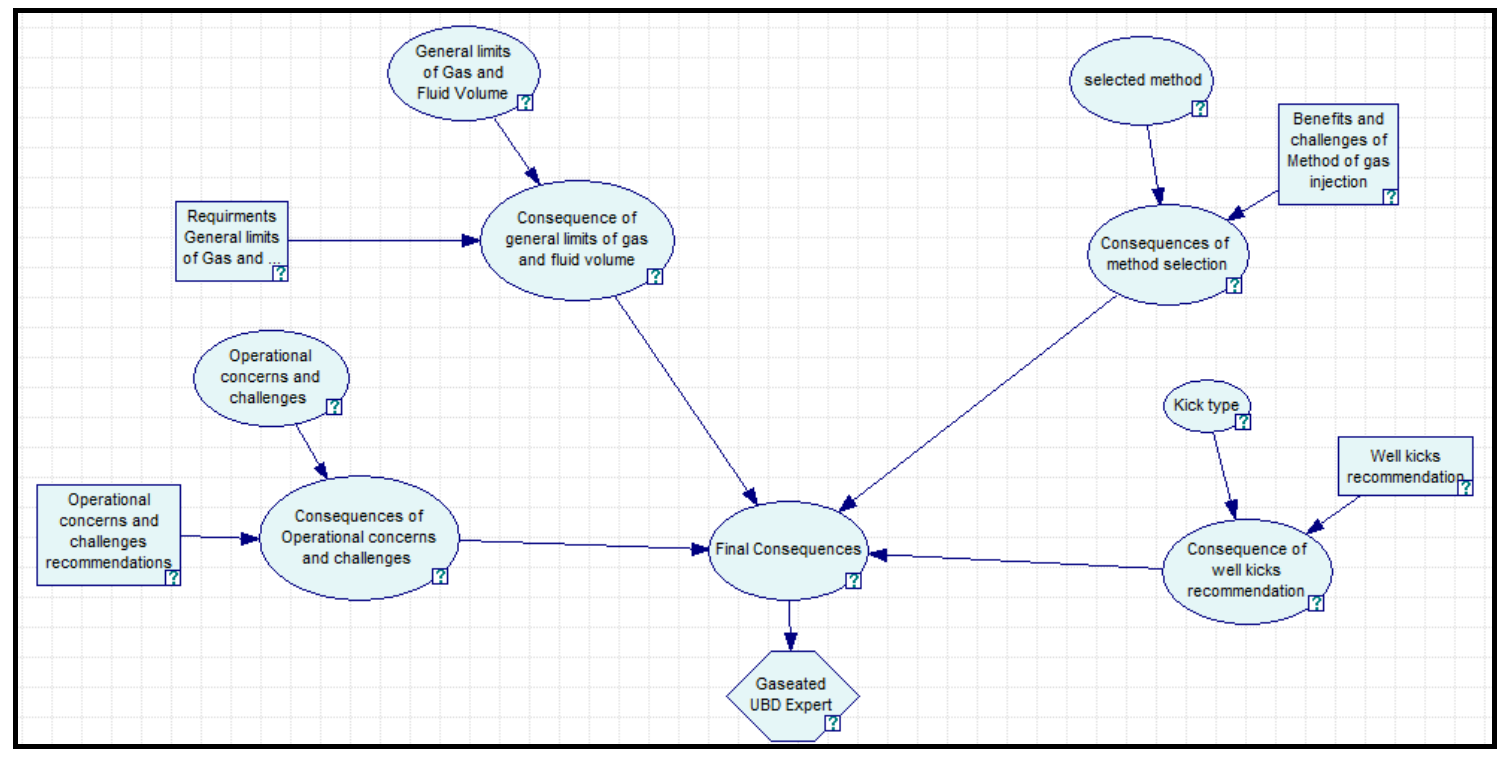

Fig.59: Overall model for gaseated UBD

Selection method probabilities are shown in Fig.60 and general limits of gas and fluid volume probabilities are shown in Fig.61. 


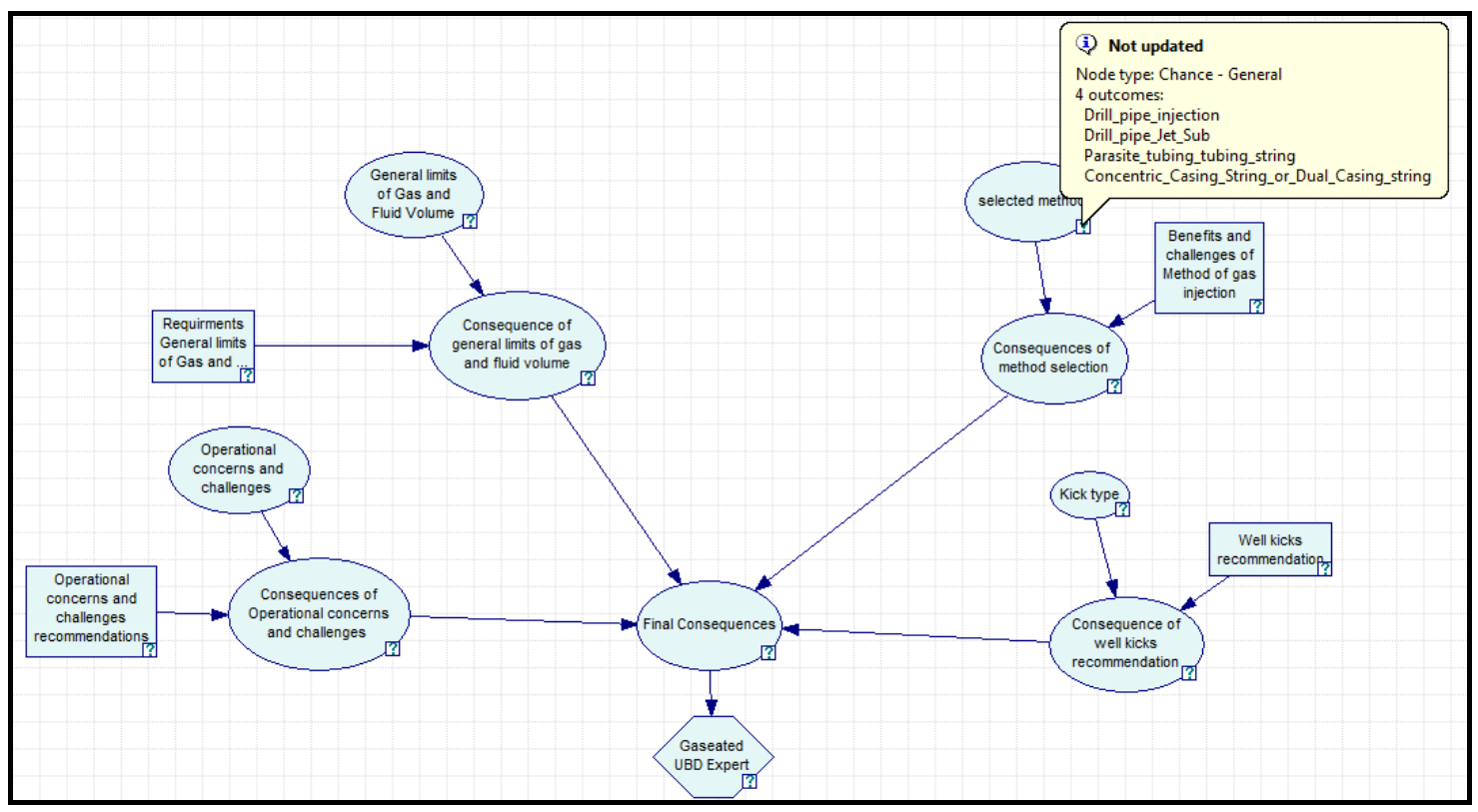

Fig.60: A list of gaseated methods

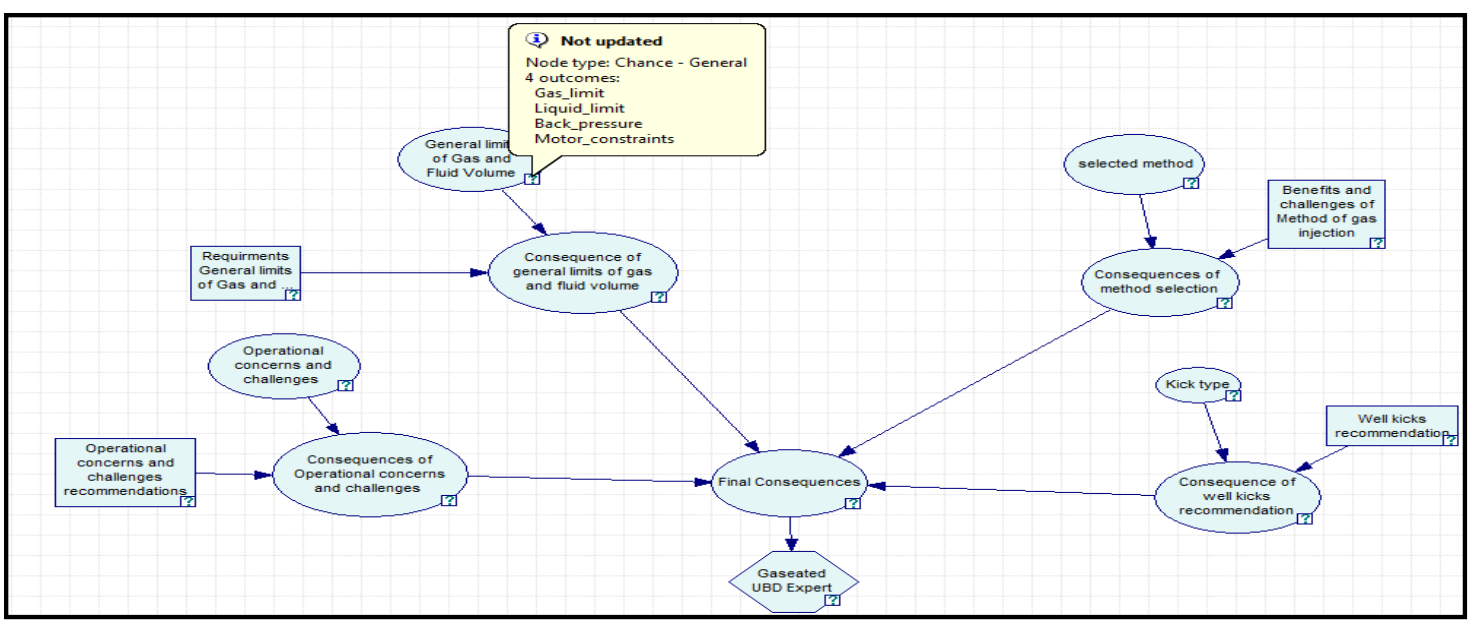

Fig.61: Possible general limits of gas and fluid volume 
Operational concerns and challenges are shown in Fig. 62 and kick types probabilities are shown in Fig. 63.

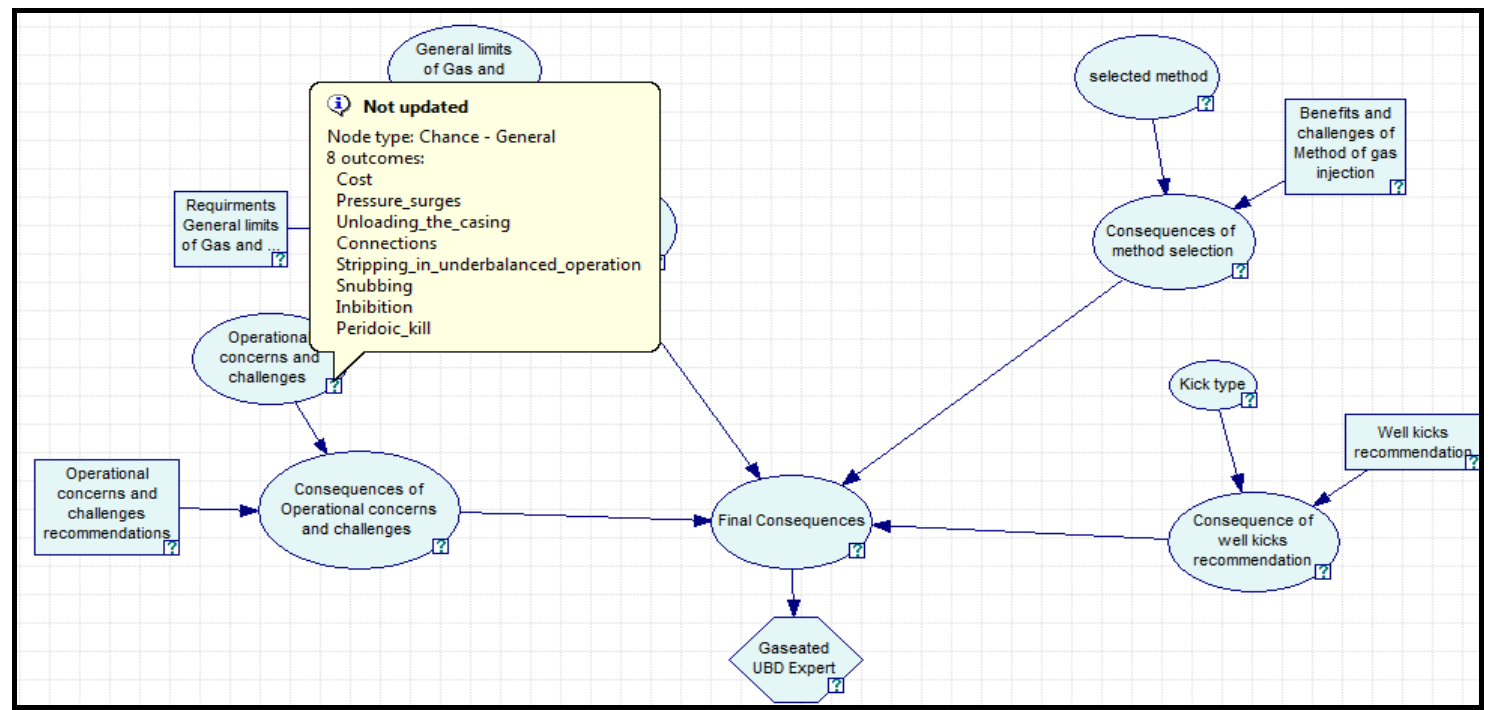

Fig.62: Possible operational concerns and challenges

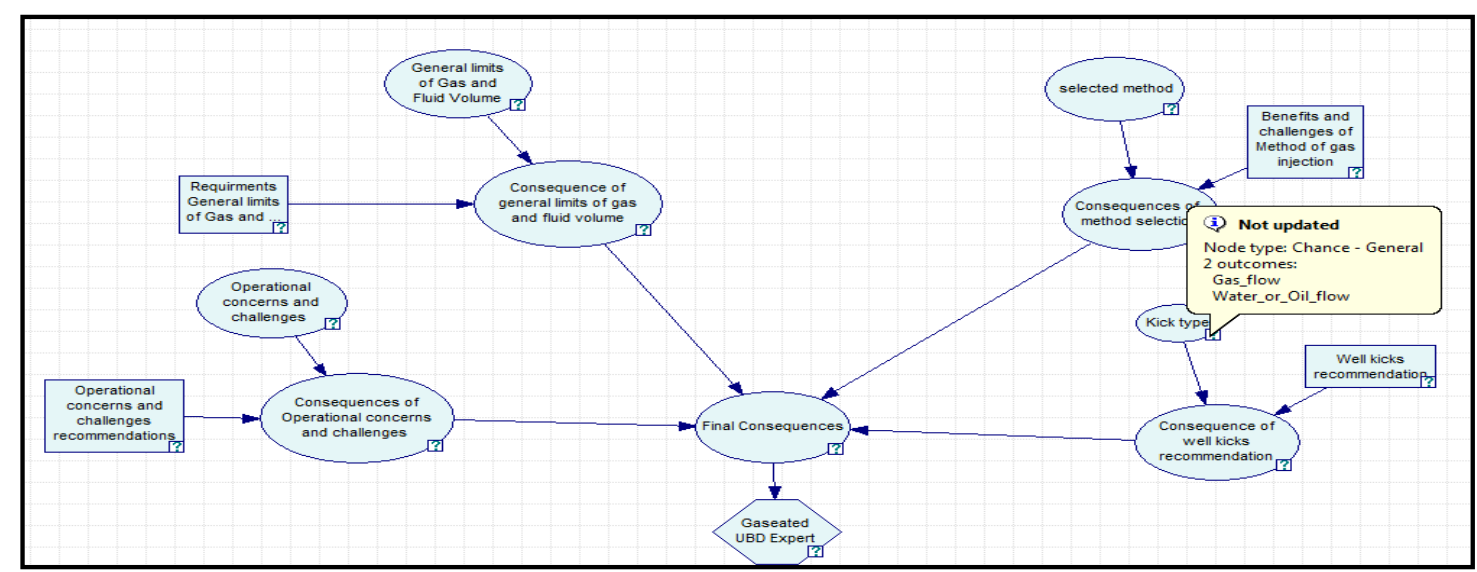

Fig.63: Possible kick types 
7.4 Foam underbalanced drilling model

Fig.64 shows the overall model of foam UBD. The model is divided into two parts (challenges and technical limits with foam system and basic designs of foam systems).

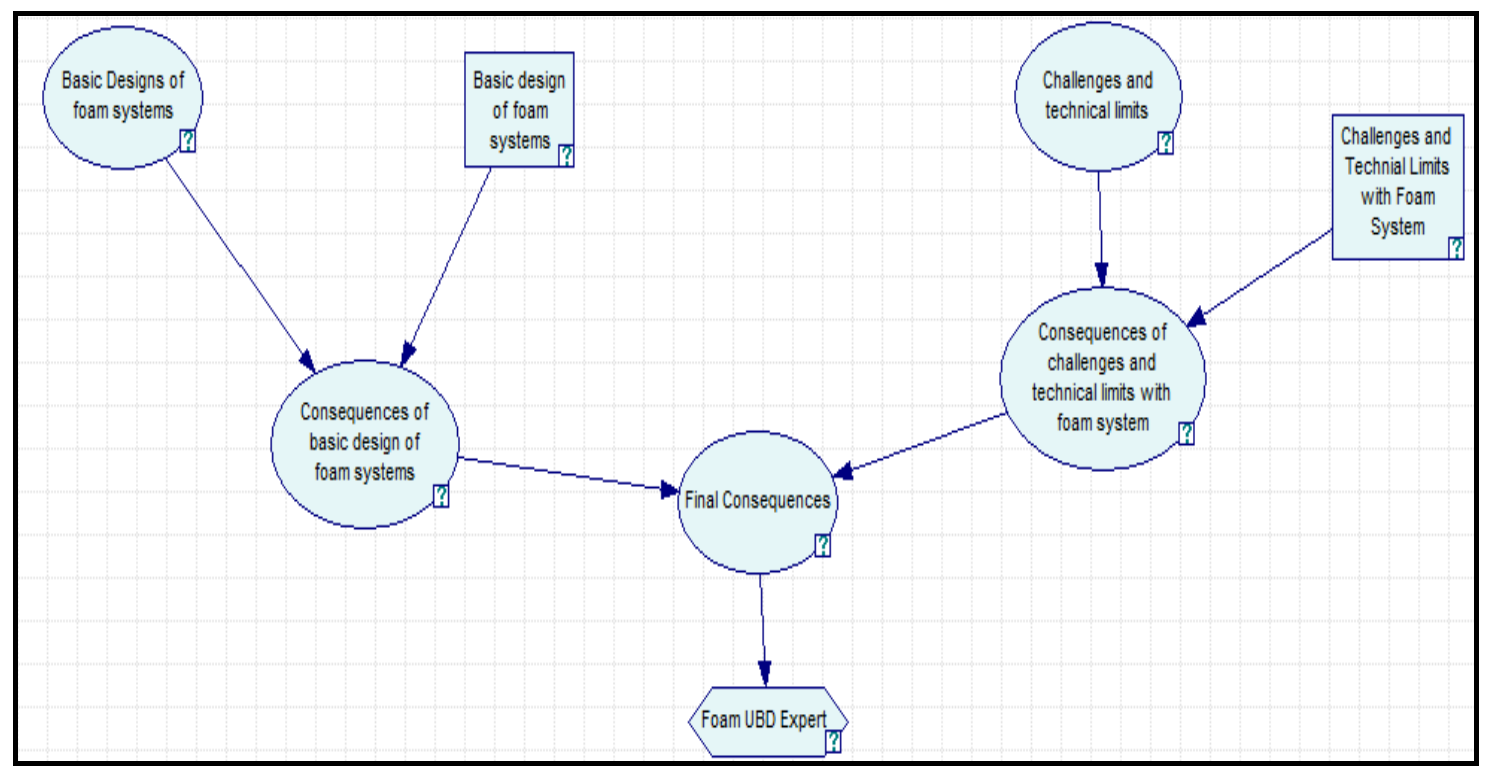

Fig.64: Overall foam model

Challenges and technical limits probabilities are shown in Fig. 65 and basic design of foam system probabilities are shown in Fig. 66. 


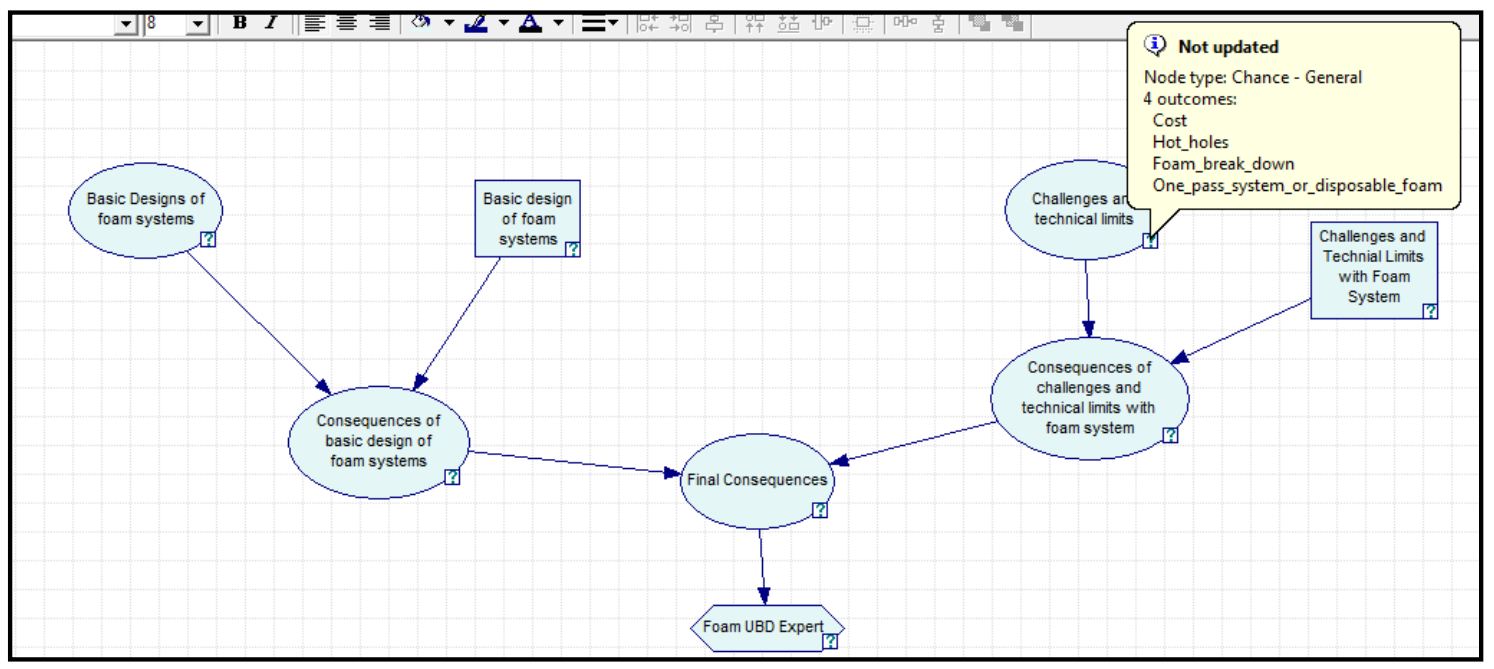

Fig.65: Possible challenges and technical limits of foam UBD

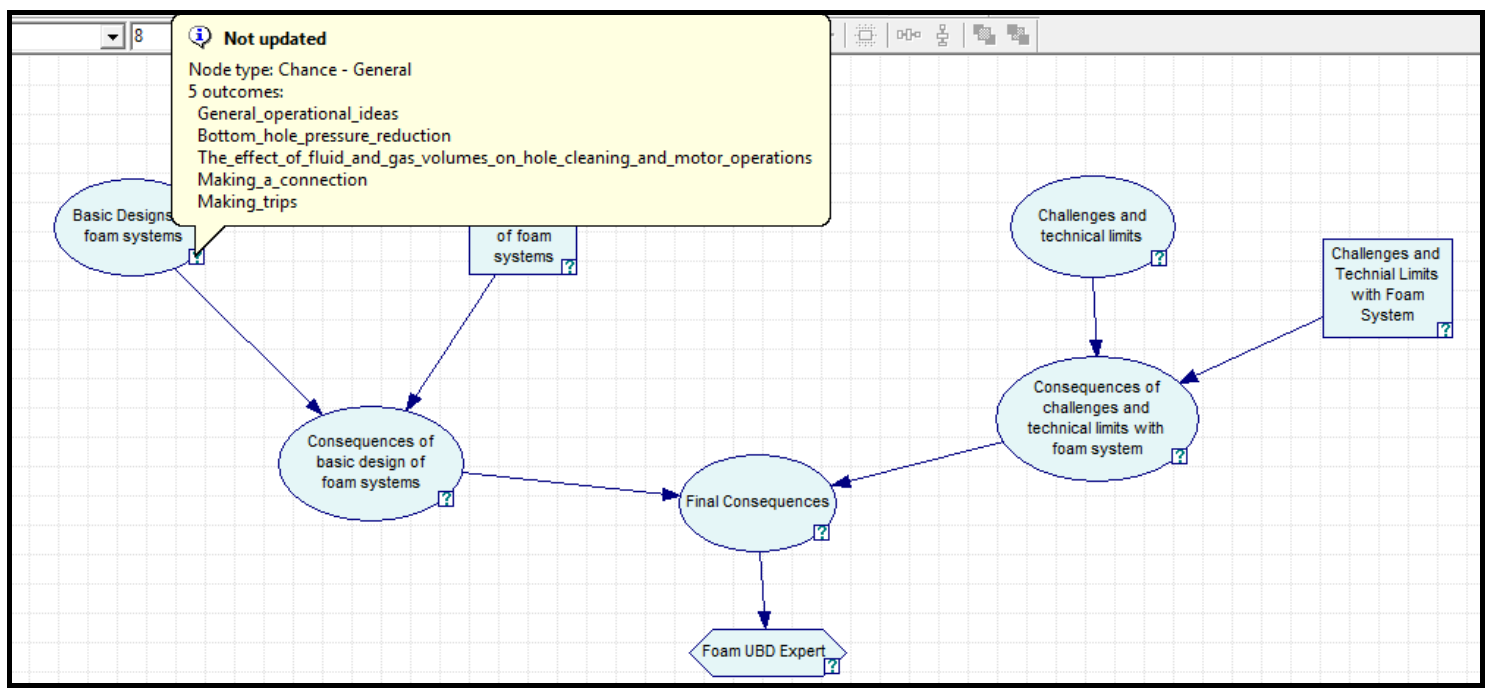

Fig.66: A list of basic designing steps in foam UBD 
7.5 Air and gas underbalanced drilling model

Fig.67 shows the overall model of air and gas UBD. The model is divided into four parts. The first part is rotary and hammers drilling probabilities and recommendations. The second part is limits and challenges to gas drilling probabilities and recommendations. The third part is rig requirements and recommendations. The fourth part is gas drilling operations probabilities and recommendations.

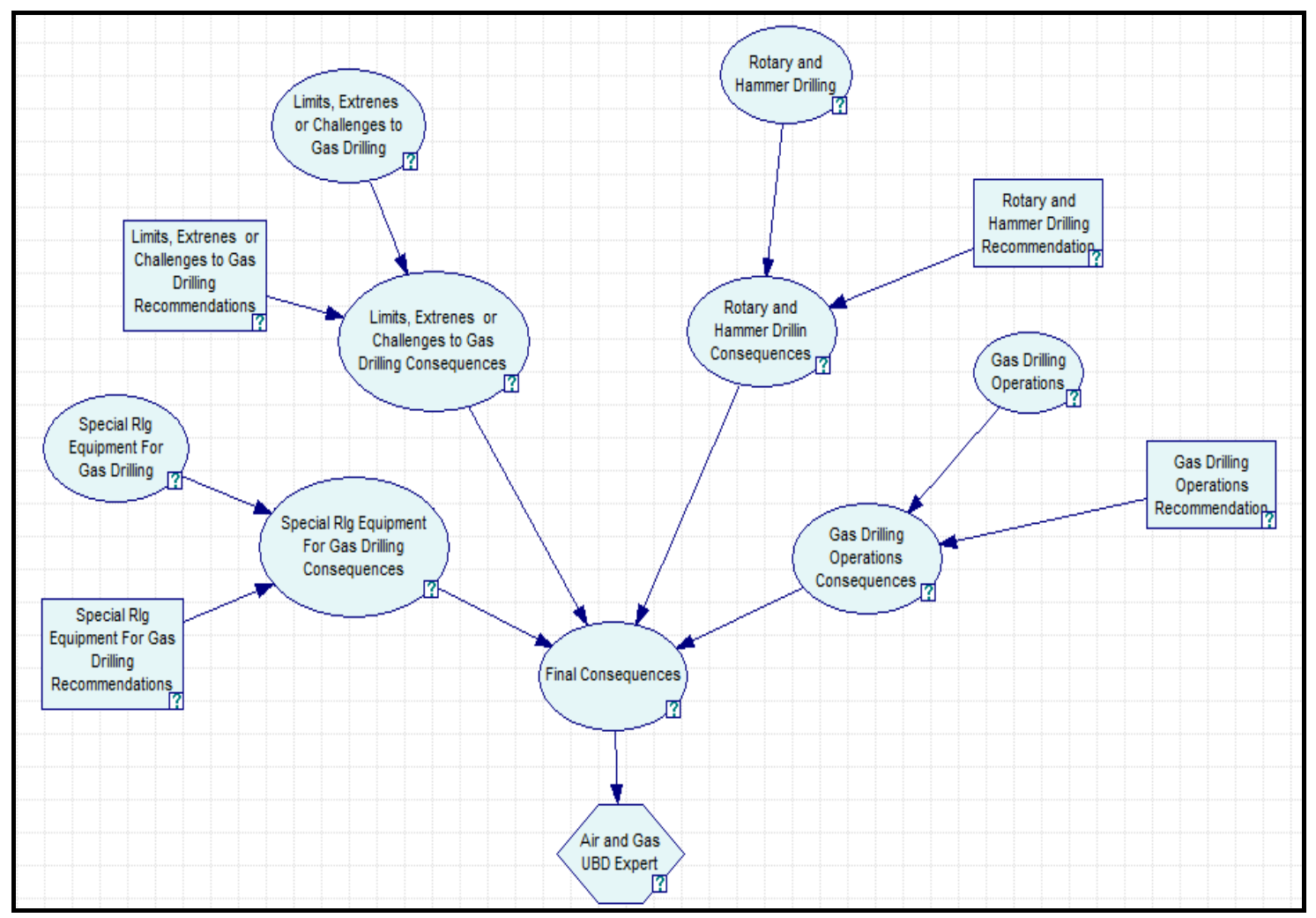

Fig.67: Overall air and gas UBD 
Rotary and hammer drilling probabilities are shown in Fig. 68 and limits or challenges probabilities are shown in Fig. 69.

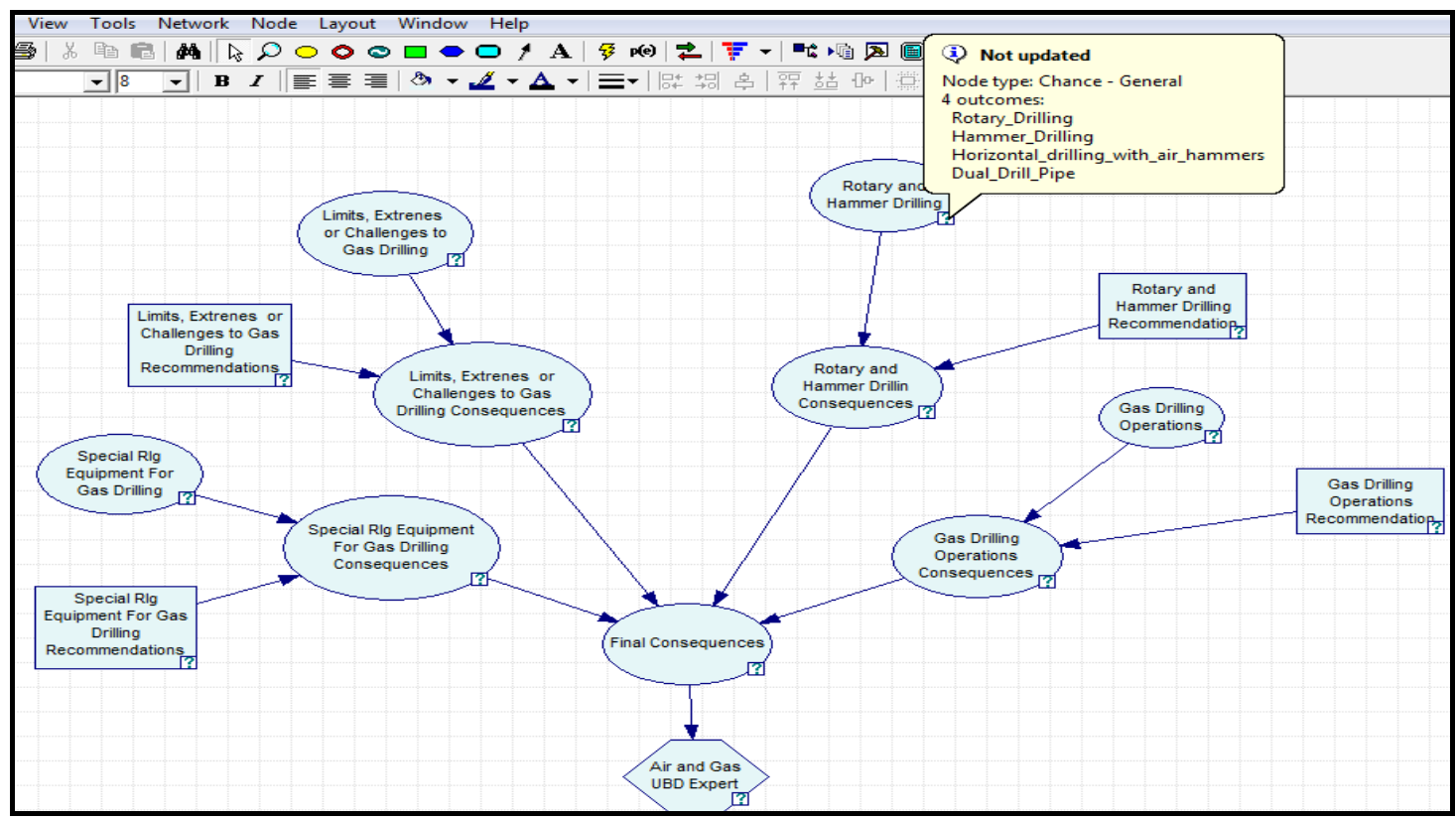

Fig.68: Rotary and hammer drilling options 


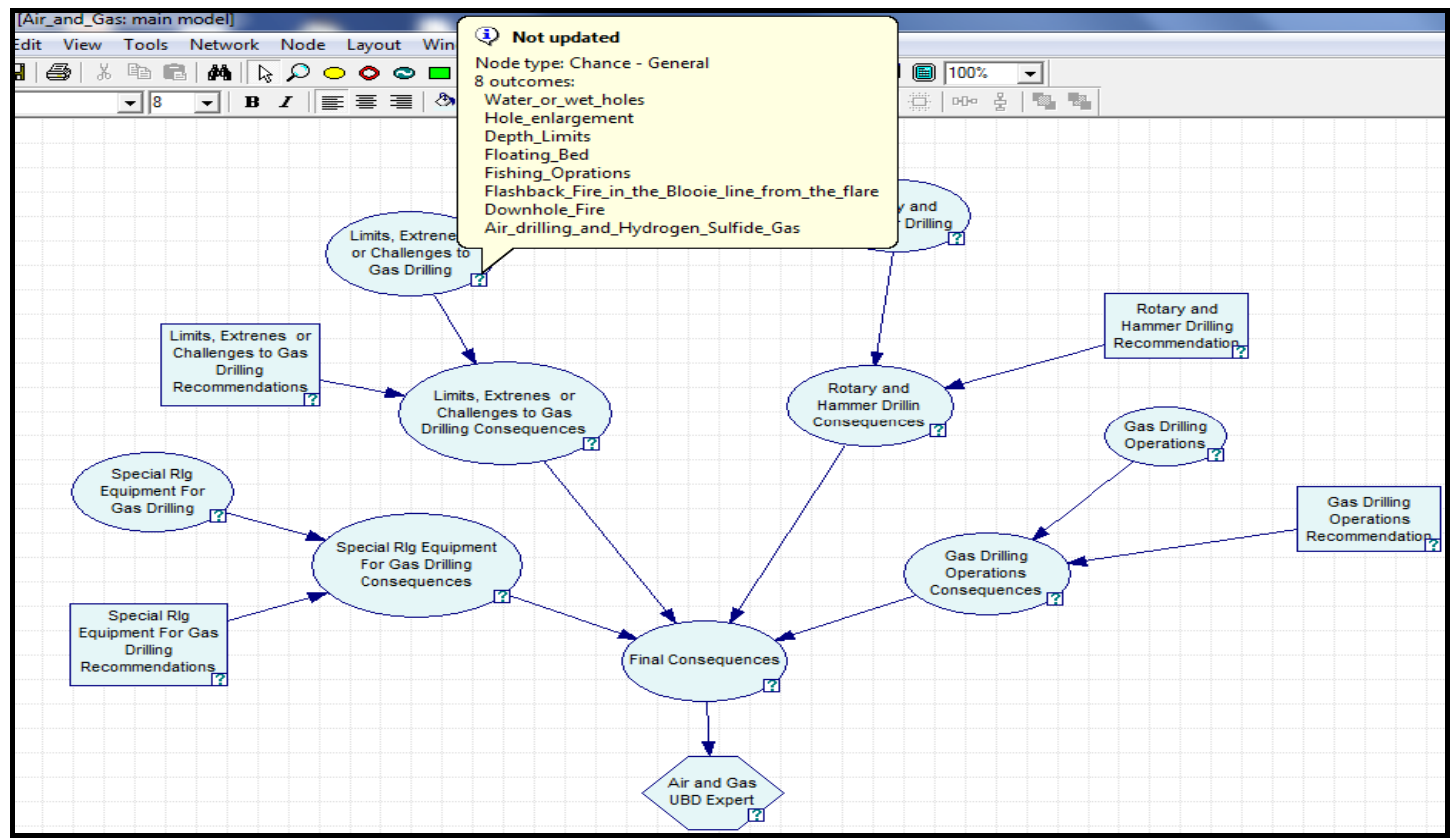

Fig.69: A list of limits and challenges for air and gas UBD

Gas drilling operation probabilities are shown in Fig. 70 and special rig equipment for gas drilling probabilities are shown in Fig. 71. 


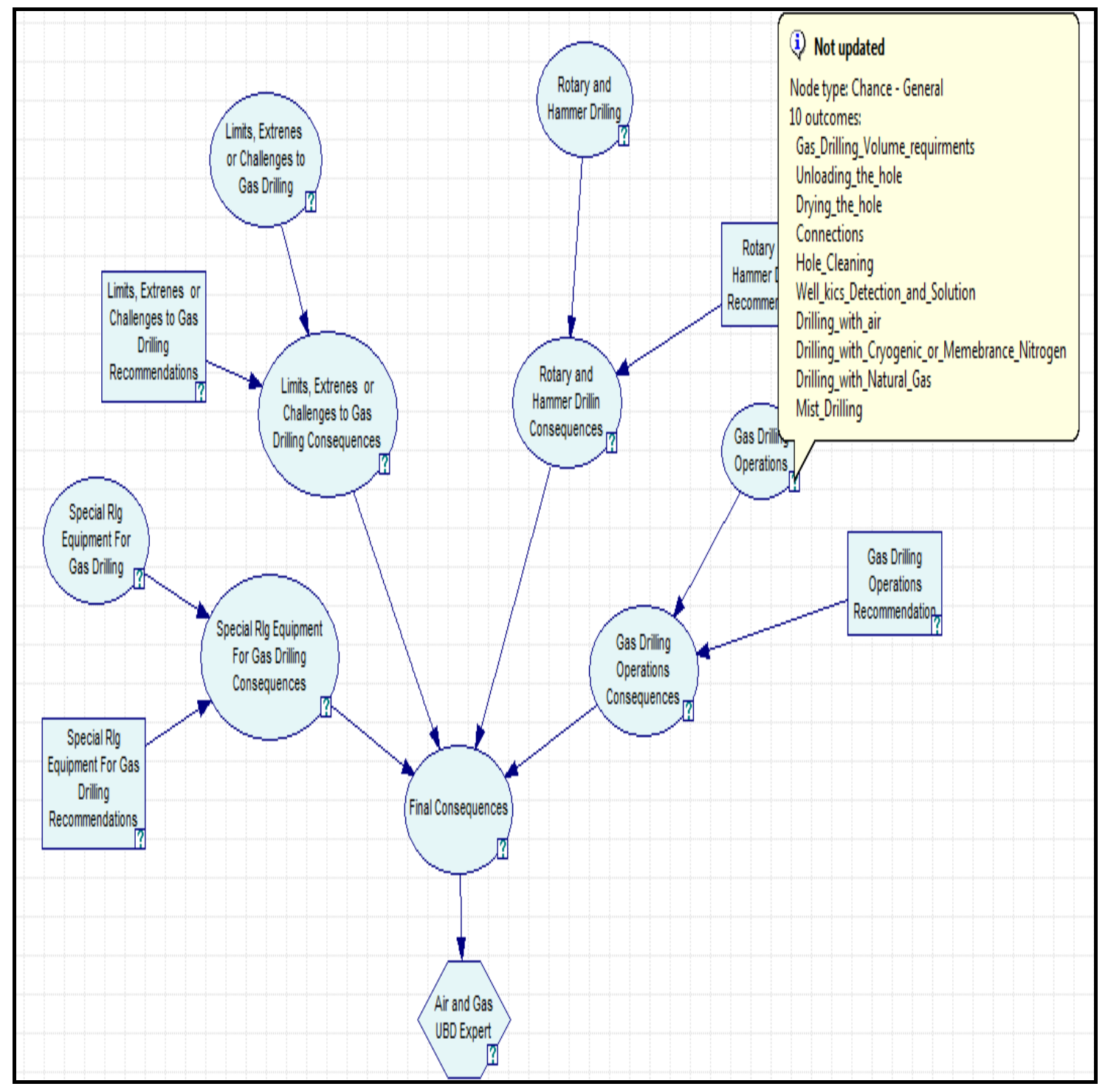

Fig.70: A list of possible gas drilling operations 


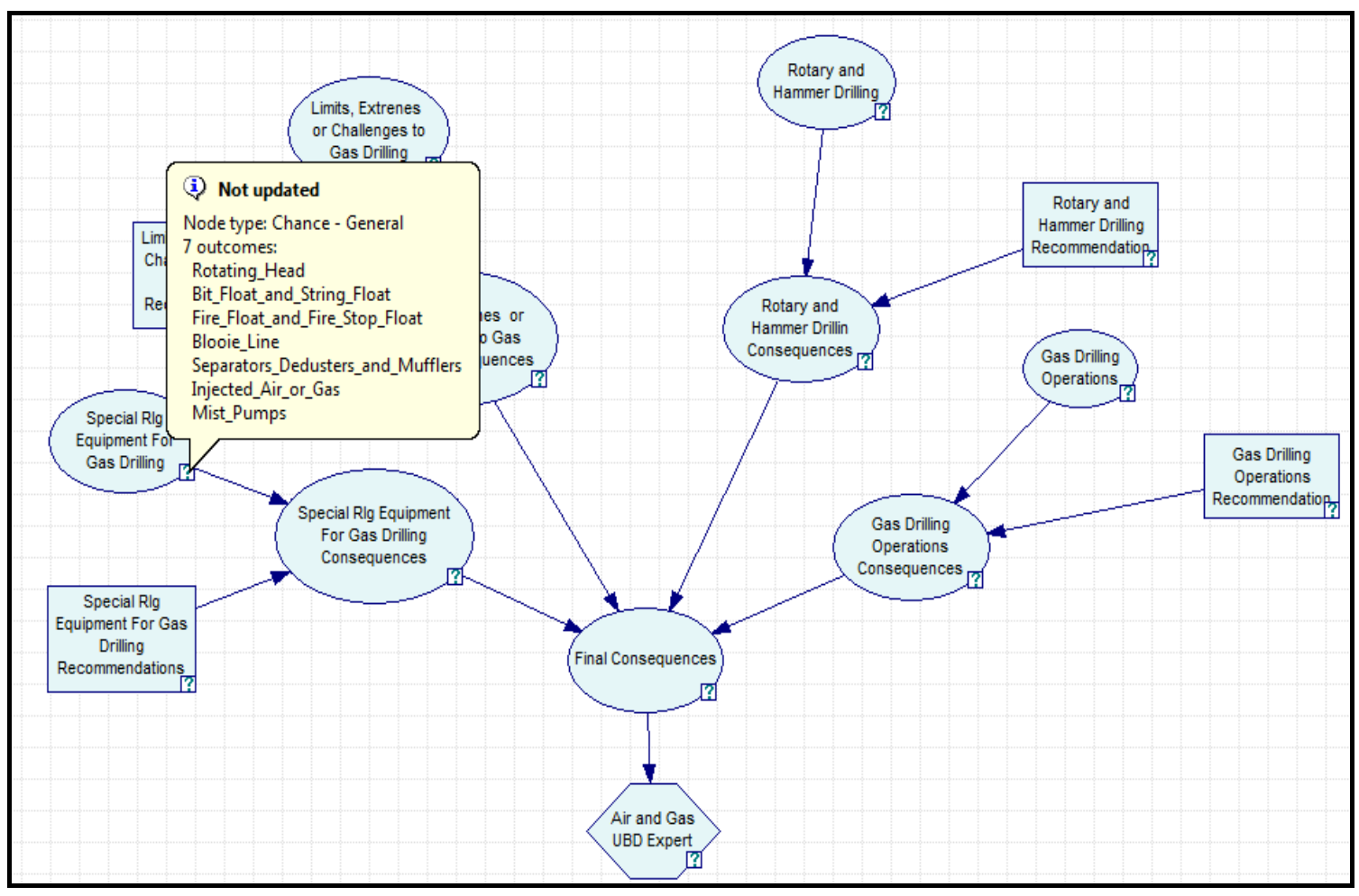

Fig.71: A list of possible rig equipment for gas drilling

\subsection{Mud cap model}

Fig.72 shows the overall model of mud cap model. The model is divided into three parts. The first part is background to mud cap drilling probabilities and recommendations. The second part is drilling problems probabilities and recommendations. The third part is floating mud cap drilling in depleted formation probabilities and recommendations. 


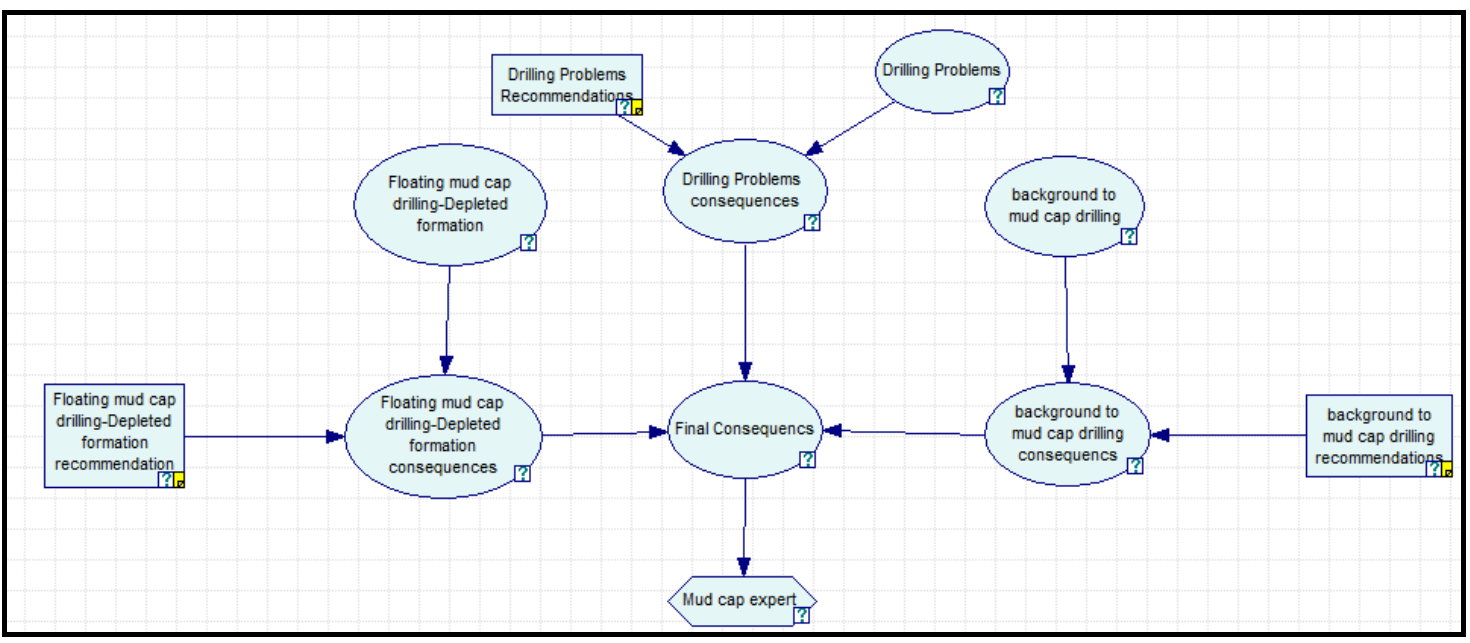

Fig.72: Mud cap overall model

Background mud cap drilling probabilities are shown in Fig. 73 and drilling problems probabilities are shown in Fig. 74.

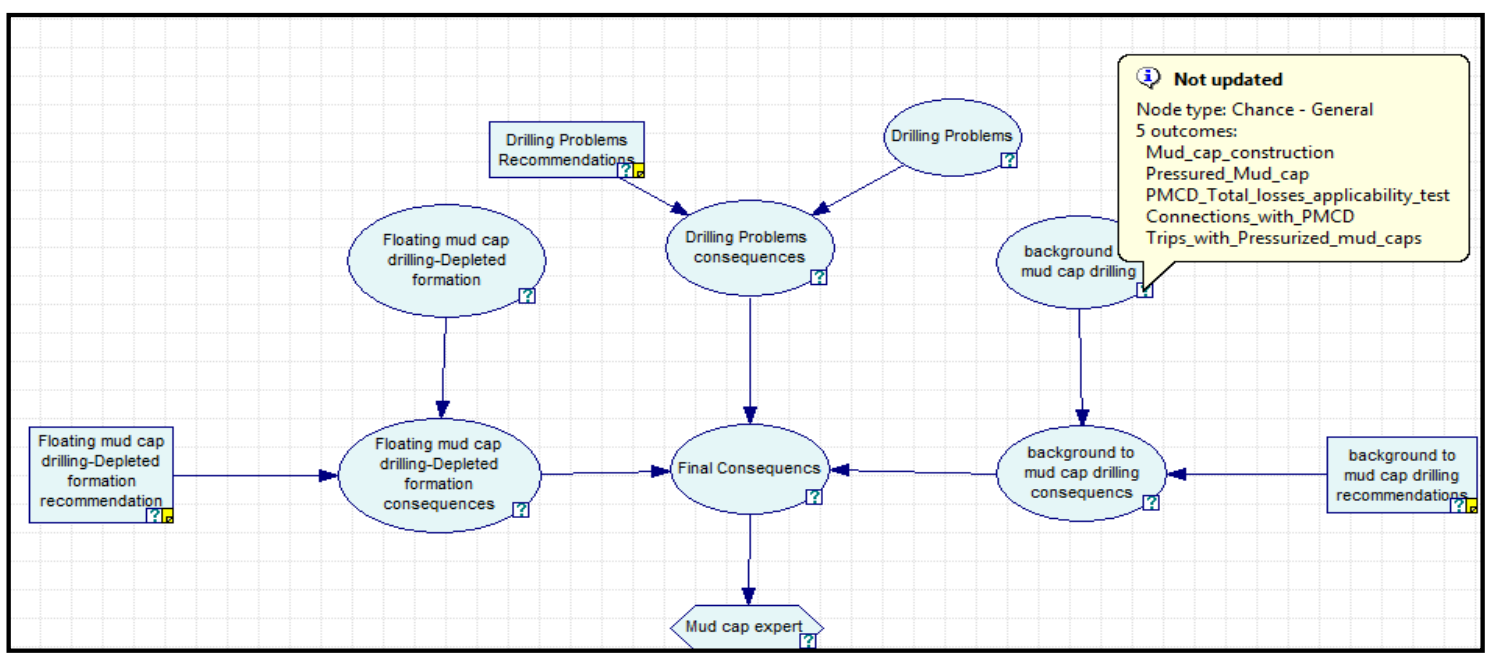

Fig.73: A list of background mud cap drilling 


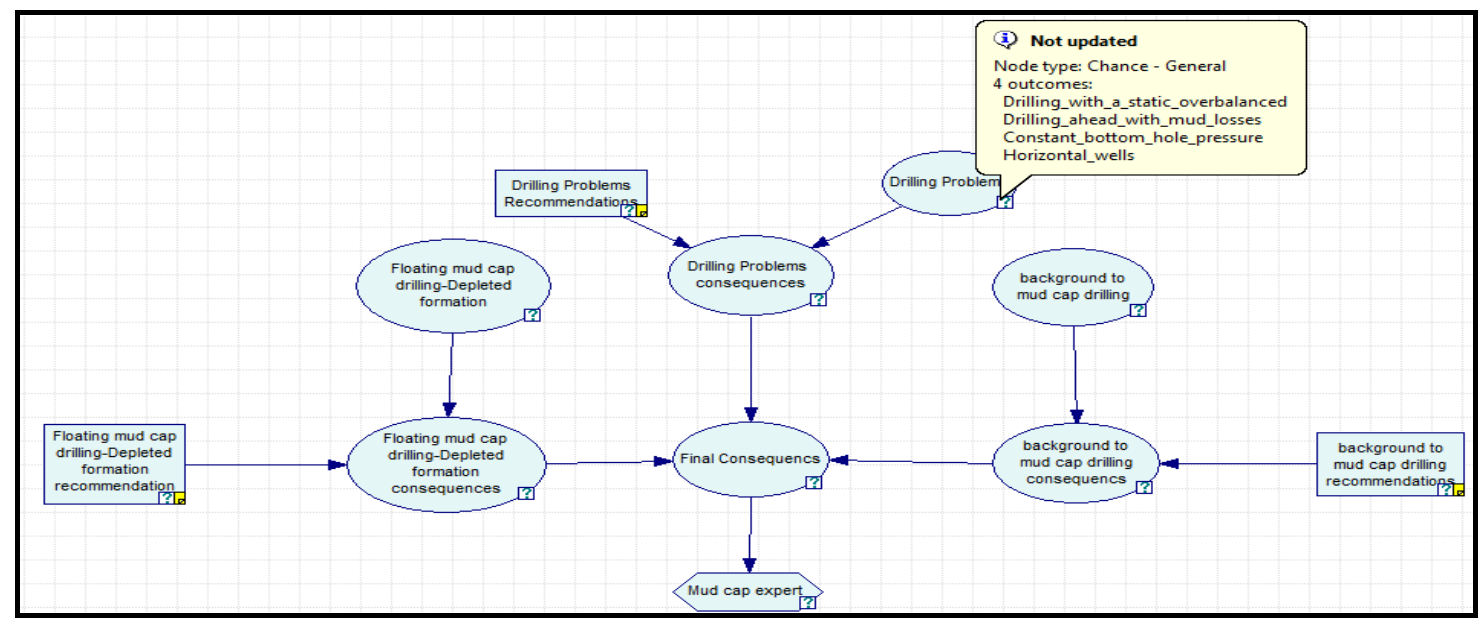

Fig.74: A list of mud cap drilling problems

Floating mud cap drilling in depleted formation probabilities are shown in Fig.

75.

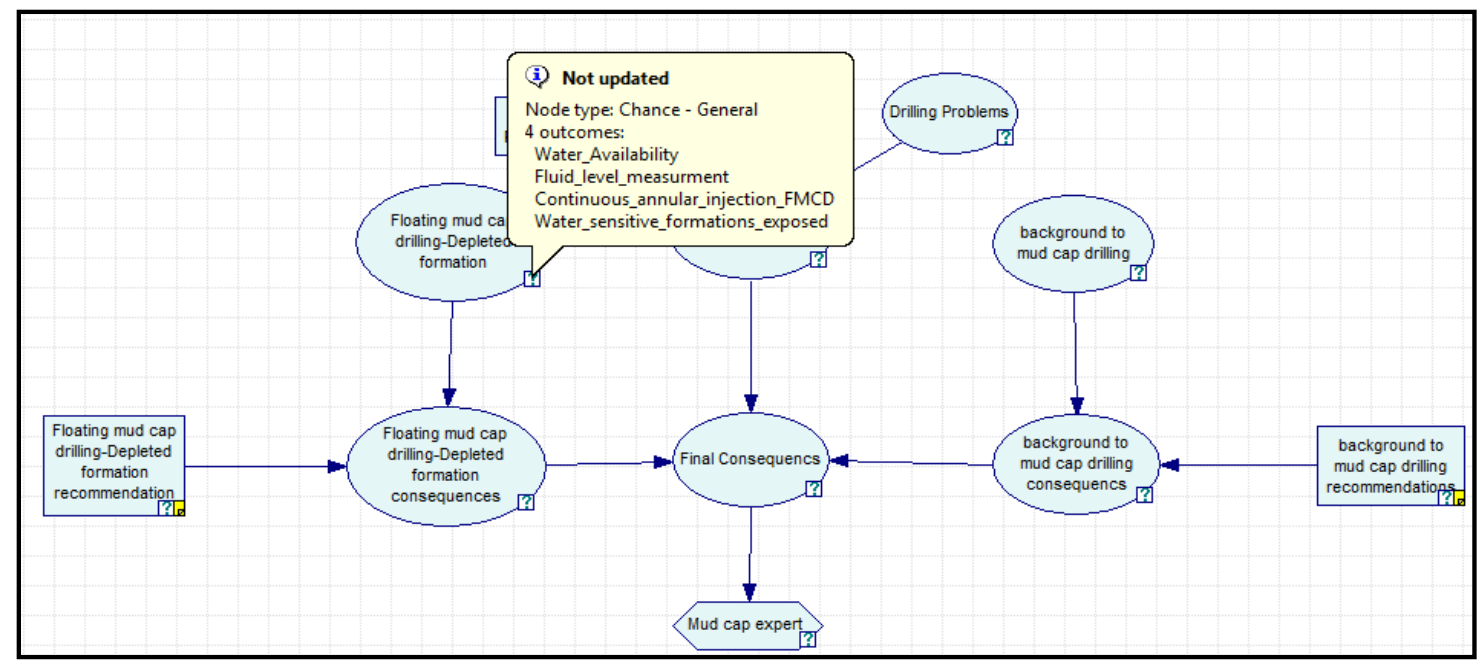

Fig.75: Floating mud cap drilling options 
7.7 Underbalanced liner drilling model

Fig.76 shows the overall model of UBLD model. The model is divided into three parts. The first part is basic planning probabilities and recommendations. The second part is drilling problems that can be solved and recommendations. The third part is limits and challenges probabilities and recommendations.

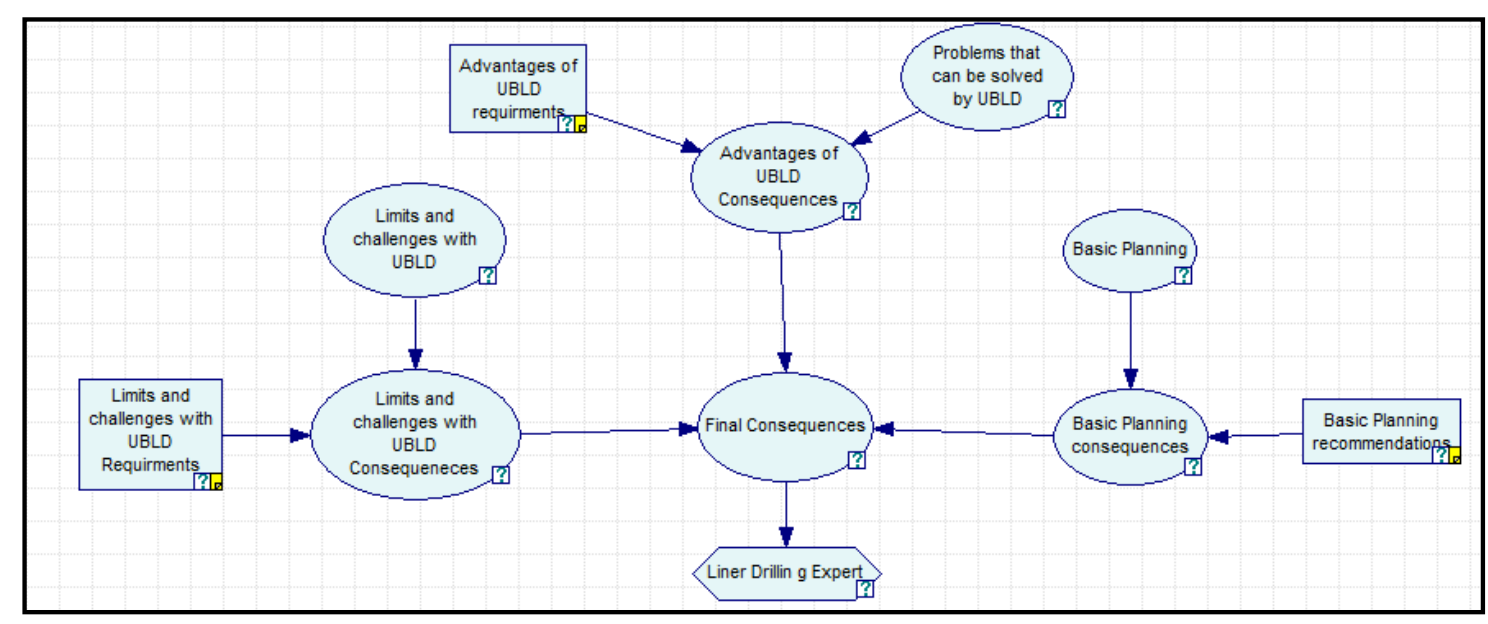

Fig.76: Overall model for UBLD

Problems that can be solved by UBLD (Fig. 77) and limits and challenges probabilities are shown in Fig. 78. Basic planning probabilities are shown in Fig. 79 


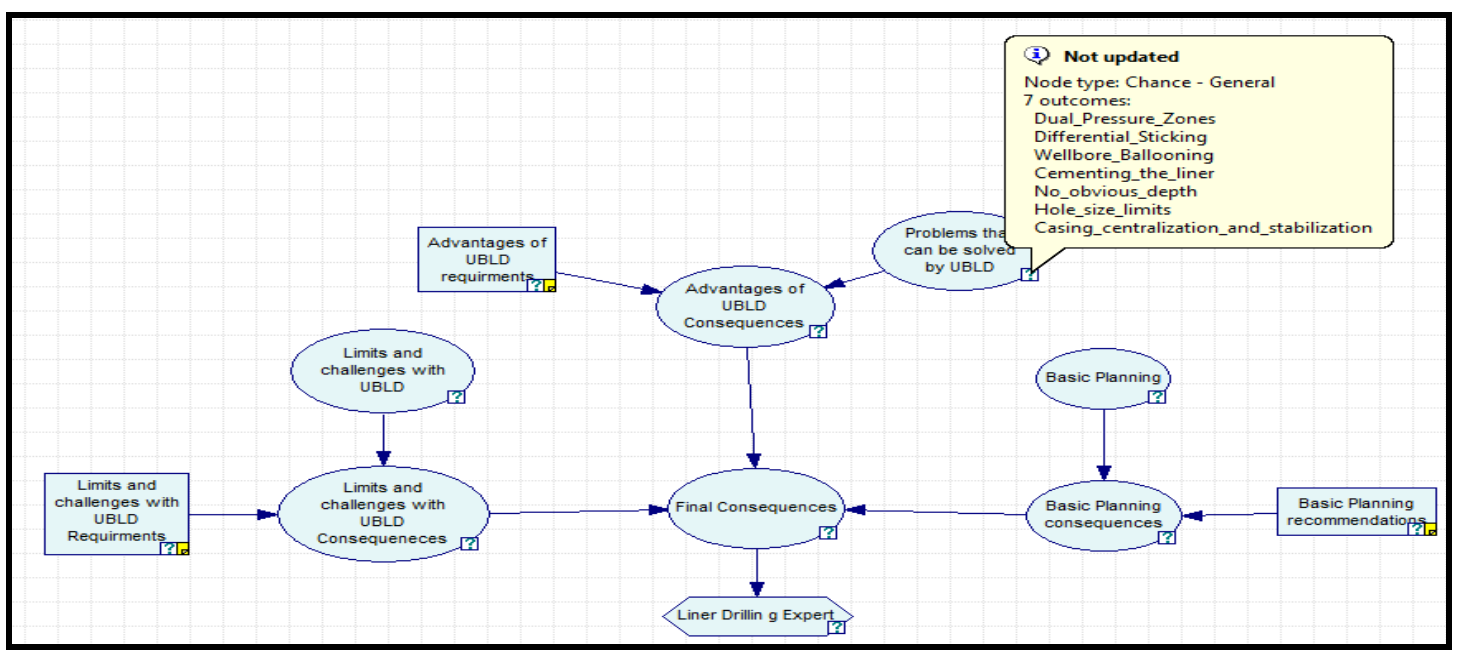

Fig.77: A list of problems that can be solved by UBLD

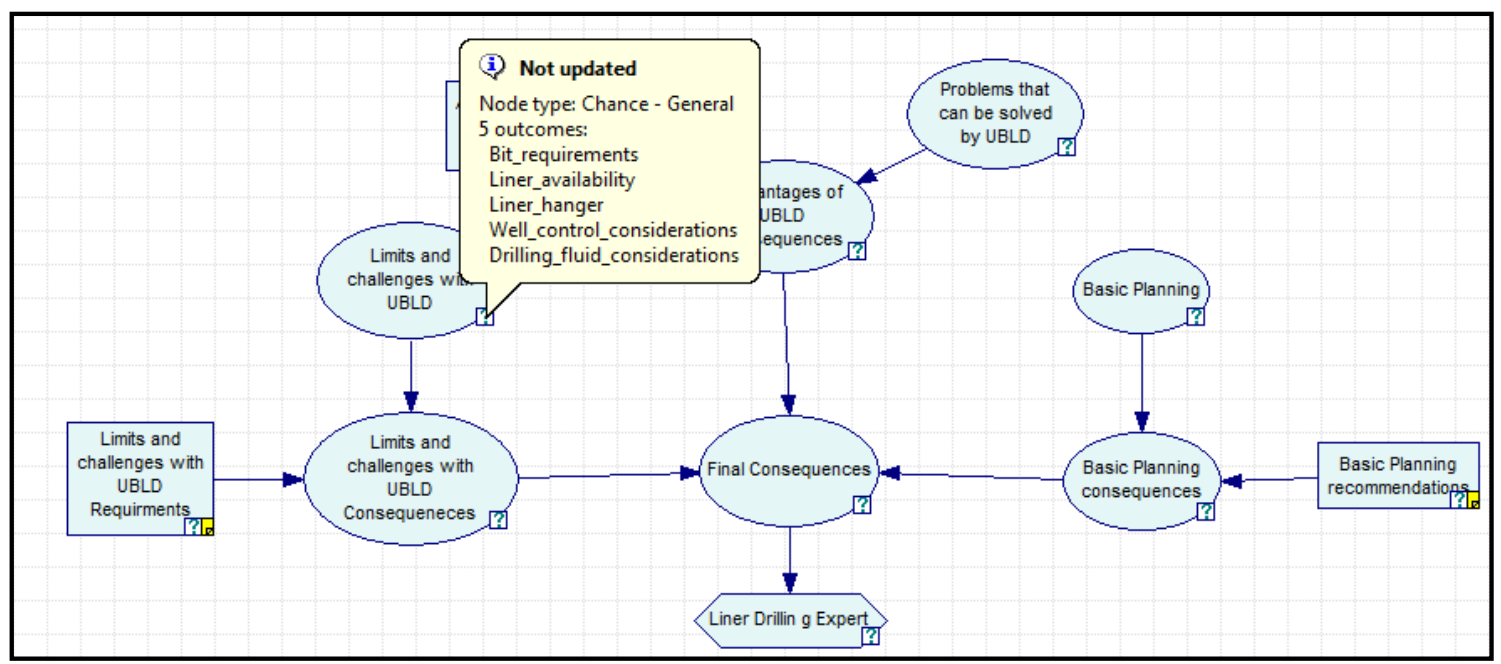

Fig.78: Limits and challenges with UBLD 


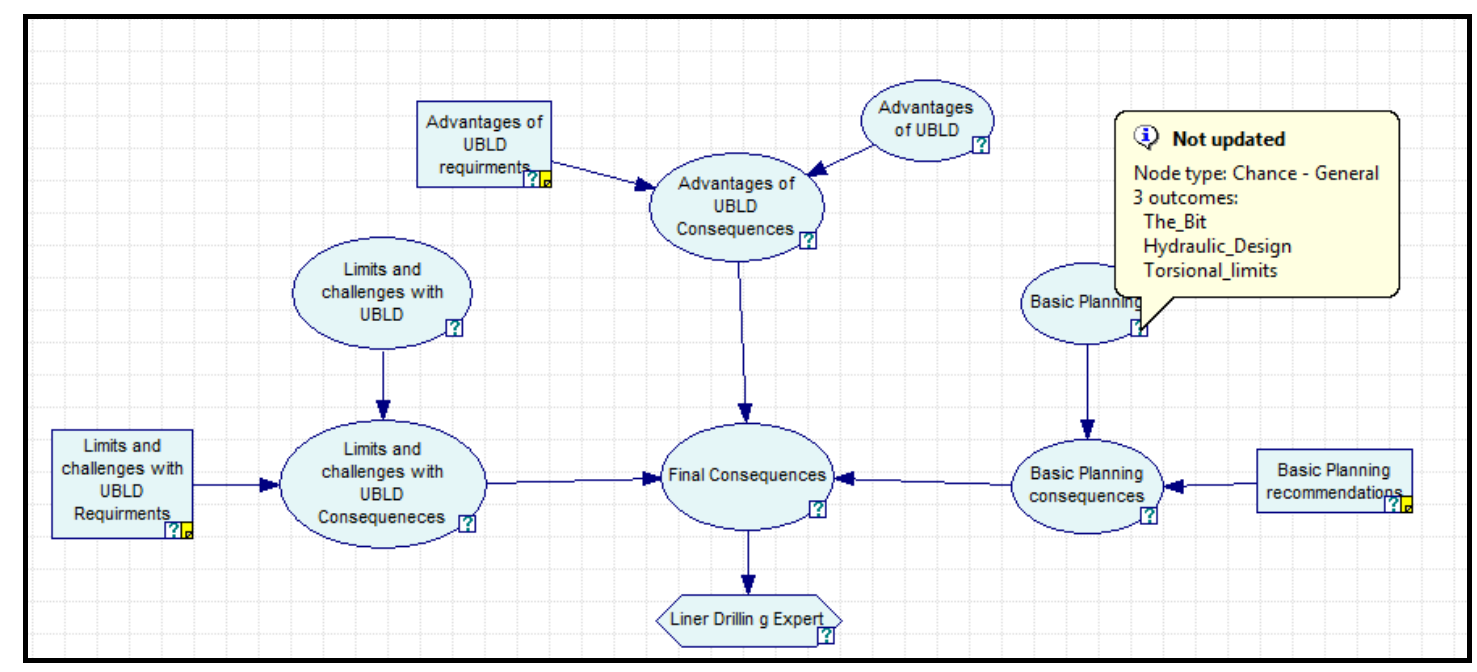

Fig.79: Basic planning for UBLD options

7.8 Underbalanced coil tube model

Fig.80 shows the overall model of UBCT model. The model is divided into two parts. The first part is pre-planning probabilities and requirements. The second part is drilling challenges probabilities and solutions.

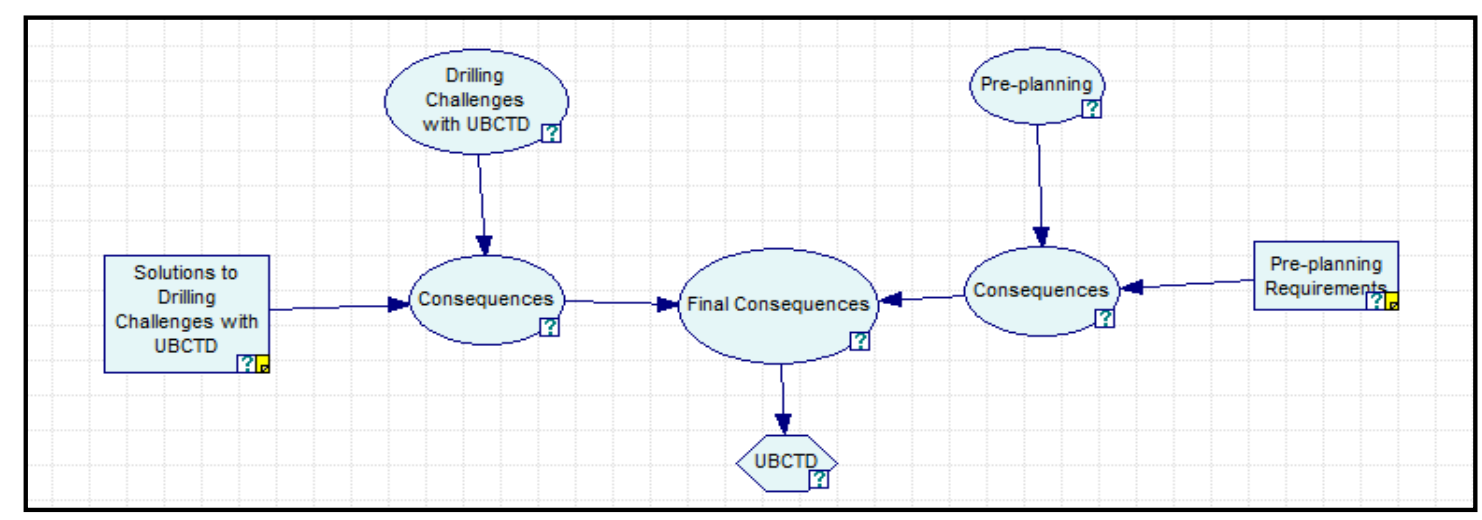

Fig.80: Overall model for UBCT 
Pre-planning probabilities are shown in Fig. 81 and drilling challenges probabilities are shown in Fig. 82.

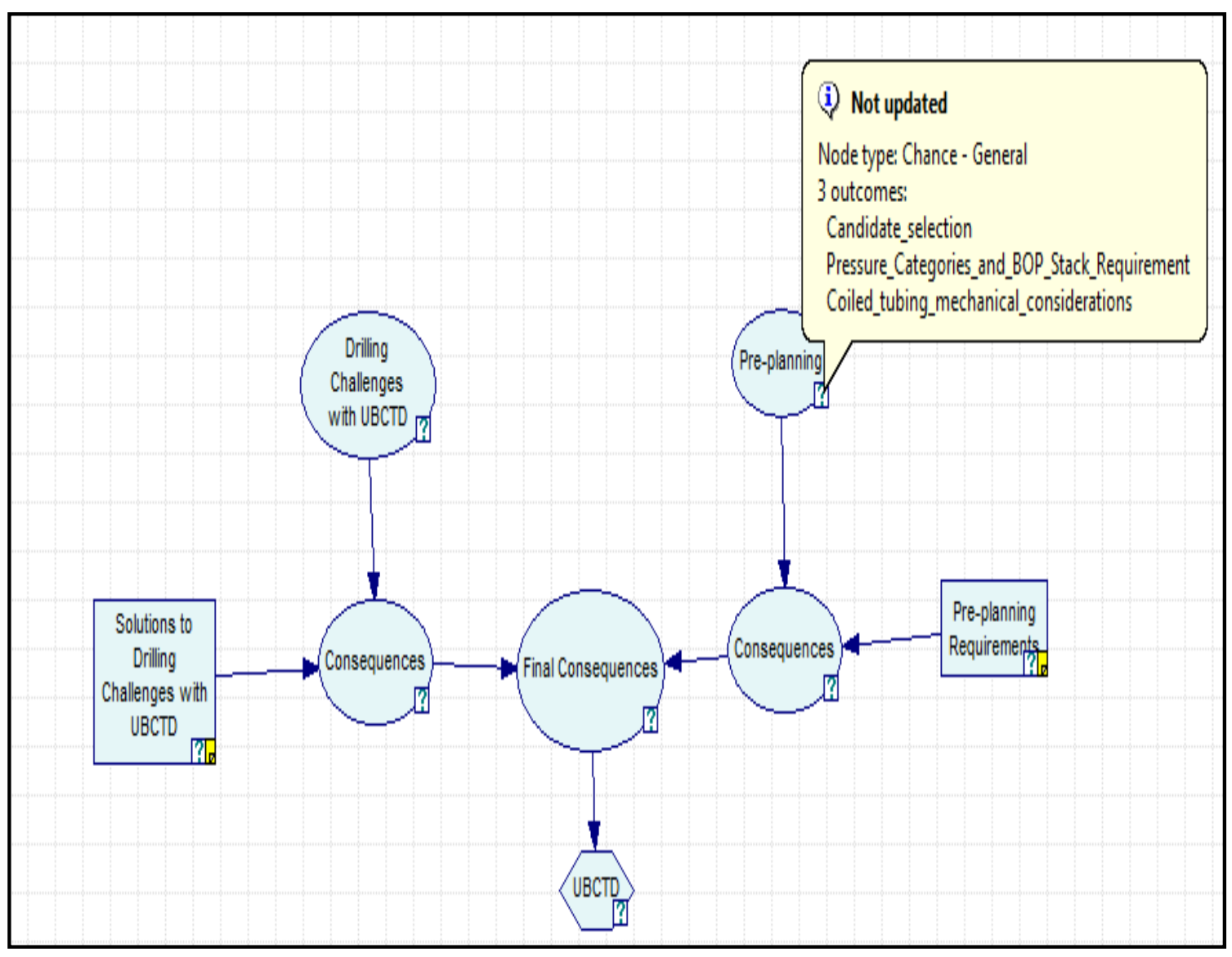

Fig.81: A list of pre-planning possibilities 


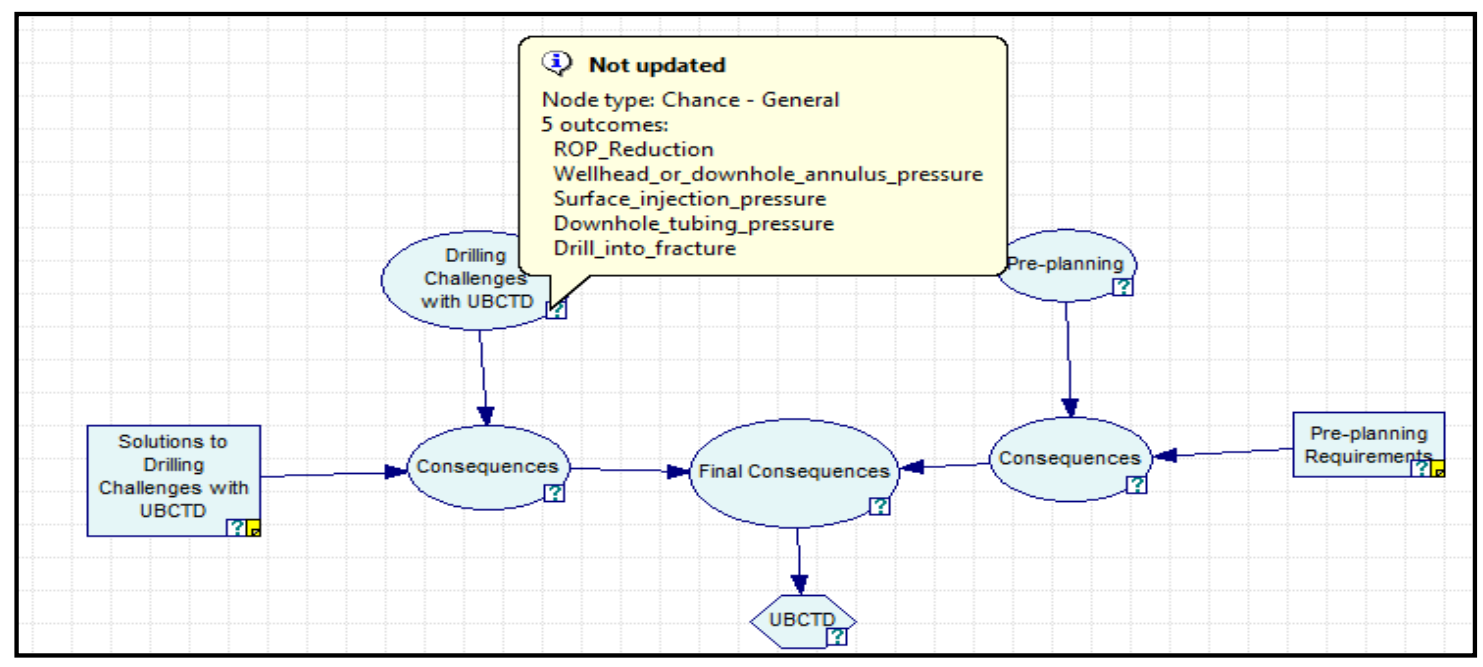

Fig.82: A list drilling challenges with UBCTD

7.9 Snubbing and stripping model

Fig.83 shows the overall model of snubbing and stripping model. The model is divided into four parts. The first part is basic snubbing probabilities and recommendations. The second part is snubbing units' probabilities and recommendations. The third part is general stripping procedure and recommendations. The fourth part is snubbing operations probabilities and its recommendations. 


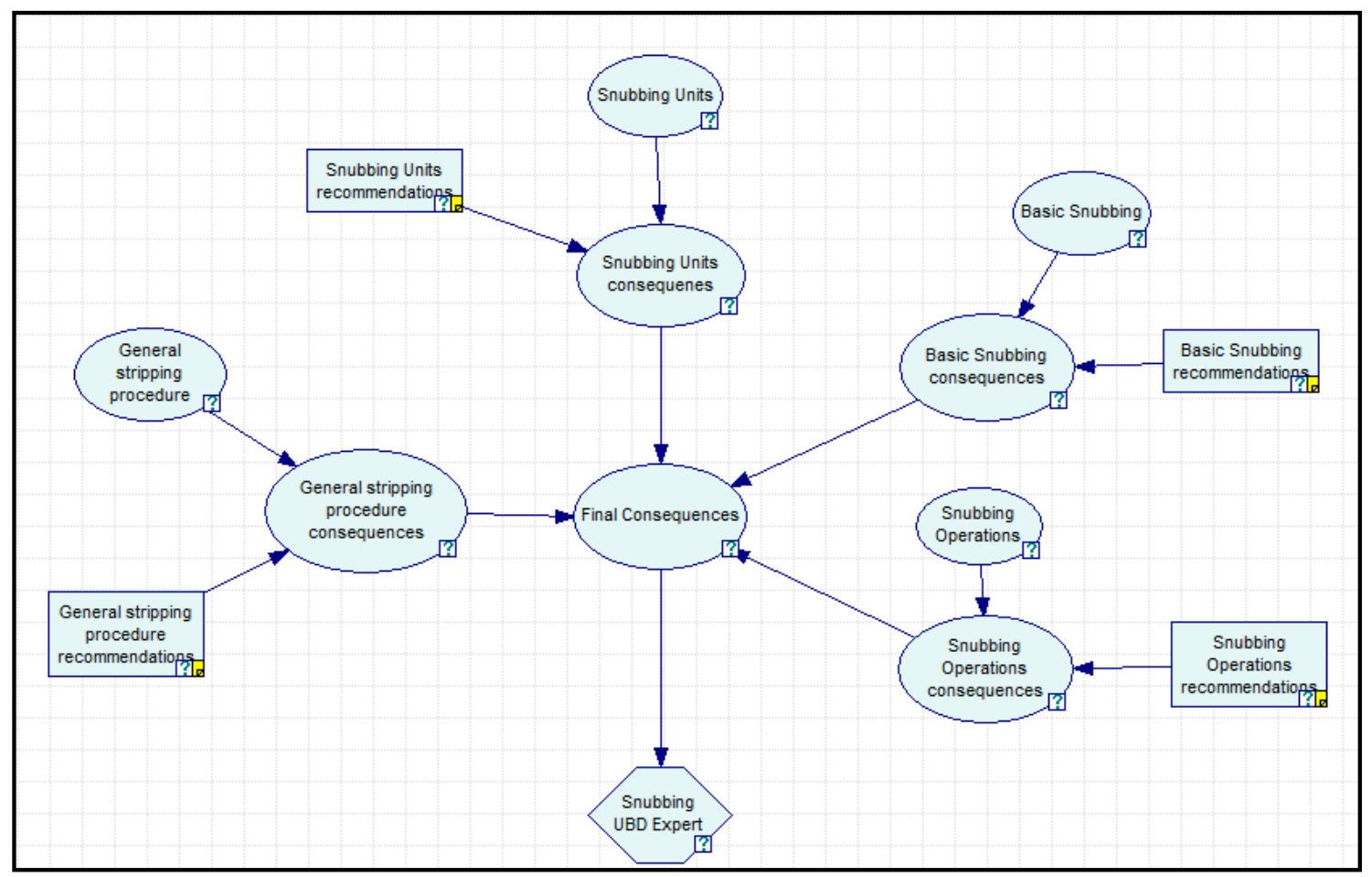

Fig.83: Overall model for snubbing and stripping

Basic snubbing probabilities (Fig. 84) and snubbing units' probabilities are shown in Fig. 85. 


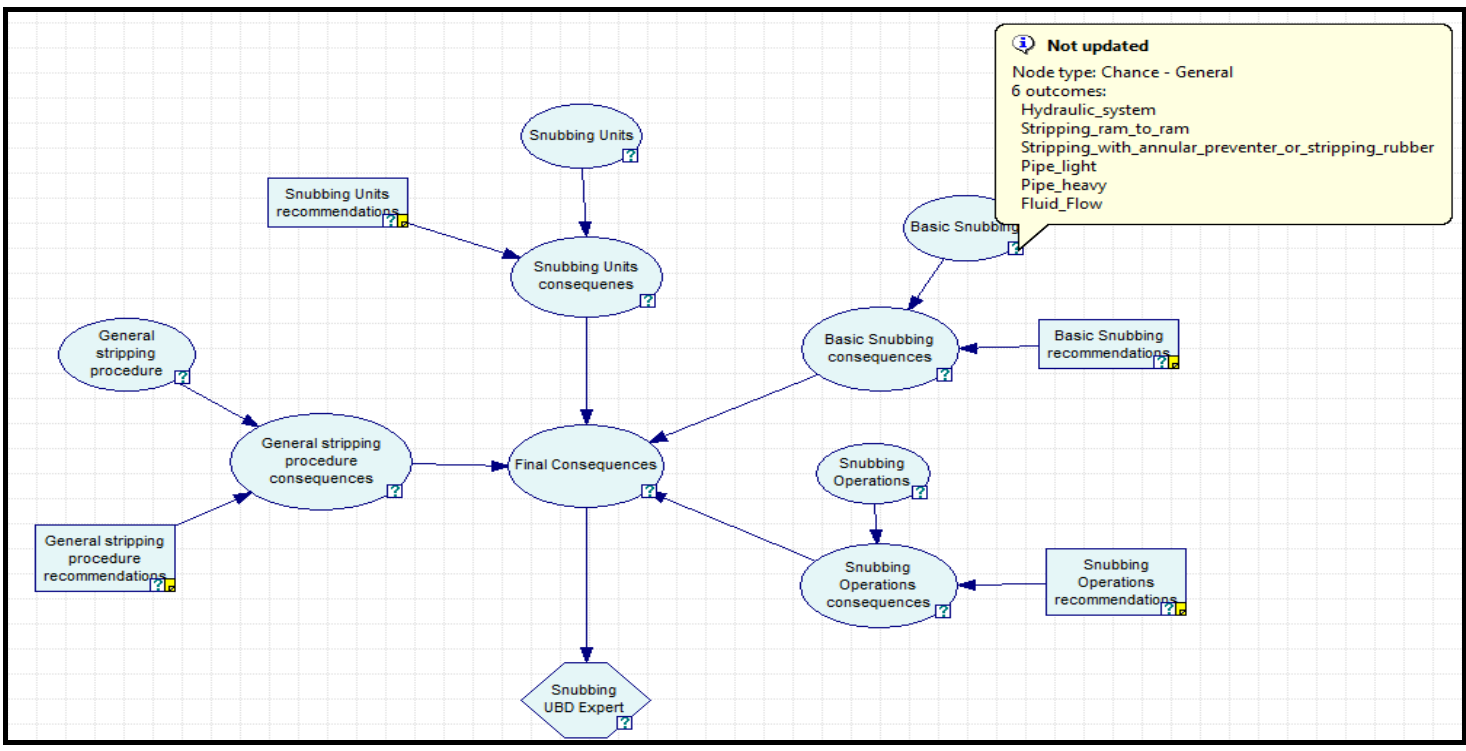

Fig.84: A list of basic snubbing options

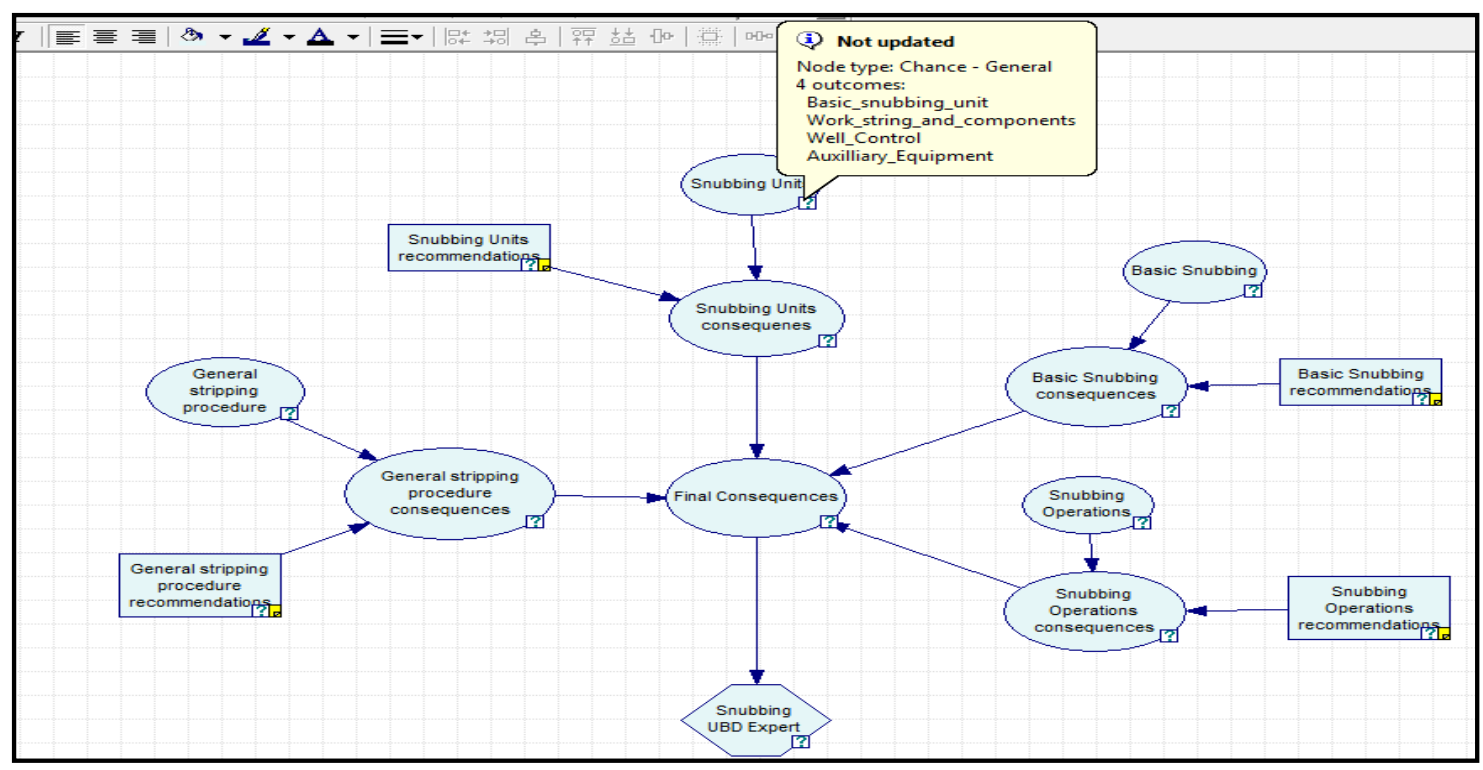

Fig.85: A list of snubbing unit 
General stripping procedure (Fig. 86) and snubbing operations probabilities are shown in Fig. 87.

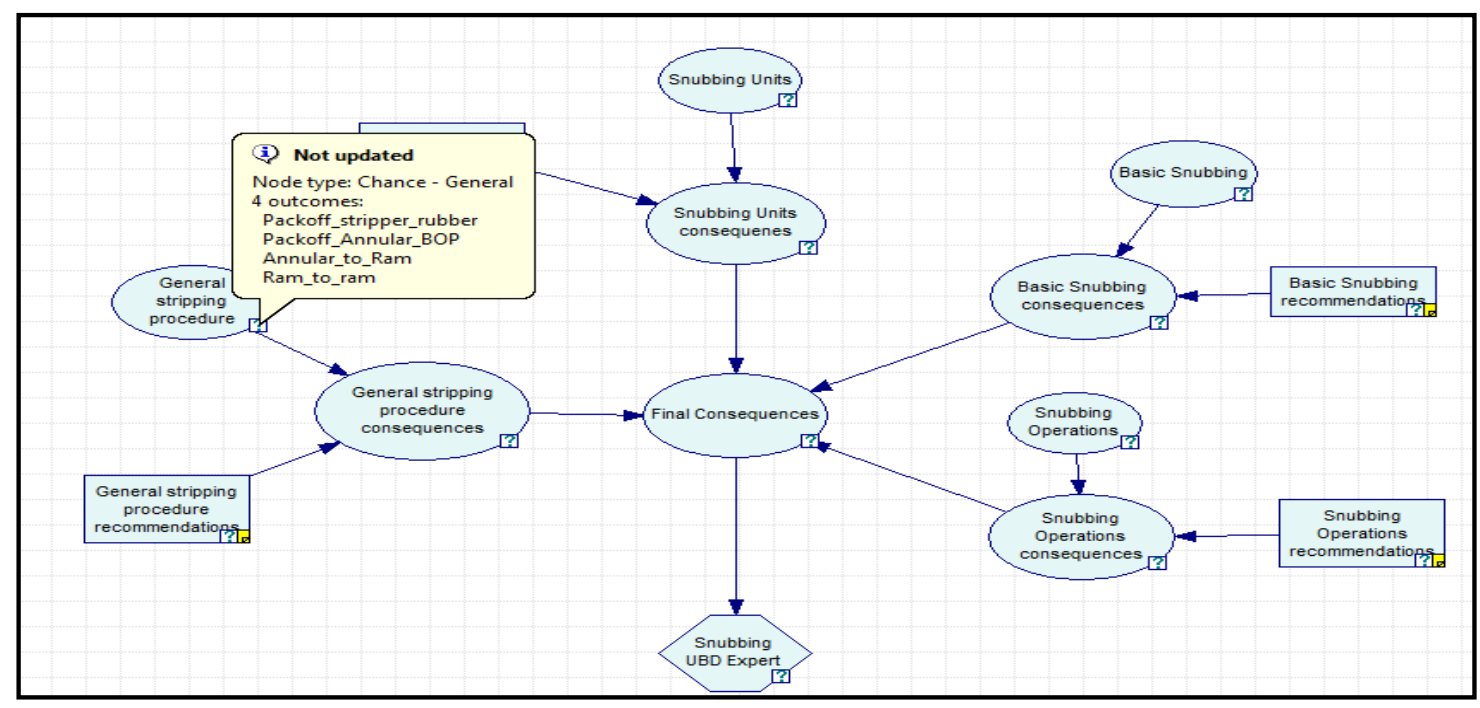

Fig.86: A list of possible stripping procedure

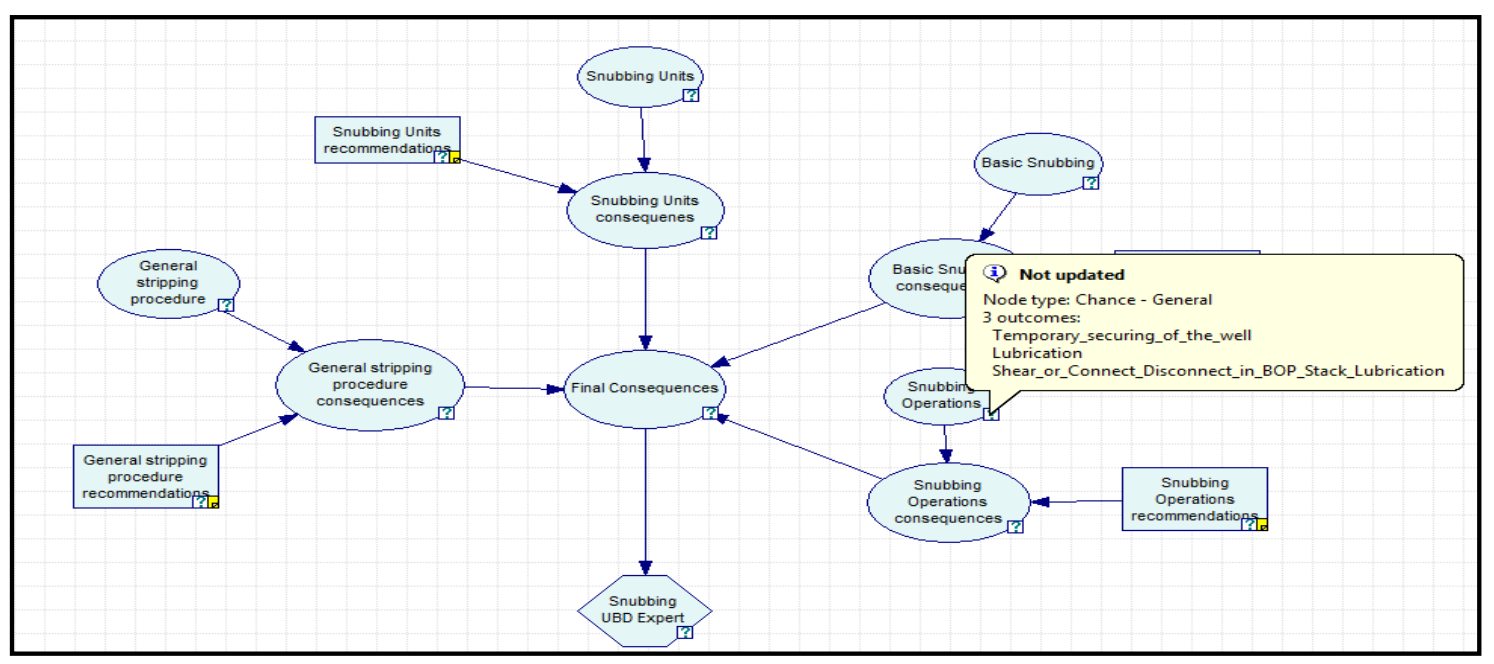

Fig.87: A list of possible snubbing operations 


\section{CHAPTER VIII}

\section{RESULTS AND DISCUSSION*}

In this chapter, examples for different scenarios are shown and explained from the models developed here. This chapter is divided into five sections (completion, drilling fluids, well control, cementing, and underbalanced drilling).

*Reprinted with permission from "Expert System for the Optimal Design and Execution of Successful Completion Practices Using Artificial Bayesian Intelligence," by Al-Yami, A.S., Schubert, J., and Beck, G., 2011, SPE 143826, Copyright (C) 2012, Society of Petroleum Engineers.

*Reprinted with permission from "Drilling Fluids Consultation System: Development and Field Applications," by Al-Yami, A.S. and Schubert, J., 2012a, SPE 152098, Copyright (C) 2012, Society of Petroleum Engineers.

*Reprinted with permission from "Development of Optimum Well Control Practices Using Artificial Bayesian Intelligence," by Al-Yami, A.S. and Schubert, J., 2012c, OTC 22882, Copyright $\mathbb{C}$ 2012, Society of Petroleum Engineers.

*Reprinted with permission from "Drilling Expert System for the Optimal Design and Execution of Successful Cementing Practices," by Al-Yami, A.S., Schubert, J., Medina, C., and Ok-Youn, Y., 2010b, IADC/SPE 135183, Copyright (C) 2010, Society of Petroleum Engineers

*Reprinted with permission from "Guidelines for Optimum Underbalanced Drilling Practices Using Artificial Bayesian Intelligence," by Al-Yami, A.S. and Schubert, J., 2012d, OTC 22883, Copyright (C 2012, Society of Petroleum Engineers. 


\subsection{Well Completion model}

This section shows the use of this model in one scenario where the user selects his conditions, Figs. 88-93. To view the results once the model is executed can be done by obtaining the optimum results from each section separately, Figs. 94-100. Figs. 98 and 99 shows that no need to do perforation or openhole gravel packing since our optimum lateral completion is openhole expandable screens. If we change the four uncertainties (cost, zonal isolation, reliability and productivity) to (moderate, poor, moderate, and good) then our optimum lateral completion will be openhole gravel packing, Fig.101. Since the lateral completion is openhole gravel packing, the user can get more details by selecting his desired conditions, Fig.102-103. The optimum slurry density for openhole gravel packs is shown in Fig. 104. 


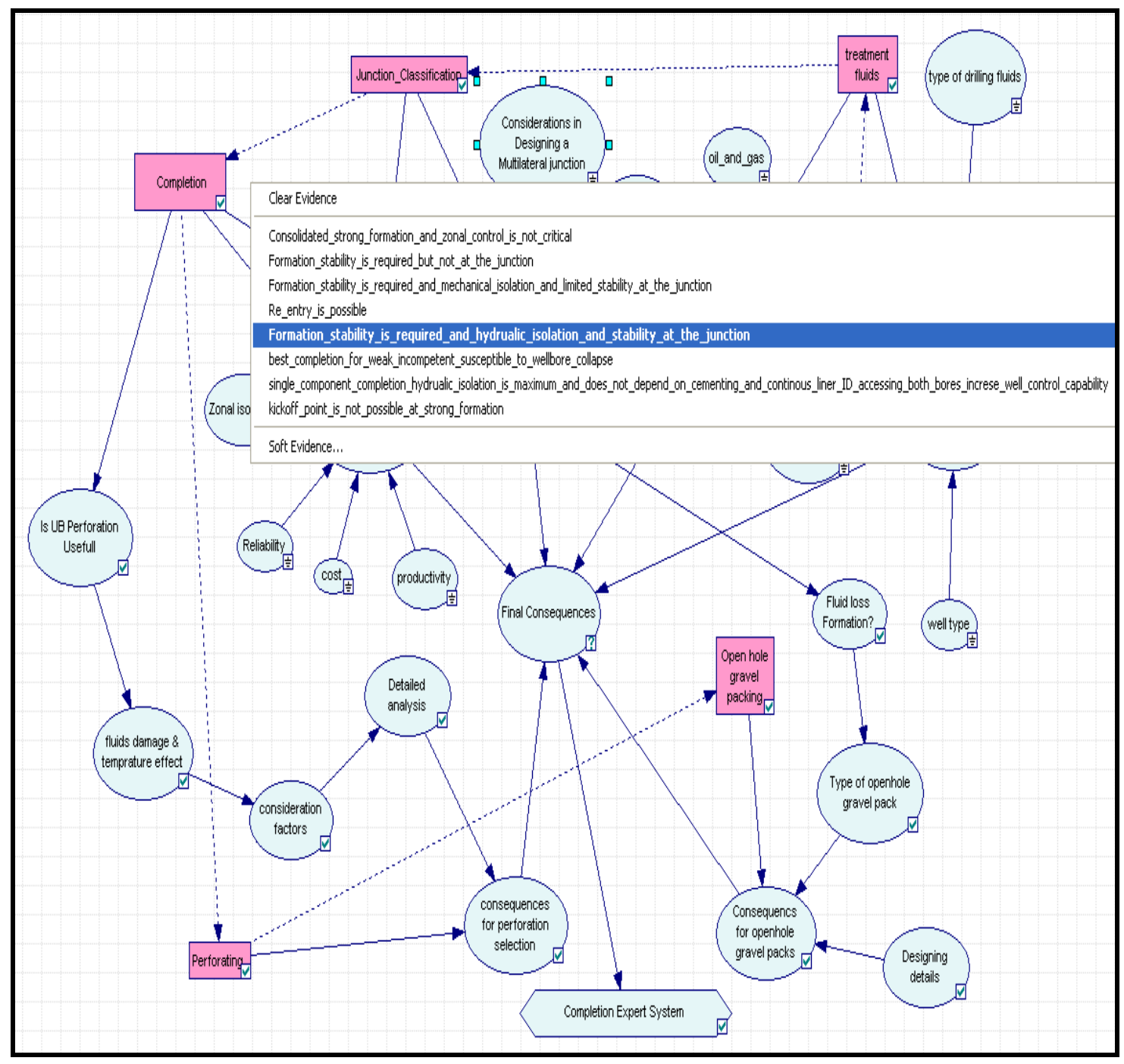

Fig.88: Selection of considerations of designing a multilateral junction 


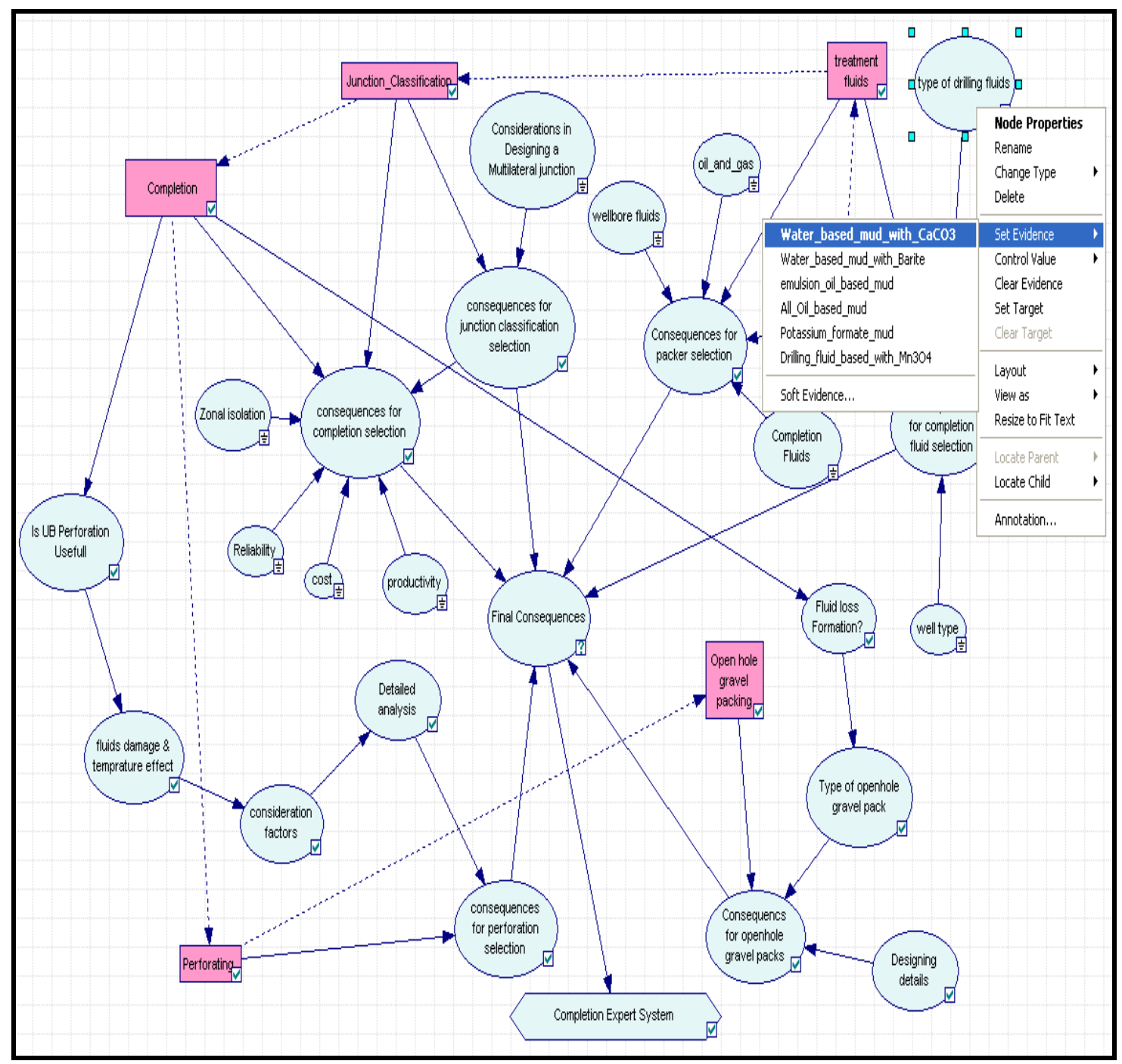

Fig.89: Selection of considerations of type of drilling fluid 


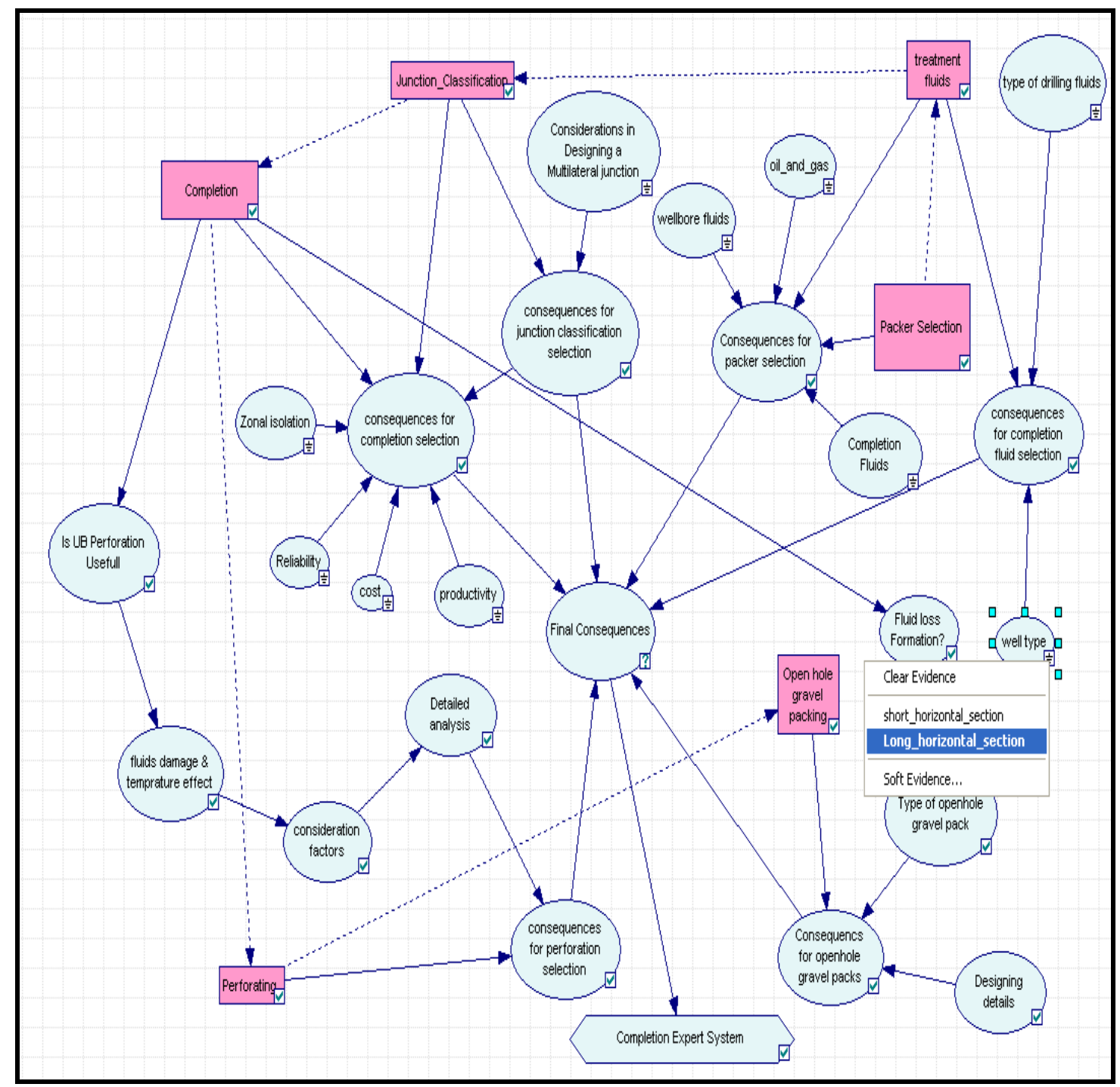

Fig.90: Selection of well type 


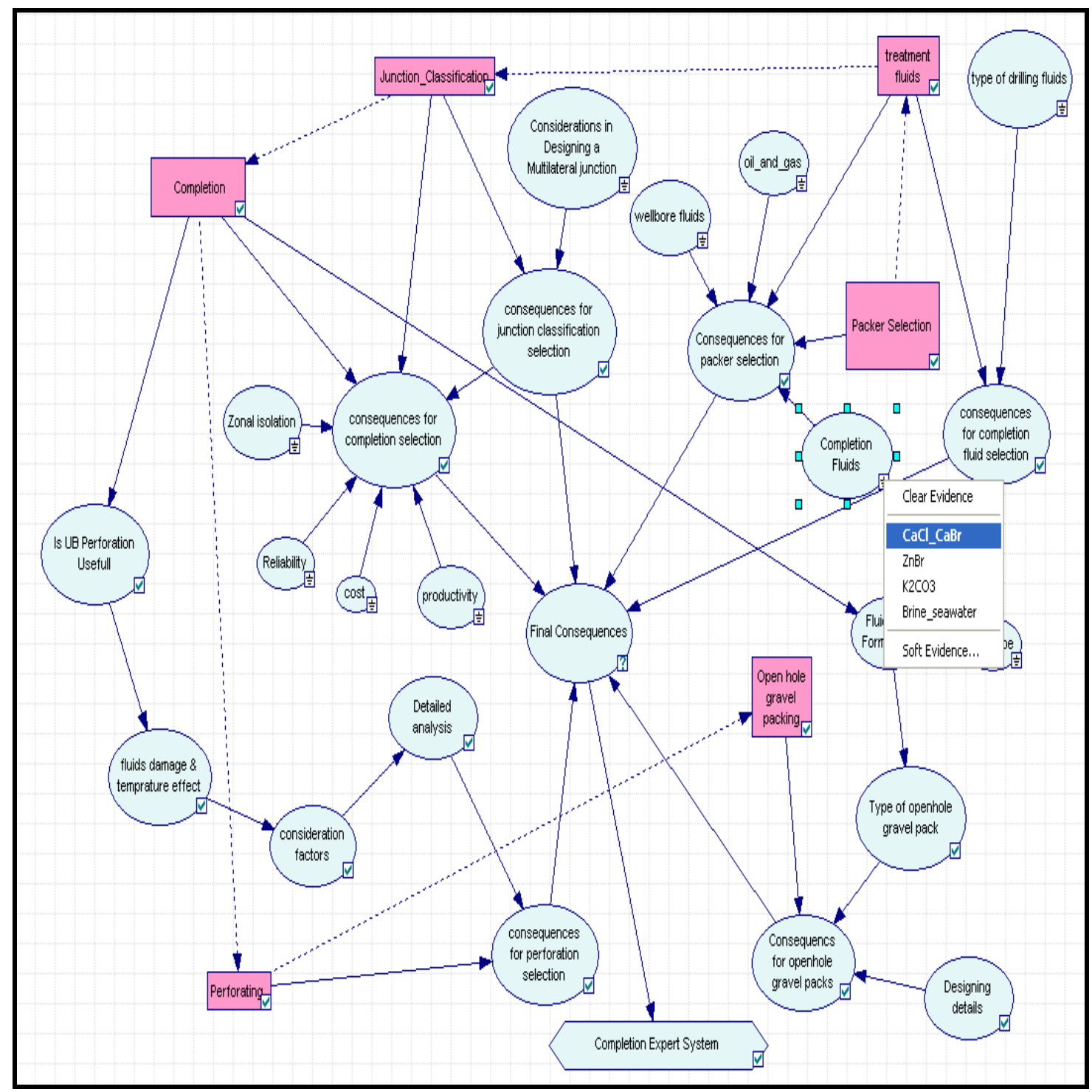

Fig.91: Selection of completion fluids 


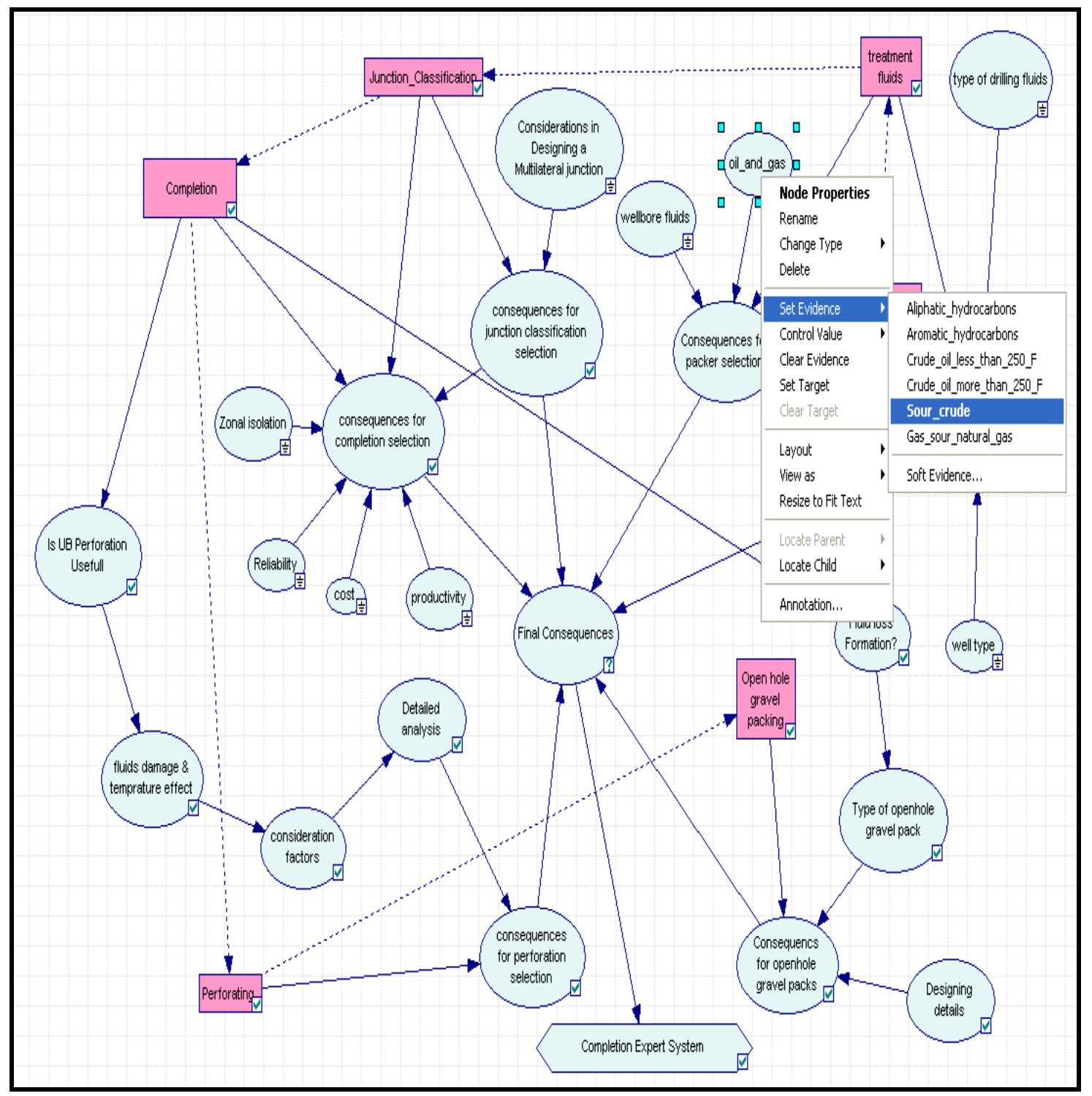

Fig.92: Selection of oil and gas characteristics 


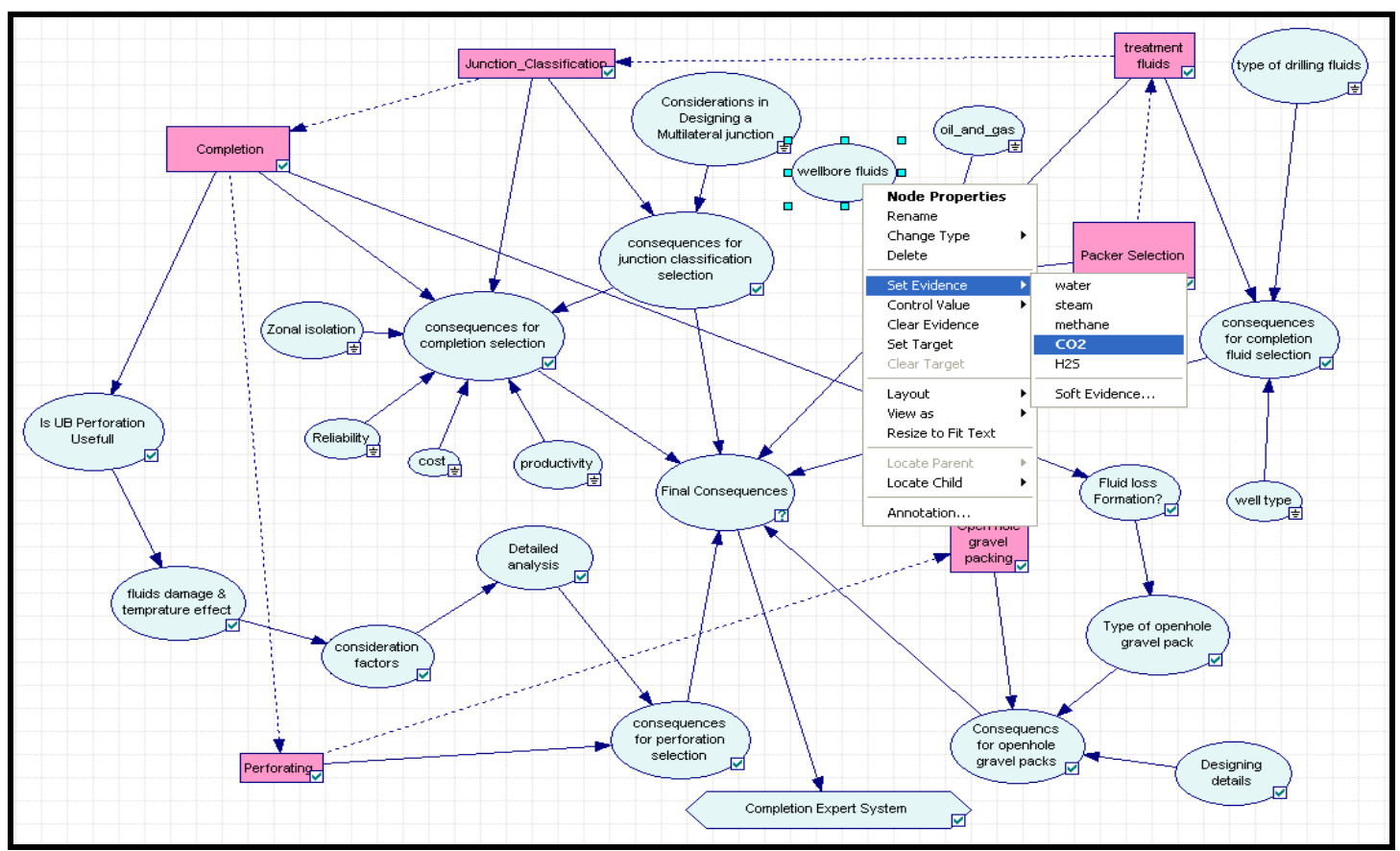

Fig.93: Selection of wellbore fluids

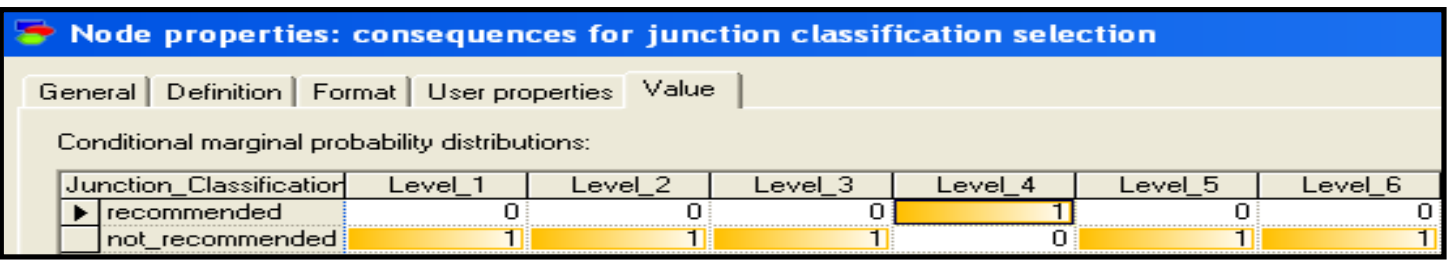

Fig.94: Optimum selection of junction classification 


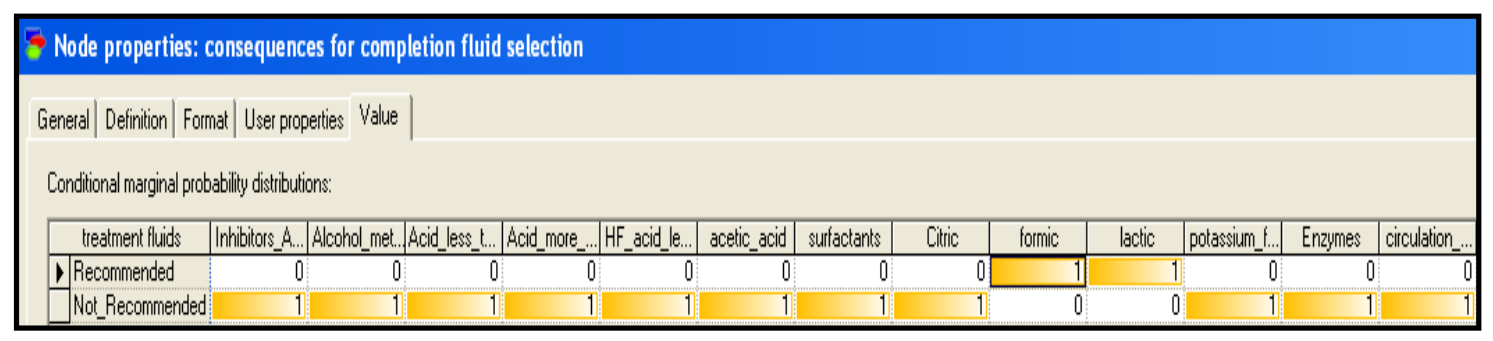

Fig.95: Optimum selection of completion (treatment) fluid

\section{Node properties: consequences for completion selection}

Genera|| Defintion | Format| User properties Value

Conditional marginal probabality distibutions:

\begin{tabular}{|c|c|c|c|c|c|c|c|c|c|c|}
\hline Junction_Classification & & \multicolumn{5}{|c|}{ Leve__4 } & \multicolumn{4}{|c|}{ Level 5} \\
\hline Completion & Openhole_e. & Standalone_screen & Open__hole_glavel__ack & Cased_hole_glavel_ack & Frac_pack & Openhole_expandable_screens & Standalone.. & Open_hole. & Cased_hols & Flac_pack \\
\hline Not_feconmented & 1 & & & $x+2$ & & & 0 & 1 & & 1: \\
\hline Dit Recommended & 0 & & & 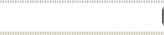 & & & ( & 0 & 0 & 0 \\
\hline
\end{tabular}

Fig.96: Optimum selection of completion selection

\section{Node properties: consequences for perforation selection}

General| Defintion $\mid$ Format| User properties Value $\mid$

Conditional magignal probability distributions:

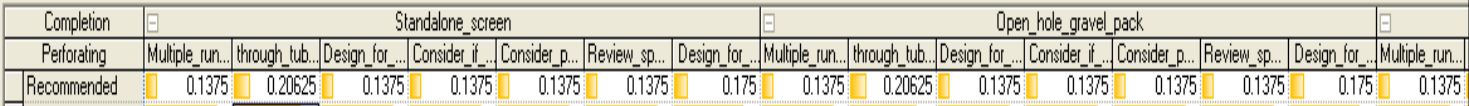

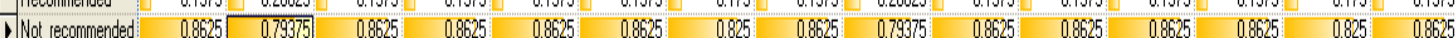

Fig.97: Optimum selection of perforation selection 


\section{Node properties: Consequencs for openhole gravel packs}

General| Defintion | Format| User properties Value

Conditional maginal probability distibutions.

Completion $\quad \exists \quad$ Standalone_screen

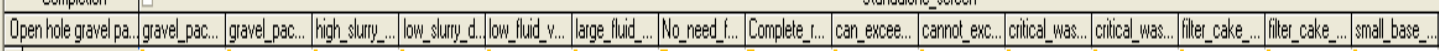

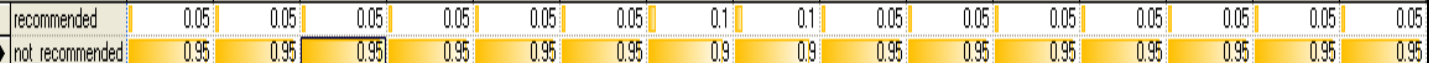

Fig.98: Optimum selection of openhole gravel packs details

\begin{tabular}{|c|c|c|c|}
\hline \multicolumn{4}{|c|}{ Node properties: Packer Selection } \\
\hline Gen & Definition | Format & User properties & Value \\
\hline \multicolumn{4}{|c|}{ Expected utilities for different policies: } \\
\hline \multirow{14}{*}{ • } & CR Magnrane & 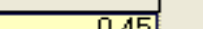 & \\
\hline & $\begin{array}{l}\text { LFi_Neoprene } \\
\Delta E \text { AU Urethane }\end{array}$ & $\frac{0.401}{0.45}$ & \\
\hline & NBR Nitrile & 0.45 & \\
\hline & ECO_Hydrin & 0.45 & \\
\hline & PVDF_Coflon & 0.9 & \\
\hline & HNBR_Therban & 0.45 & \\
\hline & FKM_Viton & 0.9 & \\
\hline & ETFE_Tefzel & 0.9 & \\
\hline & FCM_Aflas & 0.9 & \\
\hline & PEEK_Victrex & 0.9 & \\
\hline & FFKM_Kalrez & 0.9 & \\
\hline & PTFE_Teflon & 0.9 & \\
\hline & oil_swelling_packer & 0.9 & \\
\hline & water_swelling_packer & 0 & \\
\hline
\end{tabular}

Fig.99: Optimum selection of packers

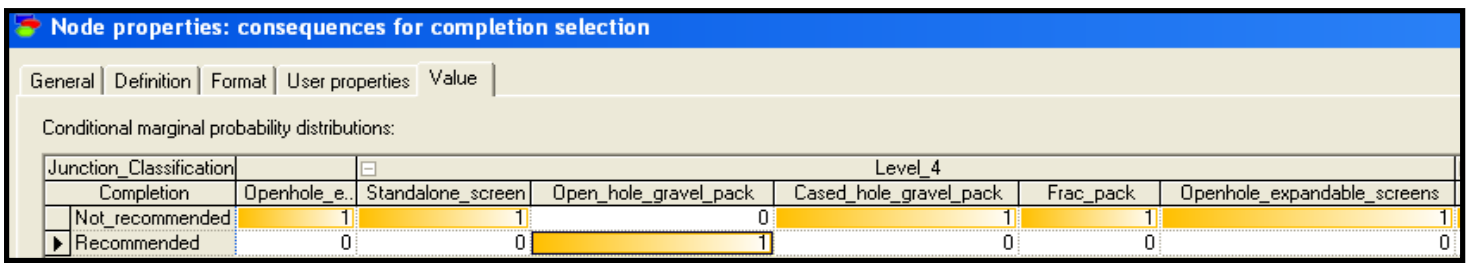

Fig.100: Optimum selection of completion (openhole gravel pack) selection for different conditions 


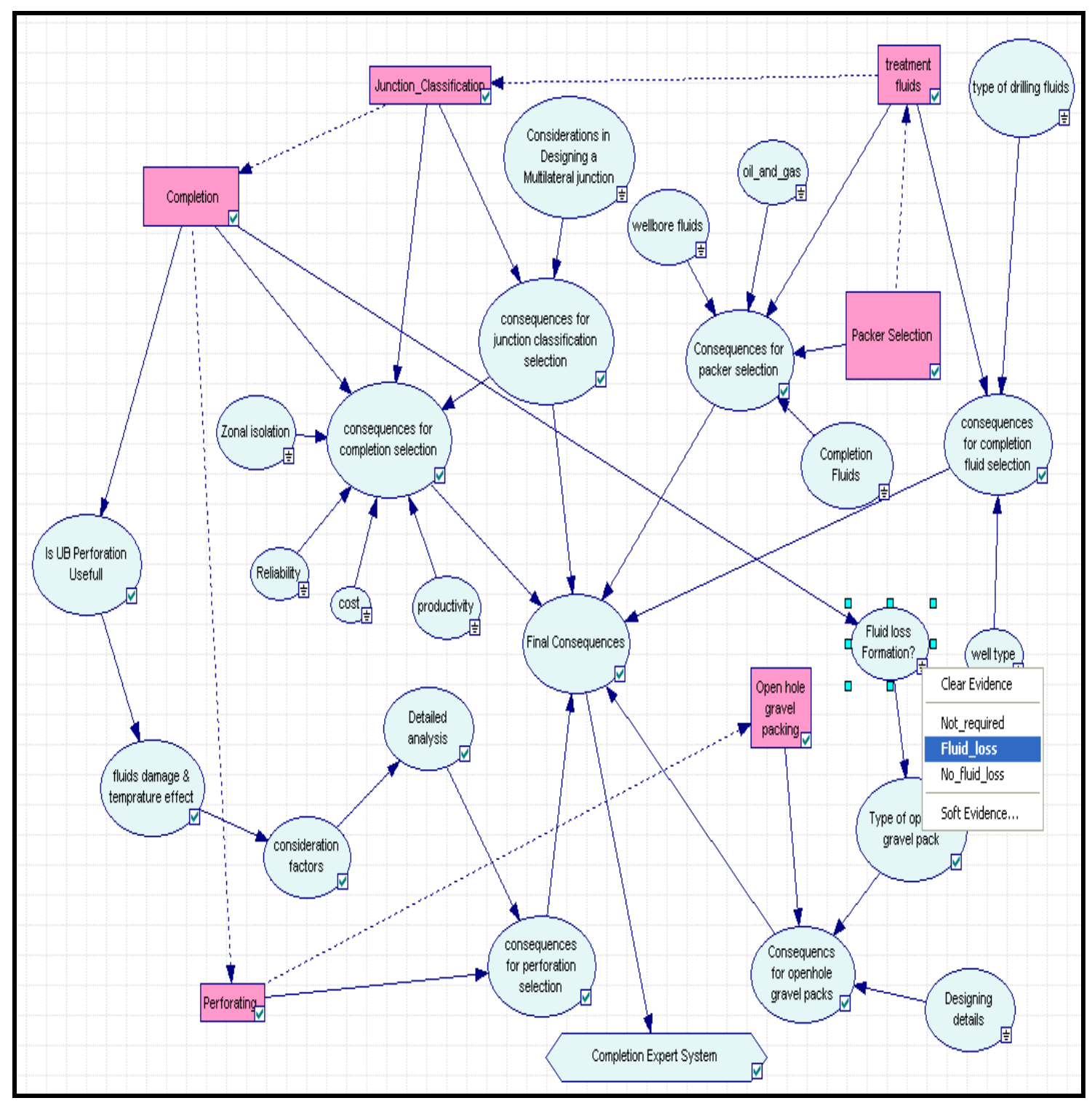

Fig.101: Selection of fluid loss formation 


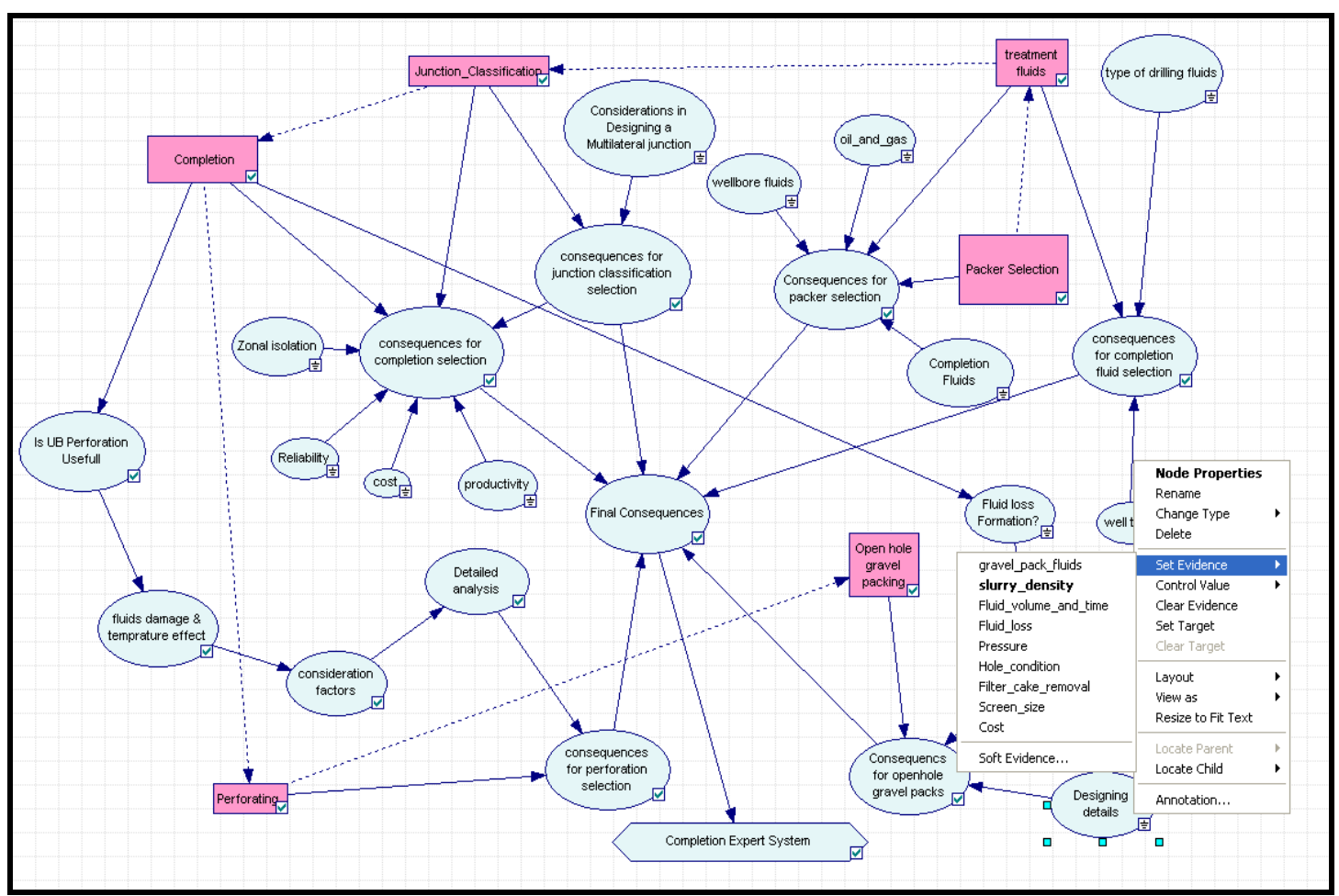

Fig.102: Selection of required slurry density from designing details

\begin{tabular}{|c|c|c|c|c|}
\hline \multicolumn{5}{|c|}{5 Node properties: Consequencs for openhole gravel packs } \\
\hline \multicolumn{5}{|c|}{ General| Definition |Format| User properties Value } \\
\hline \multicolumn{5}{|c|}{ Condtional marginal probability distributions: } \\
\hline Open hole gravel pa.. & gravel_pack_fluid_of_water_or_oil_with_viscositier & gravel_pack_fluid_of_water_used_with_friction_reducer & high_slurry_density_of___ppa & low_slurry_density_of_upto___ppa \\
\hline 1 recommended & 0 & & & 0 \\
\hline Dnot_recommended & 1 & & & \\
\hline
\end{tabular}

Fig.103: part of consequences of openhole gravel packs showing optimum slurry density

The above example showed how using the model in selecting the optimum practices for junction classification, treatment fluid, lateral completion, perforation, 
openhole gravel packing, and packer selection. The states of probabilities in the above tables were obtained by literature review and experts opinions. In case new practices or different experts' opinions are presented then all we need to do is simply change the states of probabilities. In case that the above model is missing other factors then we can also update the model and its corresponding states of probabilities. The flexibility of Bayesian Network in terms of updating the structure model and its beliefs makes this method the first systematic approach to build experts systems.

The main borehole and the lateral are cased and cemented in level 4 completion. In level 3, the mechanical integrity by casing is only observed at the junction. Level 4 requires cementing at the junction resulting in enhanced mechanical integrity and hydraulic isolation, Hill et al. (2008).

Acidic completion brines utilizing $\mathrm{HCl}$ are not effective in removing filter cake in long contact horizontal reservoirs. Lactic, acetic esters showed promising results in removal filter cake from water based drilling fluids, Al-Yami et al. (2009).

Openhole expandable screen lateral completion is selected because the user wants good productivity, cost and zonal isolation. Skin factors close to zero have been observed in the field when using expandable screens. The cost is higher than standalone screen but cheaper than openhole gravel packs, cased hole gravel packs and frac packs. Good zonal isolation has been observed in the field, Jonathan (2009).

Once we change the four uncertainties (cost, zonal isolation, reliability and productivity) to (moderate, poor, moderate, and good) the optimum lateral completion will be openhole gravel packing. 
Basically there are two ways to perform openhole gravel packs. The first one is alternate path which is suitable when we have lost circulation formation. The other way is circulating pack which requires full returns. The user selected lost circulation formation and wants to know the required slurry density. Higher concentration around 8 ppa (pound of proppant added per gallon of clean fluid) is required for alternate path open hole gravel packs, Jonathan (2009).

One of the packers selected was oil swelling packers. Studies done by Al-Yami et al. (2008) showed that they are resistant against different salinity fluids and acids. Water swelling packers are not selected because they can be damaged by $\mathrm{CaCl}_{2}$ fluids and strong acids, Al-Yami et al. (2010a)

\subsection{Drilling fluids model}

The user can select the potential hole problem that might be faced by assigning a probability of one to any of the available probabilities. For example the user selects potential formation damage, Fig.104. A temperature range of 220 to $330{ }^{\circ} \mathrm{F}$ was selected, Fig. 105. The utility node named drilling fluid expert system shows examples of recommended drilling fluids, Figs.106\&107. 


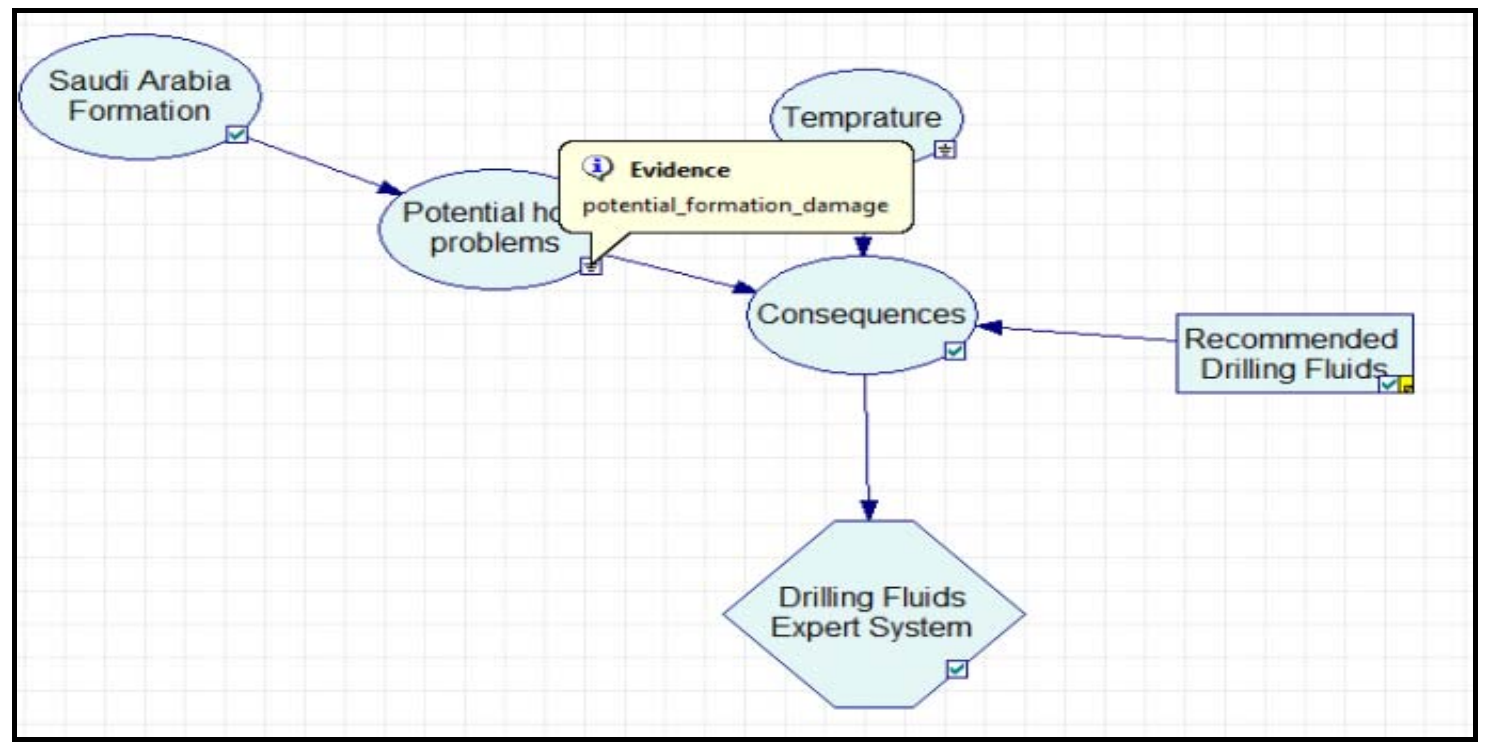

Fig.104: Selecting formation damage as a potential hole problem (example 1)

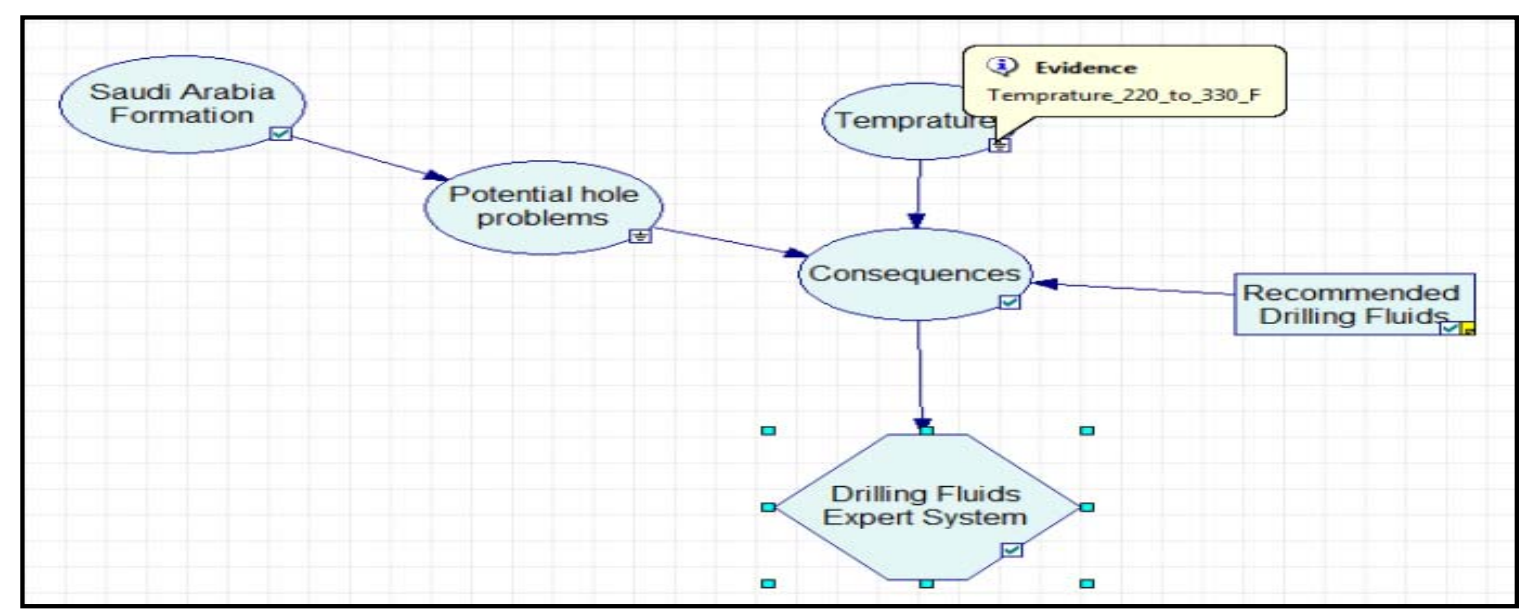

Fig.105: Selecting temperature range (example 1) 
Fig.106: Some possible drilling fluids recommendation for the conditions user selected (example 1)

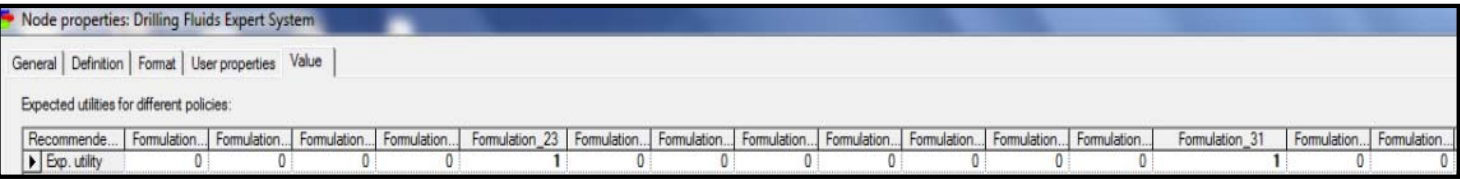

Fig.107: More possible drilling fluids recommendation for the conditions user selected (example 1)

Selection of 120 to $220^{\circ} \mathrm{F}$ range (Fig.108) and loss of circulation and water flows (Fig.109) can lead to another example of drilling fluid recommendation, Fig.110. 


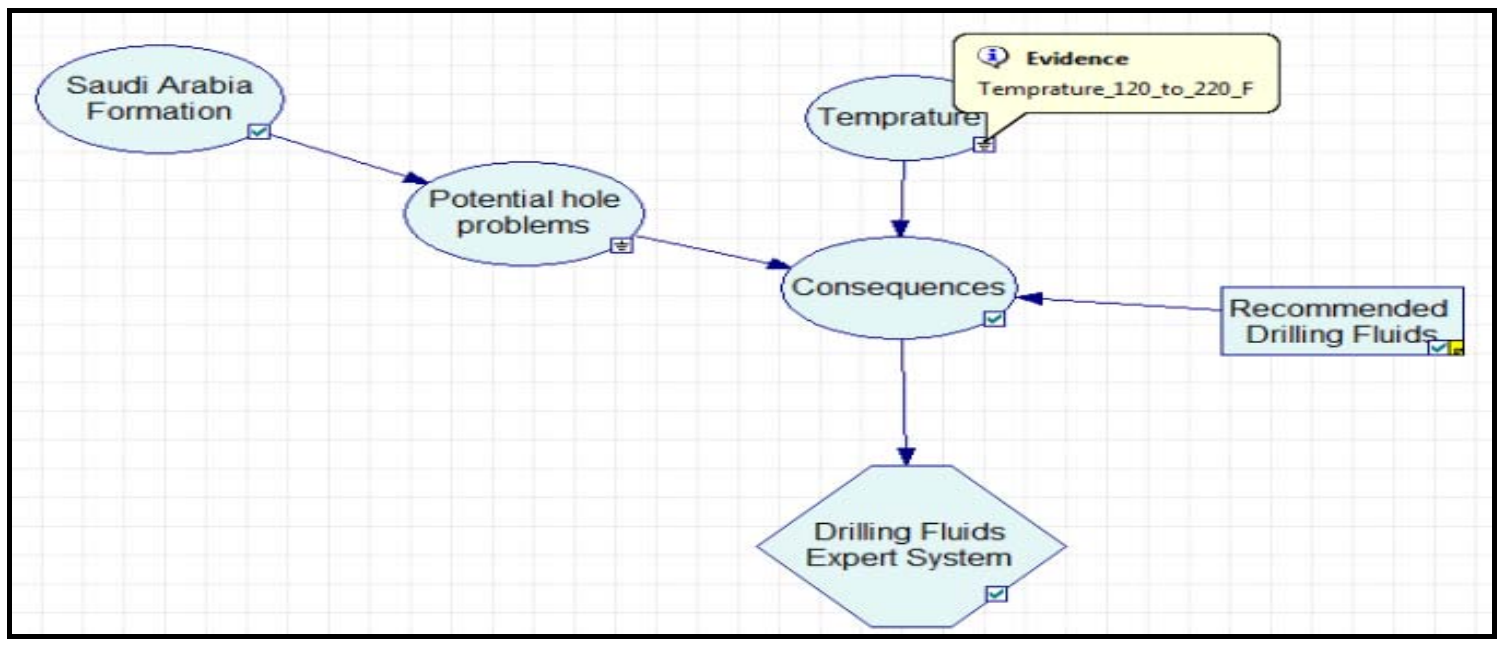

Fig.108: Selecting temperature range (example 2)

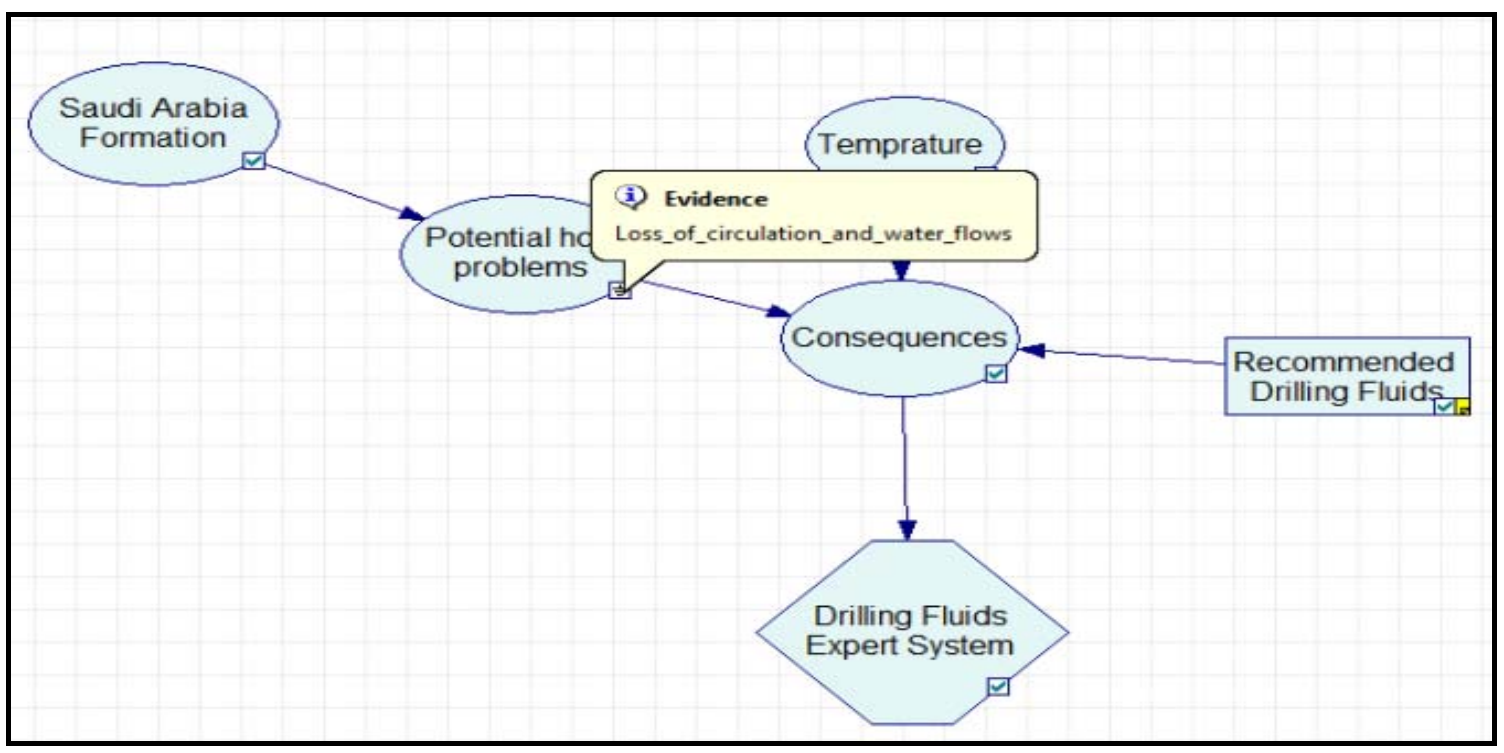

Fig.109: Selecting loss of circulation and water flows as a potential hole problem (example 2) 
Fig.110: Formulation 7 is an example of a drilling fluid that will work in the selected conditions (example 2)

Selection of 220 to $330{ }^{\circ} \mathrm{F}$ range (Fig.111) and tight hole and flow with abnormal pressure (Fig.112) can lead to another example of drilling fluid recommendation, Figs.113 \& 114

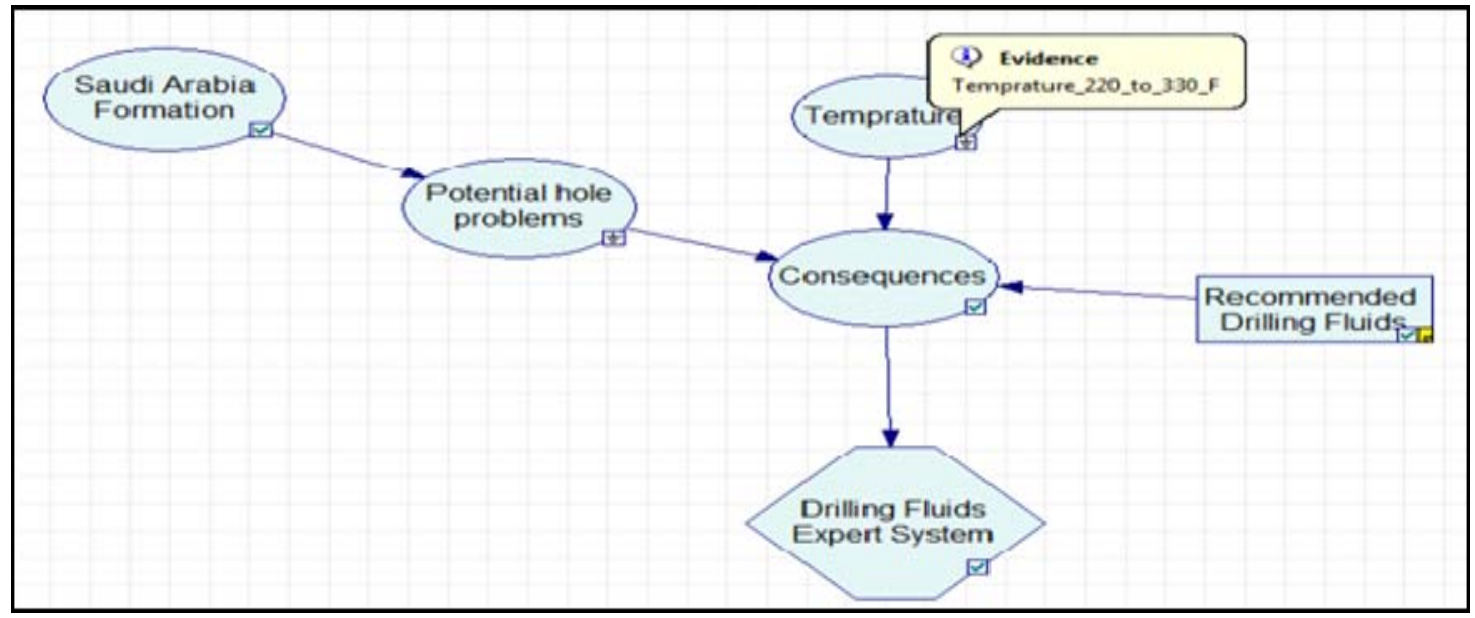

Fig.111: Selecting temperature range (example 3) 


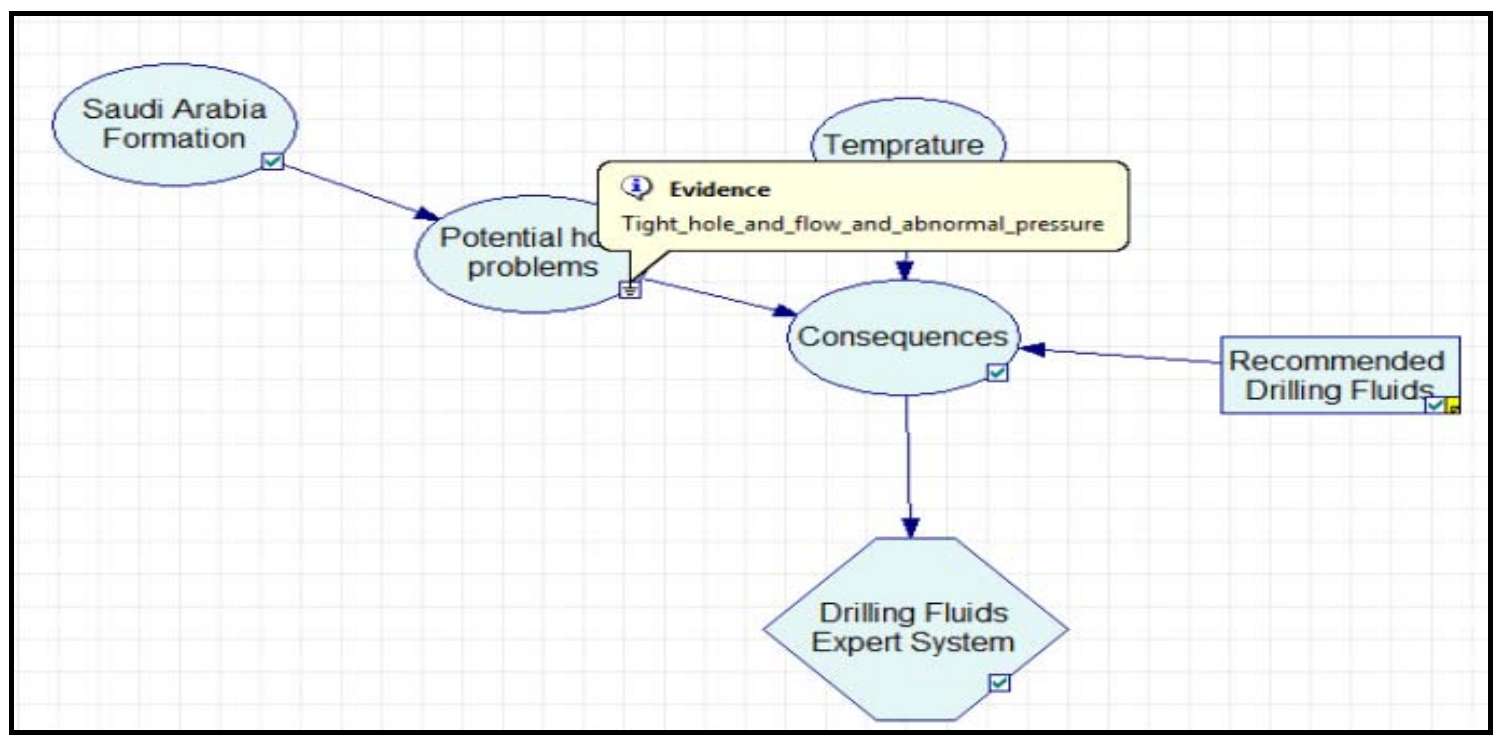

Fig.112: Selecting loss of circulation and water flows as a potential hole problem (example 3)

Node properties: Drilling Fluids Expert System

General | Defintion | Fomat | User propeties Value |

Expected utitities for different policies:

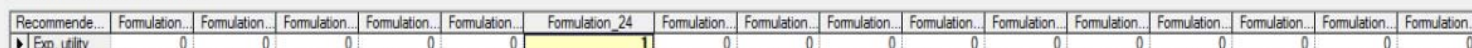

Fig.113: Formulation 24 is an example of a drilling fluid that will work in the selected conditions (example 3)

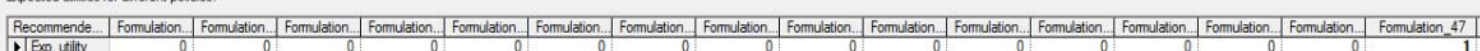

Fig.114: Formulation 47 is another example of a drilling fluid that will work in the selected conditions (example 3 ) 
If the user only knows the temperature range (Fig.115) and formation name (Fig.116) he can still use the model since the potential hole problems is affected by the formation name. Selecting Arab-D formation leads to five potential hole problems probabilities shown in Fig.117. Different drilling fluids formation can be used in this case, Fig.118.

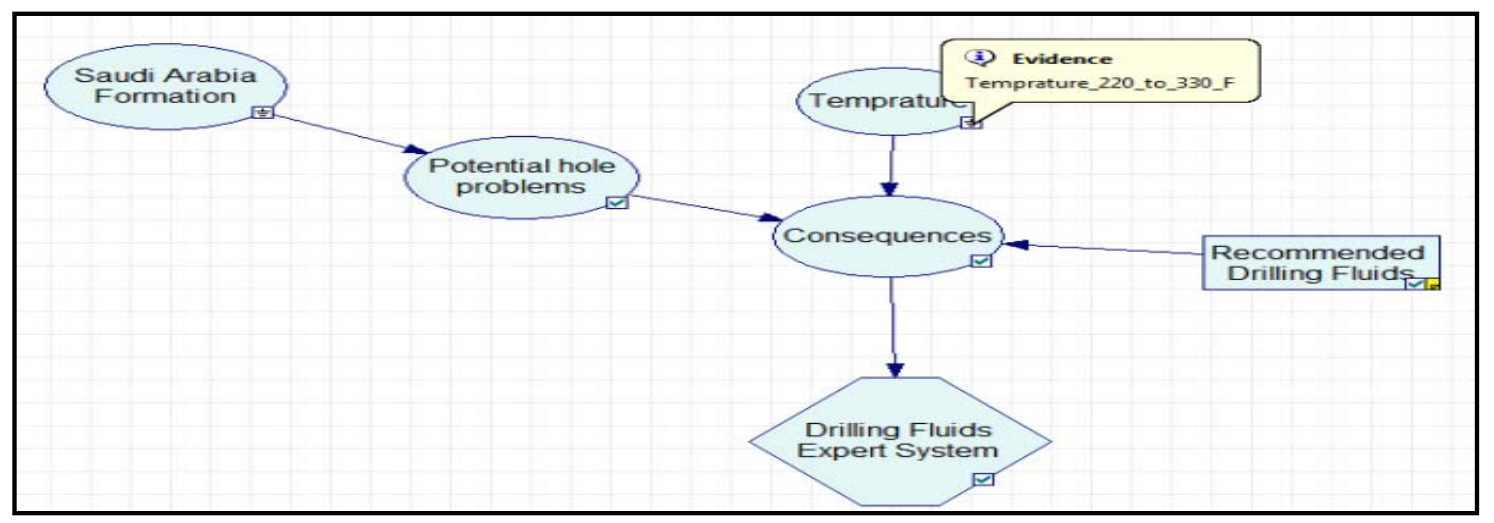

Fig.115: Selecting temperature range (example 4)

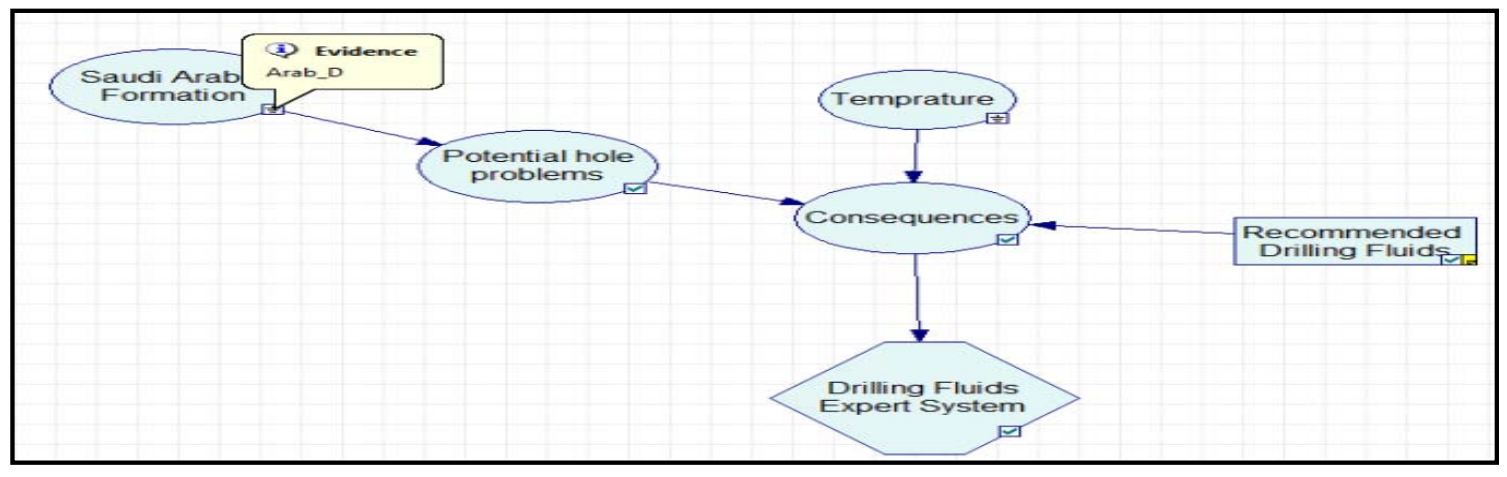

Fig.116: Selecting Saudi Arabia formation (example 4) 


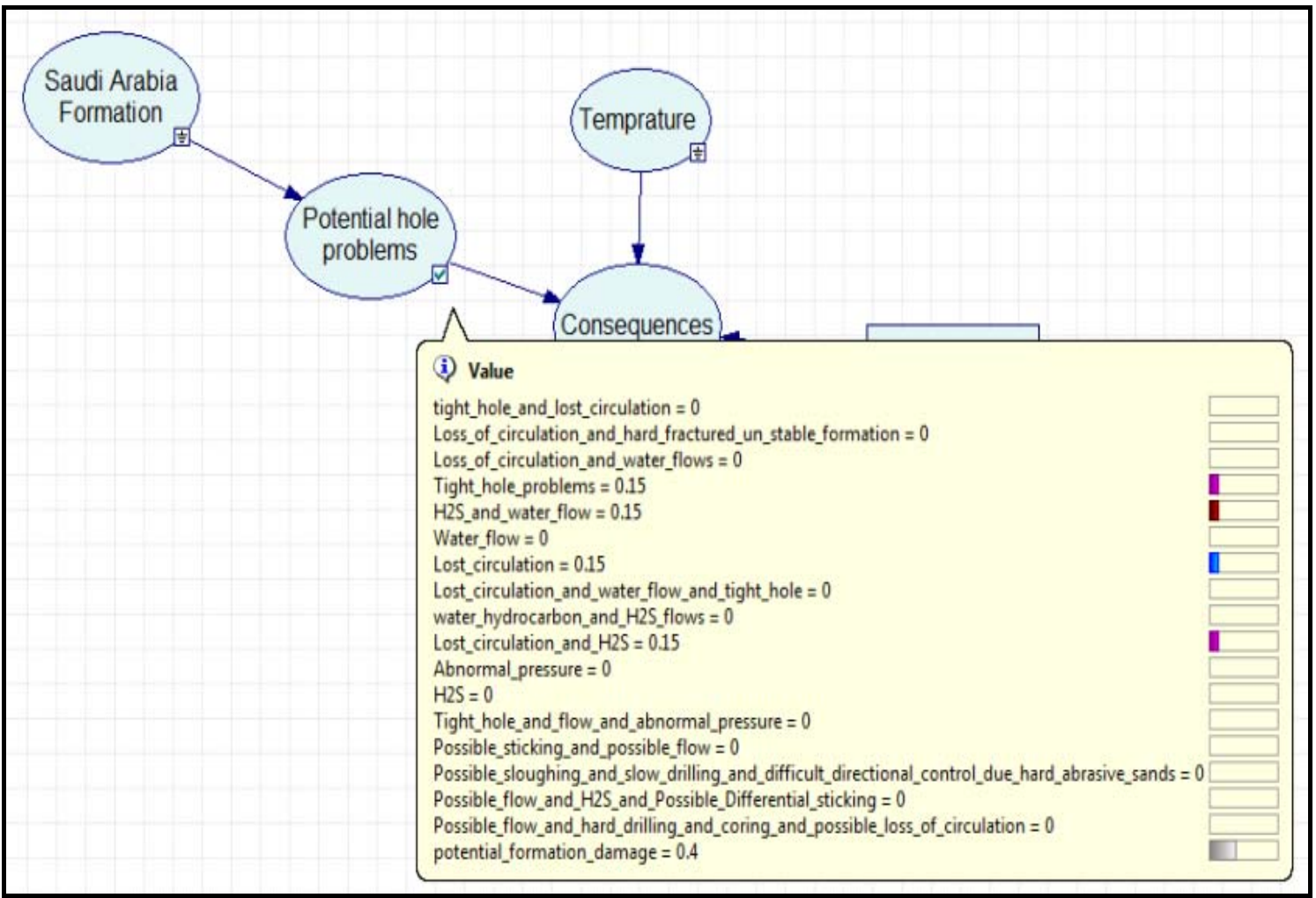

Fig.117: Showing resultant potential hole problems in Arab D formation as selected before (example 4)

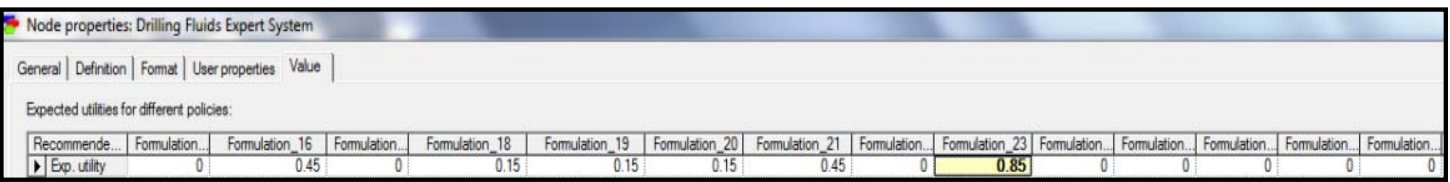

Fig.118: Drilling fluid 23 is the optimum fluid in this case (example 4)

A temperature probability of 120 to $220{ }^{\circ} \mathrm{F}$ (Fig.119) and Wasia and Shuaiba formation (Fig.120) are selected. Wasia and Shuaiba formation is considered to be a 
tight hole and a lost circulation zone, Fig.121. Different drilling fluids formulations are recommended by the drilling fluid model, Figs. $122 \& 123$.

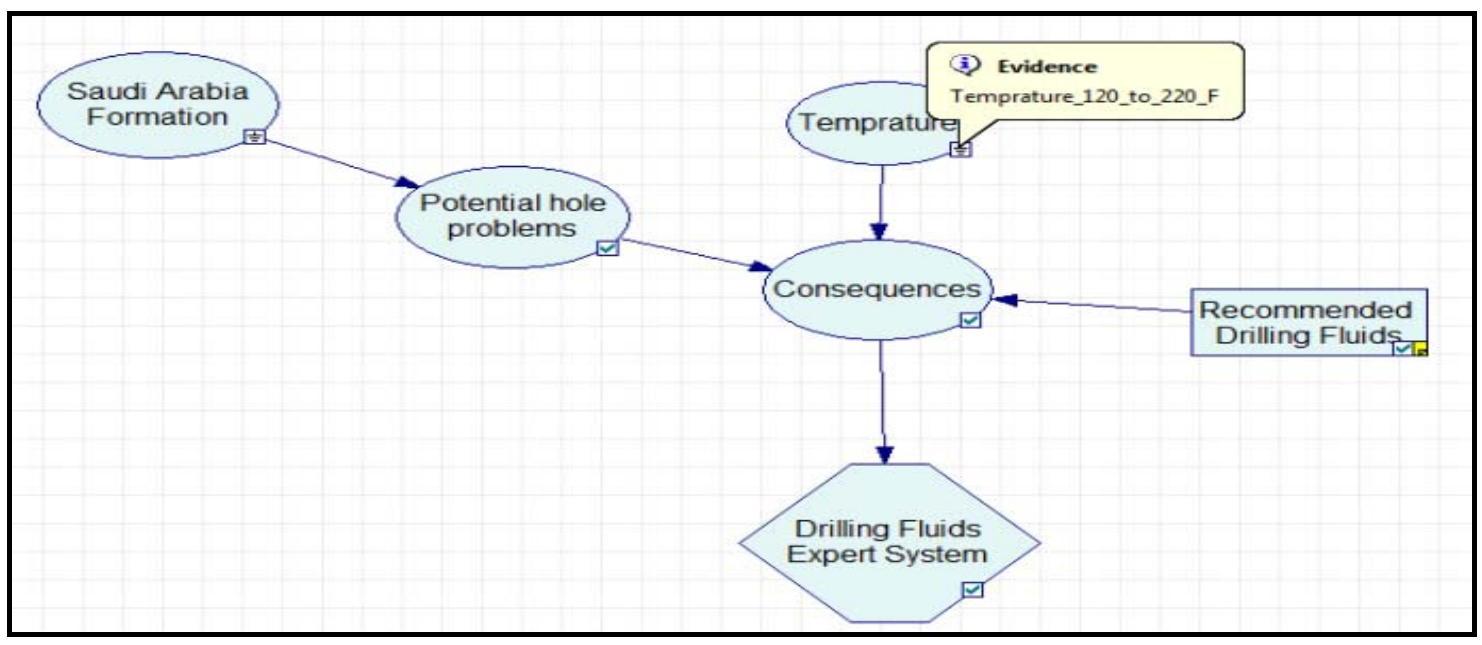

Fig.119: Selecting temperature range (example 5)

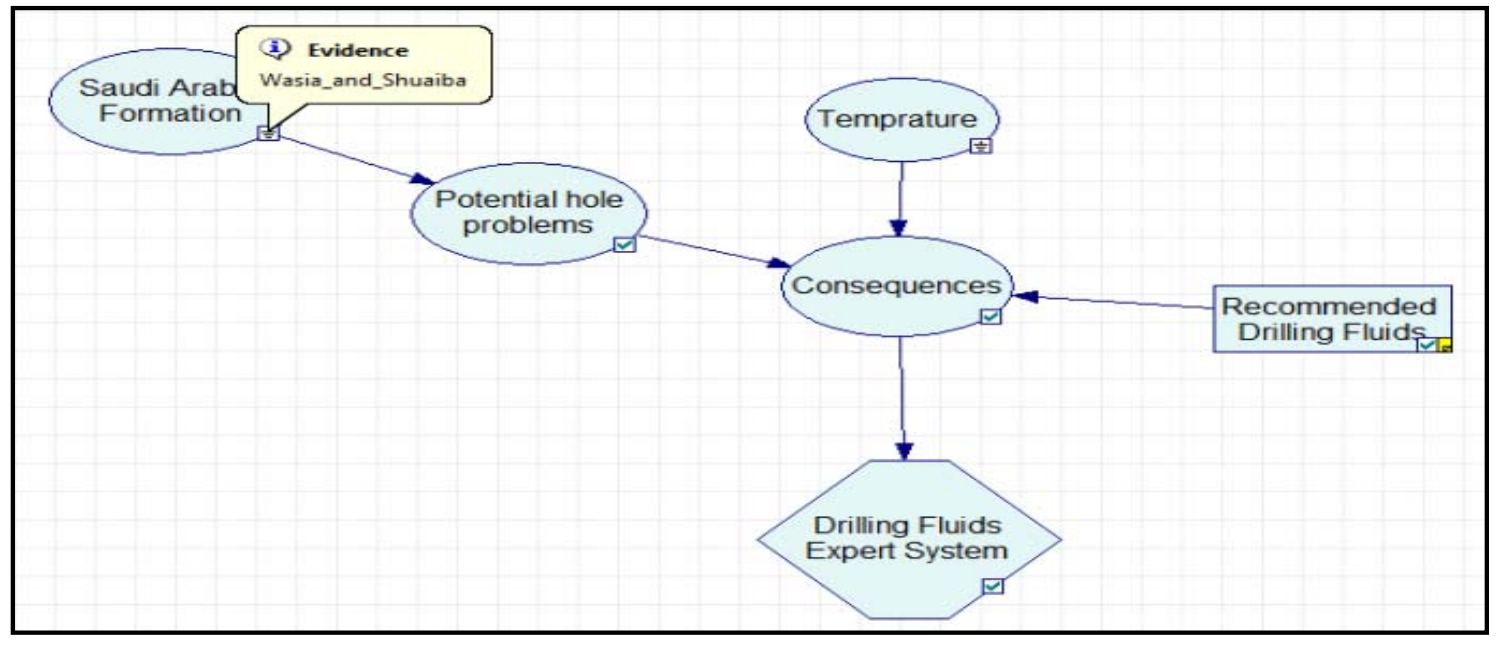

Fig.120: Selecting Saudi Arabia formation (example 5) 


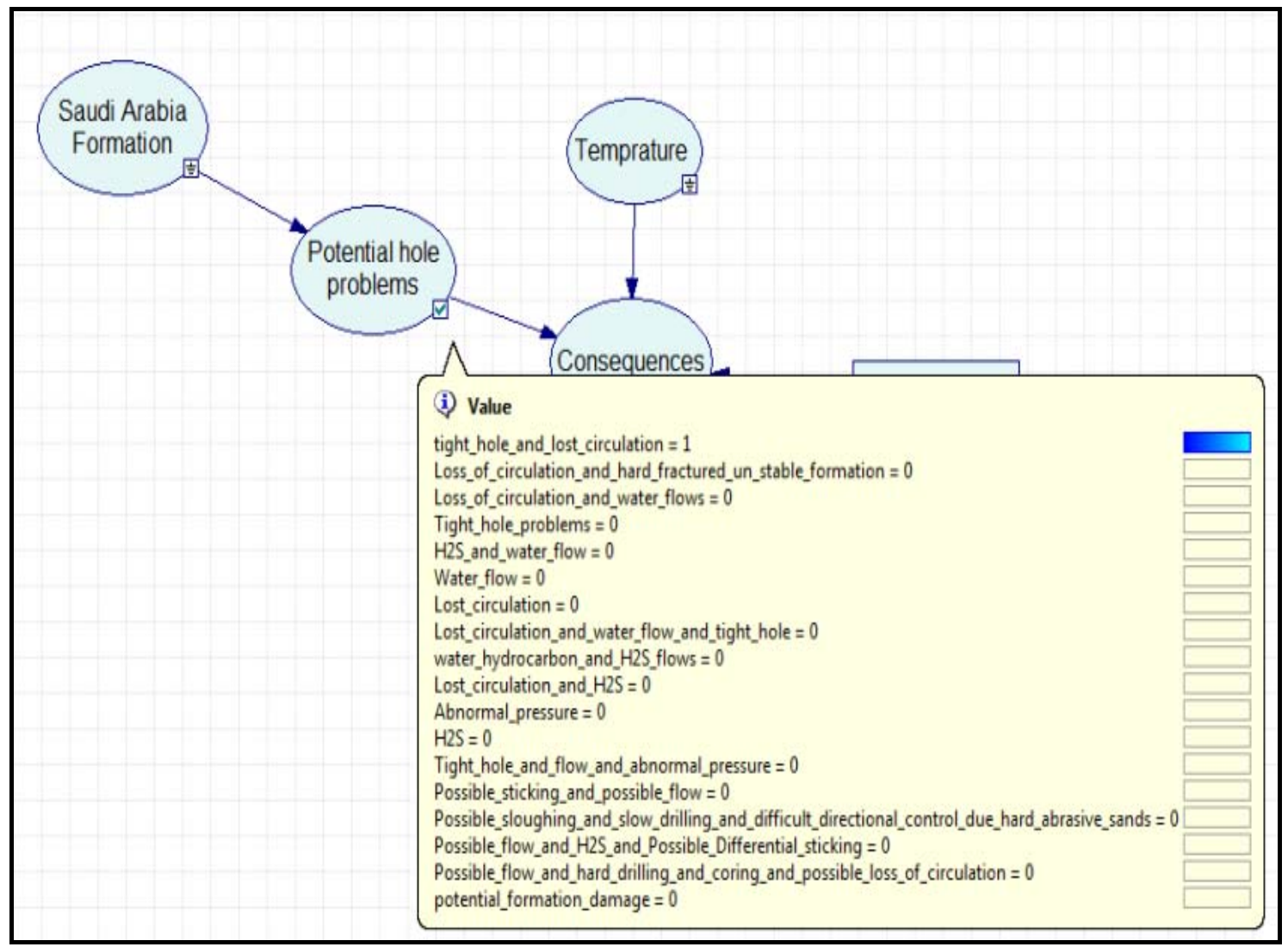

Fig.121: Showing resultant potential hole problems in Wasia and Shuaiba formations as selected before (example 5)

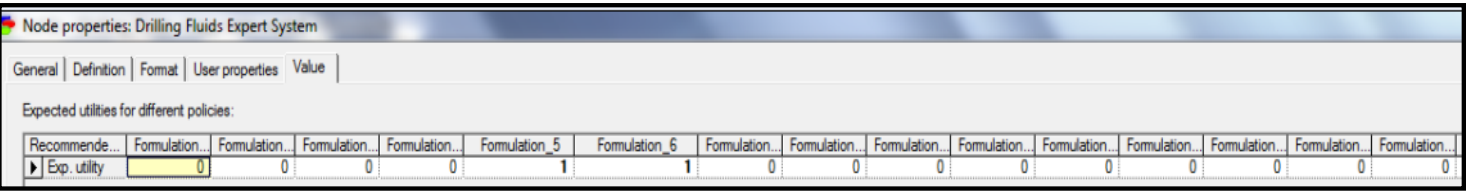

Fig.122: Showing some recommended drilling fluids for the above conditions (example 5) 


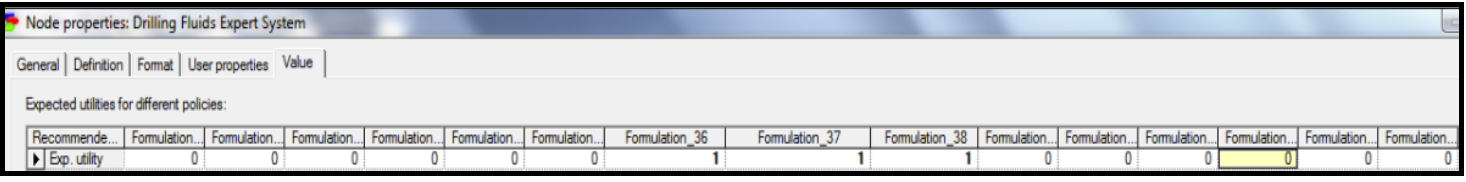

Fig.123: Showing more recommended drilling fluids for the above conditions (example 5)

Selection of a higher temperature range probability of 330 to $400{ }^{\circ} \mathrm{F}$ (Fig.124) and potential formation damage problem, Fig.125 leads to different drilling fluids formulations recommended by the drilling fluid model, Fig.126.

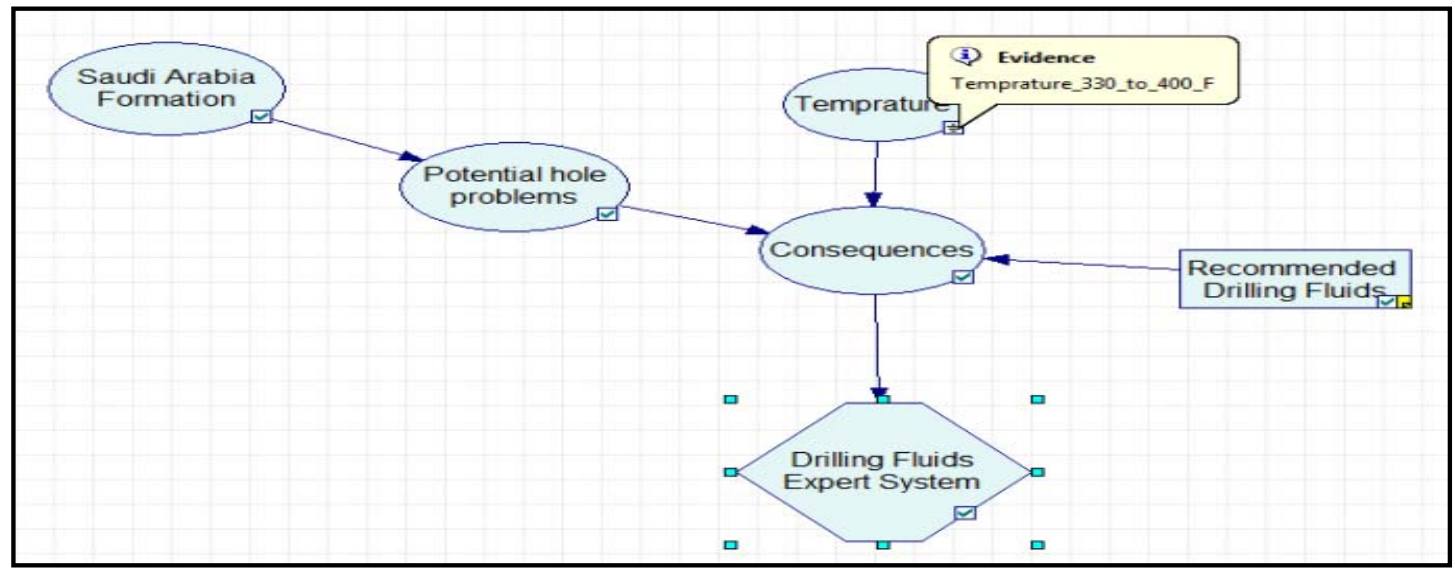

Fig.124: Selecting temperature range (example 6) 


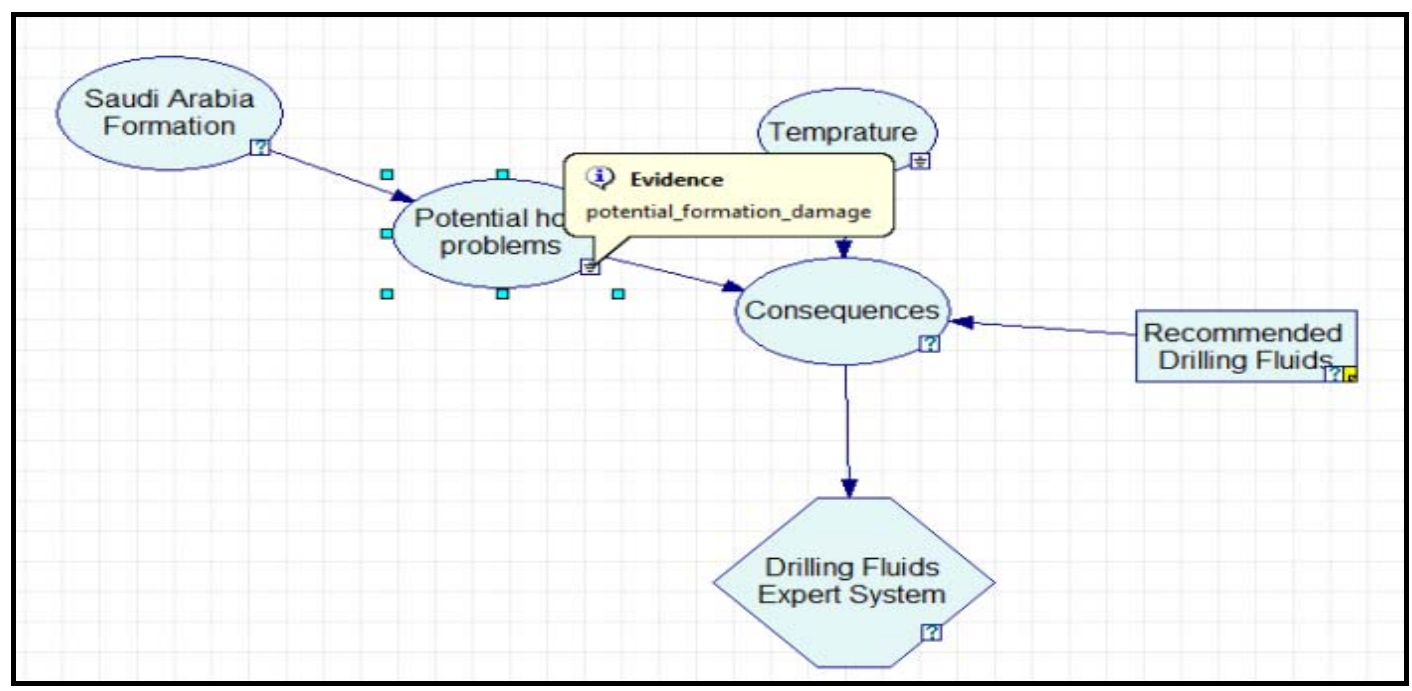

Fig.125: Selecting potential hole problem (example 6)

Node properties: Drilling Fluids Expert System

General | Defintion | Fomat | User properties Value |

Expected utilities for different policies:

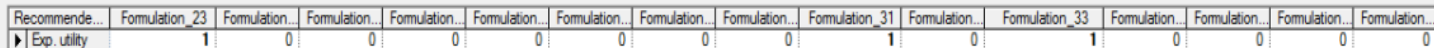

Fig.126: Showing the recommended drilling fluids for the above conditions (example 6)

The above example showed how using the model in selecting the optimum practices for drilling fluids selection. The states of probabilities in the above tables were obtained by experts' opinions. In case new practices or different experts' opinions are presented then all we need to do is simply change the states of probabilities. In case that the above model is missing other factors then we can also update the model and its corresponding states of probabilities. The flexibility of Bayesian Network in terms of 
updating the structure model and its beliefs makes this method the first systematic approach to build experts systems.

Selecting the acid soluble clay free $\mathrm{NaCl}$ brine drill-in fluid is an optimum selection to minimize formation damage problems. The polymers included in the design are suitable for the temperature range selected.

Using Barite or $\mathrm{CaCO}_{3}$ fine can be used to increase the mud density as hole conditions dictate to control water flow potential problem mentioned in example 2 . For the lost circulation problem, treatment with lost circulation material should help to cure the lost circulation zone.

Inhibitive $\mathrm{KCl}$ drilling fluid looks like a good choice since tight hole is a potential problem. Using Barite or $\mathrm{CaCO}_{3}$ can be used to increase the mud density to minimize the flow and abnormal pressure problem.

Wasia and Shuaiba formations are considered to be a tight hole and a lost circulation zone. Spud mud made up of pre-hydrated bentonite in freshwater and flocculated with lime should be sufficient to drill this interval. Curing lost circulation should be considered but in case it does not work. Drilling with water should not be practiced here which is in agreement with the model recommendation.

For temperature higher than $330^{\circ} \mathrm{F}$ and in a zone with high potential for formation damage, potassium formate can be considered as a good drilling fluid.

Downs (1992) listed some advantages of having the formate brines that make it ideal drill-in fluid. Some of these advantages are:

- Maintenance of rheological properties at high temperatures 
- Minimal circulating pressure losses

- Elimination of solids sag at high temperatures

- Low potential for differential sticking

- Very thin filter cake

- Low ECD ( equivalent circulating density) in long and narrow hole sections Brinkhorst (1994) mentioned that the potassium formate was used successfully to drill Norwegian field and no damaging effects were observed.

\subsection{Well control model}

The user can select the kick indication observed by assigning a probability of one to any of the available probabilities. For example the user selects increase in flow and pit gain, Fig.127. Once the kick has been verified (Fig.128) the user needs to select his kick details. The kick is from a horizontal or deviated well, Fig.129. Then the optimum circulation method is the driller method as shown in Fig. 130. 


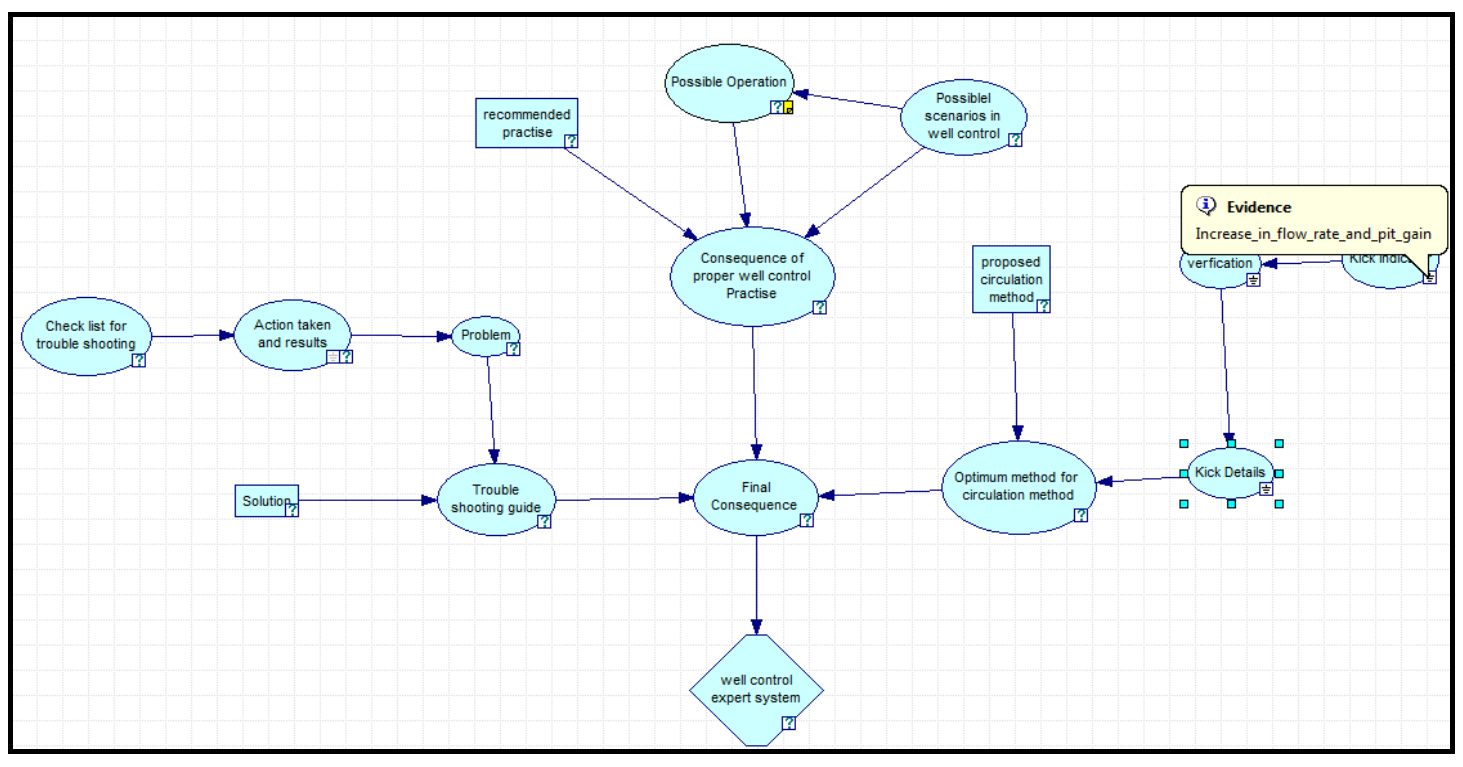

Fig.127: Kick indicator example

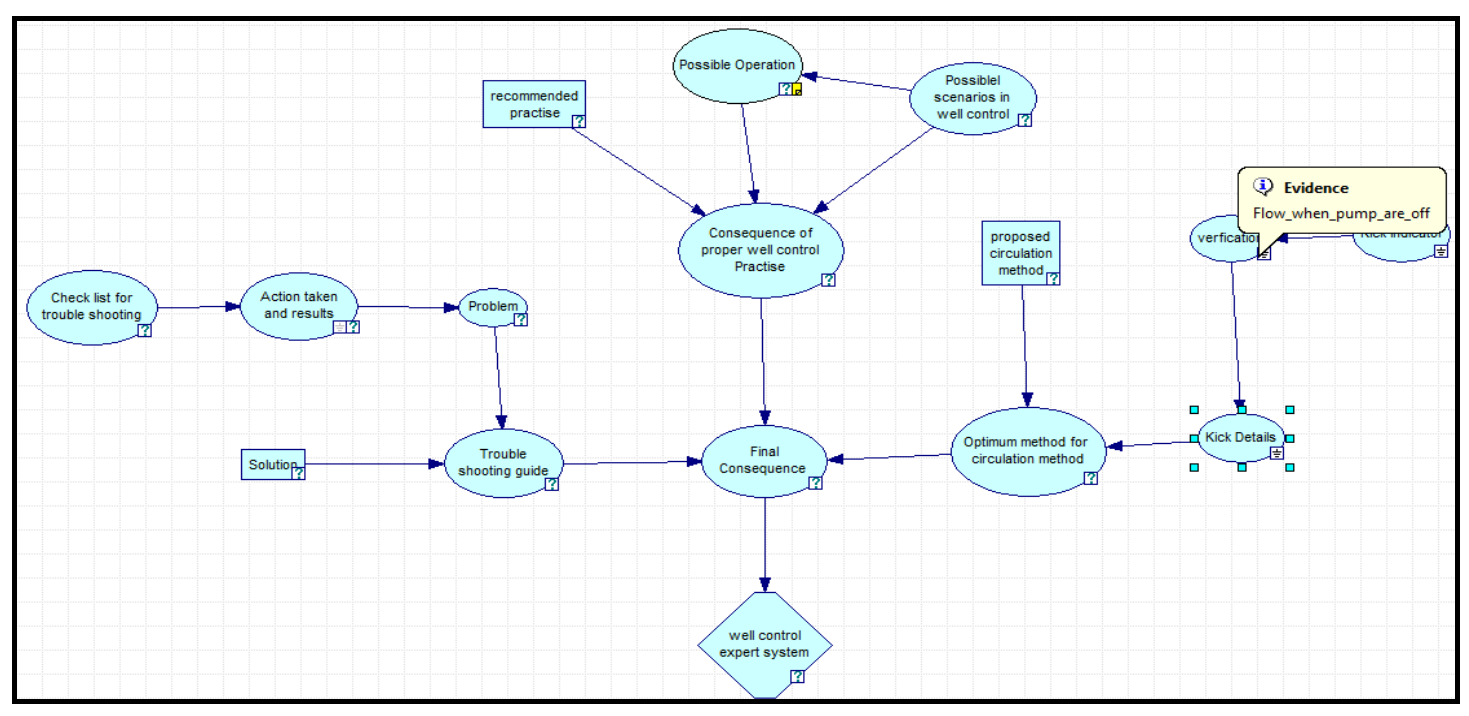

Fig.128: Verification of the kick 


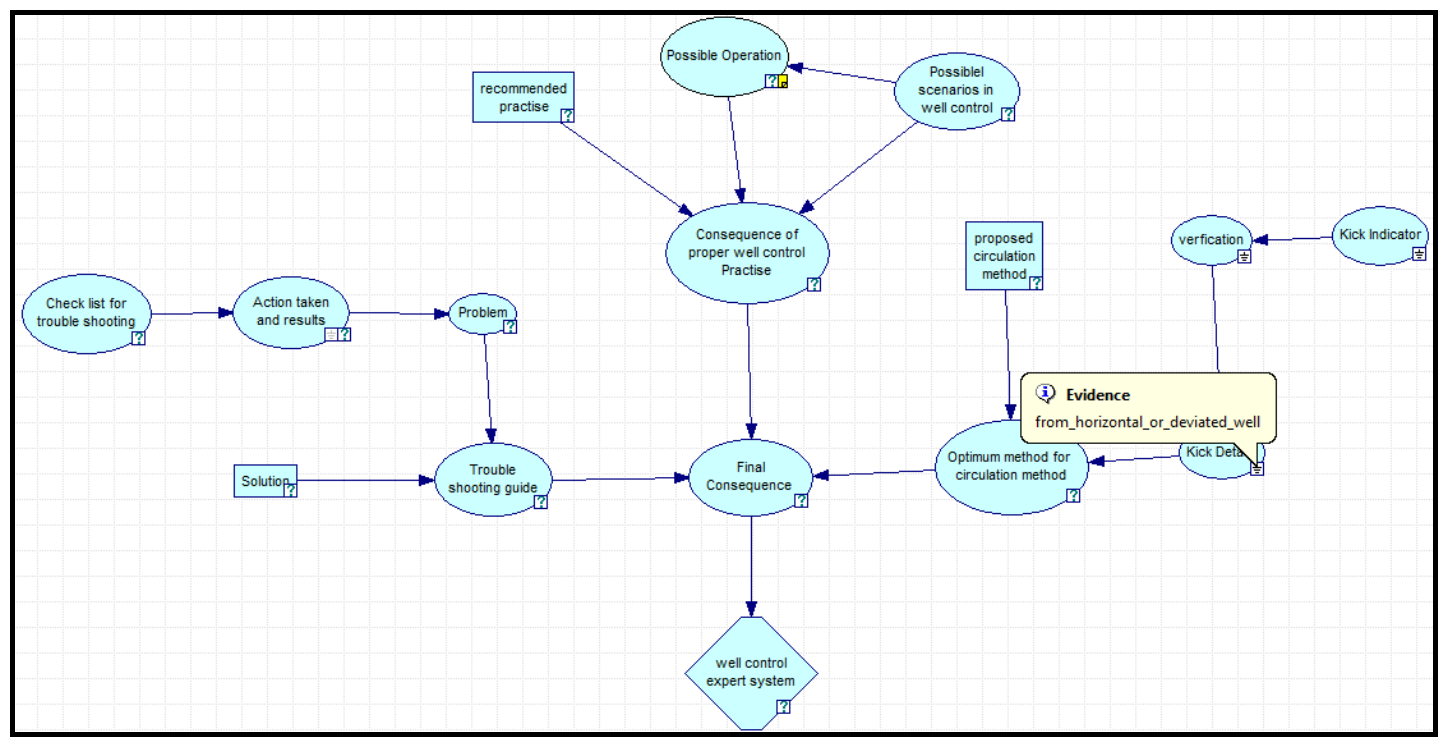

Fig.129: The kick is from a horizontal or deviated well

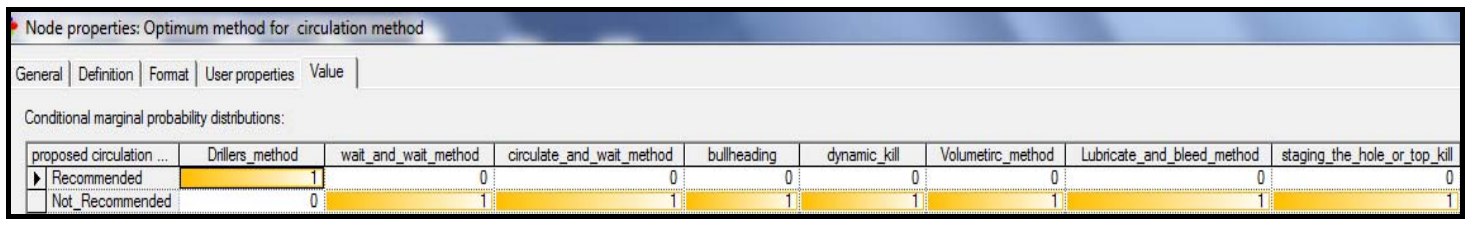

Fig.130: The recommended circulation method of this example is driller method

The user wants to use driller method to probability control the well, Fig.131. 


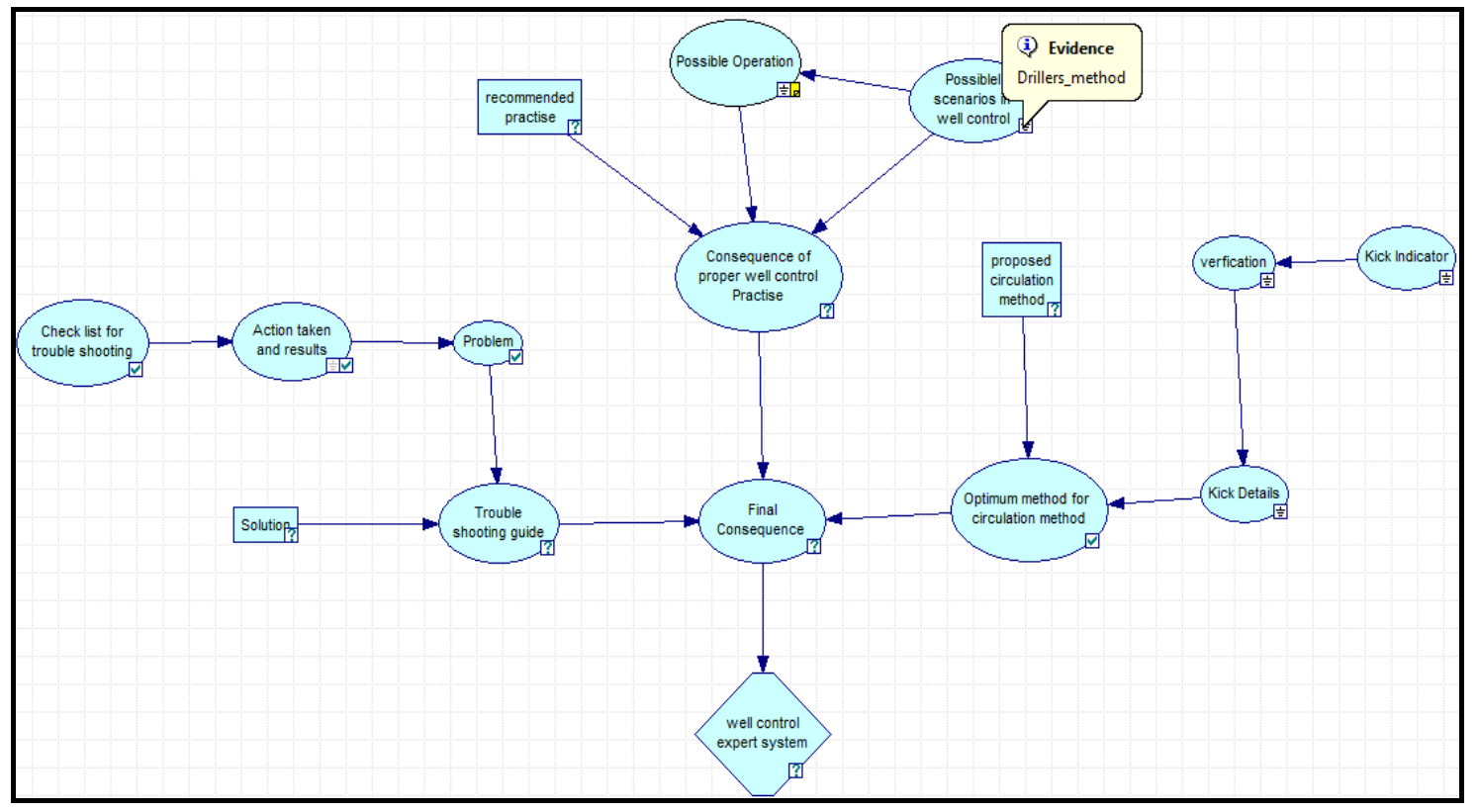

Fig.131: The user is controlling the well using driller method

The user enters his probability conditions from the possible operation node (Fig.132) and the recommended practice of increasing pump rate is calculated by the model, Fig. 133. 


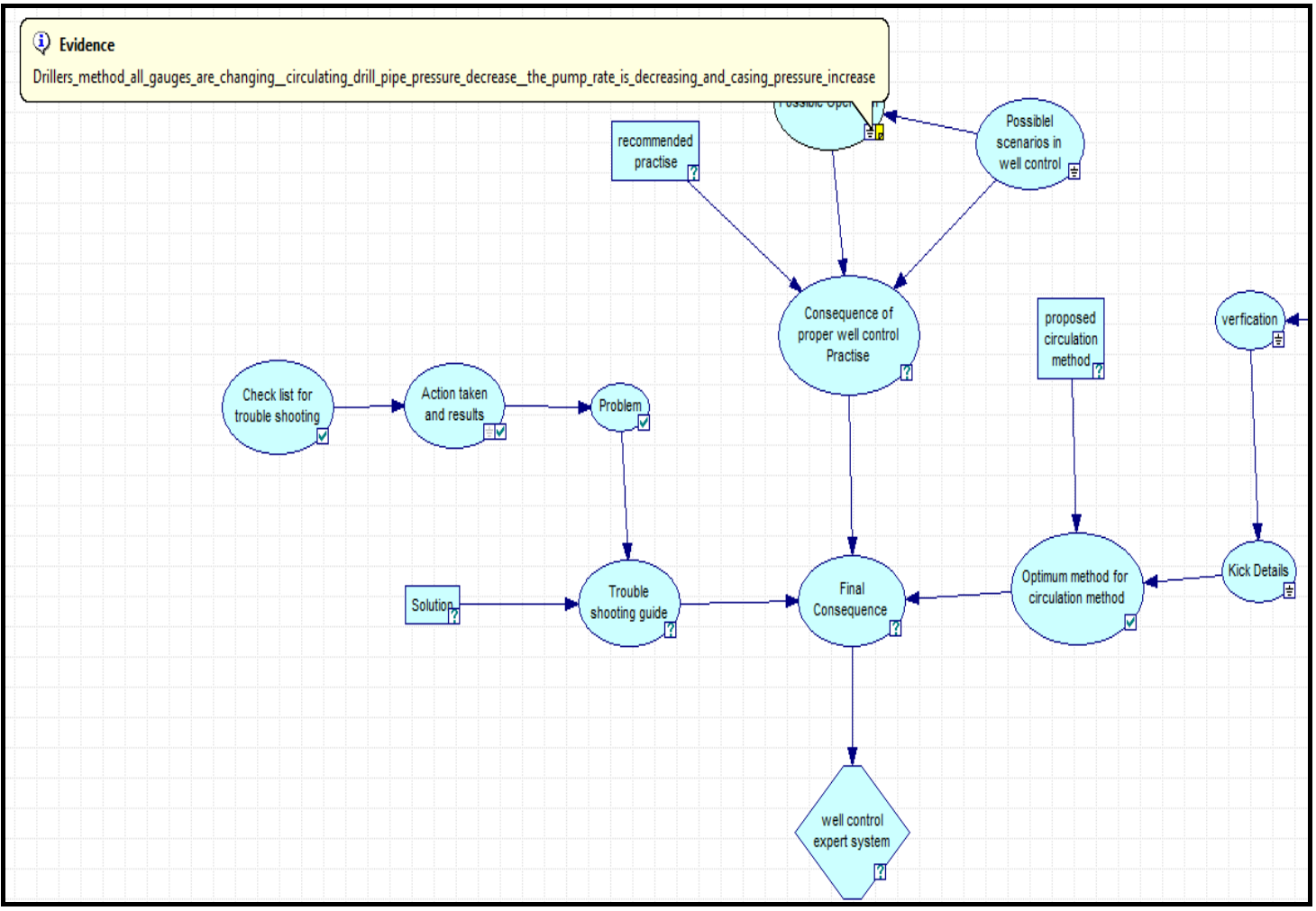

Fig.132: The user is entering his pipe, casing and pump operational conditions

\begin{tabular}{|c|c|c|c|c|c|c|}
\hline \multicolumn{7}{|c|}{ Node properties: Consequence of proper well control Practise } \\
\hline \multicolumn{7}{|c|}{$\begin{array}{l}\text { Eneral | Definition | Format | User properties Value } \\
\text { Eonditional marginal probability distributions: }\end{array}$} \\
\hline \multirow{2}{*}{\begin{tabular}{l|l} 
recommended practise \\
\end{tabular}} & Increase_choke_size & Decrease_choke_size & Increase_pump_rate & decrease_pump_rate & every_thing_is_OK_continue & Stop_the_pump_and_close_the_well_in \\
\hline & 0 & 0 & 1 & 0 & 0 & 0 \\
\hline Not_recommended & 1 & 1 & 0 & 1 & 1 & 1 \\
\hline
\end{tabular}

Fig.133: The optimum practice of proper well control is shown 
The user selects that drill pipe pressure is up and casing pressure is up about the same amount as the drill pipe pressure, Fig.134. Possible probabilities due to the selection from the check list for trouble shooting node are shown in Fig.135.

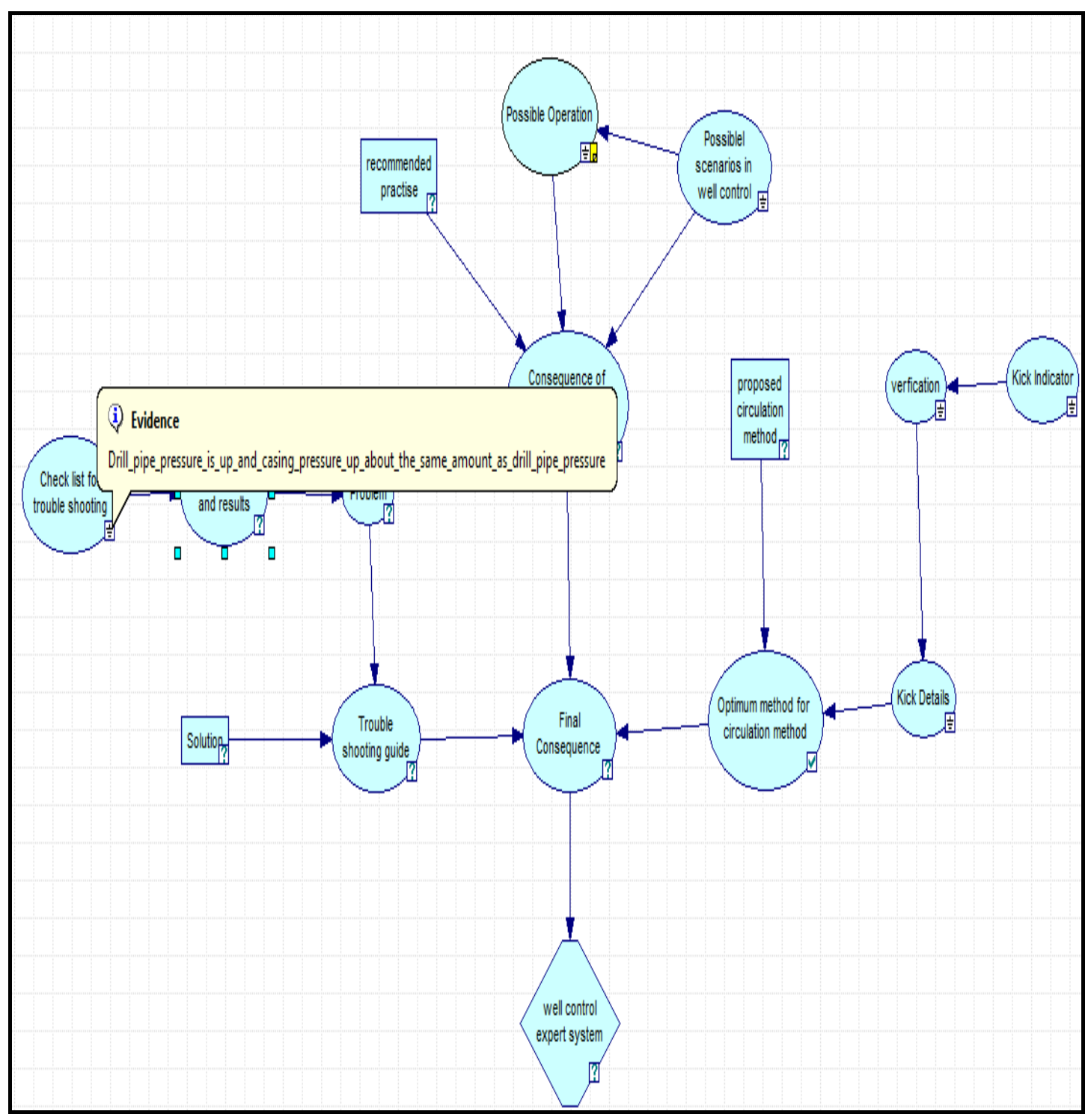

Fig.134: The user shows his problem by selecting drill pipe and casing pressure response 


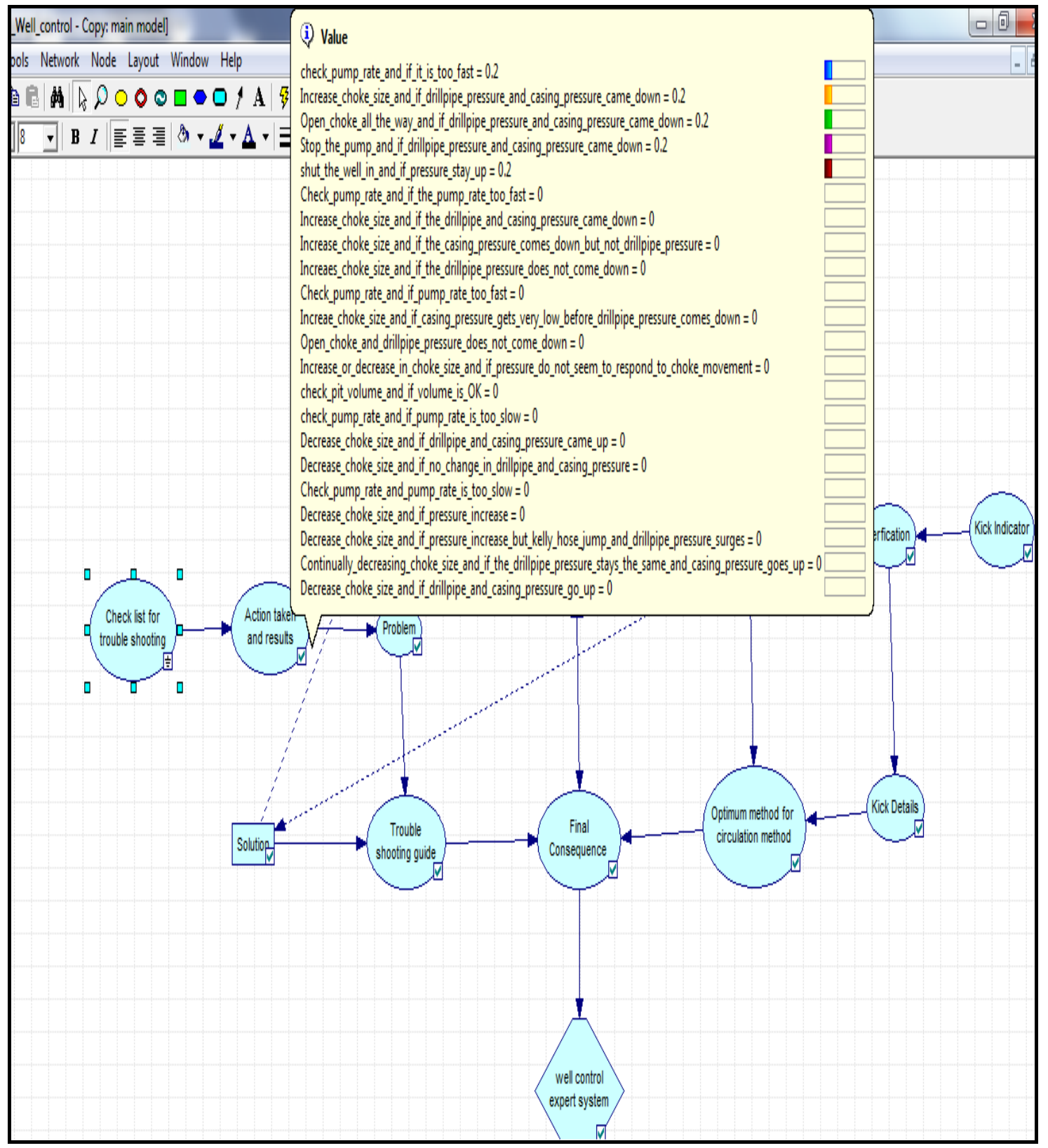

Fig.135: Possible probabilities due to the selection from the check list for trouble shooting node are shown

Selection of one of the five probabilities shown in Fig.135 is shown in Fig.136 to identify the problem while controlling the well (the choke manifold has started to plug 
up), Fig.137. The optimum solution is calculated by the model to switch to alternate choke line and clear the manifold, Fig.138. Again, expert opinions are used here in the trouble shooting guide consequence which can be updated easily in case of different opinions or field cases.

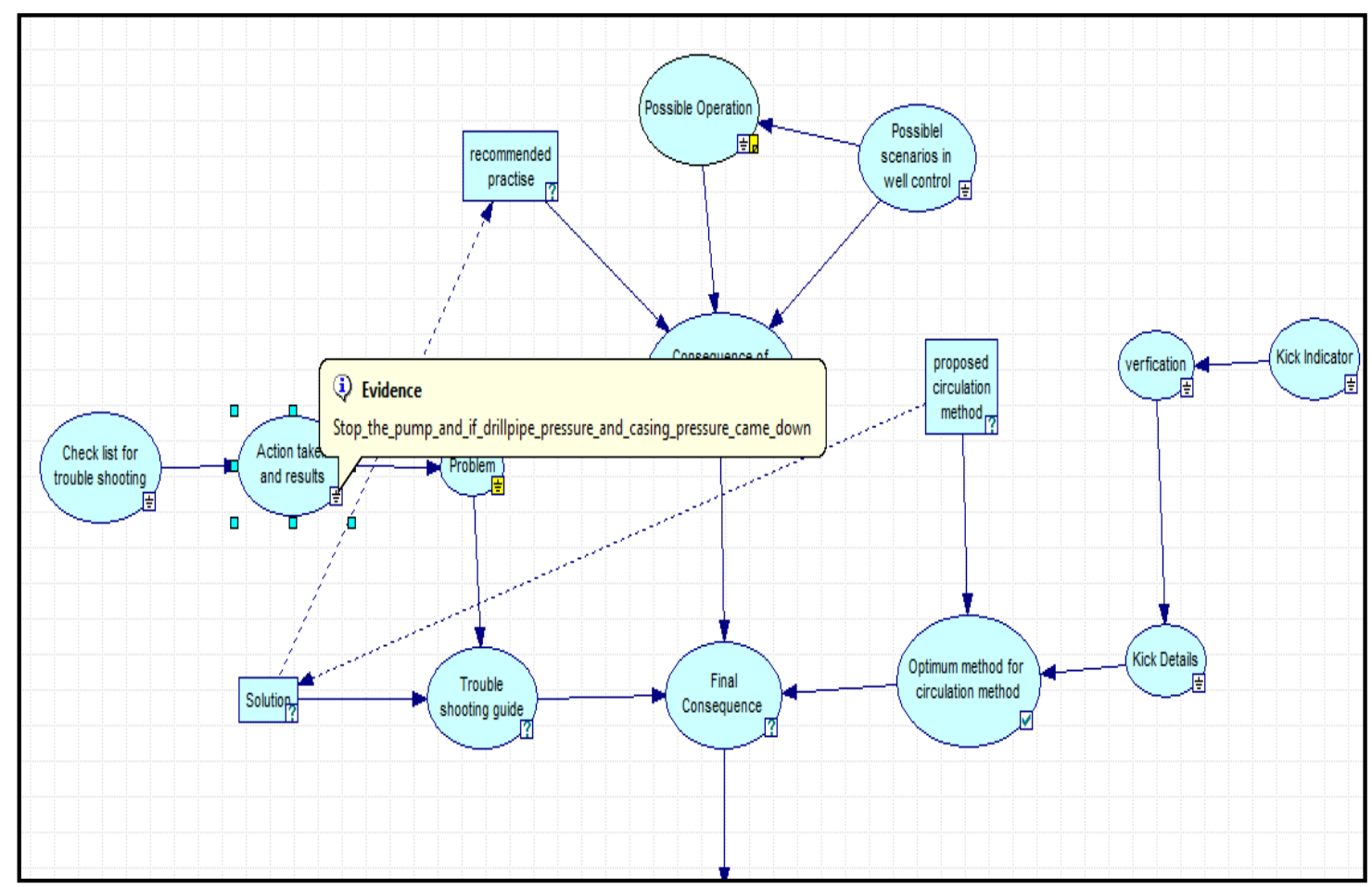

Fig.136: The user then selects an action and its corresponding result in an attempt to identify the problem 


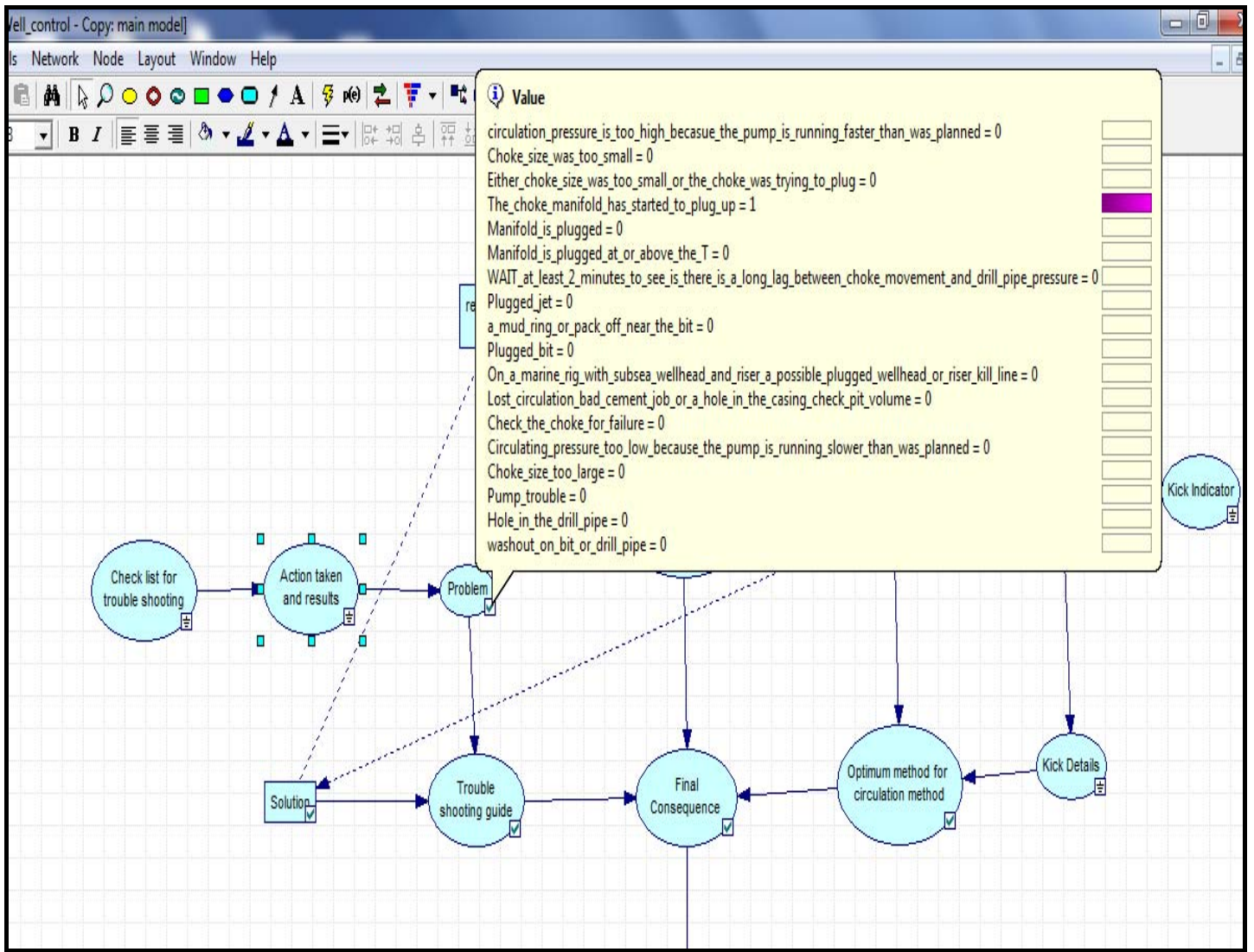

Fig.137: The problem is identified

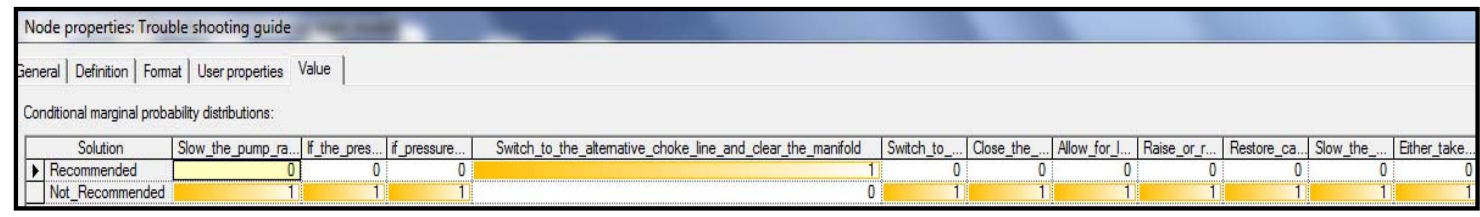

Fig.138: A recommendation is given to solve this problem 
If no pre-recorded data is available probability is selected (Fig.139) and a possible operation is selected (Fig.140) then the optimum well control practice is calculated as shown in Fig. 141.

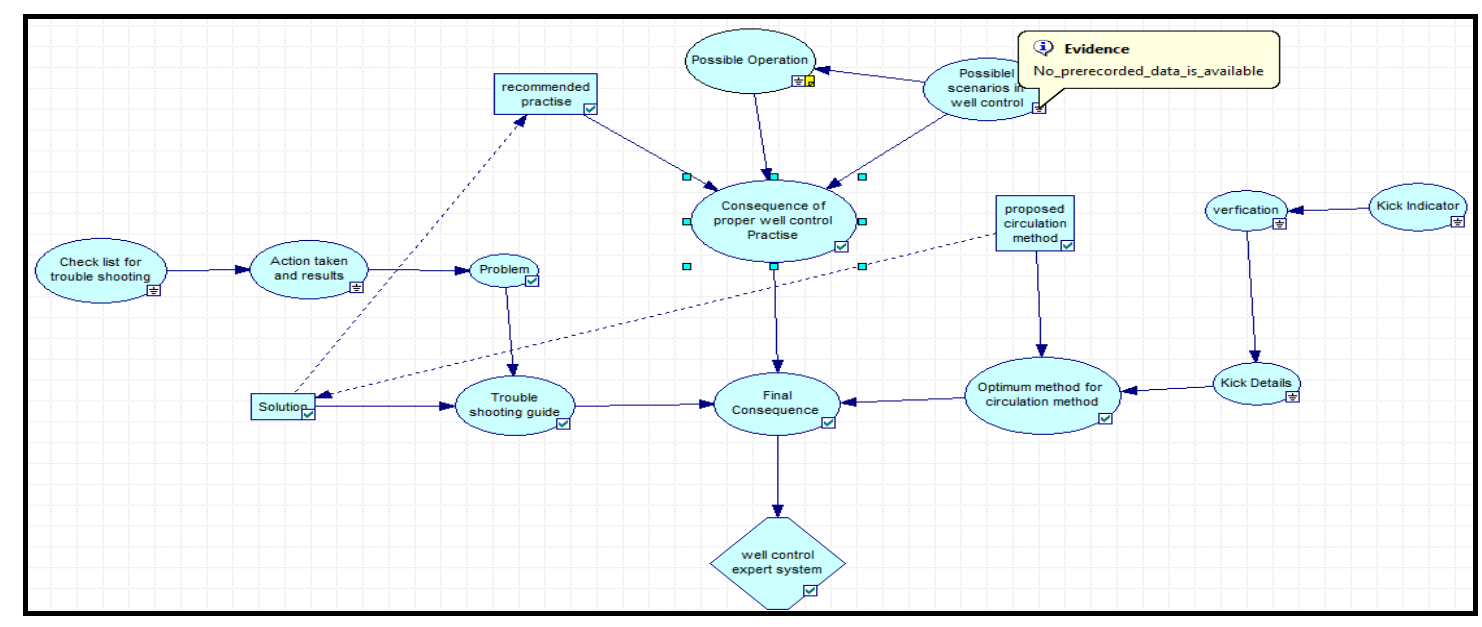

Fig.139: The user is controlling the well without any prerecorded data

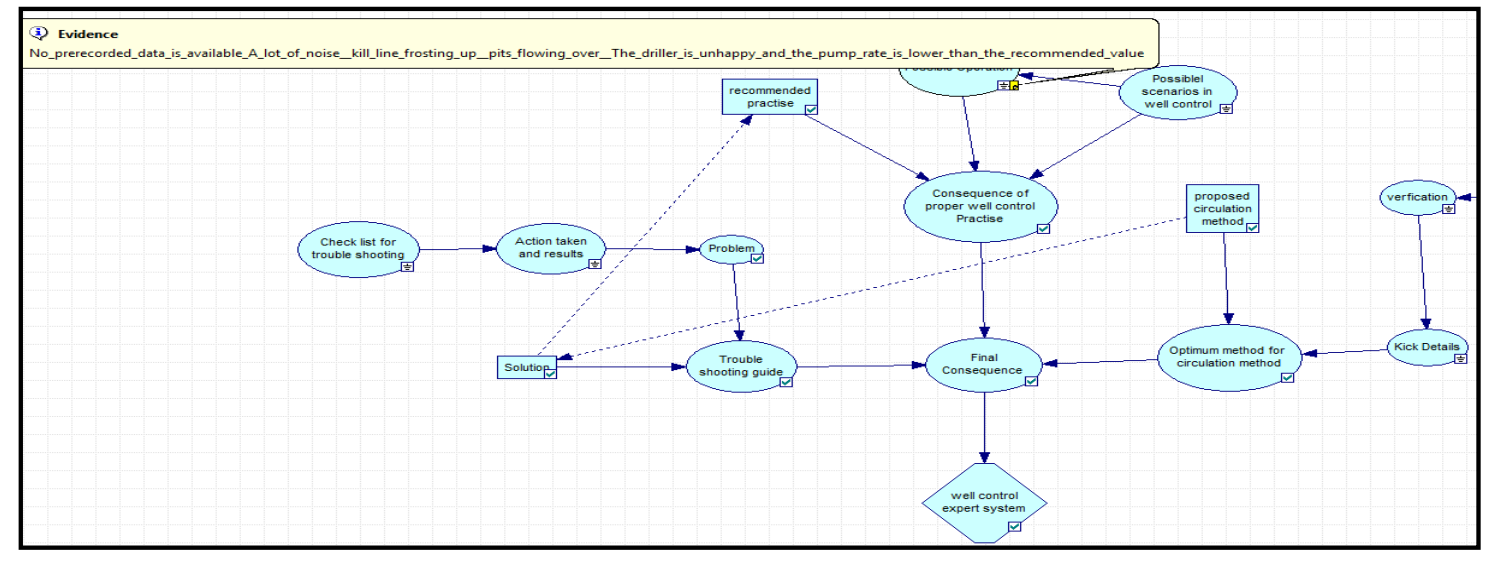

Fig.140: The user is entering his observations 


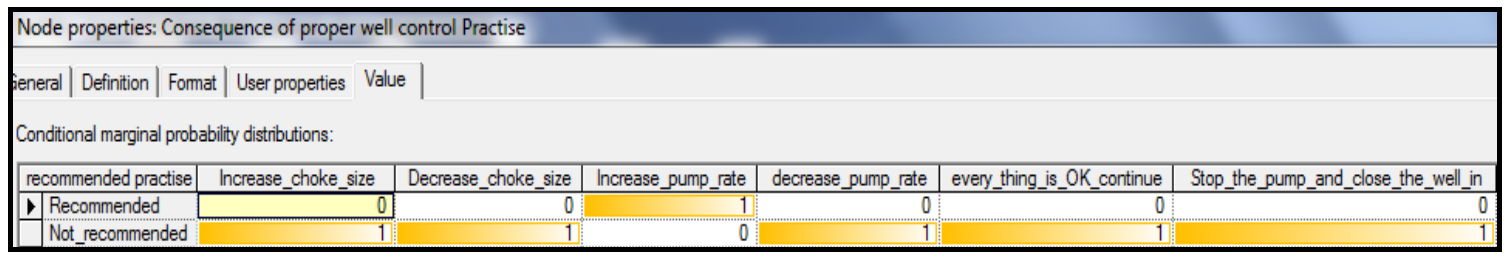

Fig.141: The recommended proper well control practice is shown

Additional examples of proper well control part are shown below. Figs 142-144 is related to pumps troubles during a kick. Figs. 145-147 are related to having a kick in deep water.

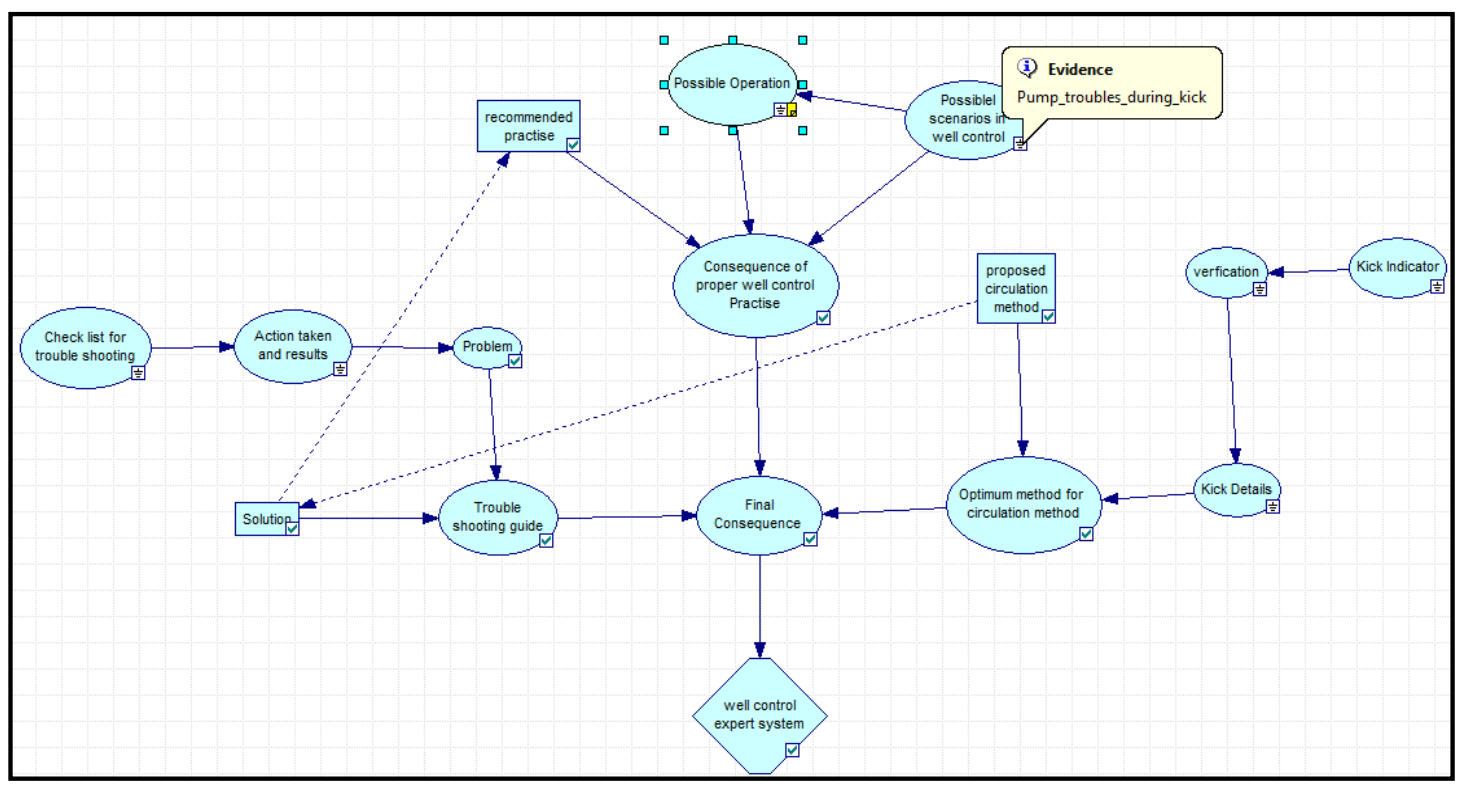

Fig.142: The user is controlling the well and he has pump troubles during a kick 


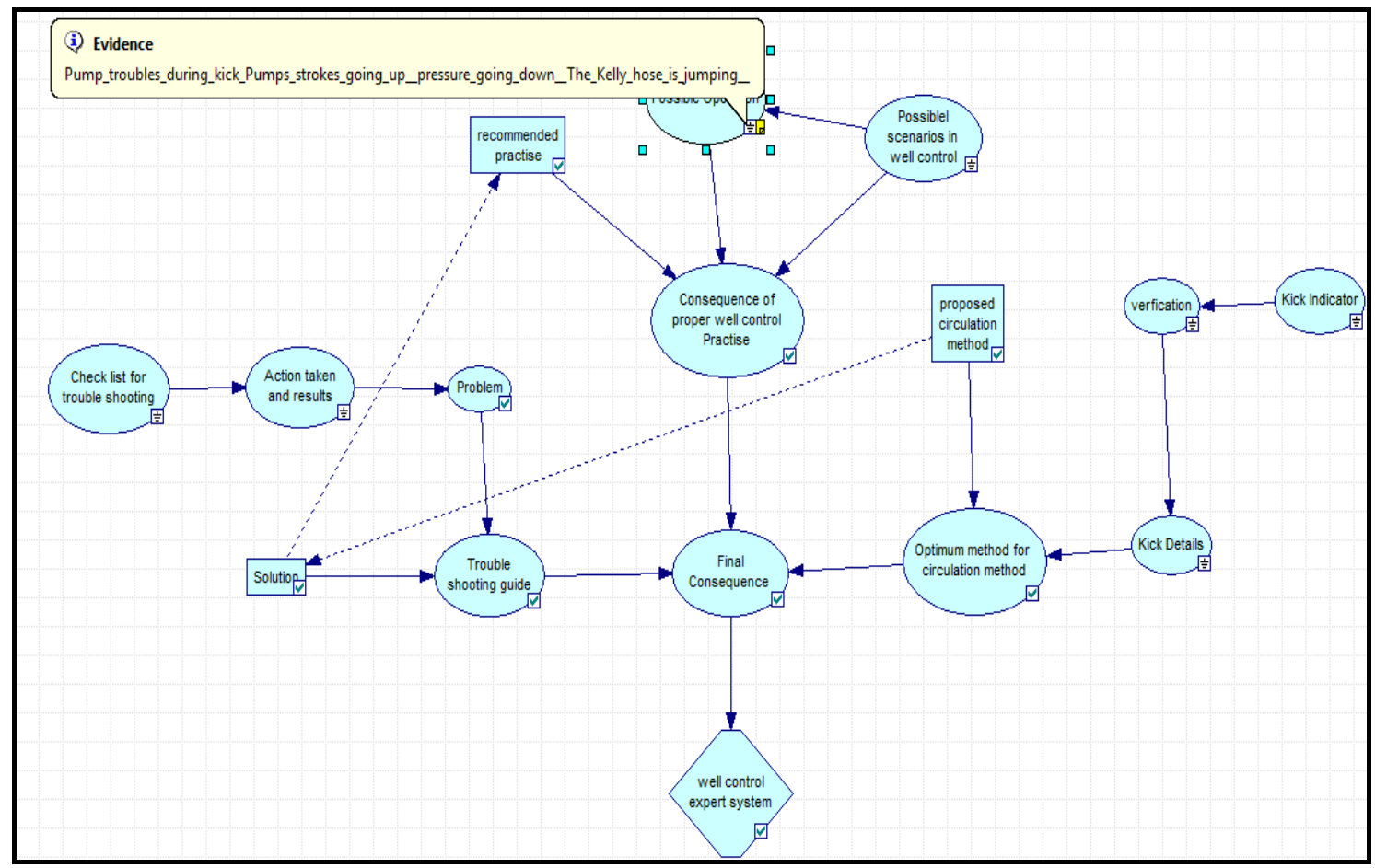

Fig.143: The user is entering his observations during the pump trouble

\begin{tabular}{|c|c|c|c|c|c|c|c|}
\hline \multicolumn{8}{|c|}{ Node properties: Consequence of proper well control Practise } \\
\hline \multicolumn{8}{|c|}{ eneral| Definition | Format | User properties Value } \\
\hline \multicolumn{8}{|c|}{ Conditional marginal probability distributions: } \\
\hline \multicolumn{2}{|c|}{ recommended practise } & Increase_choke_size & Decrease_choke_size & Increase_pump_rate & decrease_pump_rate & every_thing_is_OK_continue & Stop_the_pump_and_close_the_well_in \\
\hline \multirow{2}{*}{ 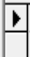 } & Recommended & 0 & 0 & 0 & 0 & 0 & 1 \\
\hline & Not_recommended & 1 & 1 & 1 & 1 & 1 & 0 \\
\hline
\end{tabular}

Fig.144: The recommended proper well control practice is shown for the selected conditions for the pump trouble during a kick 


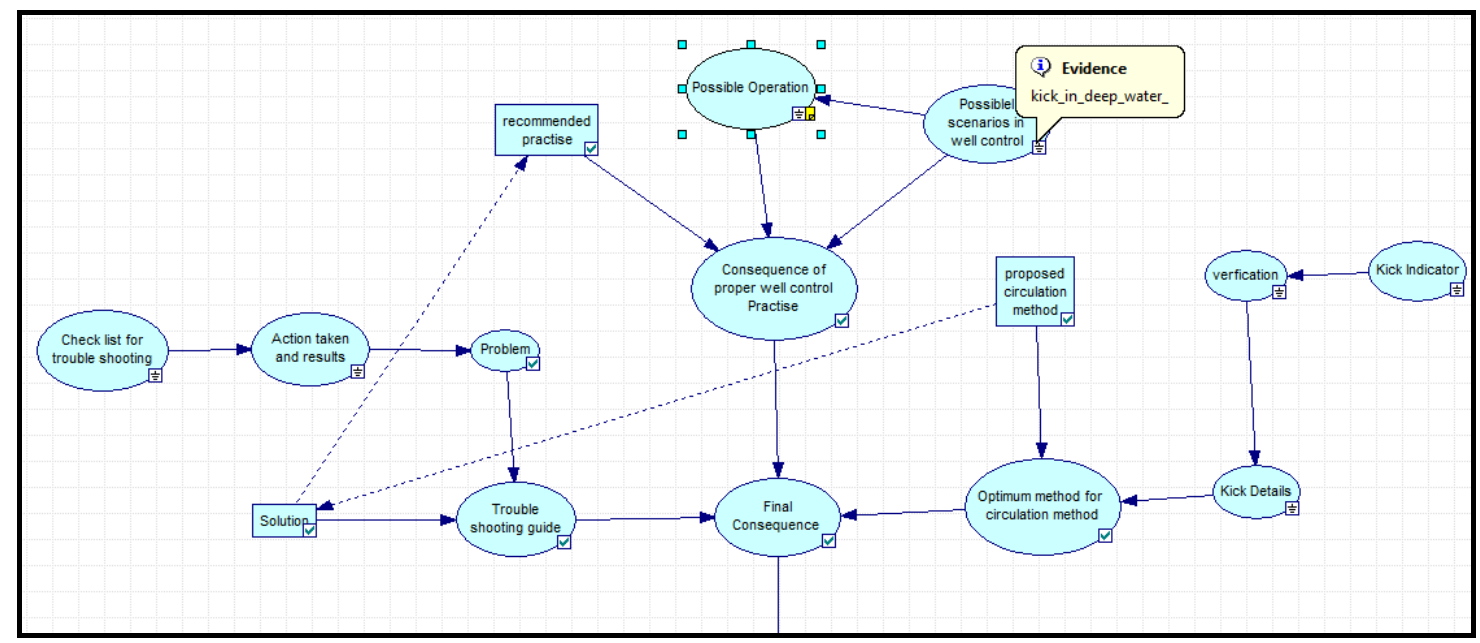

Fig.145: The user is facing a kick in deep water

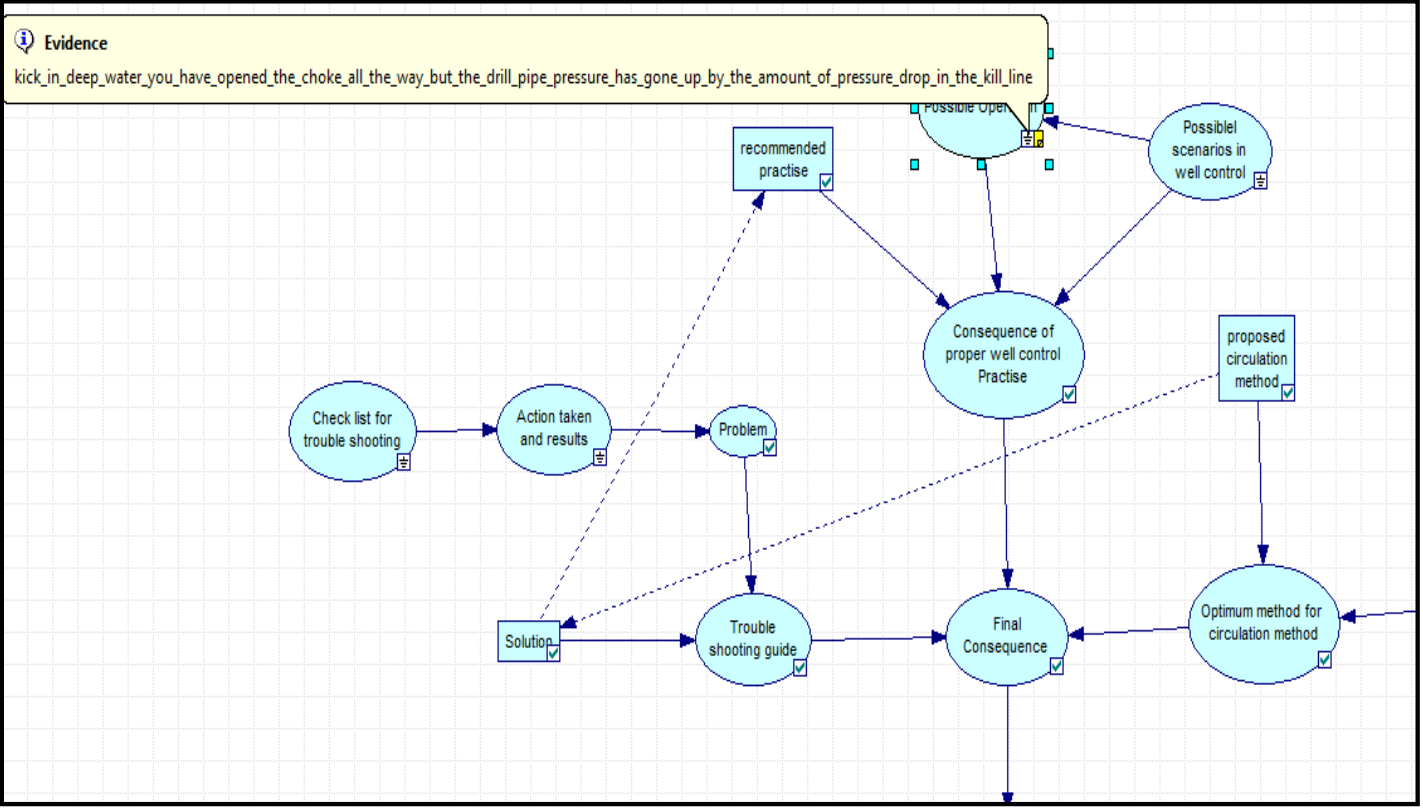

Fig.146: The user is entering his observations for the deep water kick 


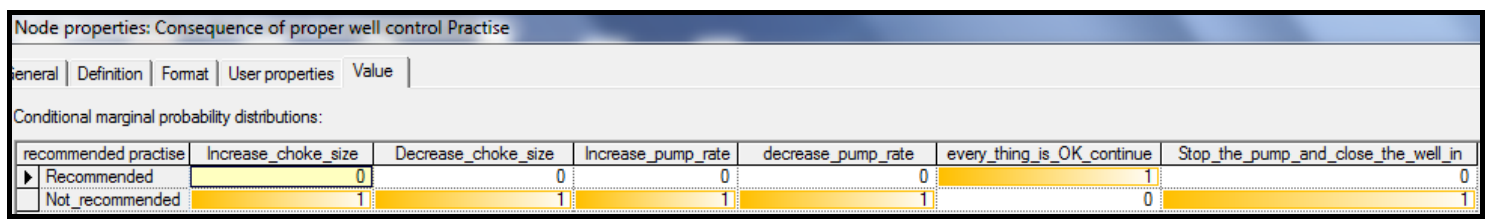

Fig.147: The recommendation for the kick in deep water

The above example showed how using the model in selecting the optimum practices for well control. The states of probabilities in the above tables were obtained by experts' opinions. In case new practices or different experts' opinions are presented then all we need to do is simply change the states of probabilities. In case that the above model is missing other factors then we can also update the model and its corresponding states of probabilities. The flexibility of Bayesian Network in terms of updating the structure model and its beliefs makes this method the first systematic approach to build experts systems.

In Figs.129 and 130 the Driller's method is well suited for horizontal well control, as immediate circulation is important. Using the Driller's method can help in avoiding complicated pressure schedule calculations associated with the Wait and Weight method. Driller's method is simple and is considered to be a good circulation method in horizontal well control situations, GRØTTHEIM (2005).

In Figs. 132 and 133, increasing pump rate is recommended to avoid another bubble from entering the bore hole on bottom. In Figs.143 and 144, stopping the pump and closing in the well is the recommended practice because the well cannot be killed if 
the pump rate is not constant. The increase in pump rate and decrease in pipe pressure might indicate a hole in the drill pipe or a bad pump. The instability movement of the Kelly hose might indicate that the problem is at the pump.

The third part in the above model is designed to assist the user to find the optimum solution for a list of potential problems that can be faced during well control operations. In general there are rules that can serve as good guides, Rehm et al. (1975):

- Unstable movement of Kelly hose or surging pump pressure gauge is a sign of pump problems.

- If the pipe pressure only goes up then the bit or nozzle is plugged.

- If the drill pipe and casing pressure increase suddenly then the choke or manifold is plugged.

- If the drill pipe pressure is decreased then there might be a hole in the pipe.

- If the drill pipe pressure and casing pressure does not respond to the choke, you might have a lost circulation problem.

\subsection{Cementing model}

This section shows the use of this model in one scenario where the user select his conditions, Figs.148-151. The conditions are:

- Well Type: Oil well

- Bottom Hole Static Temperature: $300-400^{\circ} \mathrm{F}$

- Objective: Production Liner

- Drilling Fluid Type: Water based mud 


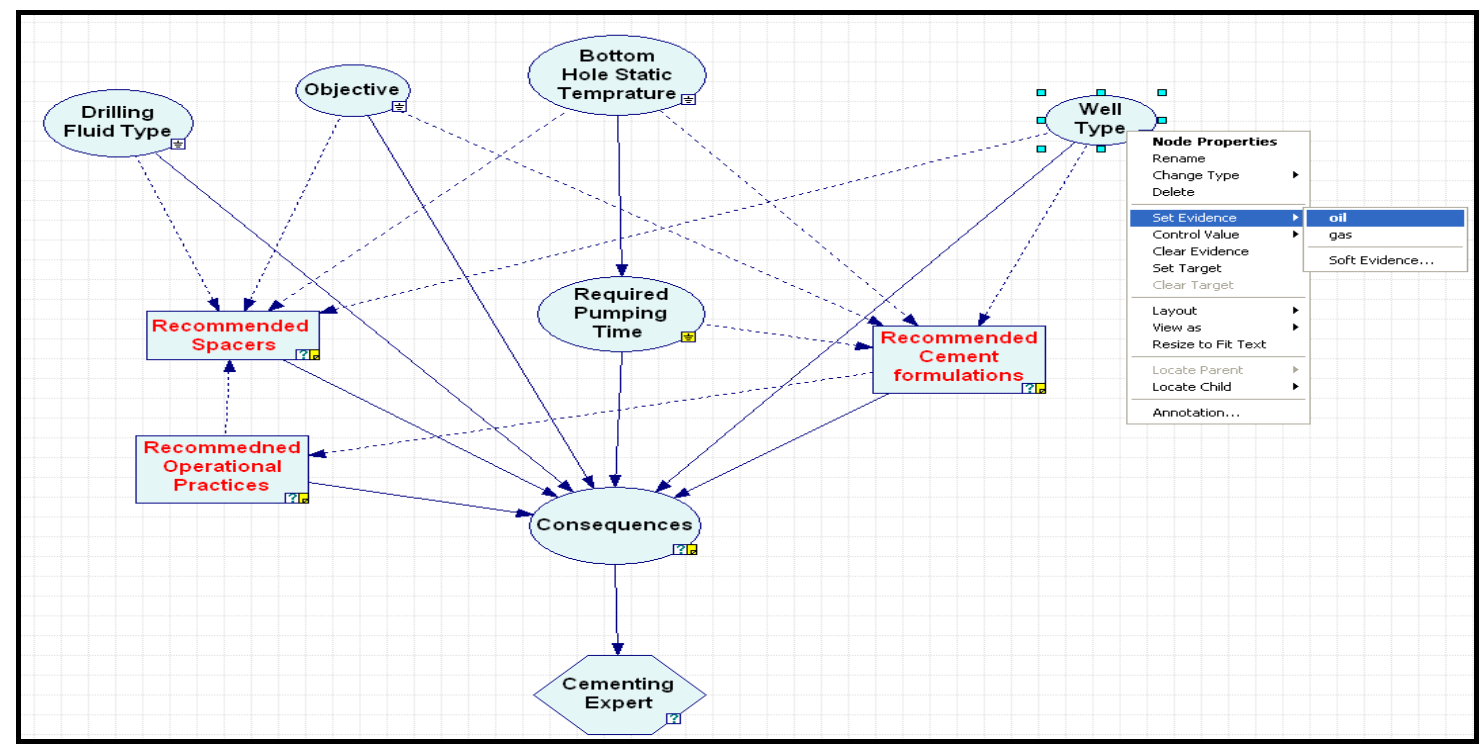

Fig.148: Selection of well type

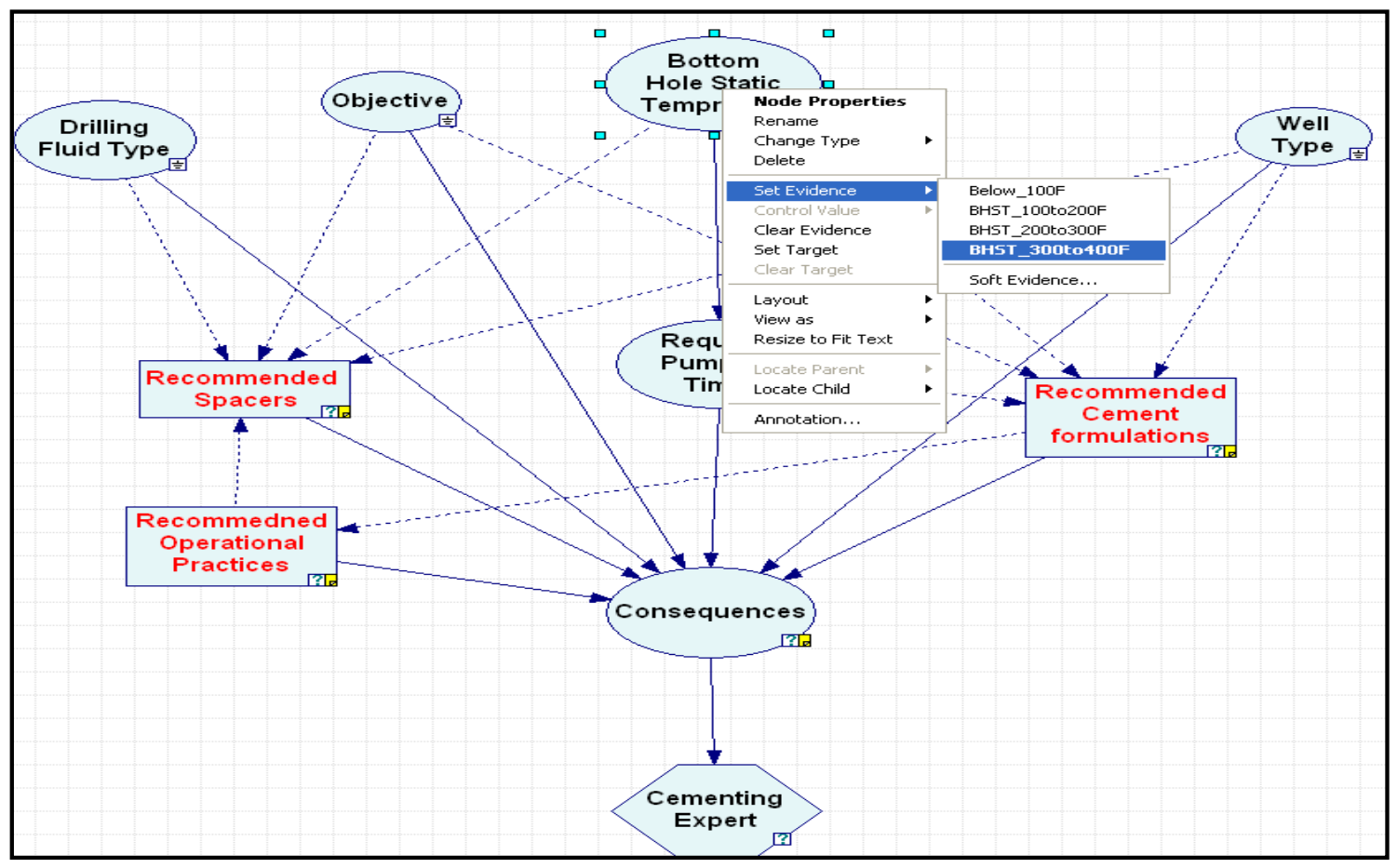

Fig.149: Selection of bottom hole static temperature 


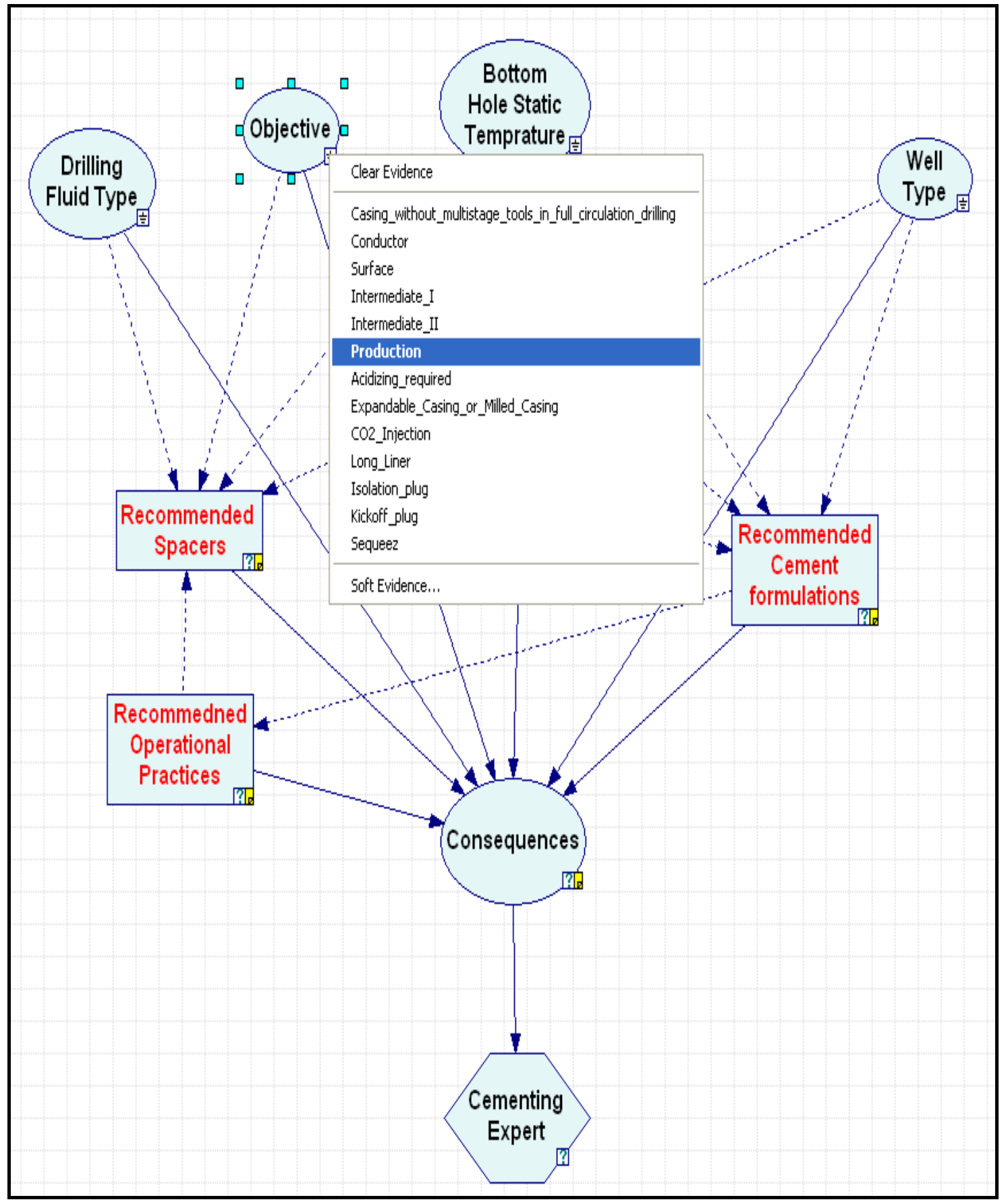

Fig.150: Selection of well objective 


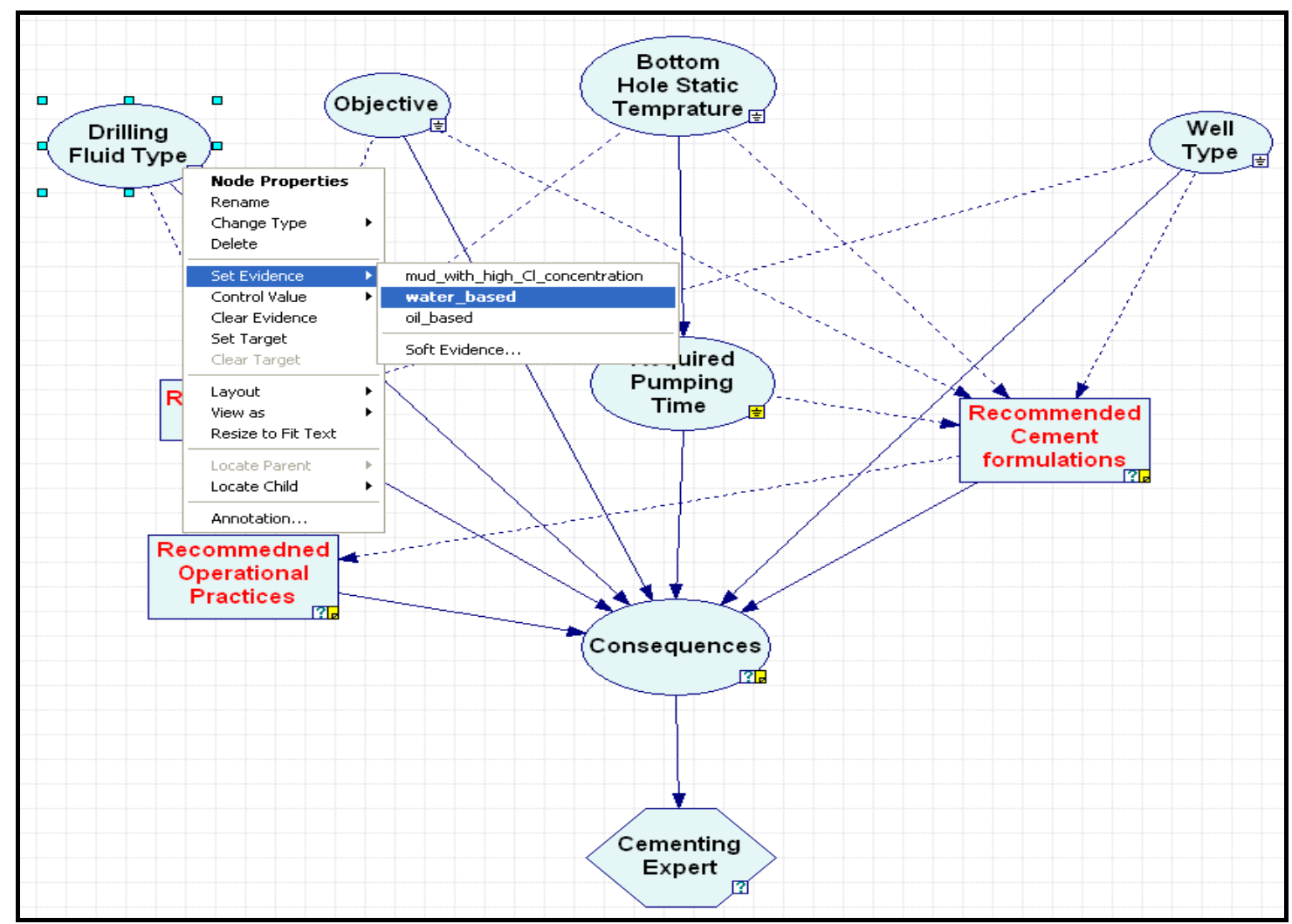

Fig.151: Selection of drilling fluid

The consequences node combines the four uncertainty nodes (well type, required pumping time, objective and drilling fluid) and the three decision nodes (recommended cement formulations, recommended spacers and recommended operational practices). Cementing expert opinion was used to assign and define the node conditional probability distribution. The model then calculate based on the given above conditions that the optimum practice to cement the liner, Figs.152-153. 


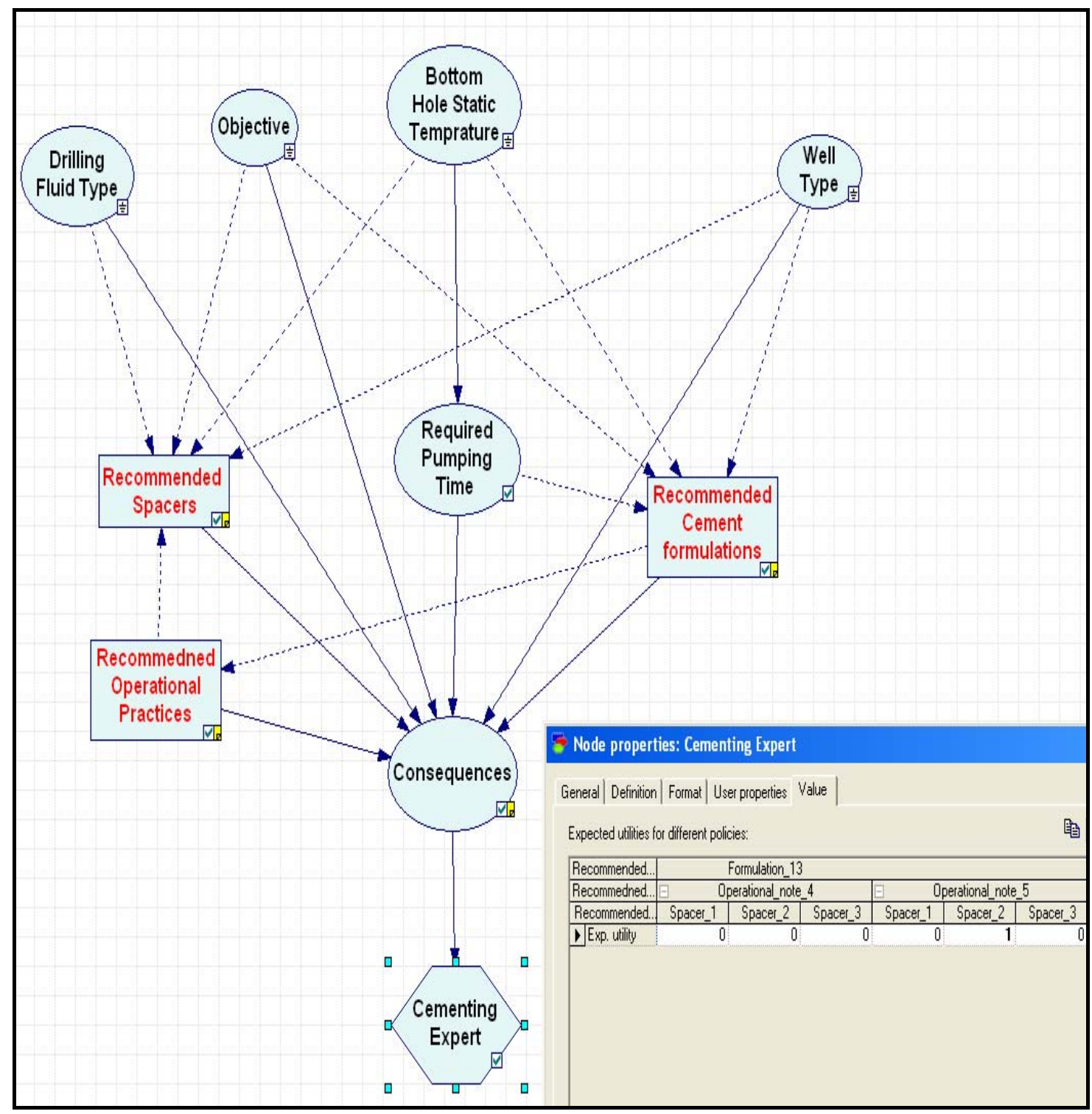

Fig.152: The cementing expert system recommends formulation 13, operational note 5 and spacer 2 to be used in this application 


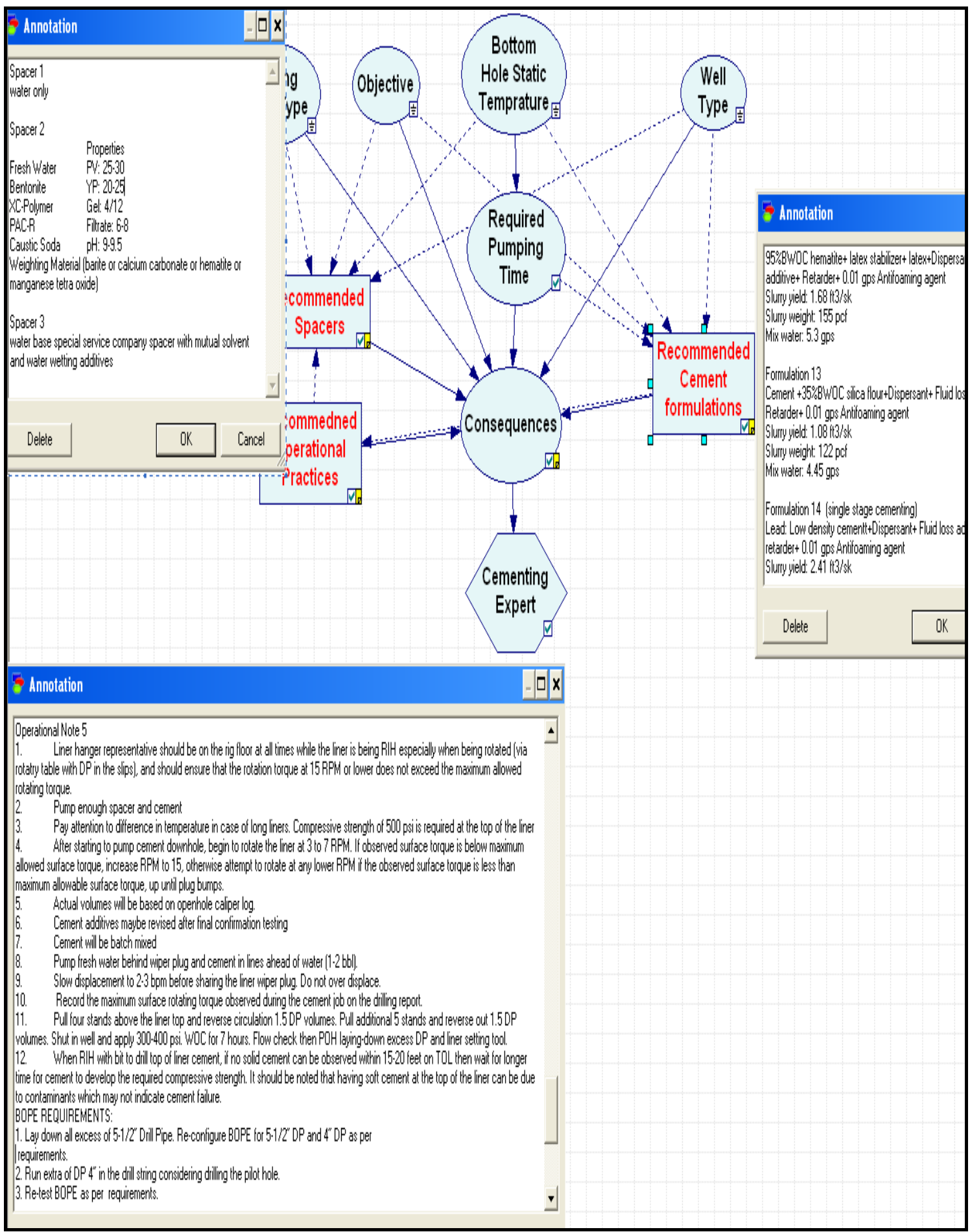

Fig.153: The model showing more details for this application (Example 1) 
Another example is shown below:

- $\quad$ Well Type: Gas well

- $\quad$ Bottom Hole Static Temperature: $300-400^{\circ} \mathrm{F}$

- $\quad$ Objective: Long Liner

- $\quad$ Drilling Fluid Type: Oil based mud

The model then calculates and shows in Fig.154 the optimum practice to cement the long liner. 


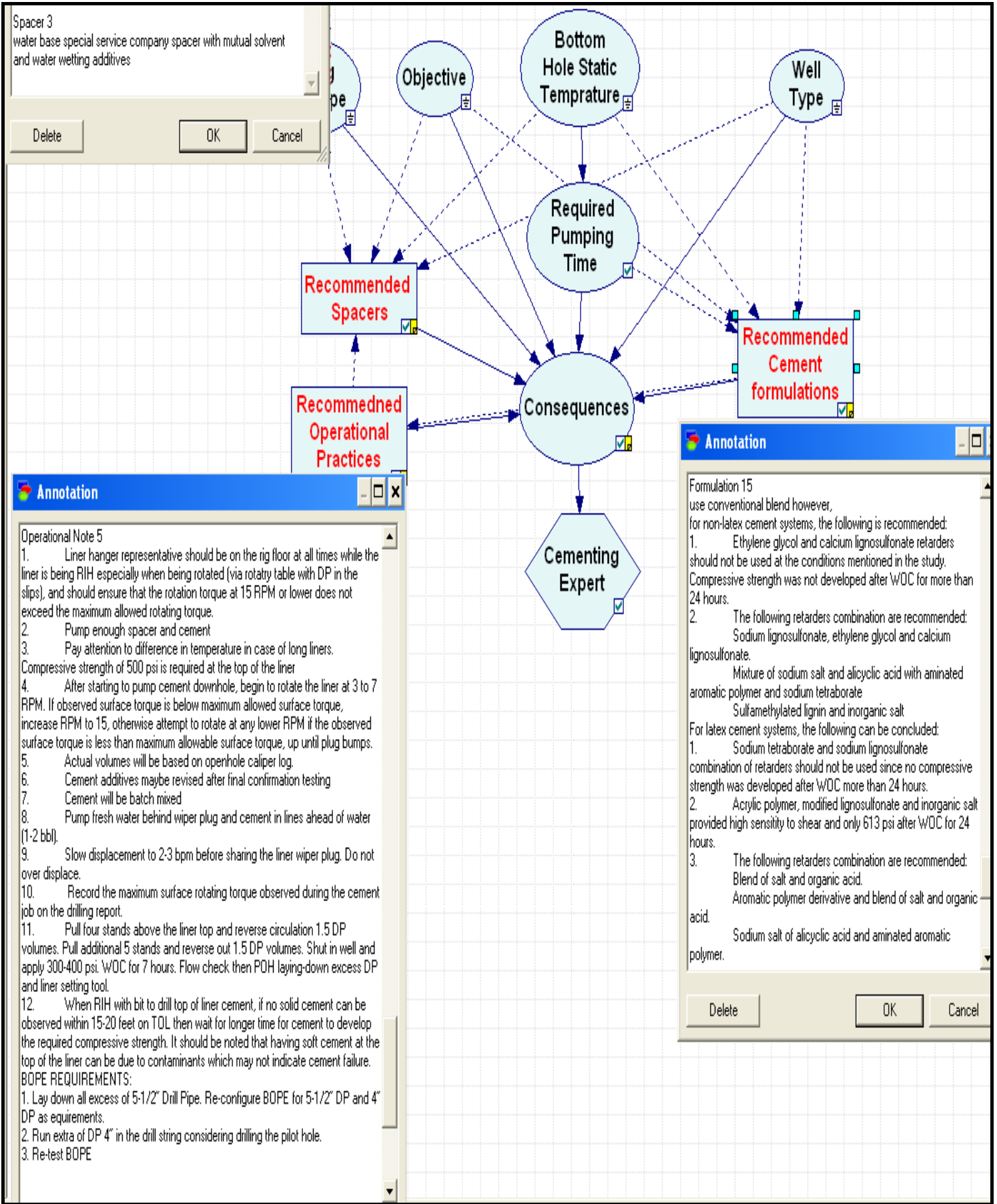

Fig.154: The model showing more details for this application (Example 2) 
The drilling expert system for cement was based on field and lab experience. It is not possible to outline this in this manuscript. For the first example, selection of the following cement slurry design: Cement $+35 \%$ BWOC silica flour+Expansion additive + Dispersant + Fluid loss additive + Retarder +0.01 gps Antifoaming agent is suitable. The temperature is high $\left(300-400^{\circ} \mathrm{F}\right)$ which requires the use of retarder to delay setting of cement. Lignosulfonate and some carbohydrate derivatives such as xanthan gum, cellulose and polyanionic cellulose are common retarders. Viscosity of cement slurry also affect pumping properties, at high temperature the viscosity will be reduced which might lead to solids settling. To solve this problem, additives for viscosity control are used. Dispersants are used with cement slurry to improve the rheological performance especially at higher densities without the use of additional water. Expansion additives (for example $\mathrm{CaO}$ or $\mathrm{MgO}$ ) are used to minimize shrinkage during cement slurry setting. The expansion additives are effective when bottom hole temperature is greater than approximately $300{ }^{\circ} \mathrm{F}$. Fluid loss additives are used to minimize hydration of water sensitive shale, to maintain the cement slurry water for the hydration process, and to minimize bridging in wellbore. Also the use of silica source is required to prevent strength regression.

Water based spacer can be used since we are using water based drilling fluid. The operational note indicates best field cementing practice for this case as the following:

1. Liner hanger representative should be on the rig floor at all times while the liner is being RIH especially when being rotated (via rotary table with DP in the slips), 
and should ensure that the rotation torque at 15 RPM or lower does not exceed the maximum allowed rotating torque.

2. Pump enough spacer and cement

3. Pay attention to difference in temperature in case of long liners. Compressive strength of 500 psi is required at the top of the liner

4. After starting to pump cement downhole, begin to rotate the liner at 3 to 7 RPM. If observed surface torque is below maximum allowed surface torque, increase RPM to 15 , otherwise attempt to rotate at any lower RPM if the observed surface torque is less than maximum allowable surface torque, up until plug bumps.

5. Actual volumes will be based on openhole caliper log.

6. Cement additives maybe revised after final confirmation testing

7. Cement will be batch mixed

8. Pump fresh water behind wiper plug and cement in lines ahead of water (1-2 bbl).

9. Slow displacement to $2-3 \mathrm{bpm}$ before sharing the liner wiper plug. Do not over displace.

10. Record the maximum surface rotating torque observed during the cement job on the drilling report.

11. Pull four stands above the liner top and reverse circulation 1.5 DP volumes. Pull additional 5 stands and reverse out 1.5 DP volumes. Shut in well and apply 300-400 psi. WOC for 7 hours. Flow check then POH laying-down excess DP and liner setting tool. 
12. When RIH with bit to drill top of liner cement, if no solid cement can be observed within 15-20 feet on TOL then wait for longer time for cement to develop the required compressive strength. It should be noted that having soft cement at the top of the liner can be due to contaminants which may not indicate cement failure.

For the second example (cementing Gas Long Production Liner), the same operational field note above can be applied. The spacer will be a water based spacer that has mutual solvent to water wet the formation for improved formation cement bonding,

Since we have a long gas production liner the cement slurries should meet the following requirements, Al-Yami et al. (2007):

1. The thickening time must be sufficient to allow proper slurry placement.

2. Rapid compressive strength development at the top of the liner and the bottom.

3. The slurry must be easily mixable and must not exhibit free water or settling tendencies.

4. A fluid-loss of $\leq 100 \mathrm{ml} / 30 \mathrm{~min}$.

In addition to conventional additives such as fluid loss, dispersants, silica source latex must be used:

For wells that show high gas migration potential we can use latex additive. Latex is a copolymer of AMPS, N-Vinylacylamide and acrylamide, Fink (2003). The following retarders' combinations are recommended Al-Yami et al. (2007):

- Blend of salt and organic acid.

- Aromatic polymer derivative and blend of salt and organic acid. 
- Sodium salt of alicyclic acid and aminated aromatic polymer.

\subsection{Underbalanced drilling models}

\subsubsection{General approach to underbalanced drilling model}

The user can select the formation to be drilled by assigning a probability of one to any of the available probabilities. For example the user selects naturally fractured and vugular formation, Fig.155. The consideration decision is shown in Fig.156 since it shows the highest probability. Again all of these probabilities were obtained by underbalanced drilling expert opinions which can be updated by other opinions easily.

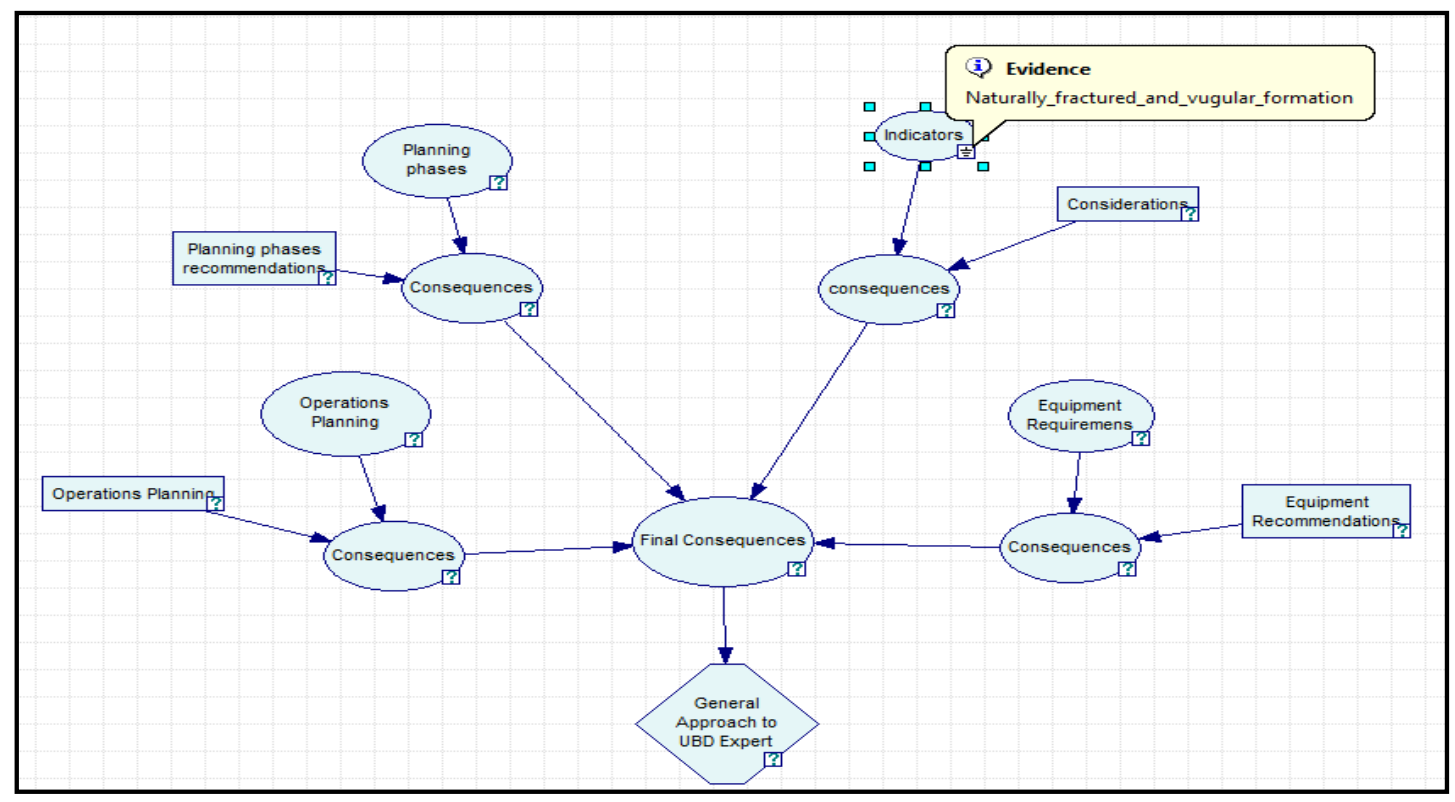

Fig.155: The user selects that he has naturally fractured and vugular formation 
Node properties: Considerations

General | Definition | Format | User properties Value |

Expected utilities for different policies:

Typically_exhibit_lost_circulation_and_differenial_sticking_problems_A_consolidated_formation_makes_an_excellent_UBD_Candidate

Usully_consolidated_and_therefore_can_sustain_UBD_UBD_will_provide_an_improvement_in_ROP_and_bit_life_in_hard_rock

Typically_exhibit_lost_circulation_and_differential_sticking_problems_a_consolidated_formation_makes_an_excellent_UBD_candidate

Fluid_invasion_can_be_minimized_or_even_eliminated_with_UBD

Fig.156: The consideration decision

\subsubsection{Flow underbalanced drilling model}

If the tripping probability is selected as RIH (Fig.157) and high permeability level

(Fig.158) then the optimum tripping operation is to use mud cap, Fig. 159.

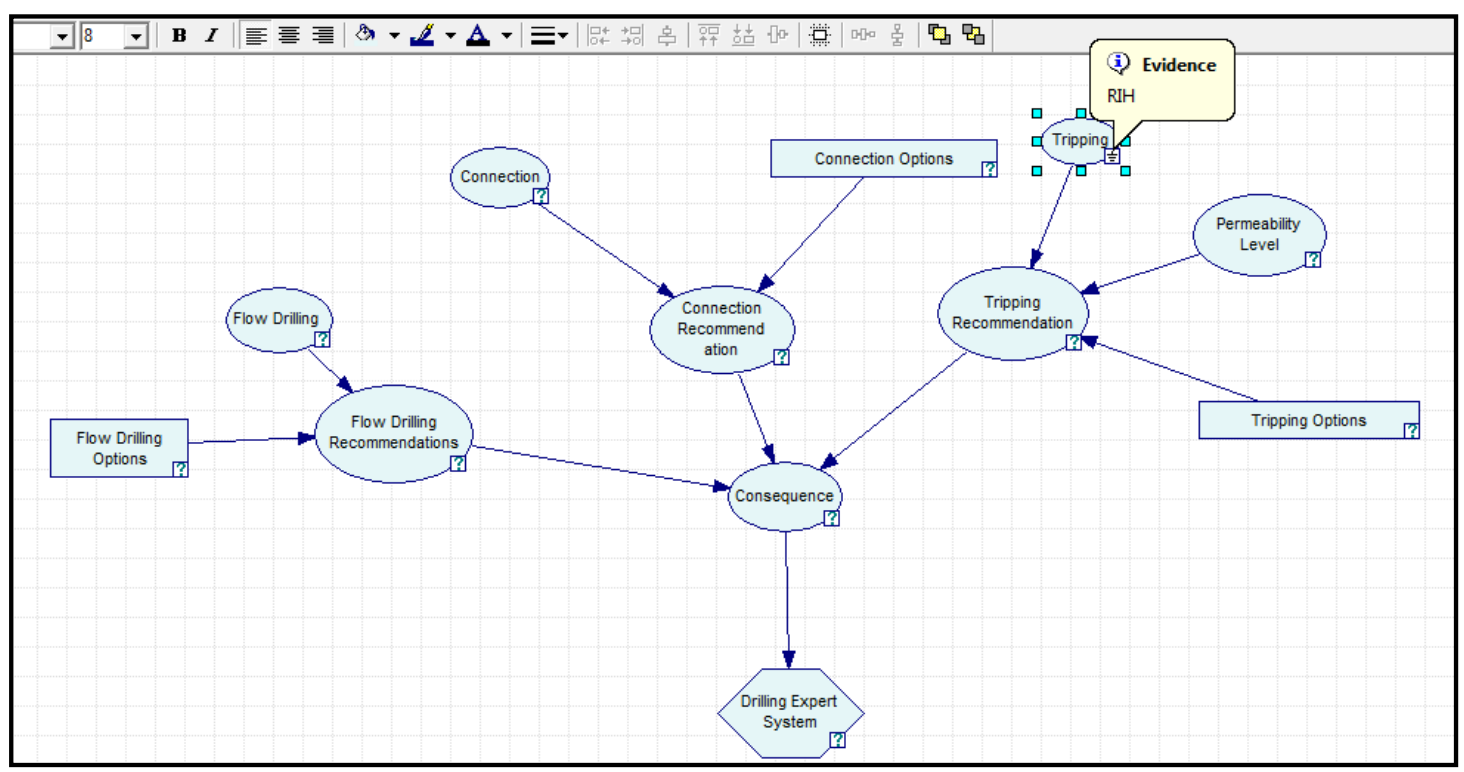

Fig.157: The user selects RIH option 


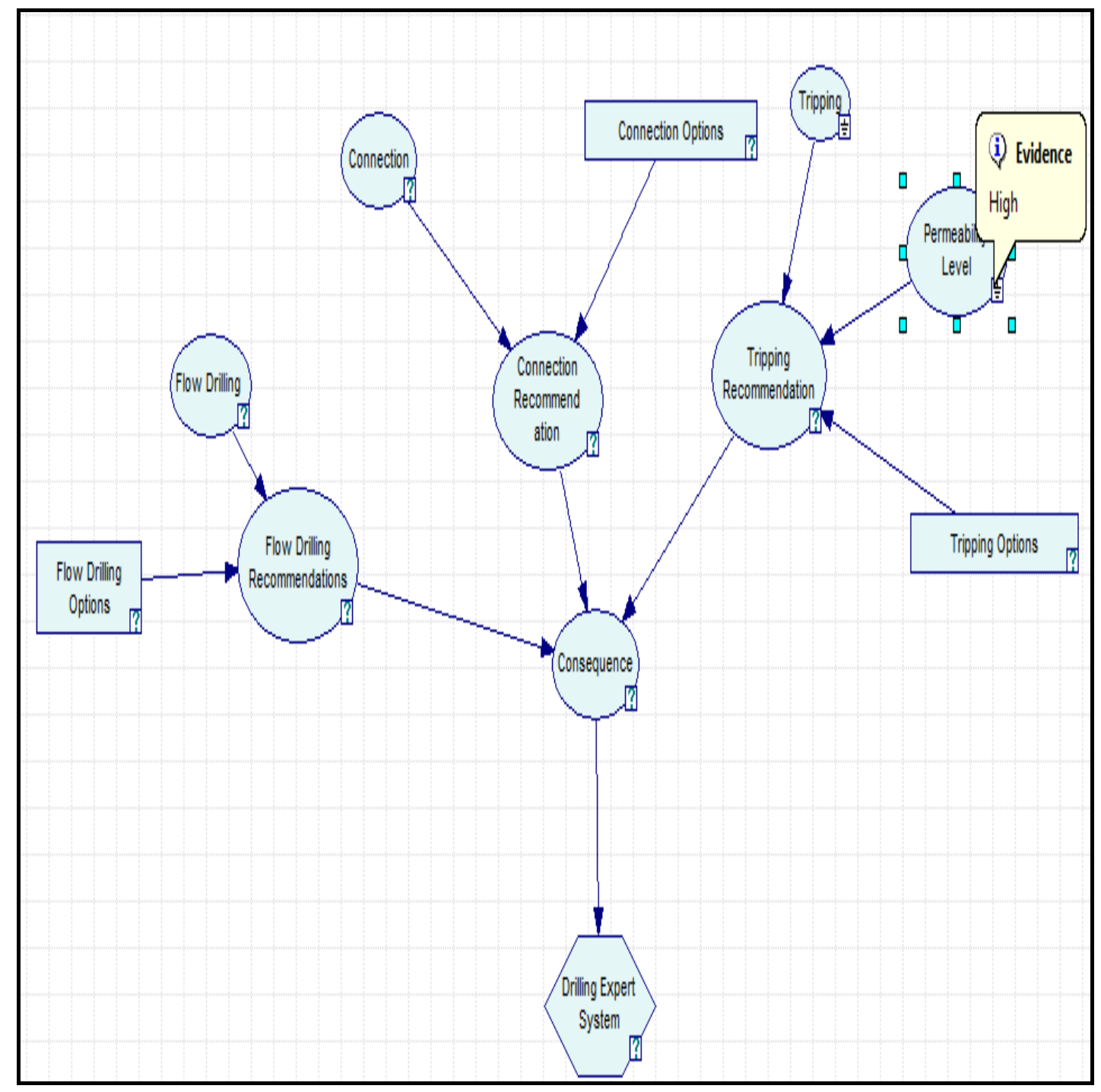

Fig.158: The user selects high permeability option 


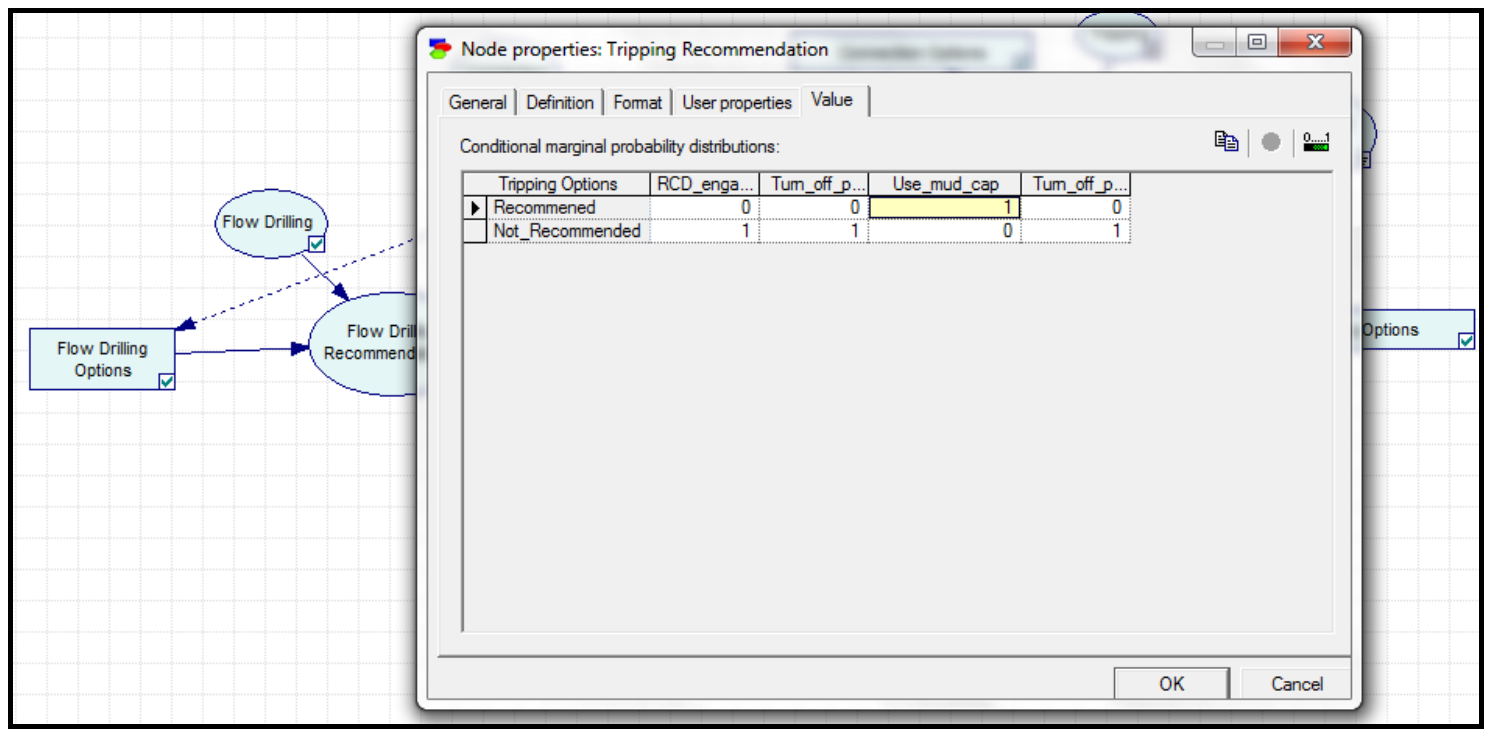

Fig.159: Tripping recommendation for low permeability formation during RIH operation

Selection of on connection probability (Fig.160) leads to optimum connection option shown in Fig.161. 


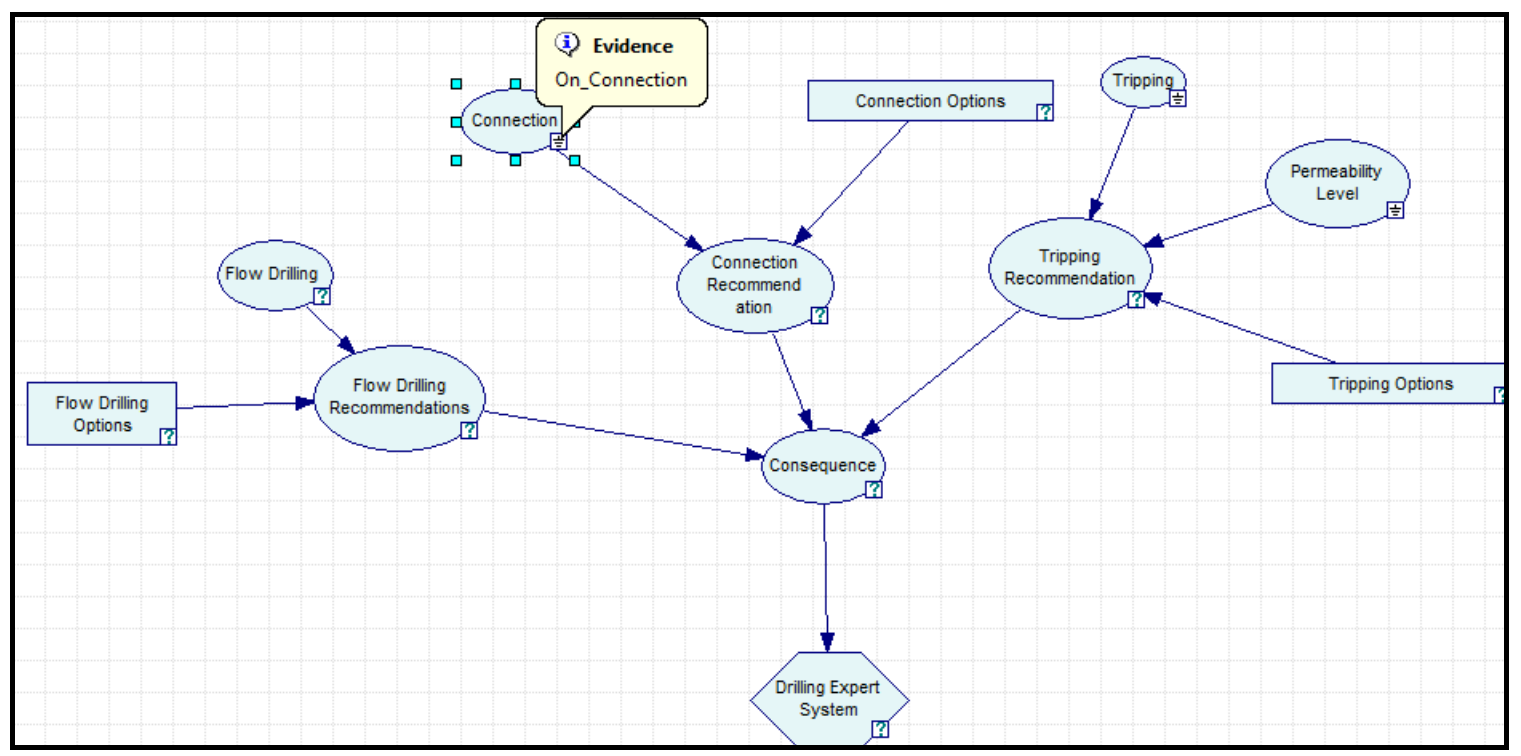

Fig.160: The user selects on connection option

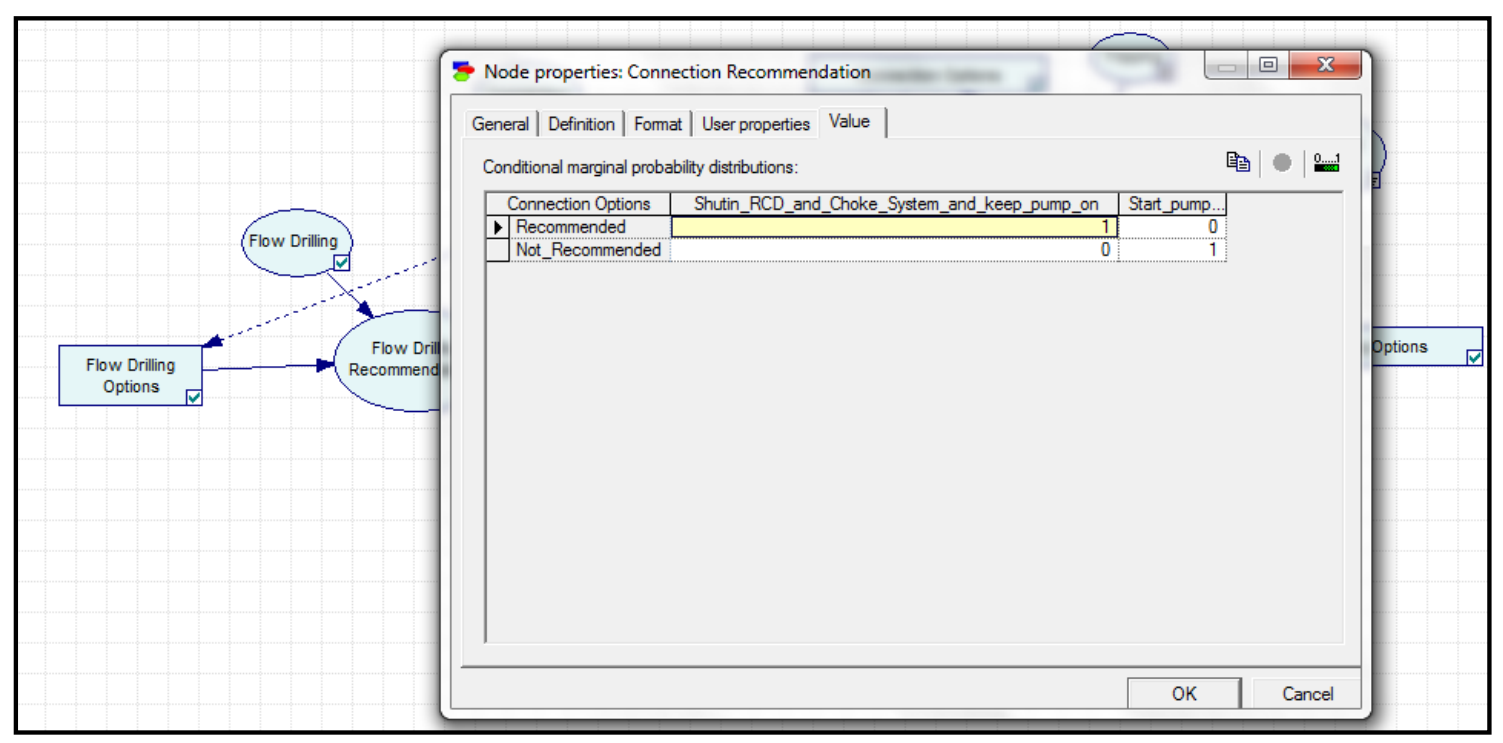

Fig.161: Connection recommendation 
Selection of flow drilling with formation gas or fluid returns (Fig. 162) leads to the optimum practice shown in Fig.163.

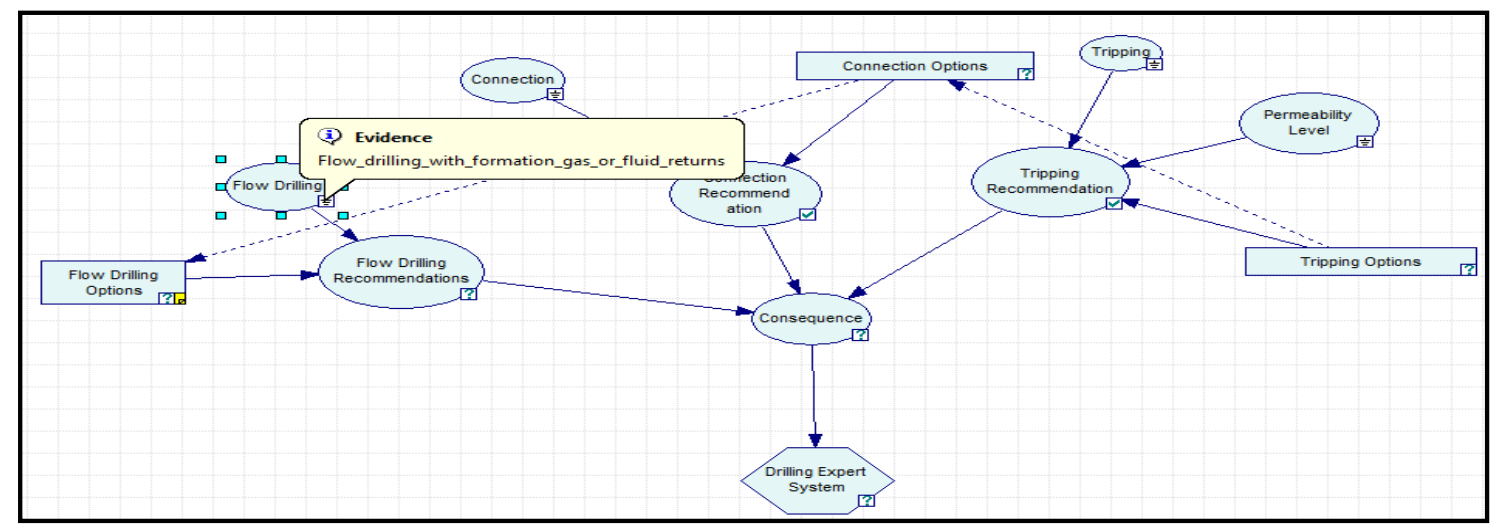

Fig.162: The user selects flow drilling takes place in formation with gas or fluid returns

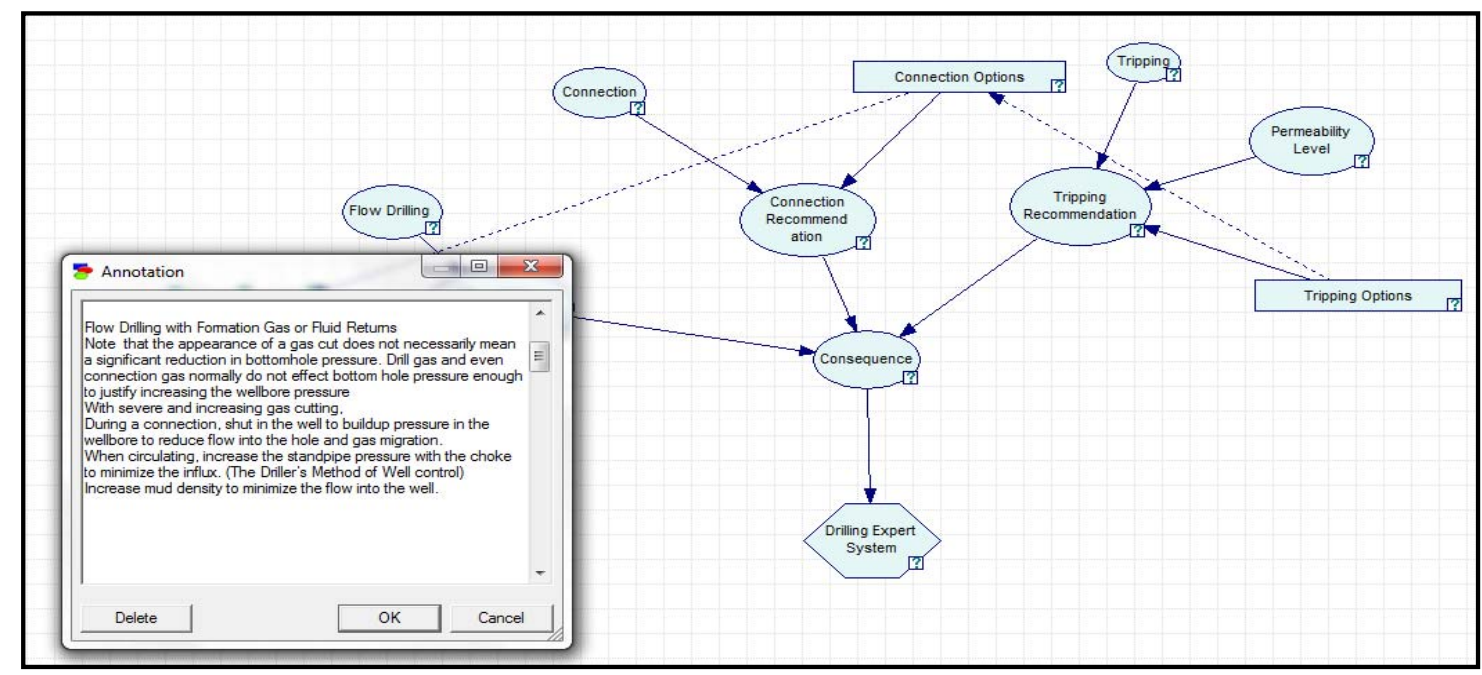

Fig.163: The recommended flow drilling with formation gas or fluid returns 


\subsubsection{Gaseated underbalanced drilling model}

Selection of concentric casing string injection method (Fig. 164) leads to benefits and challenges shown in Fig.165.

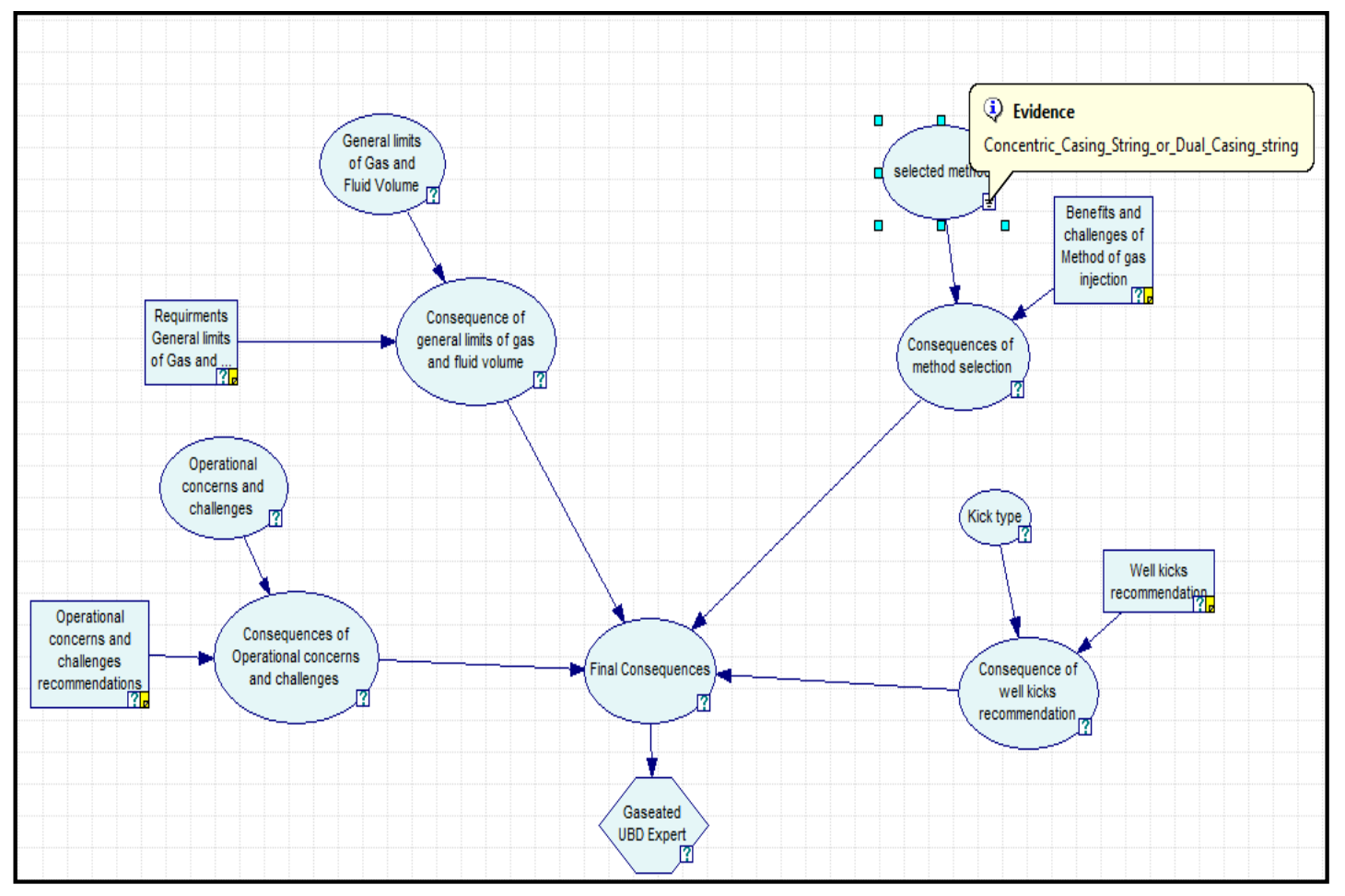

Fig.164: The user selects gaseated UBD method (dual casing string) 


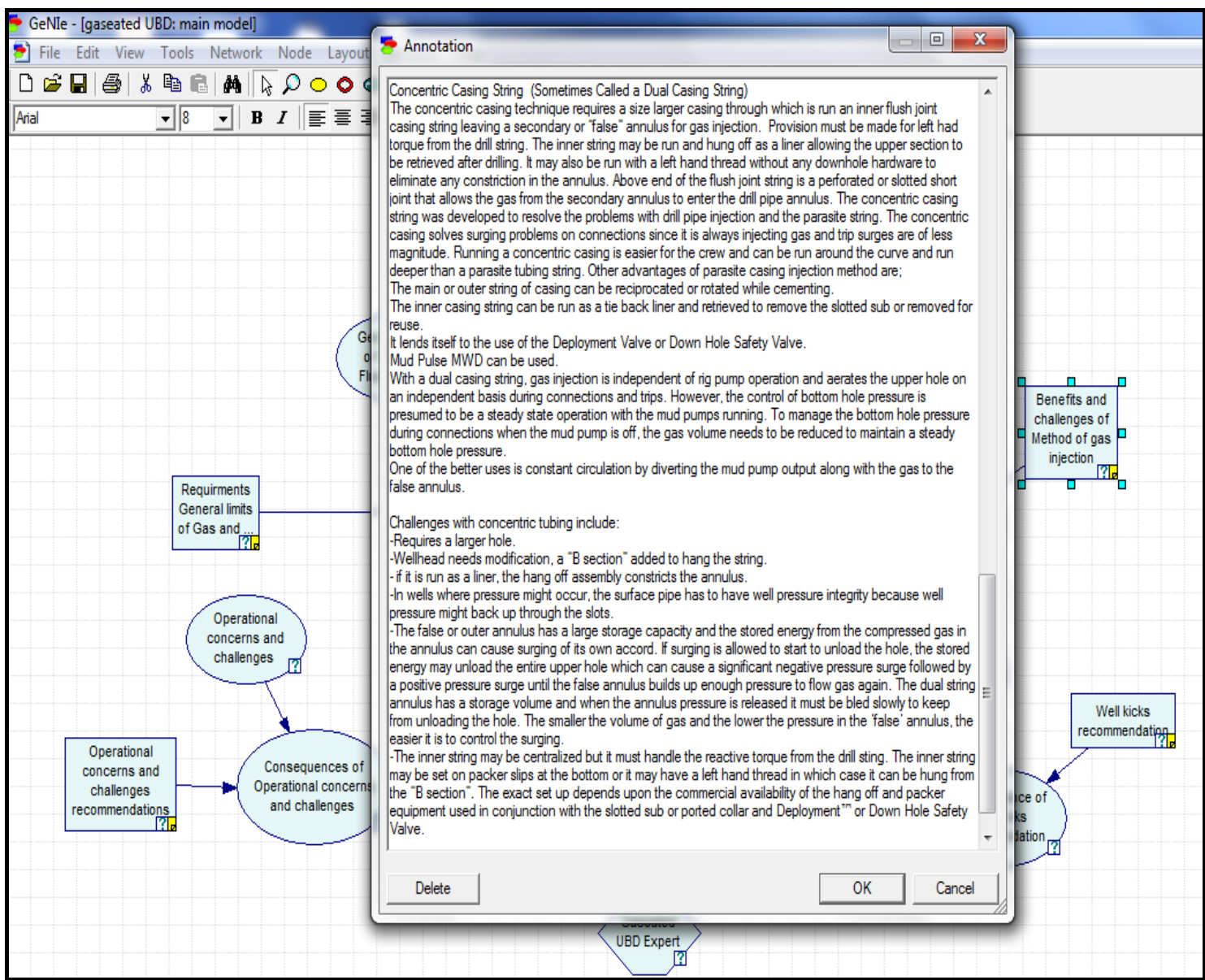

Fig.165: The recommendation for dual casing string is shown

Selection of back pressure gas and fluid limitation probability (Fig. 166) leads to the optimum recommendation shown in Fig.167. 


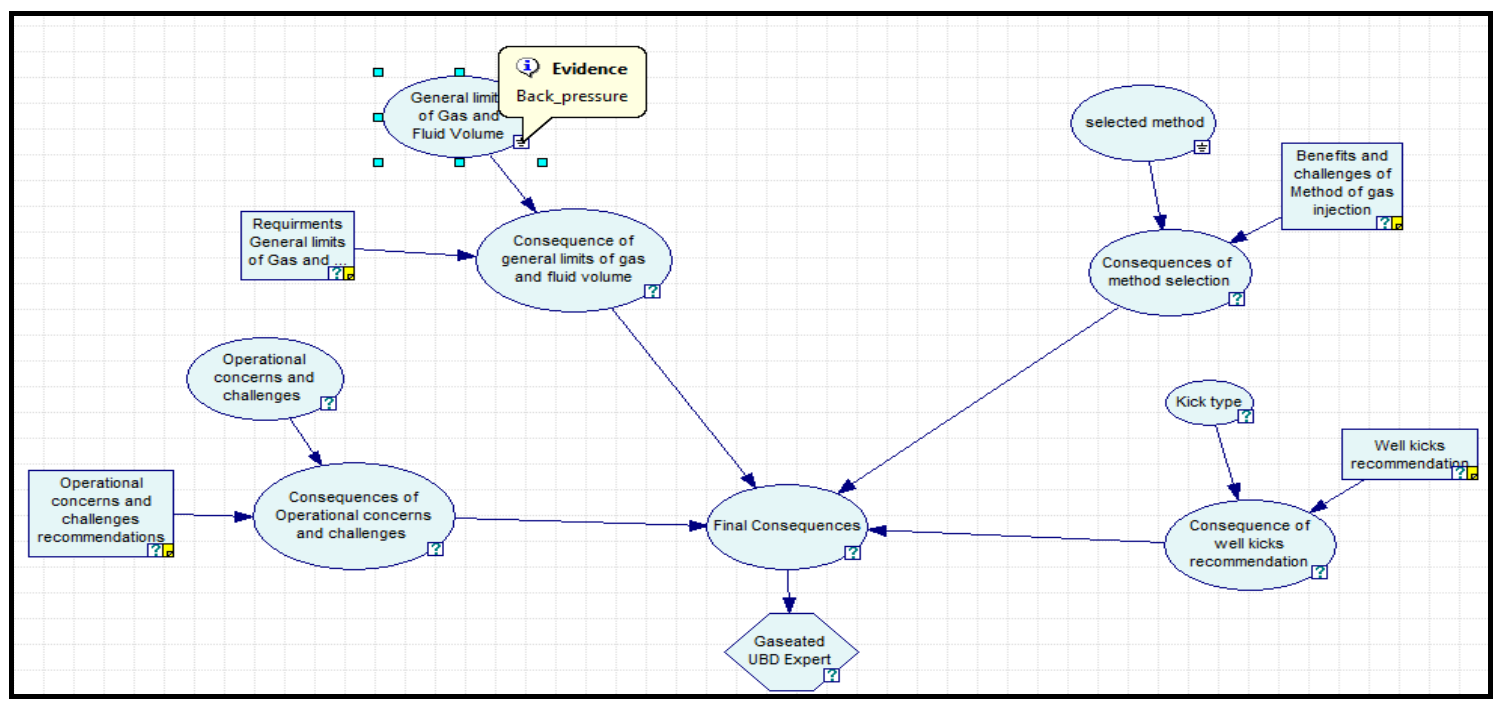

Fig.166: The user selects general limit of gas and fluid volume (back pressure)

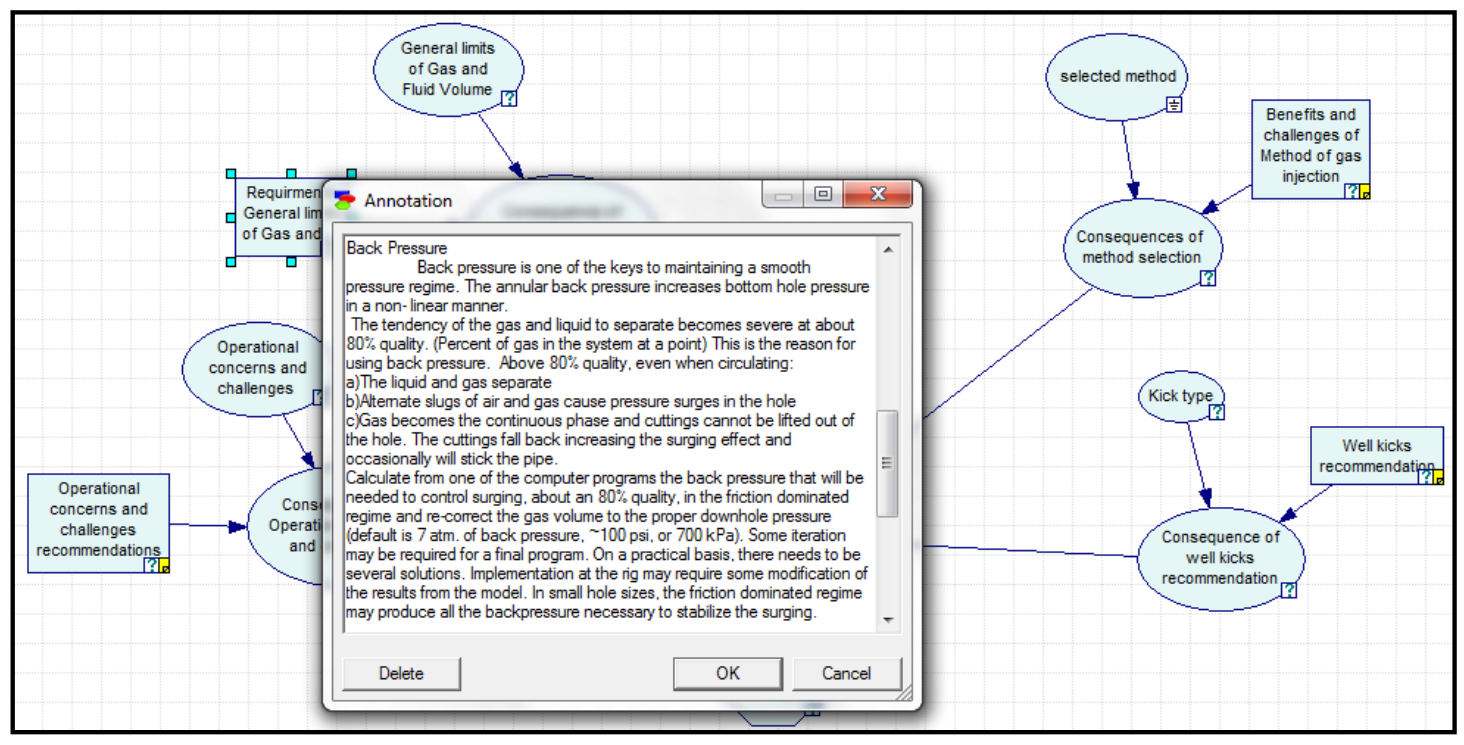

Fig.167: Back pressure recommendation 
Selection of flow drilling with formation gas or fluid returns (Fig. 168) leads to the optimum practice shown in Fig.169.

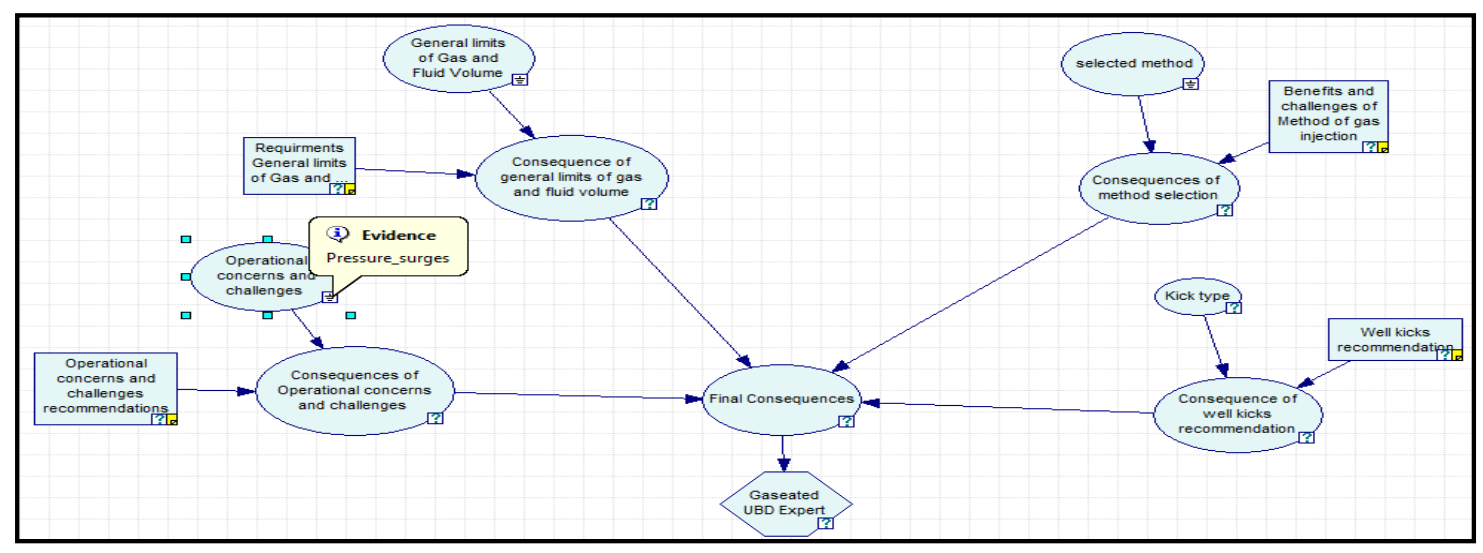

Fig.168: The user selects operational concern (pressure surges)

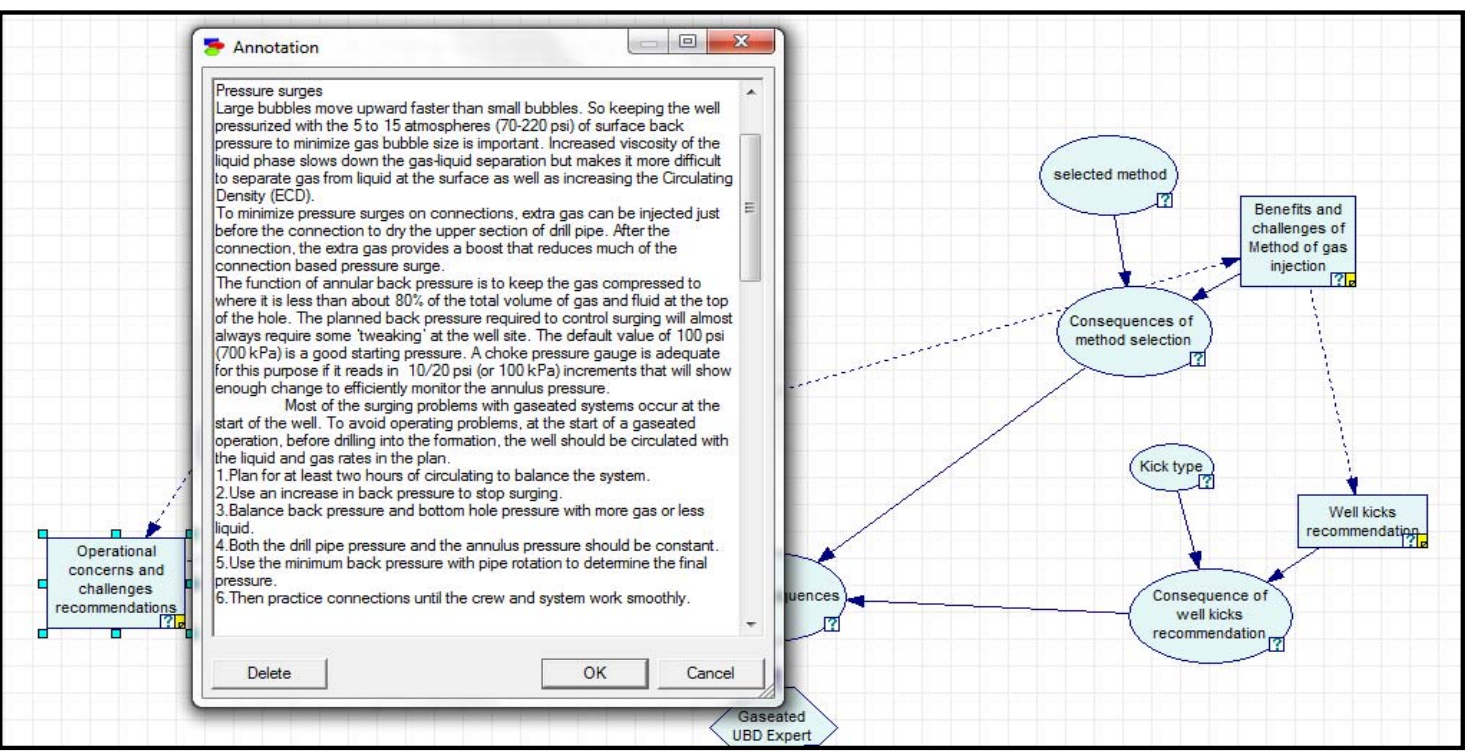

Fig.169: Pressure surges recommendation 
Selection of gas flow kick type (Fig. 170) leads to the optimum well kick recommendation shown in Fig.171.

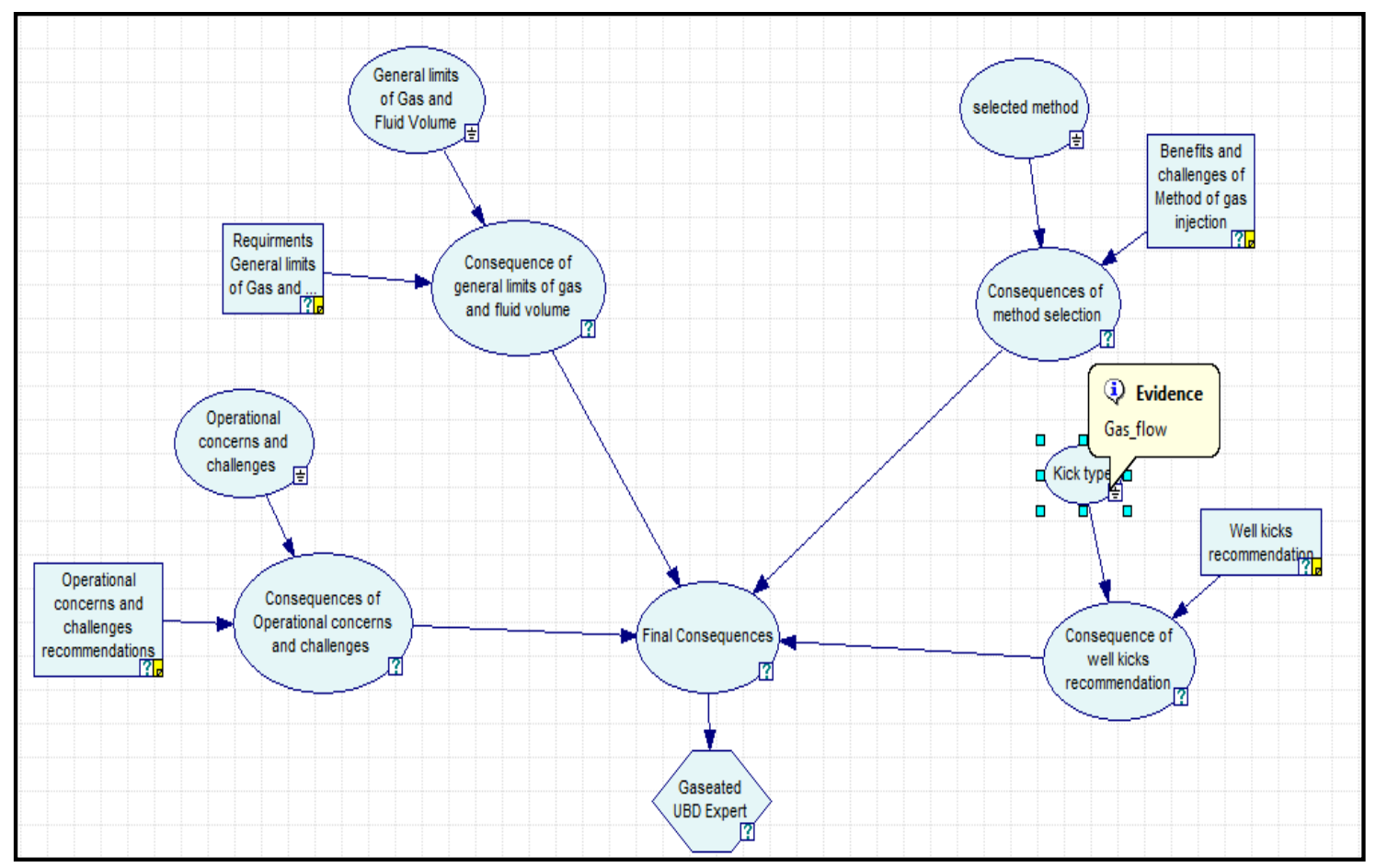

Fig.170: Selecting kick type (gas flow) 


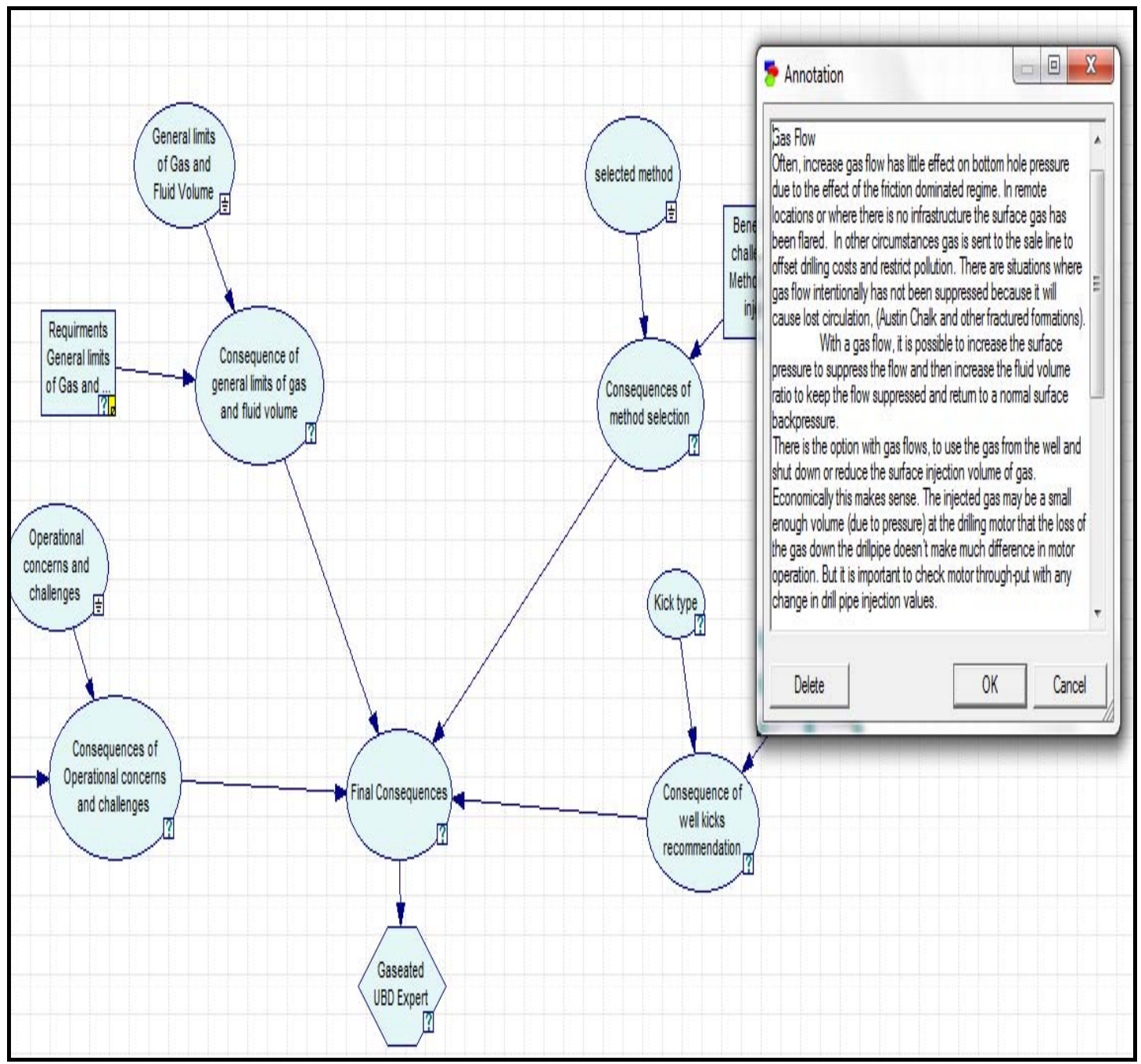

Fig.171: Recommendation for kick type (gas flow)

\subsubsection{Foam underbalanced drilling model}

Selection of hot holes as a challenge (Fig. 172) leads to the optimum recommendation shown in Fig.173. 


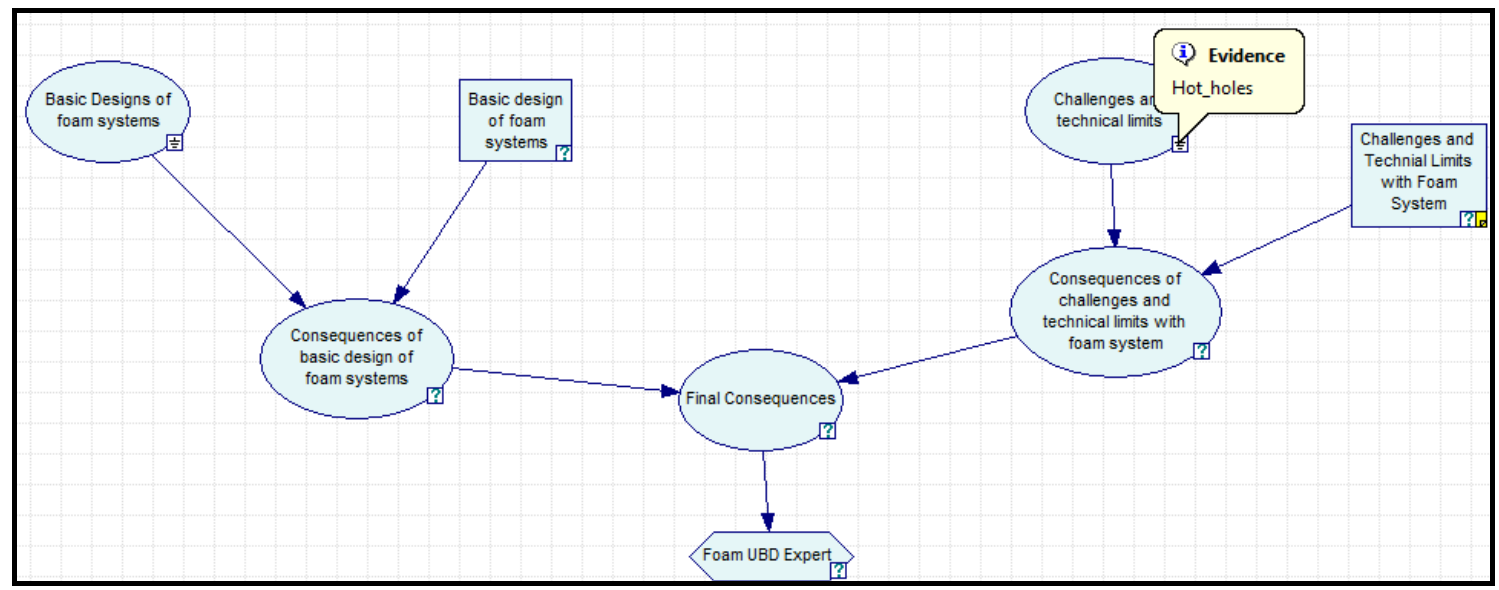

Fig.172: The user selects hot holes as a challenge

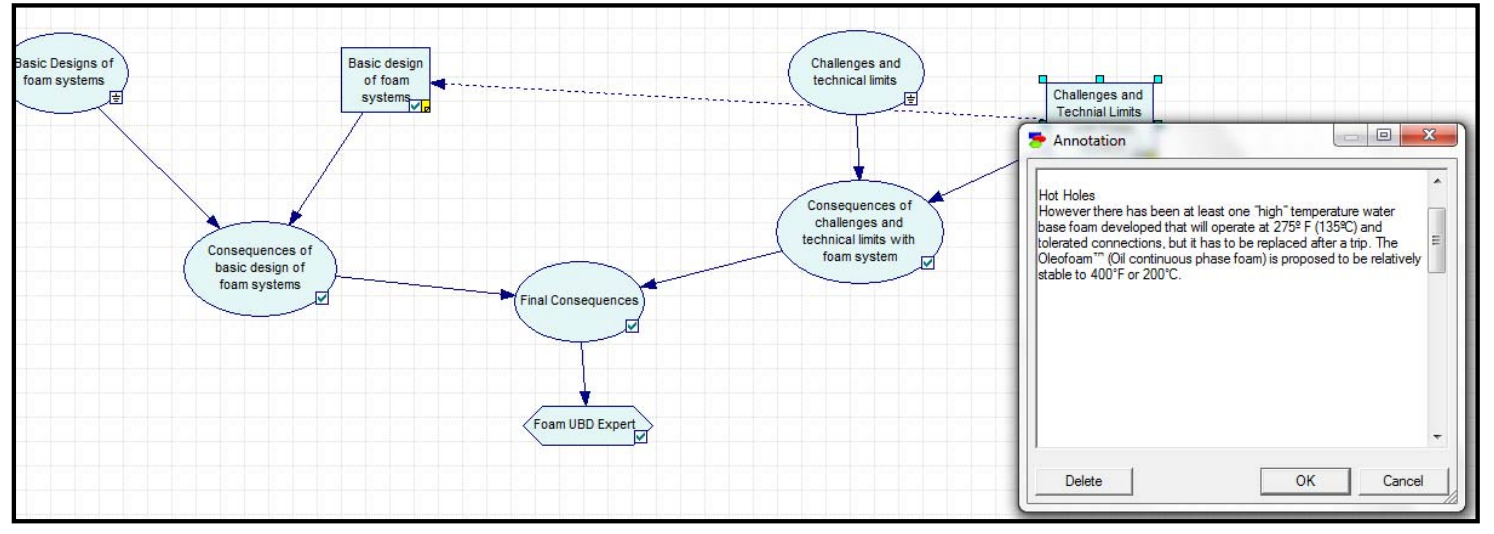

Fig.173: Hot holes recommendation

Selection of making a connection in foam underbalanced drilling (Fig. 174) leads to the optimum connection procedure detailed in Fig.175. 


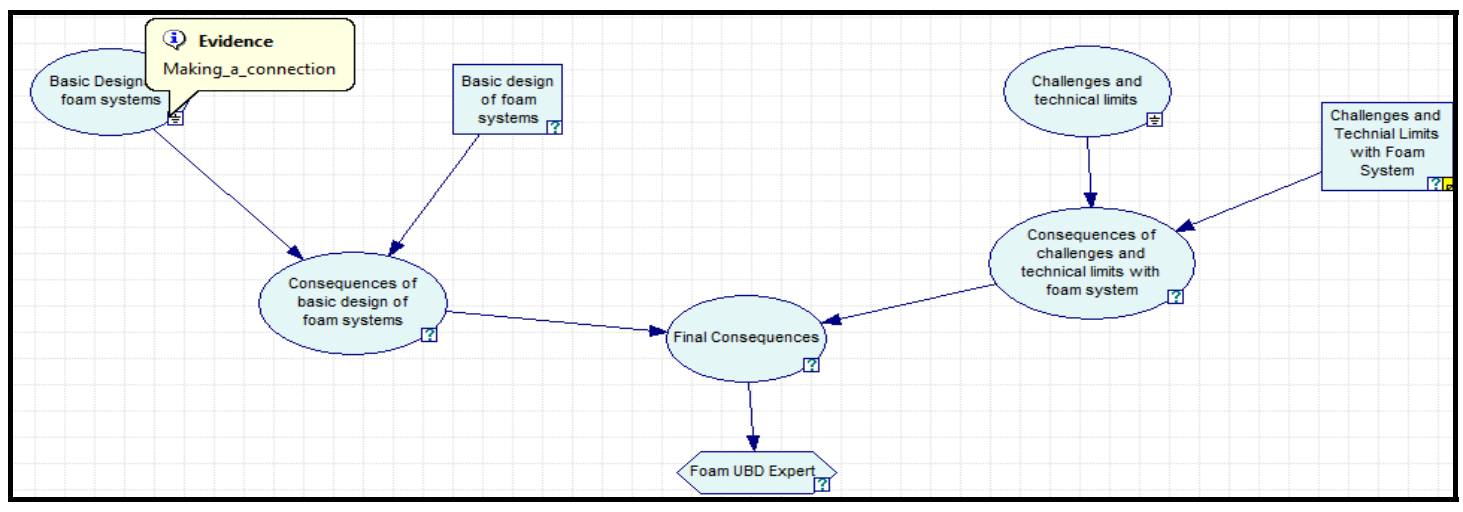

Fig.174: Selecting basic designing in making a connection in foam UBD

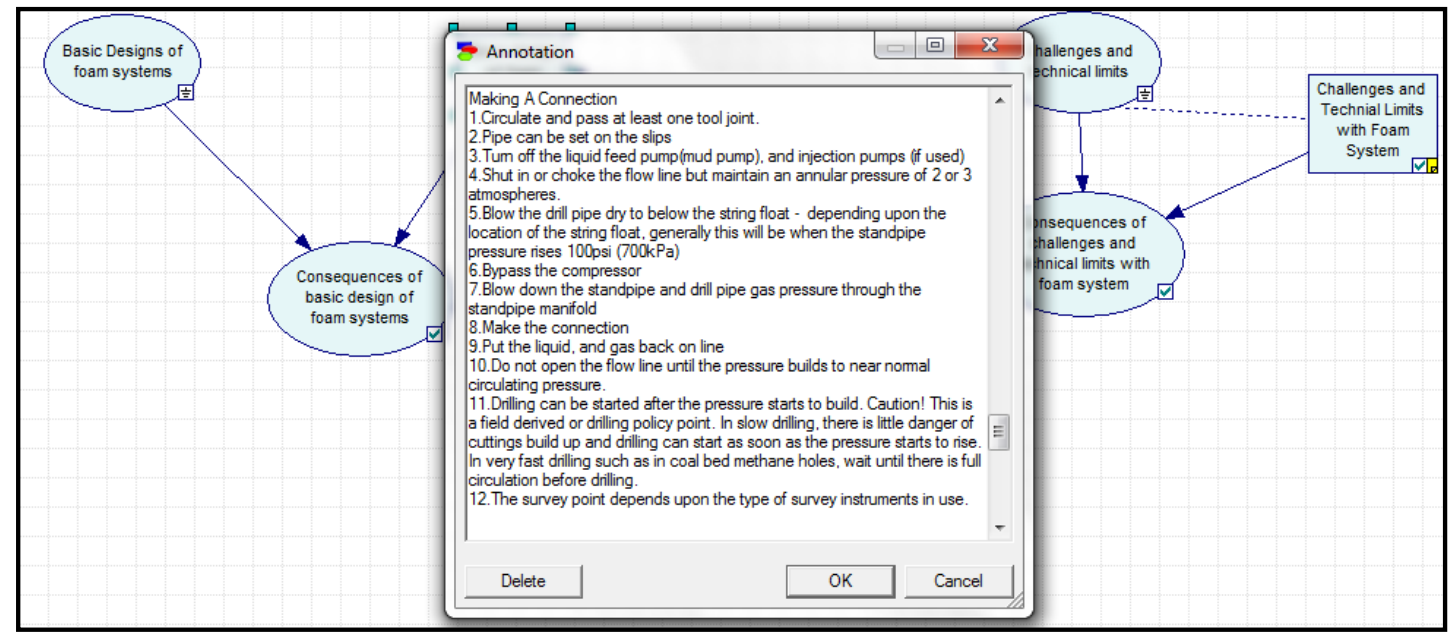

Fig.175: Recommendation for making a connection in foam UBD

8.5.5 Air and gas underbalanced drilling model

Selection of horizontal drilling with air hammers (Fig. 176) leads to the optimum recommendation detailed in Fig.177. 


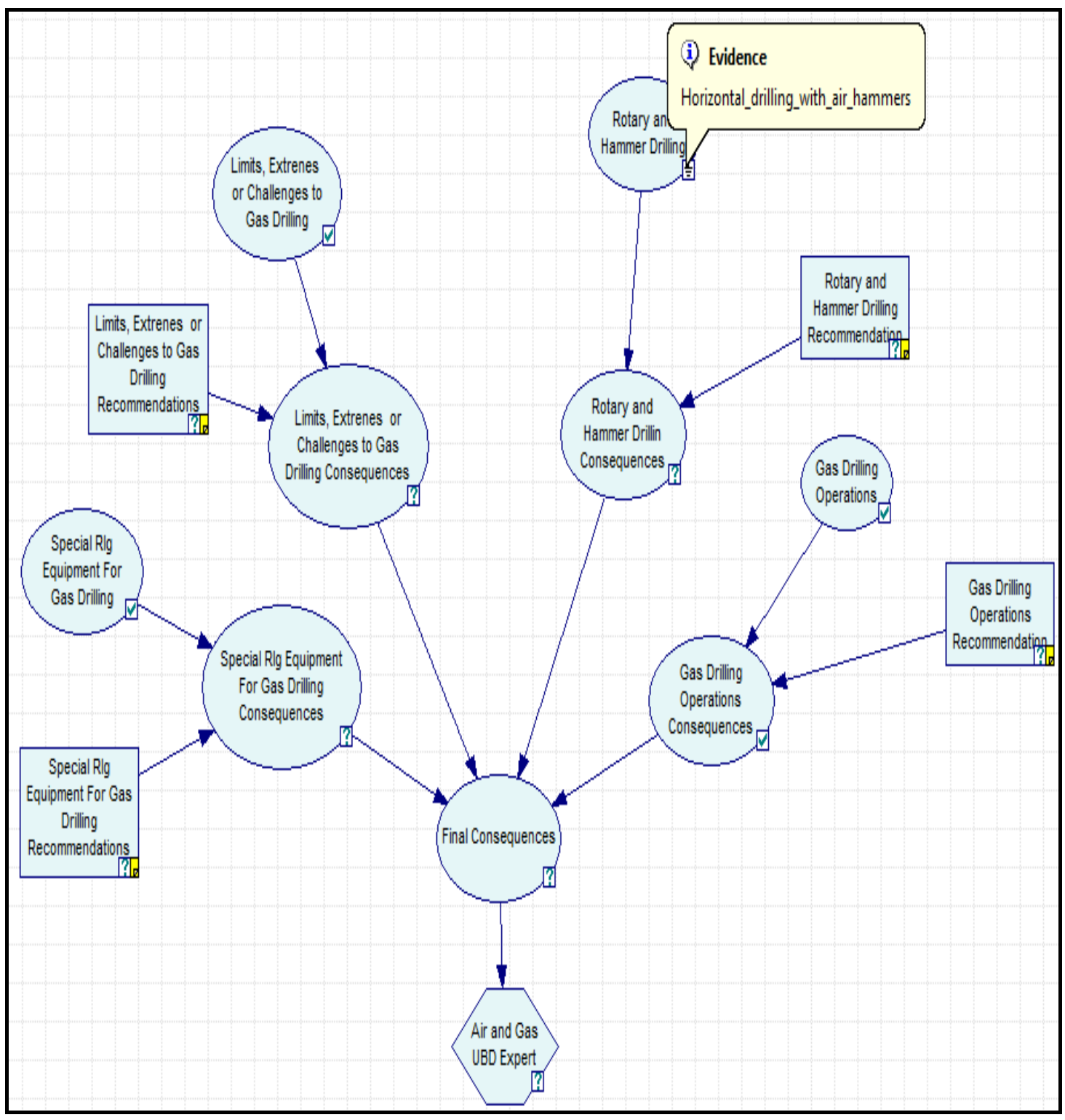

Fig.176: Selecting horizontal drilling with air hammers 


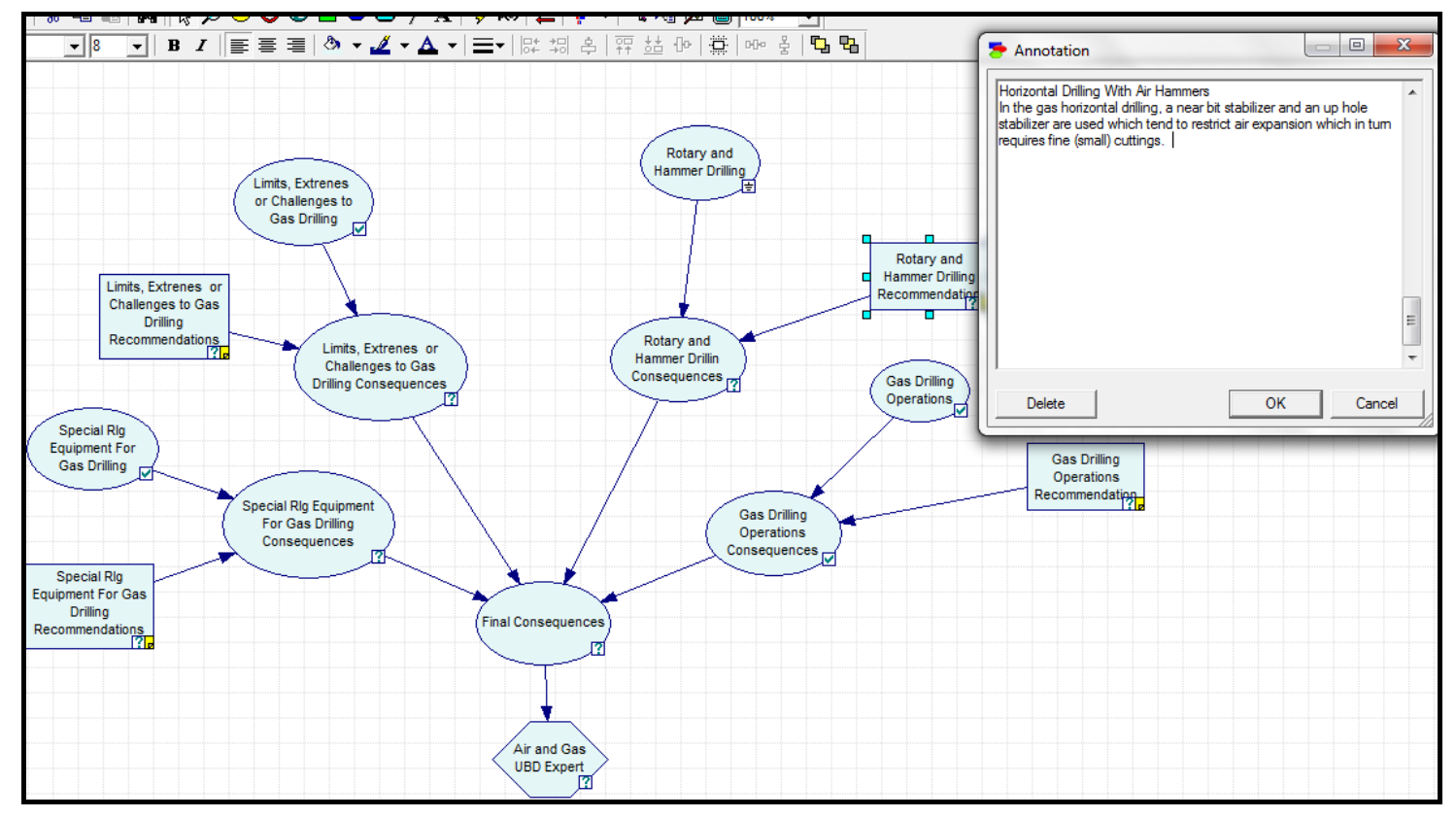

Fig.177: Recommendation for horizontal drilling with air hammers

Selection of water or wet holes probability as a challenge to gas drilling (Fig. 178) leads to the optimum recommendation detailed in Fig.179.

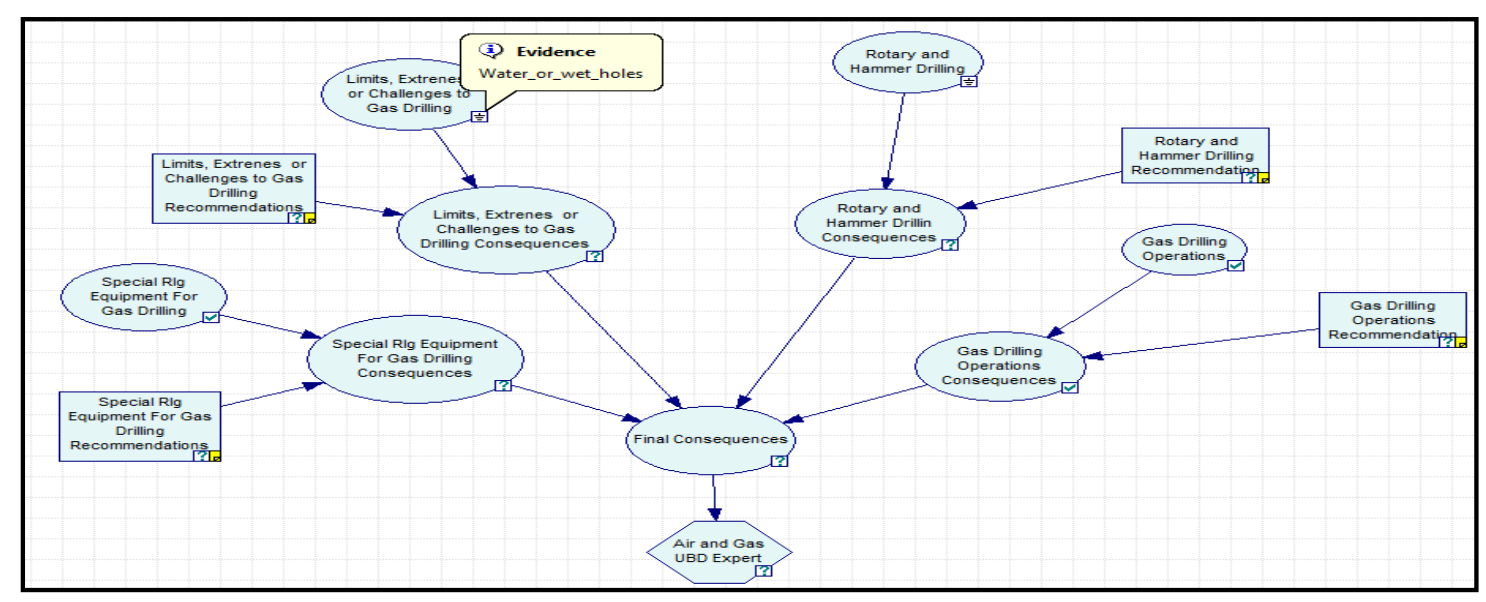

Fig.178: Selection of water or wet holes as a challenge 


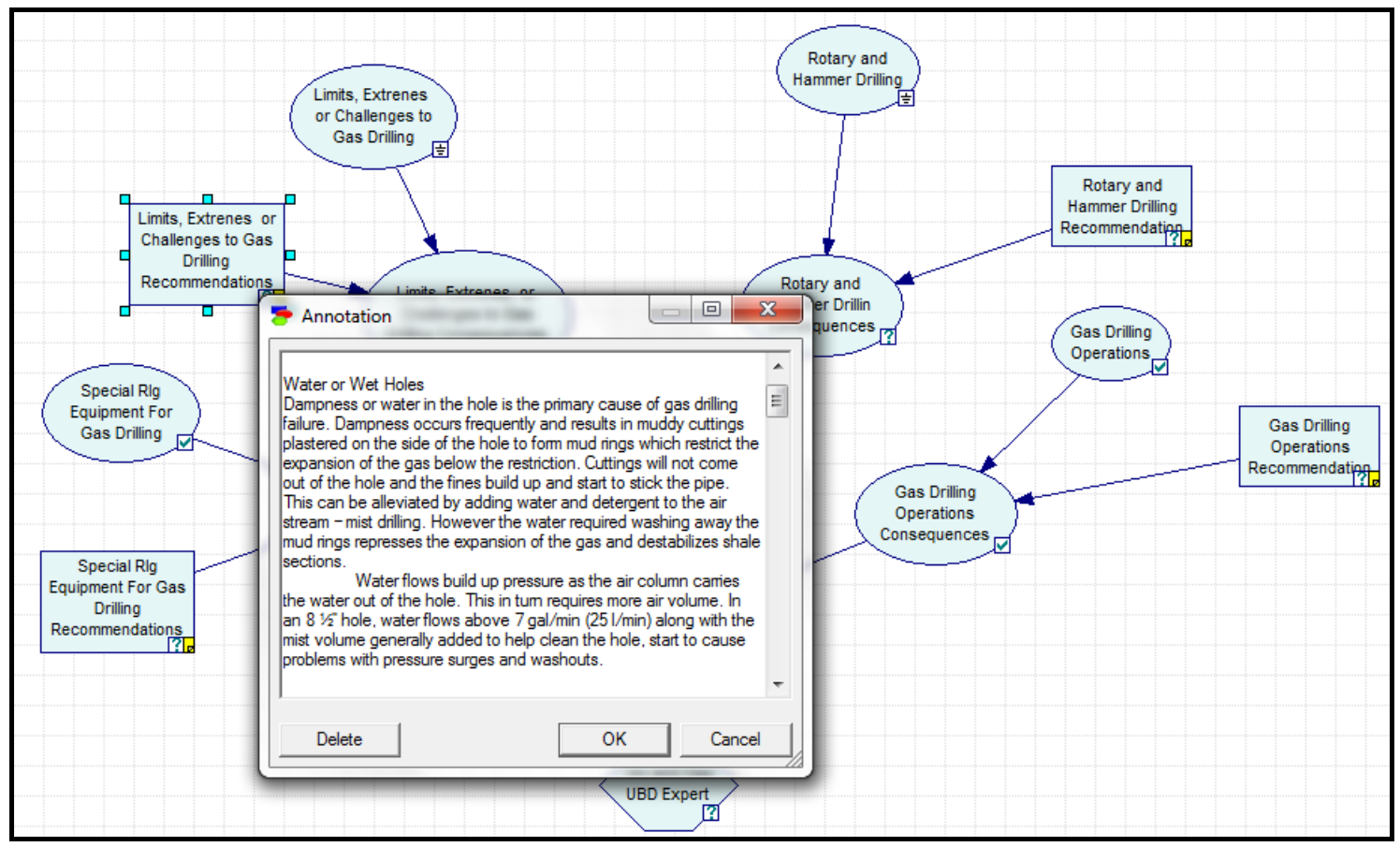

Fig.179: Water or wet holes recommendation

Selection of mist pump rig equipment probability (Fig. 180) leads to the optimum recommendation detailed in Fig.181. 


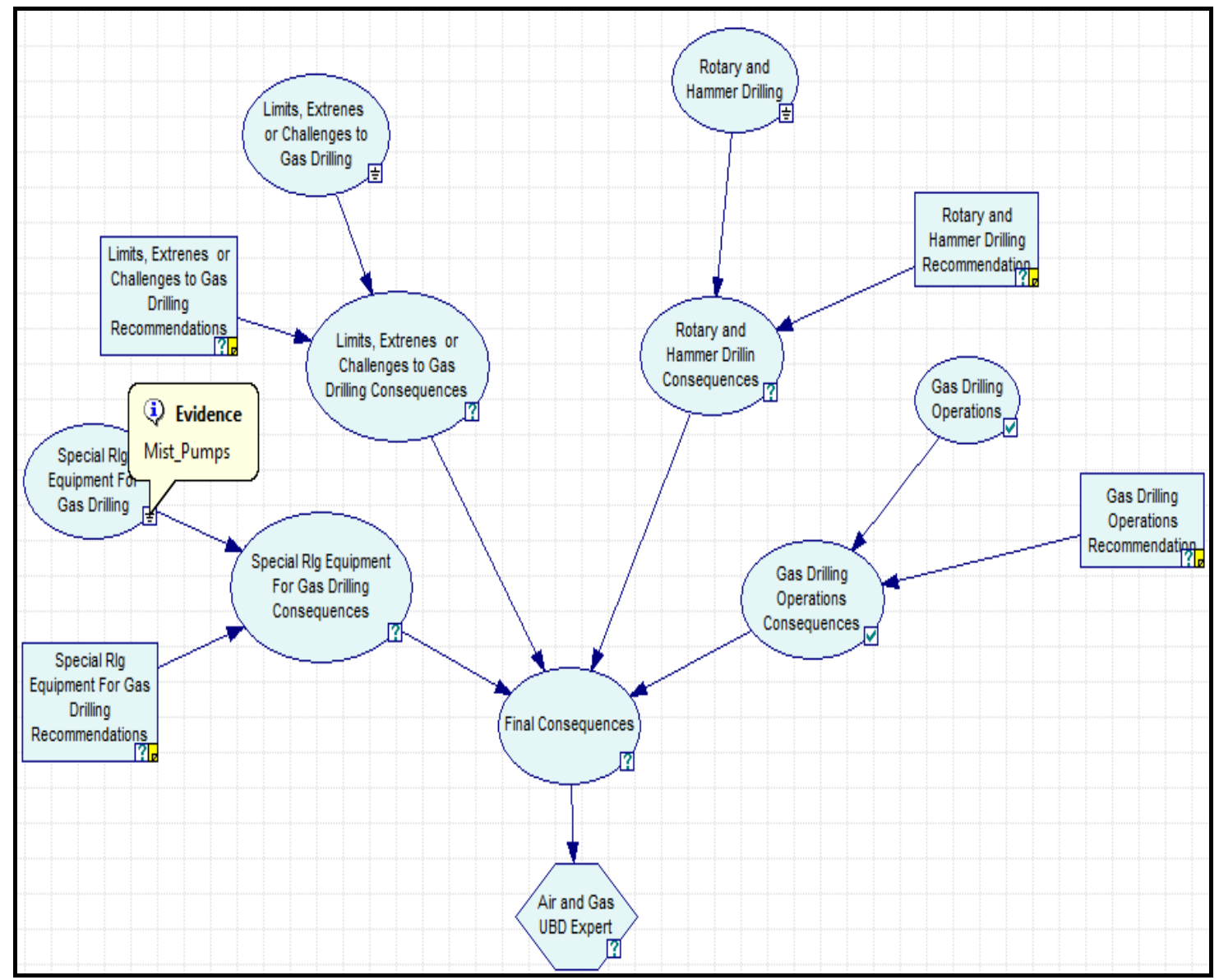

Fig.180: Selection of mist pumps 


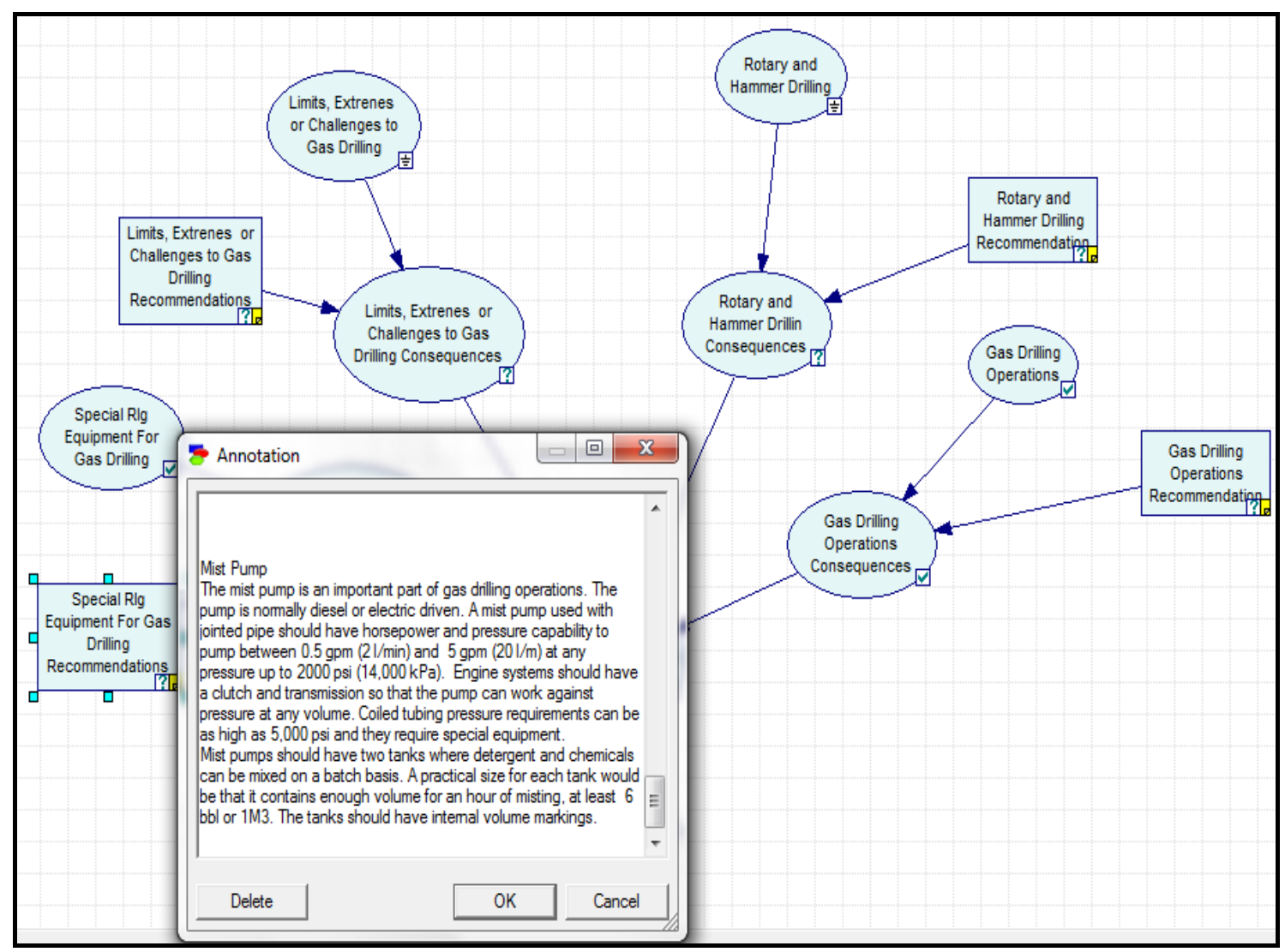

Fig.181: Recommendation for mist pump

Selection of well kicks detection and solution probability in gas drilling operation node (Fig. 182) leads to the optimum recommendation detailed in Fig.183. 


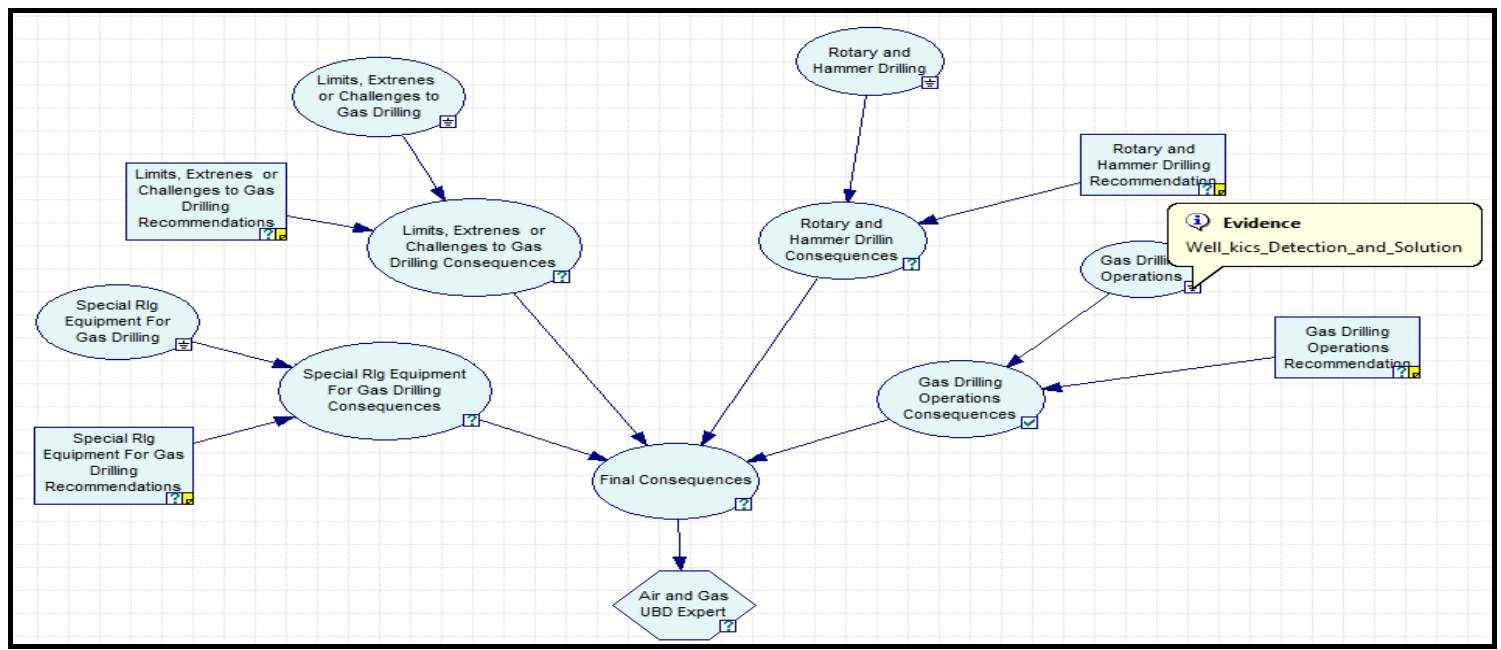

Fig.182: Selection of gas drilling operations (well kicks detection and solution)

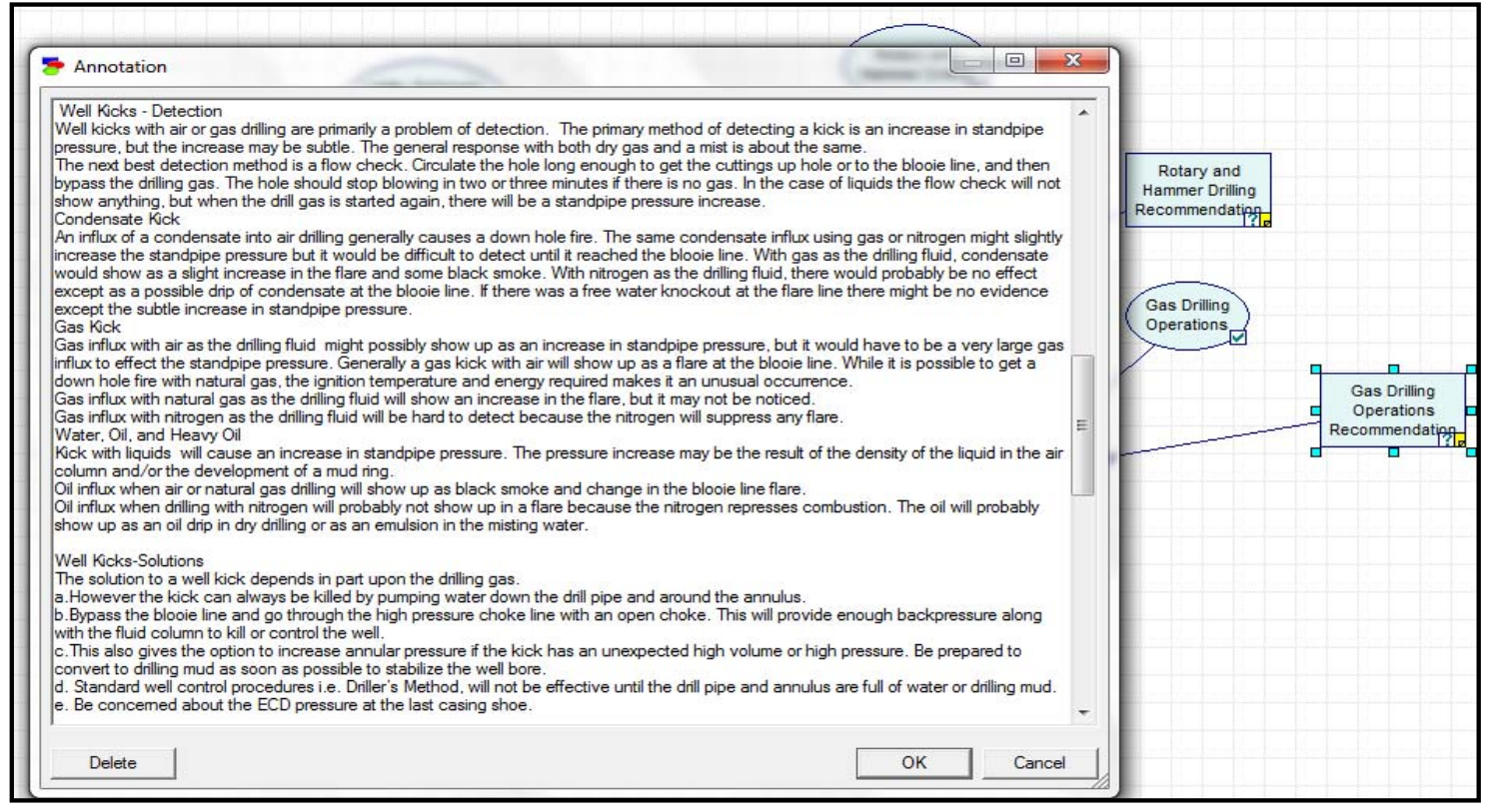

Fig.183: Well kicks detection and solution recommendation 


\subsubsection{Mud cap model}

Selection of trips with pressurized mud caps probability (Fig. 184) leads to the optimum recommendation detailed in Fig.185.

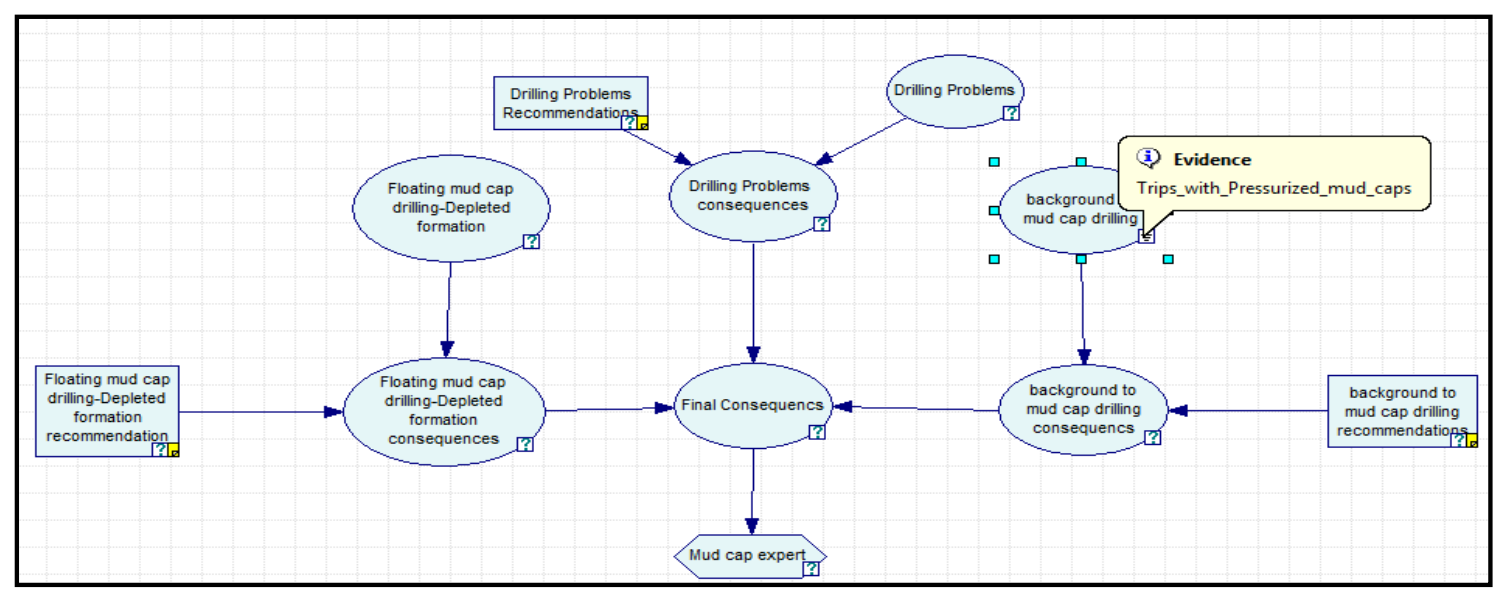

Fig.184: Selecting trips with pressurized mud caps

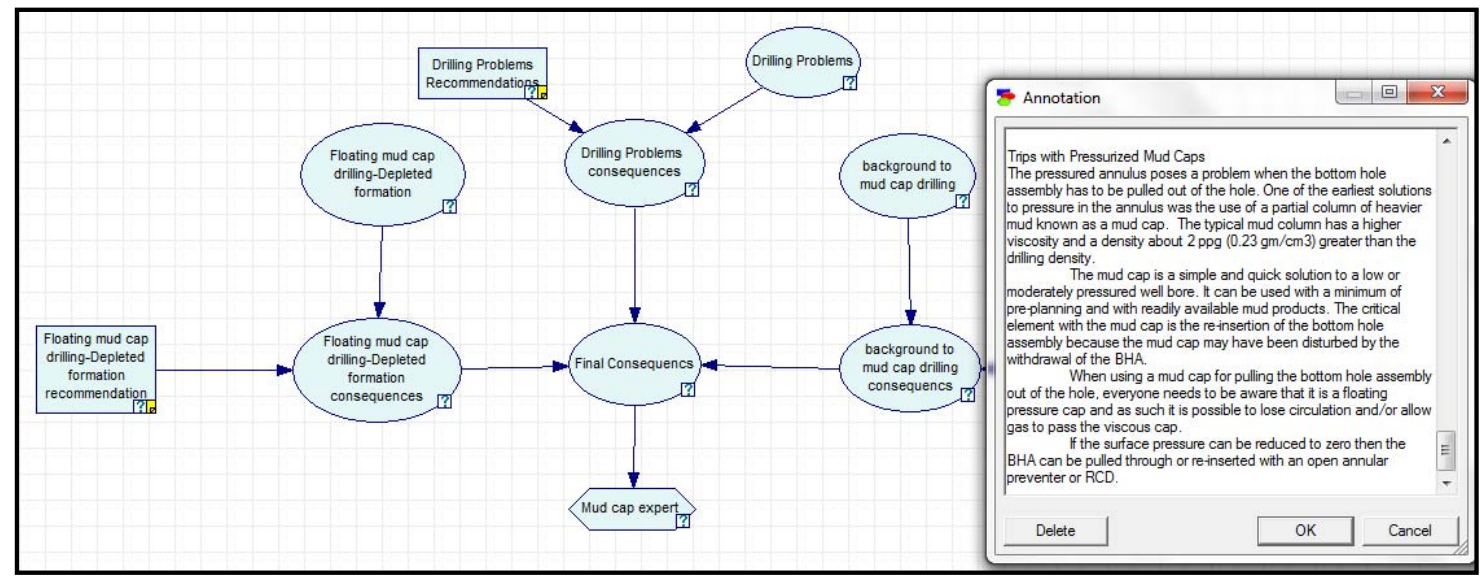

Fig.185: Recommendation for trips with pressurized mud caps 
Selection of drilling ahead with mud losses probability in drilling problem node (Fig. 186) leads to the optimum recommendation detailed in Fig.187.

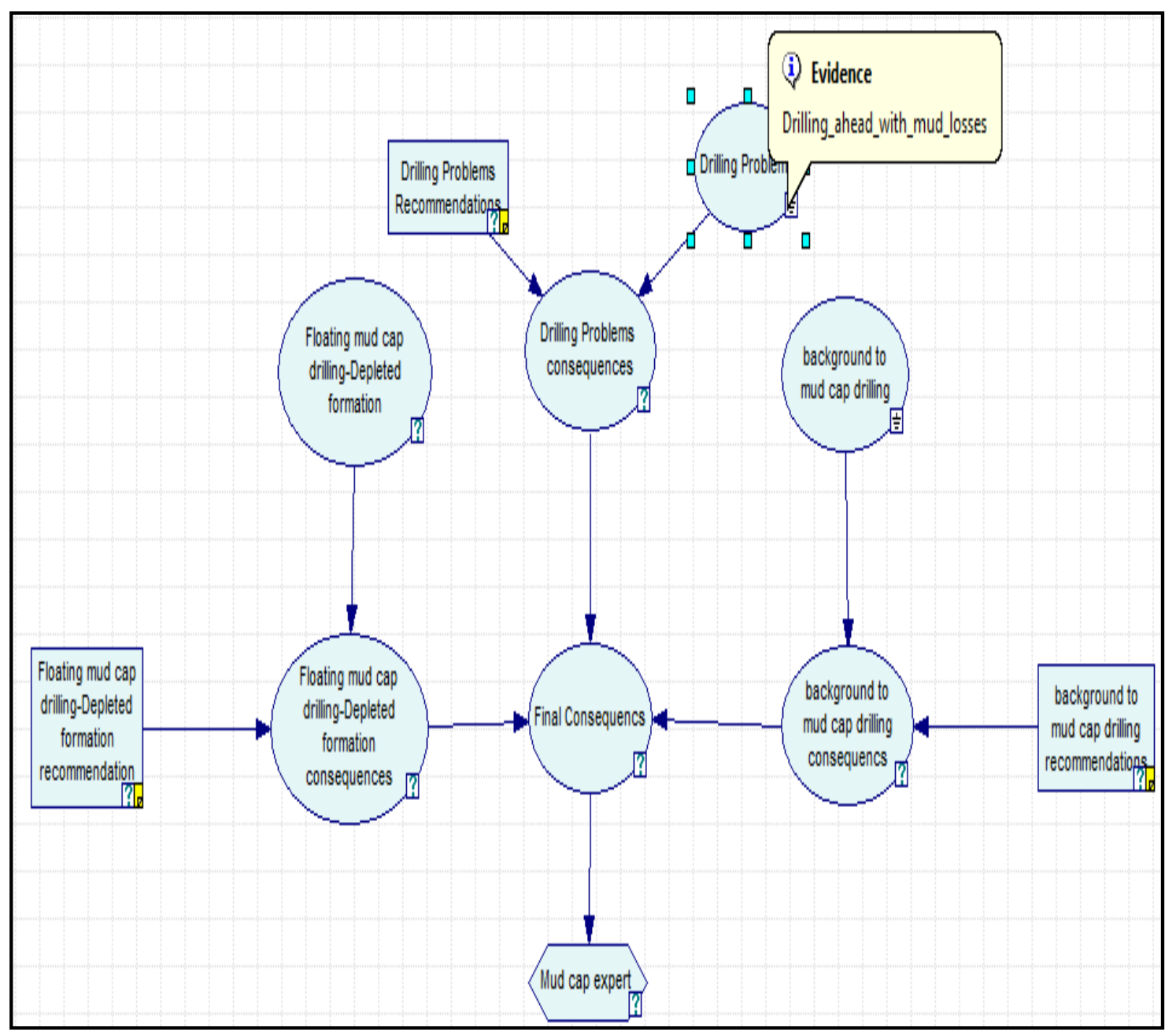

Fig.186: Selection of drilling ahead with mud losses 


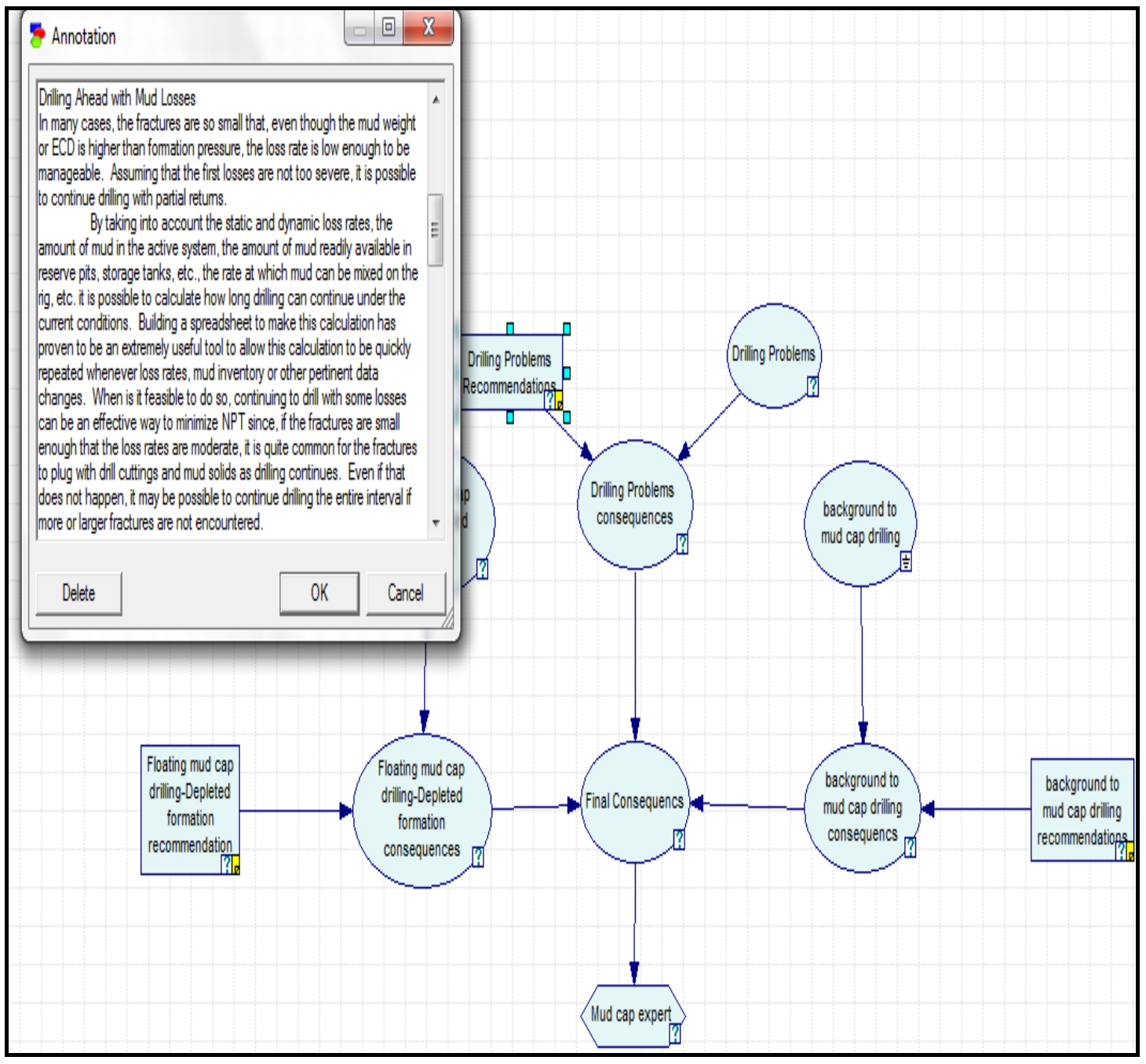

Fig.187: Recommendation for drilling ahead with mud losses

Selection of water sensitive formation exposed probability (Fig. 188) leads to the optimum recommendation detailed in Fig.189. 


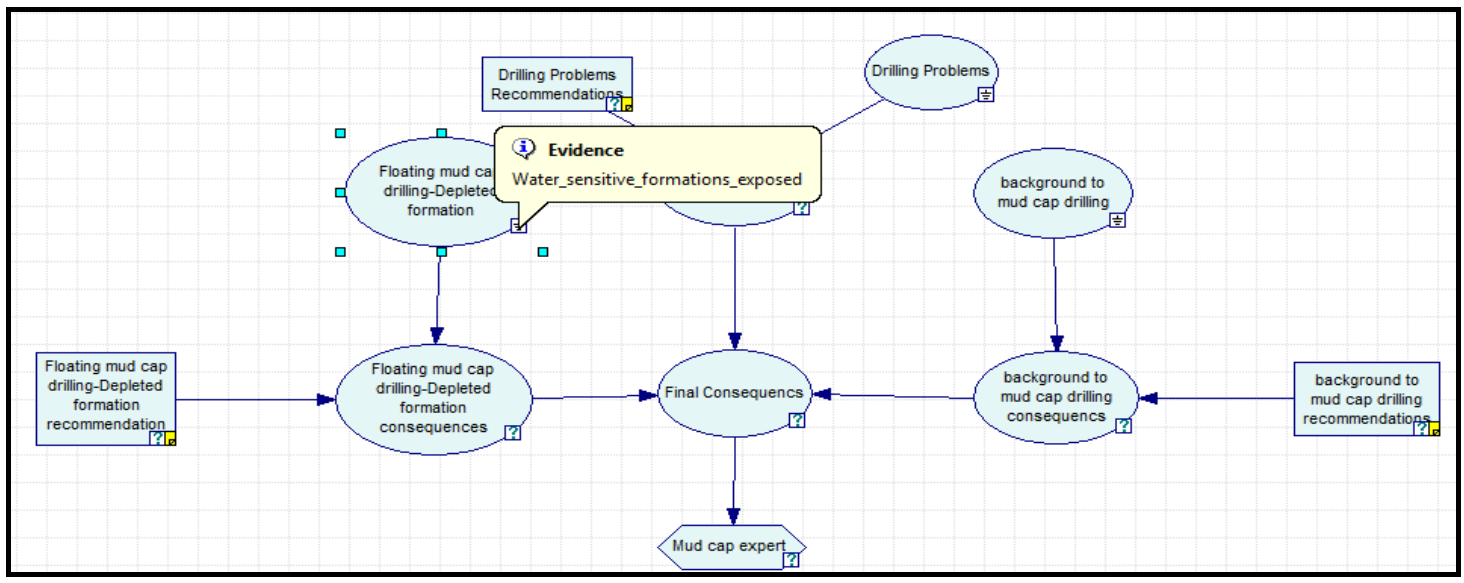

Fig.188: Selection of water sensitive formation exposed while floating mud cap drilling depleted reservoirs

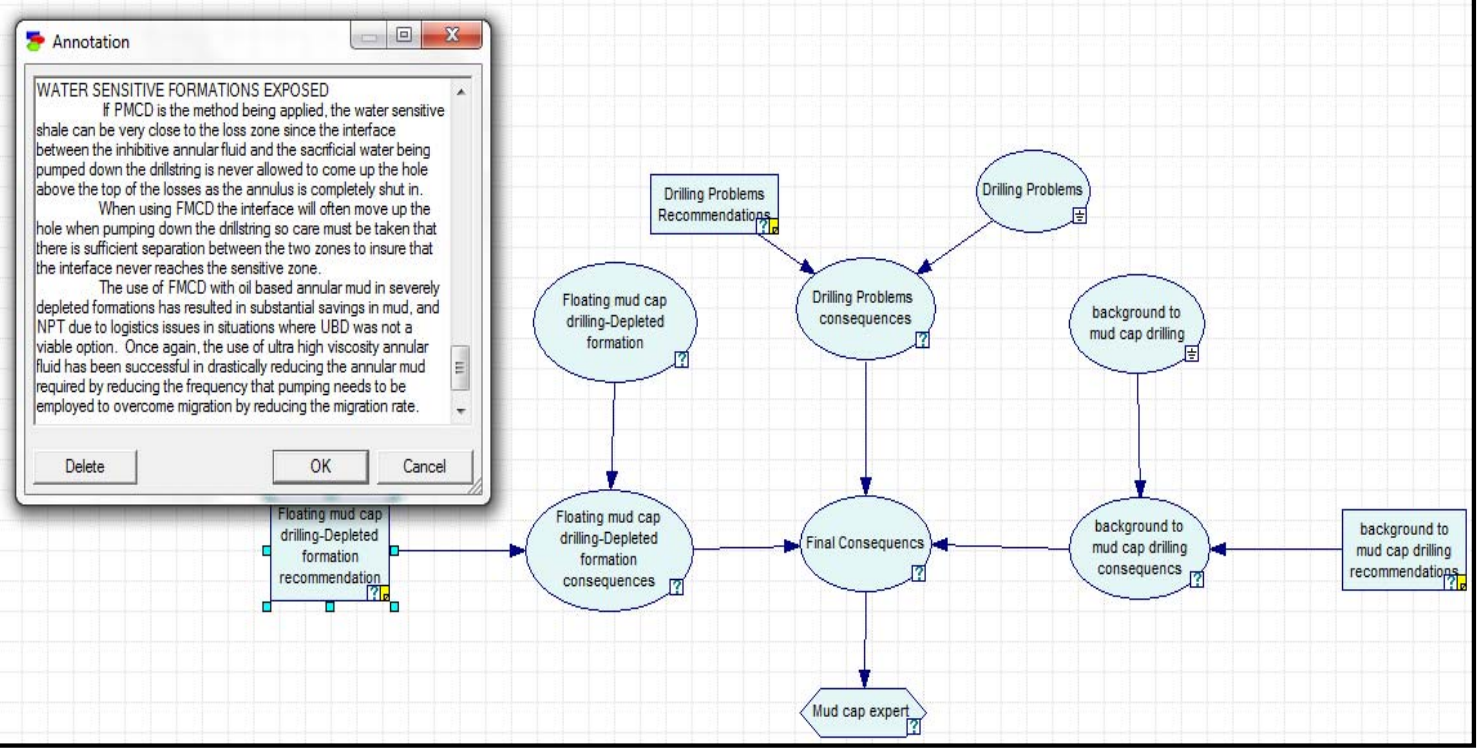

Fig.189: Recommendation for water sensitive formation exposed while floating mud cap drilling depleted reservoirs 


\subsubsection{Underbalanced liner drilling model}

Selection of the bit probability in basic planning node (Fig. 190) leads to the optimum recommendation detailed in Fig.191.

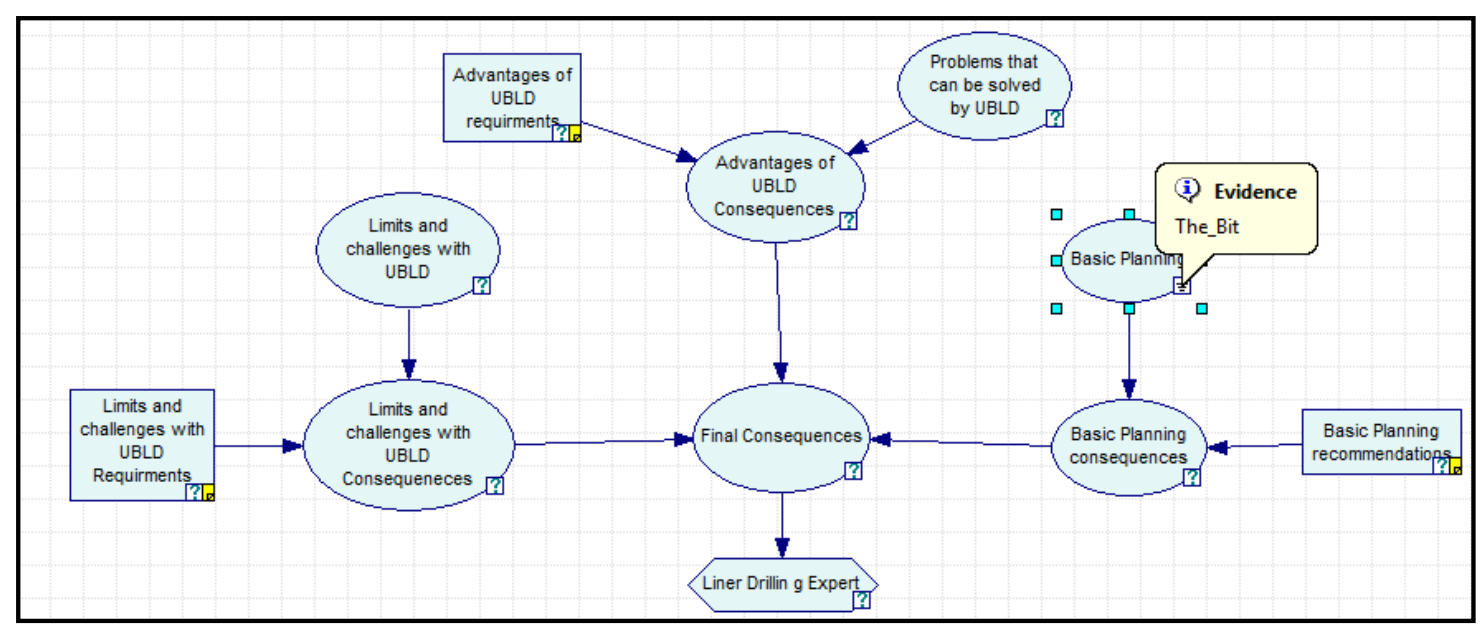

Fig.190: Selection of basic planning of the bit 


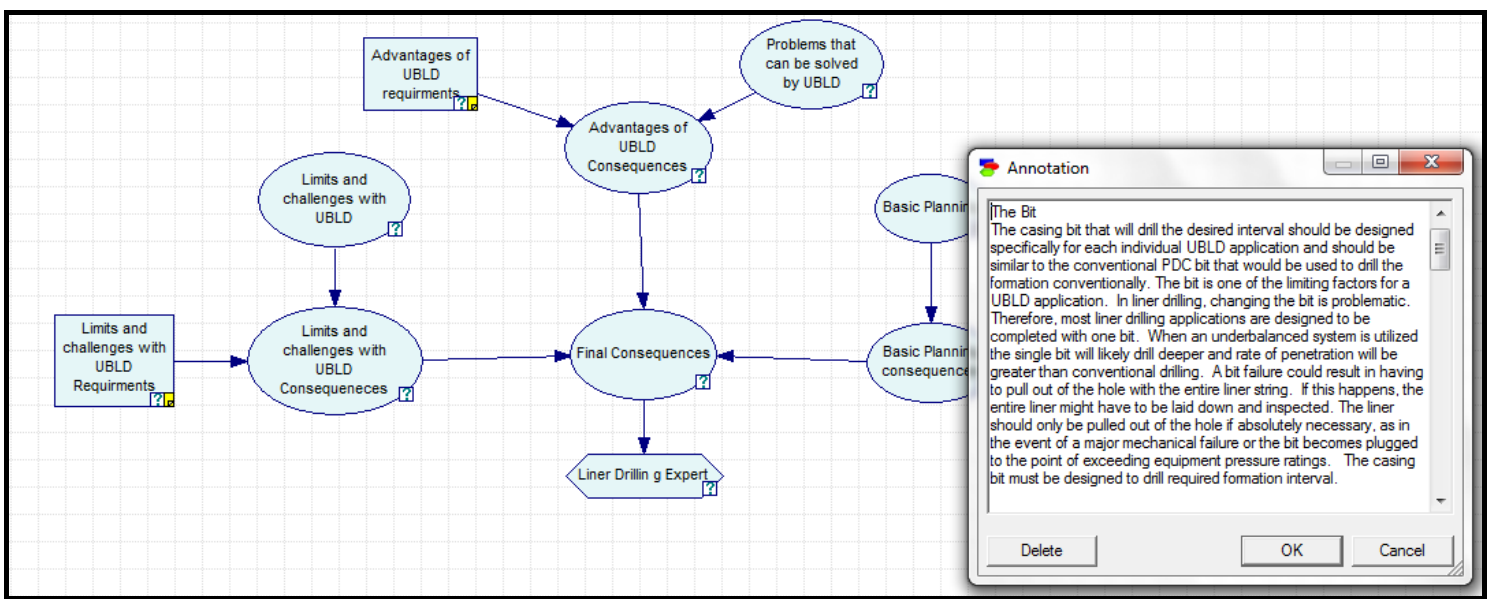

Fig.191: Recommendation for the bit used in UBLD

Selection of wellbore ballooning probability (Fig. 192) leads to the optimum recommendation detailed in Fig.193.

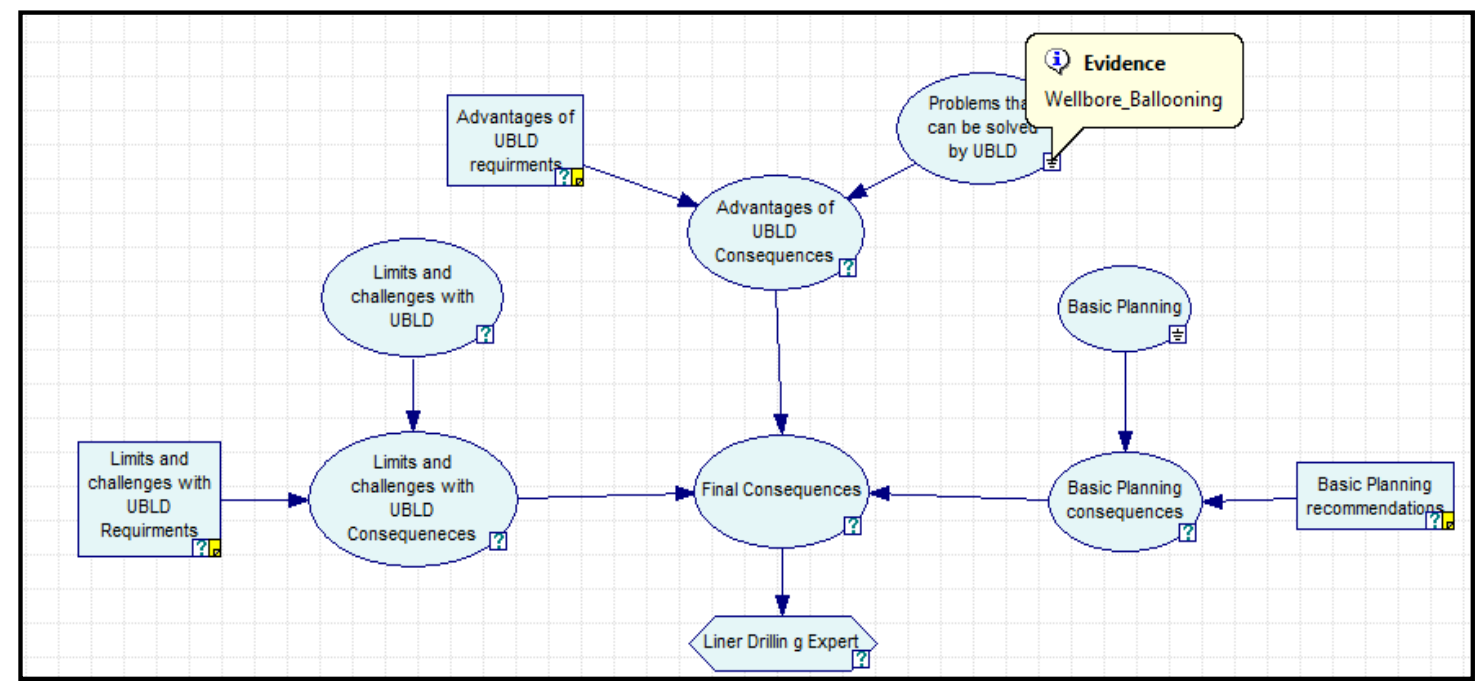

Fig.192: Selection of the potential problem (hole ballooning) 


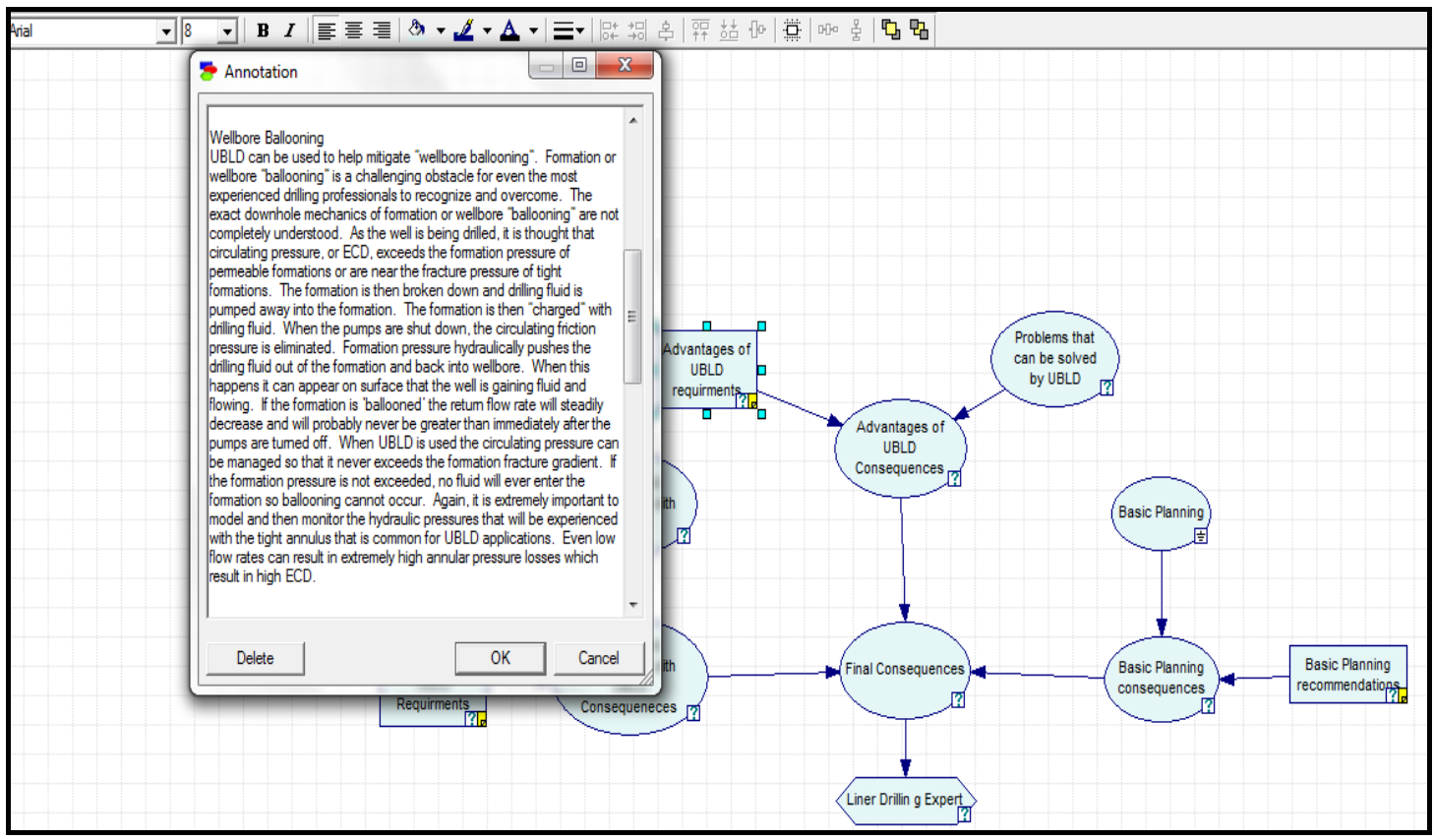

Fig.193: Showing how UBLD can solve the potential problem (hole ballooning)

Selection of liner hanger challenge probability (Fig. 194) leads to the optimum recommendation detailed in Fig.195. 


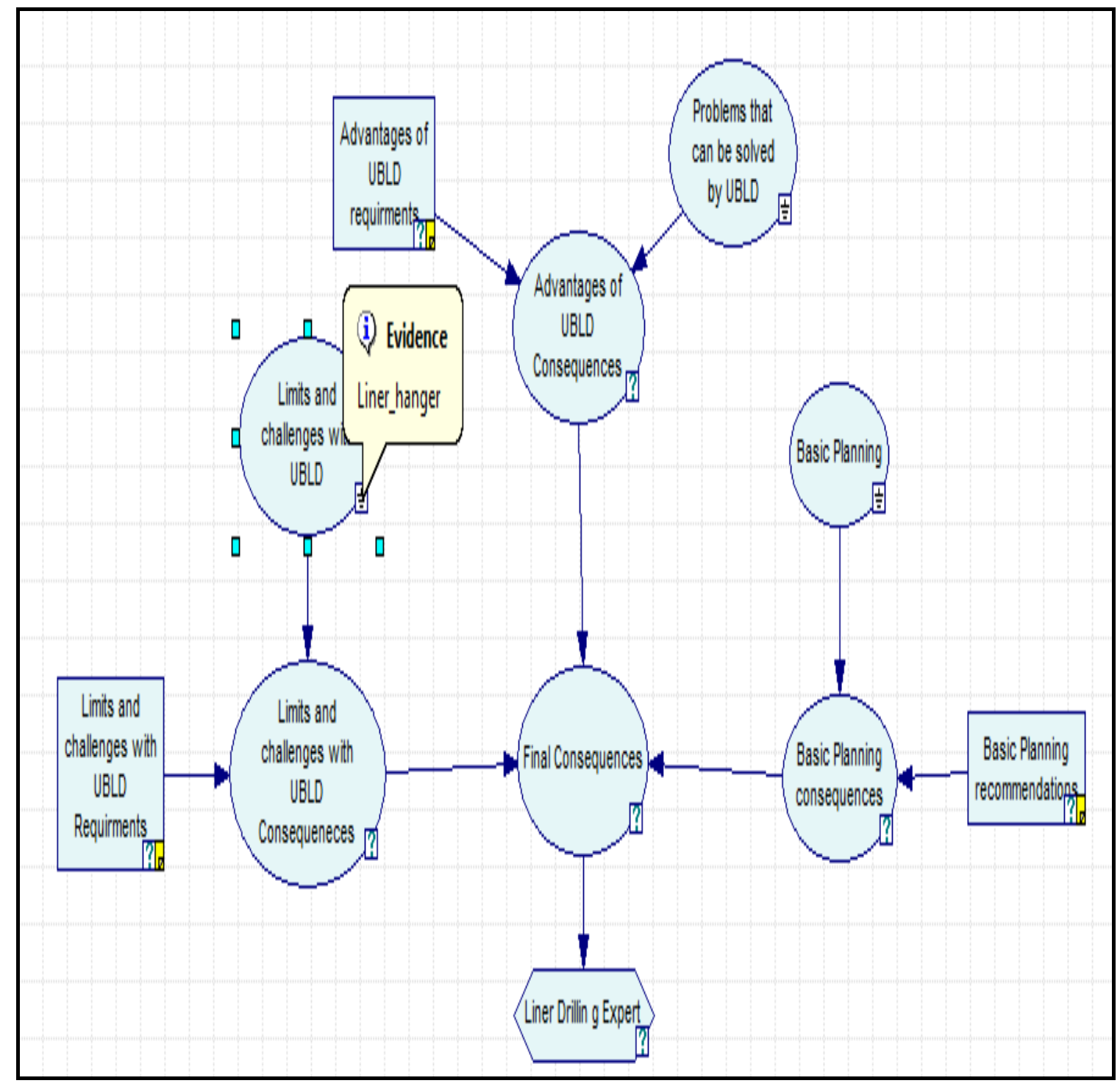

Fig.194: Selecting liner hanger as a challenge for UBLD 


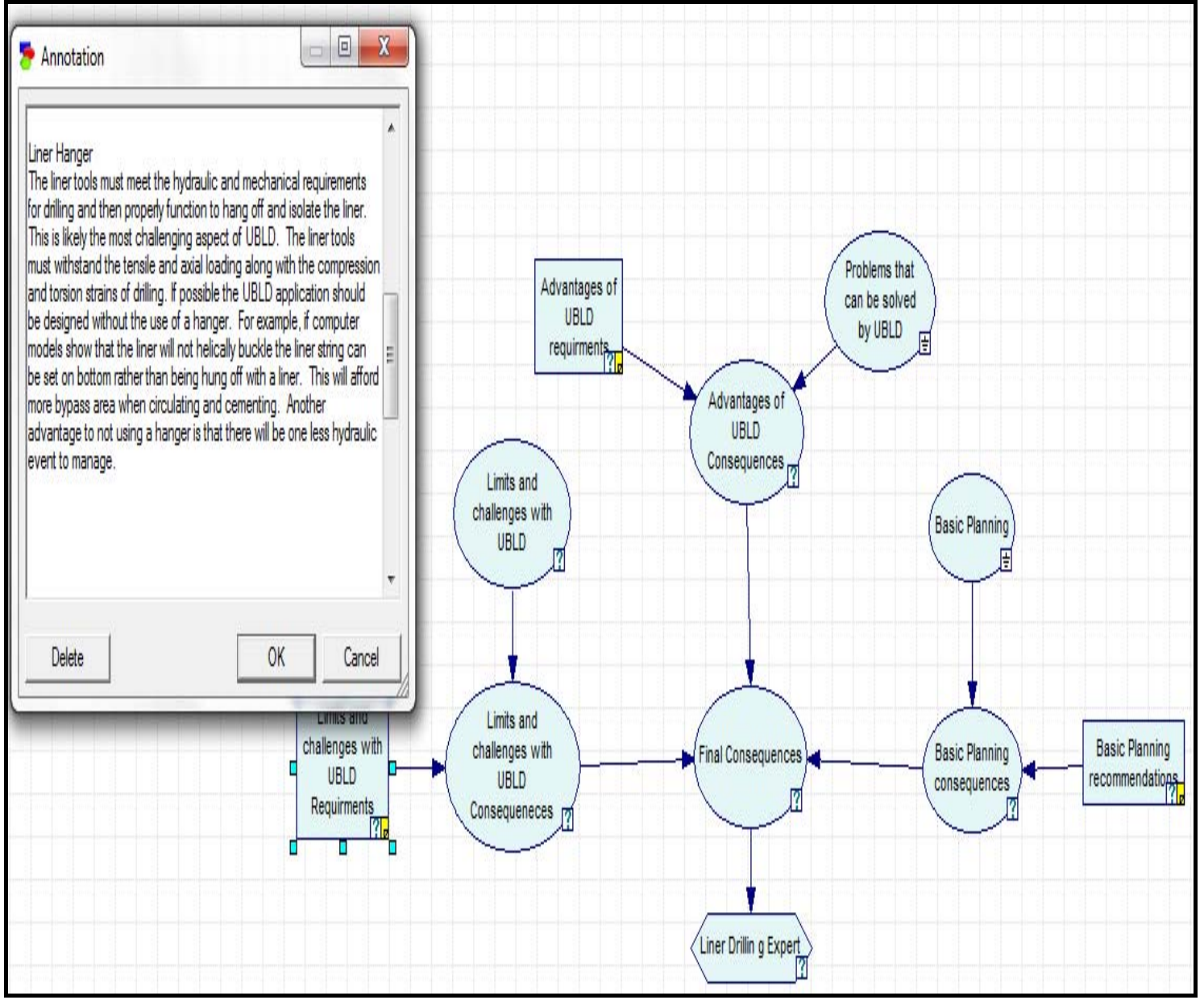

Fig.195: Recommendation for the liner hanger in UBLD

Selection of drilling fluid considerations probability (Fig. 196) leads to the optimum recommendation detailed in Fig.197. 


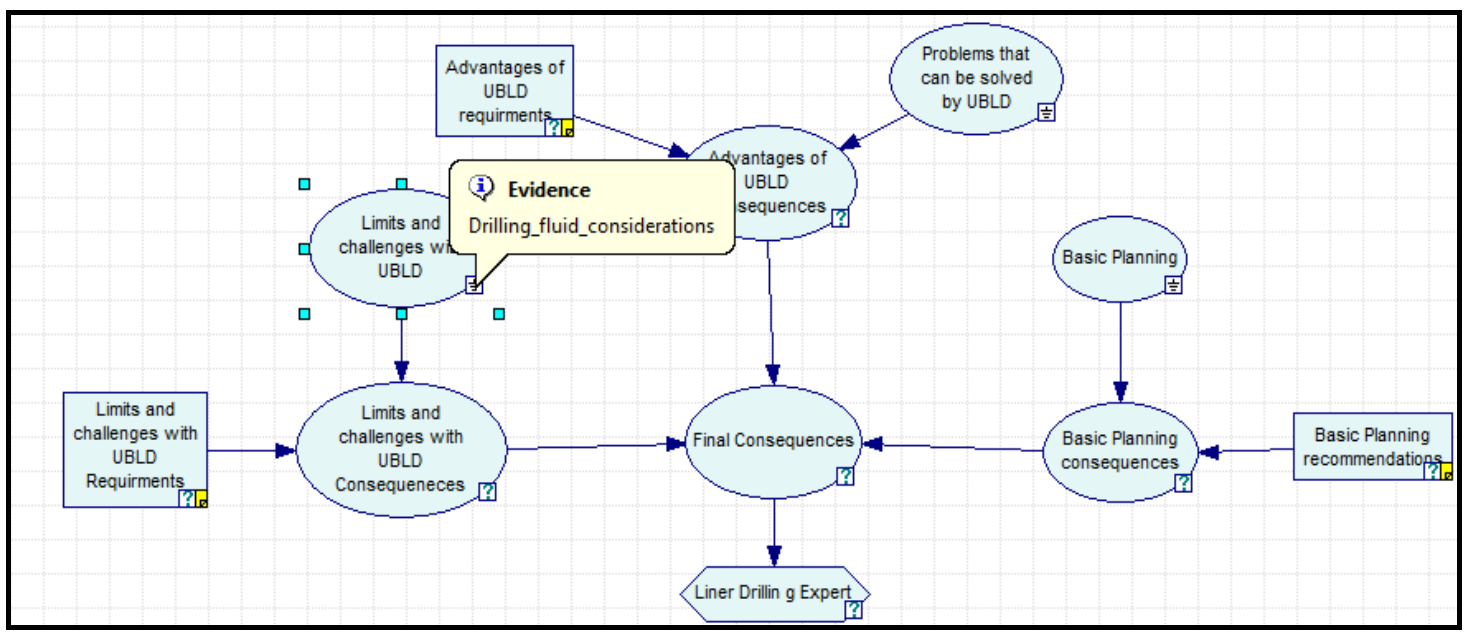

Fig.196: Selecting drilling fluids as a challenge for UBLD

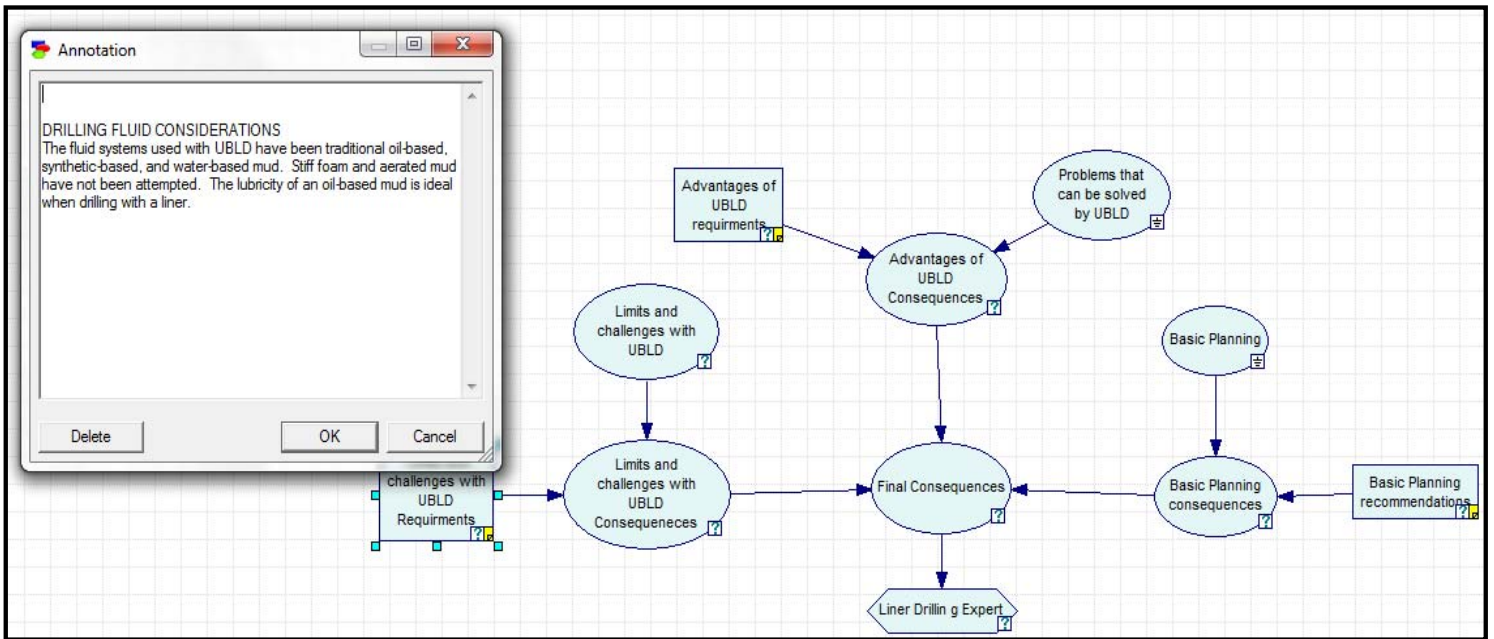

Fig.197: Recommendation for drilling fluids in UBLD 


\subsubsection{Underbalanced coil tube model}

Selection of pressure categories and BOP stack requirement probability (Fig. 198) leads to the optimum requirement detailed in Fig.199.

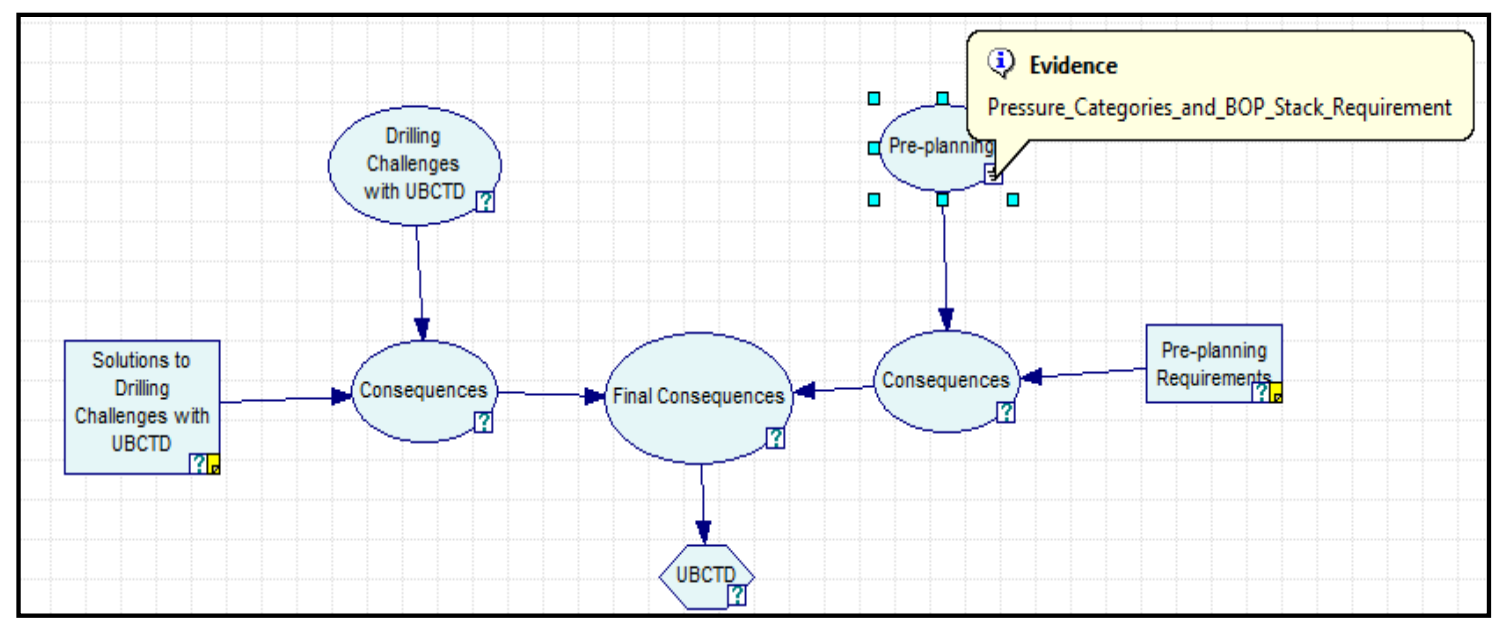

Fig.198: Selecting pre-planning option of BOP stack requirement 


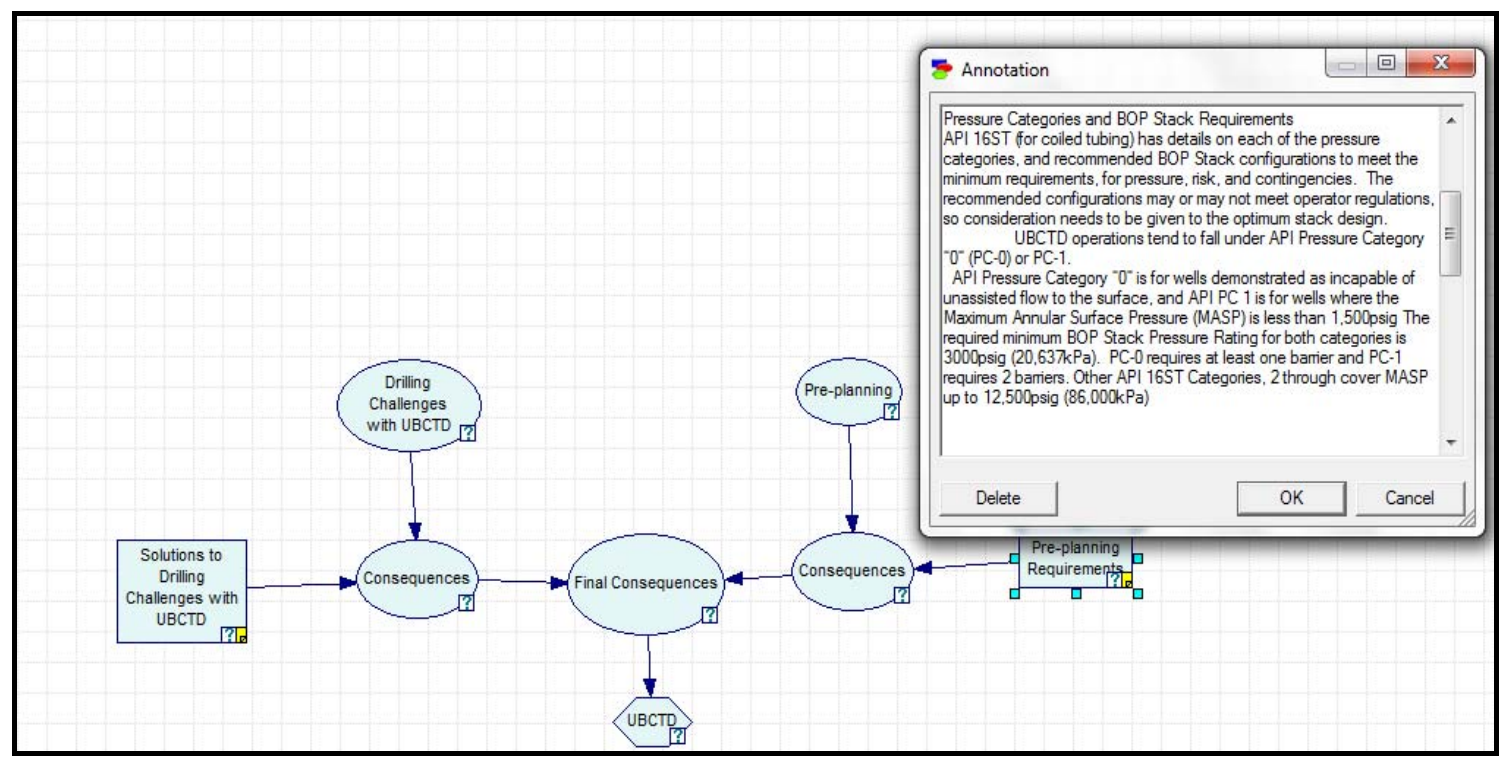

Fig.199: Recommendation of pre-planning option of BOP stack requirement

Selection of ROP reduction challenge probability (Fig. 200) leads to the optimum recommendation detailed in Fig.201.

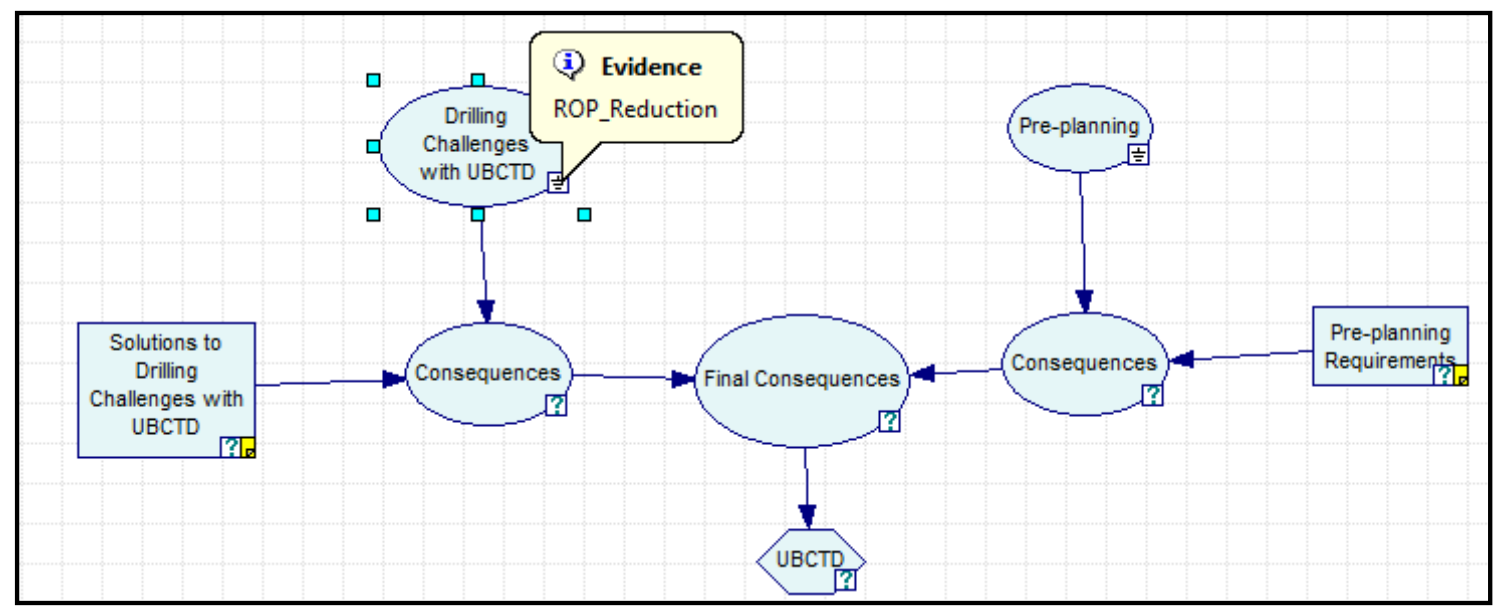

Fig.200: Selection of ROP reduction challenge in UBCTD 


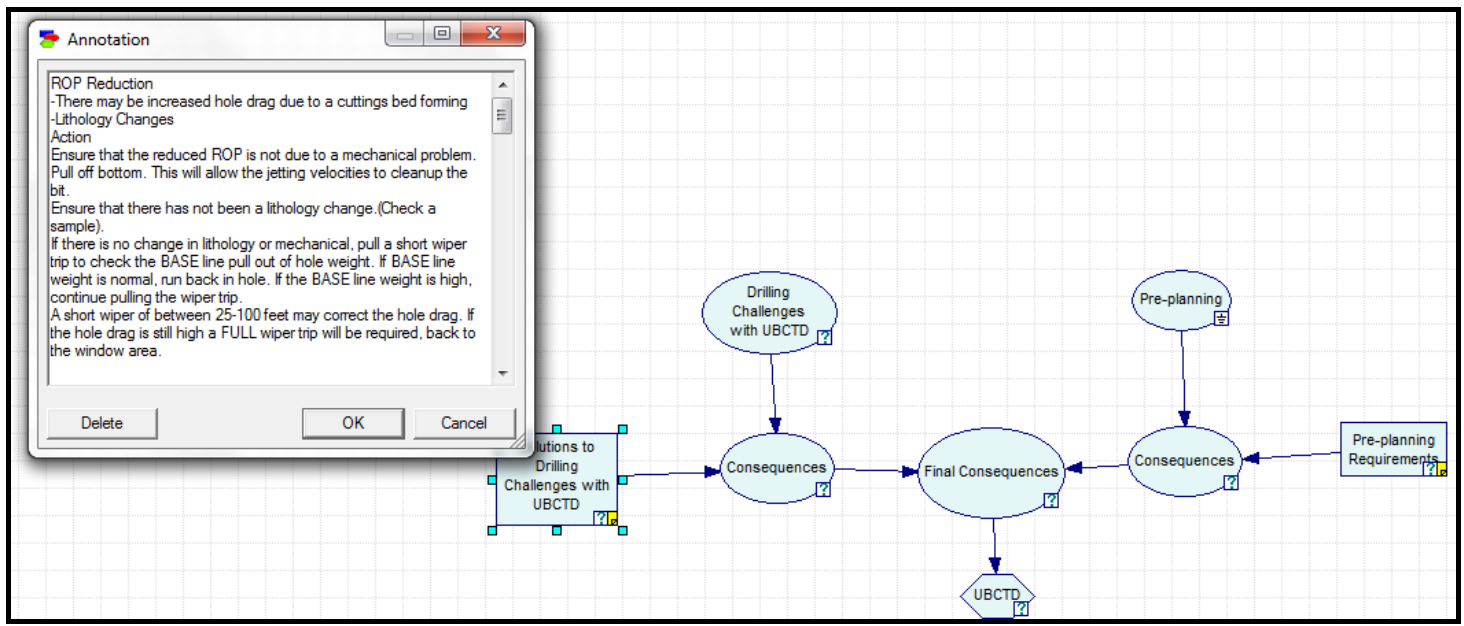

Fig.201: Recommendation for ROP reduction challenge in UBCTD

\subsubsection{Snubbing and stripping model}

Selection of stripping with annular preventer probability (Fig. 202) leads to the optimum recommendation detailed in Fig.203. 


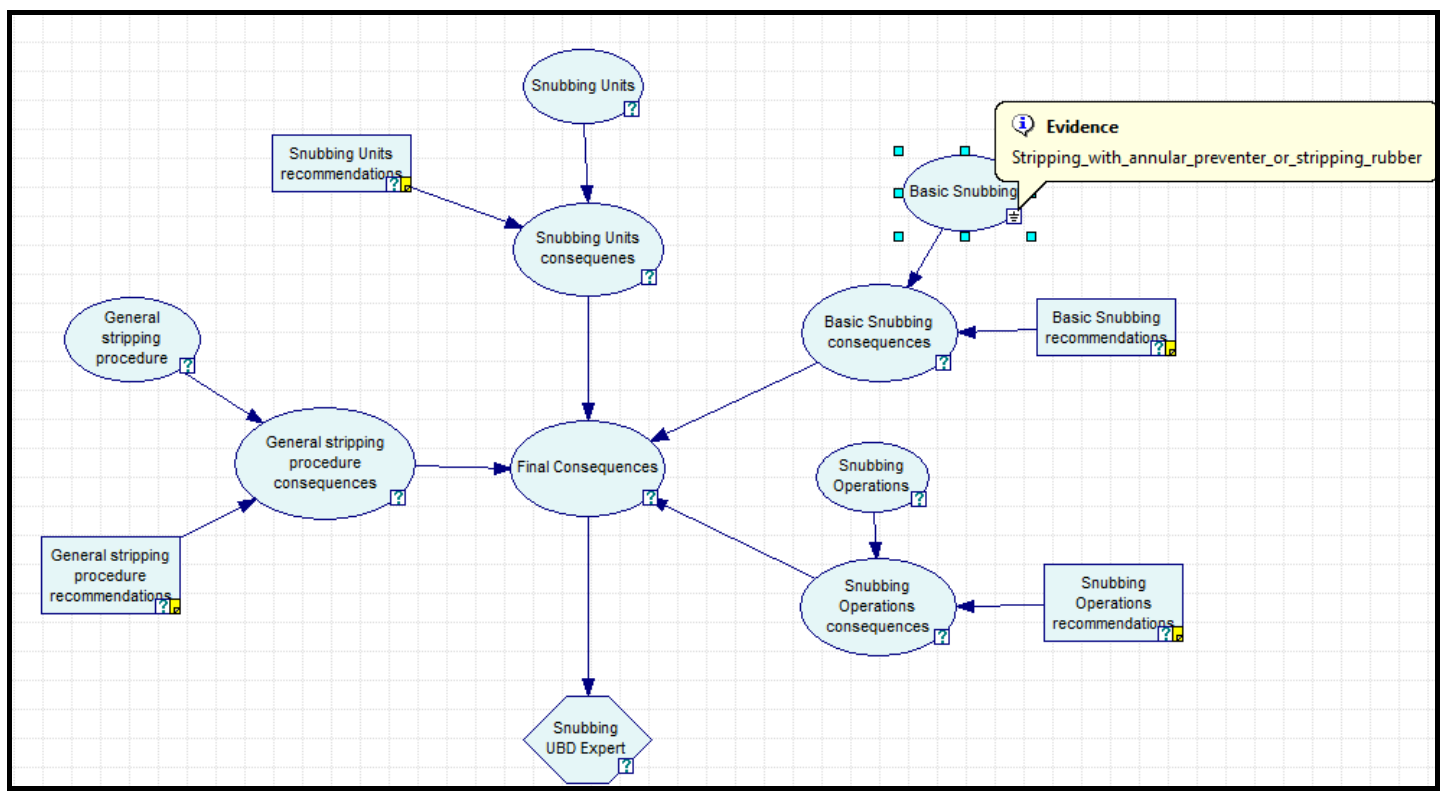

Fig.202: Selecting stripping with annular preventer or stripping rubber

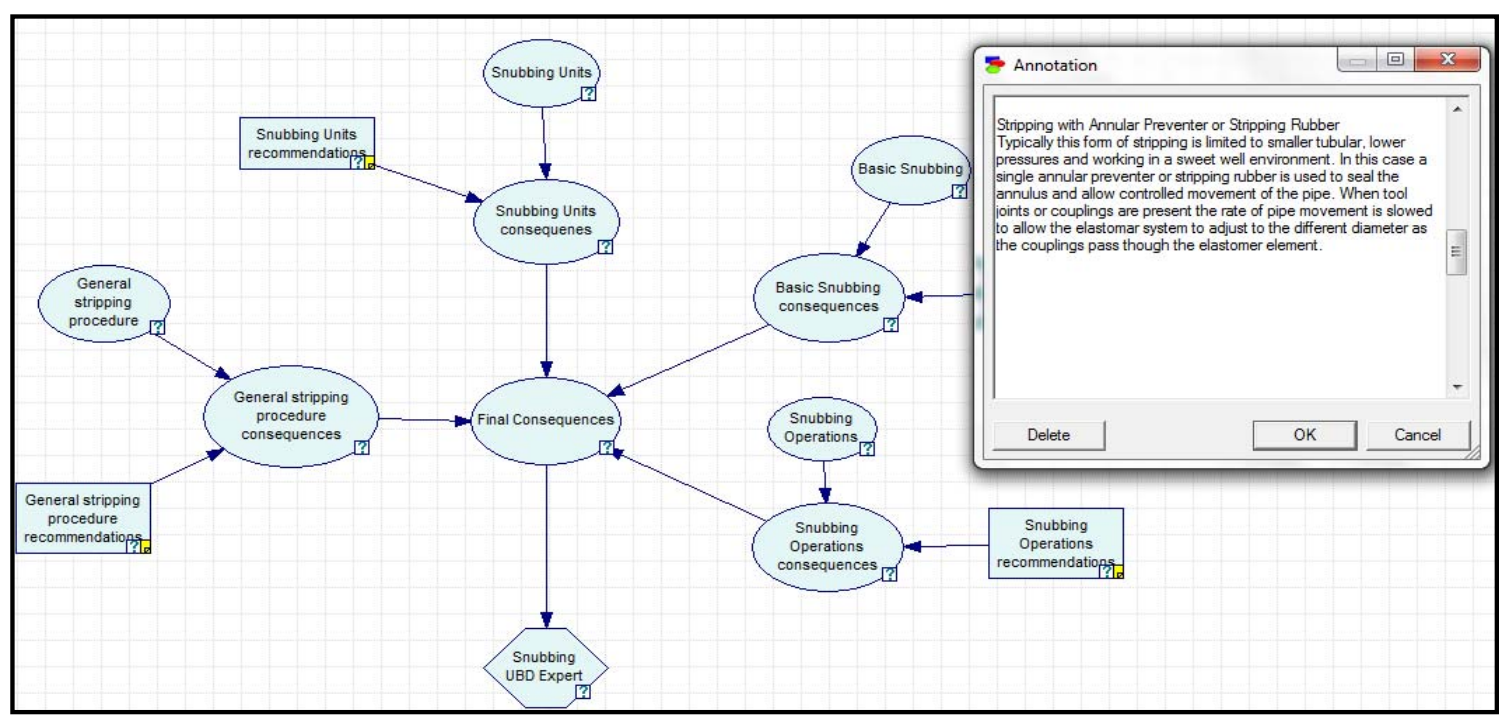

Fig.203: Recommendation for stripping with annular preventer or stripping rubber 
Selection of auxiliary equipment probability (Fig. 204) leads to the optimum recommendation detailed in Fig.205.

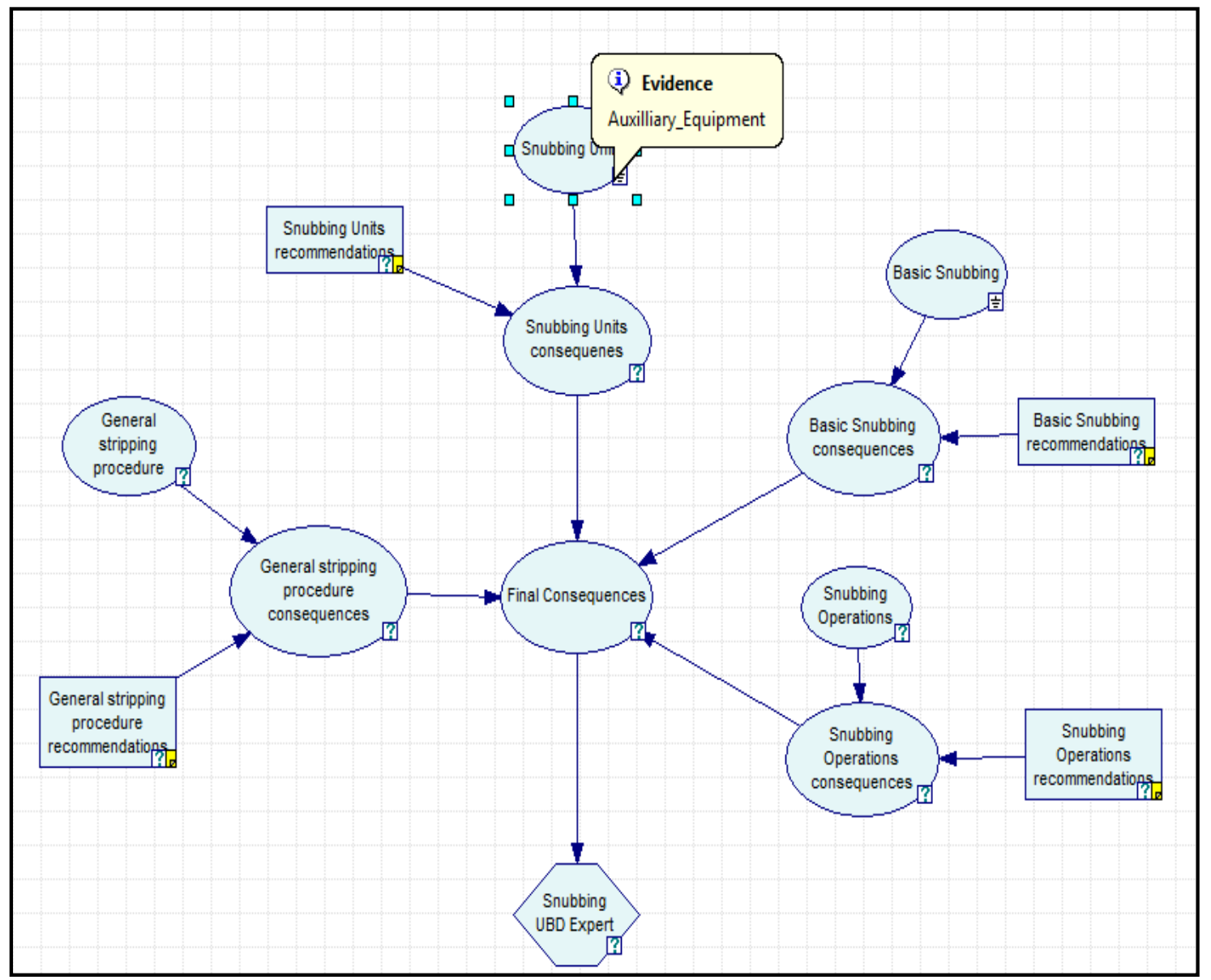

Fig.204: Selection of auxiliary equipment from snubbing unit options 


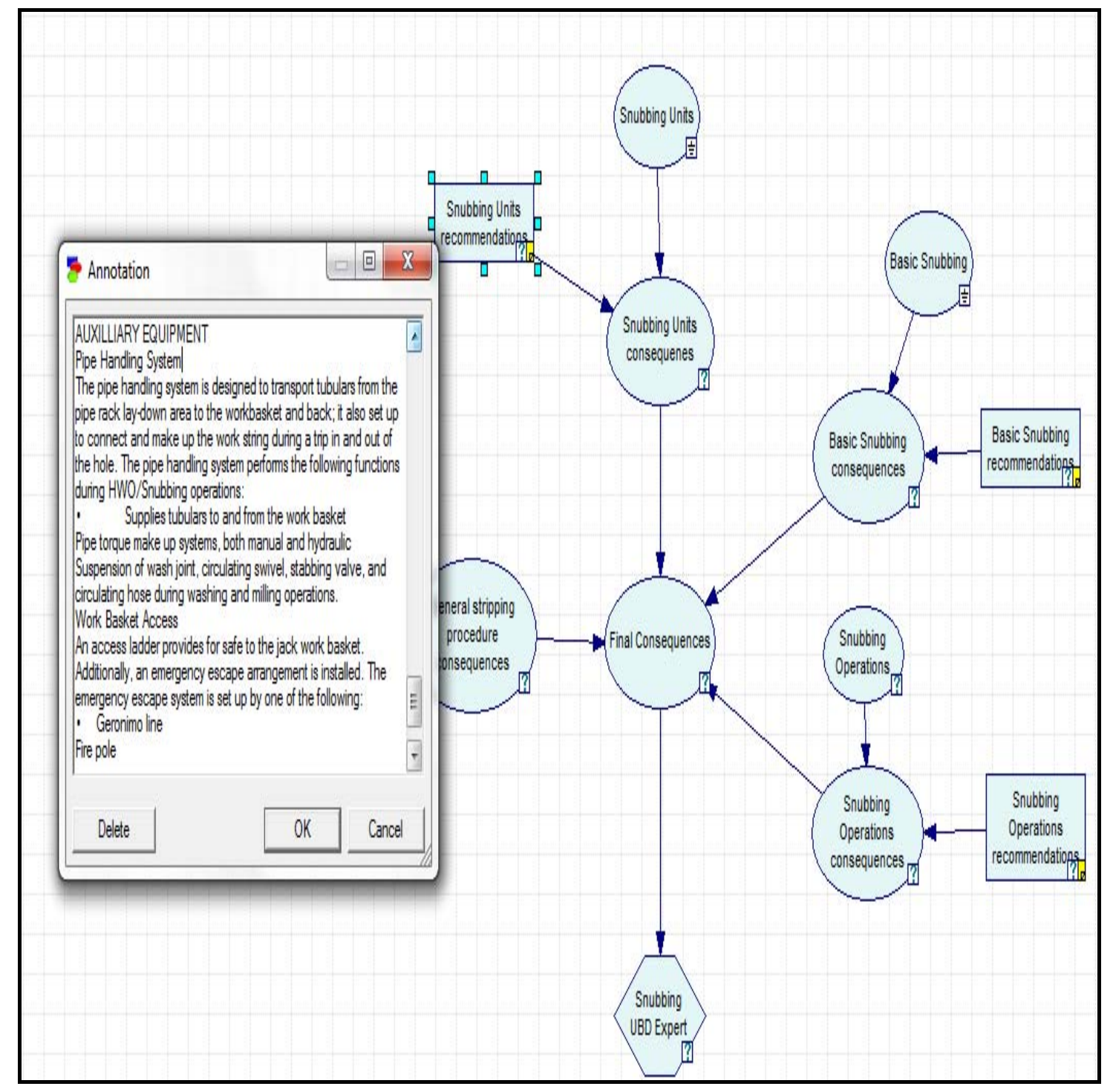

Fig.205: Recommendation for auxiliary equipment from snubbing unit options

Selection of ram to ram general stripping probability (Fig. 206) leads to the optimum recommendation detailed in Fig.207. 


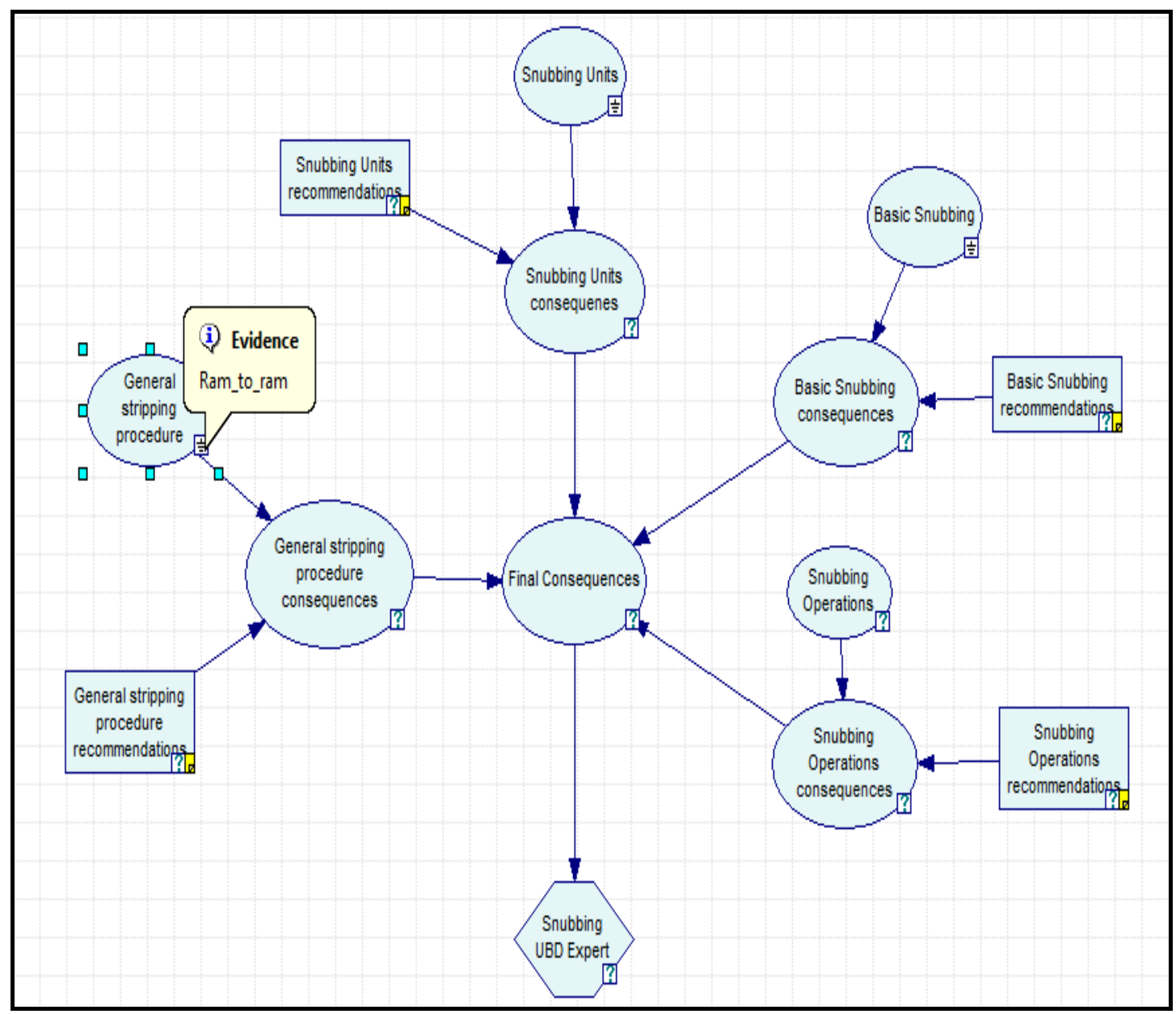

Fig.206: Selection of ram to ram stripping procedure 


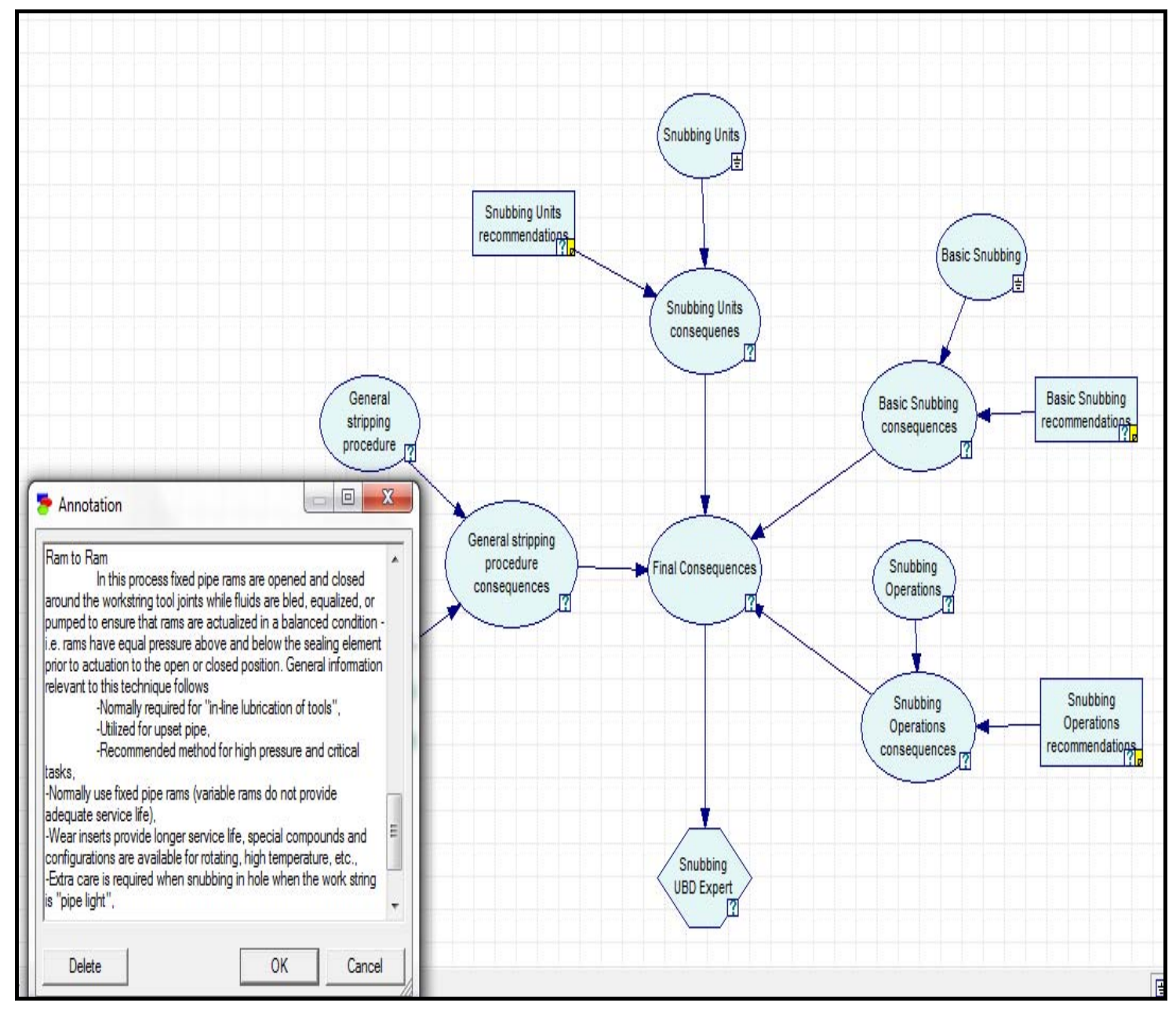

Fig.207: Recommendation for ram to ram stripping procedure

Selection of temporary securing of the well probability in the snubbing operations node (Fig. 208) leads to the optimum recommendation detailed in Fig.209. 


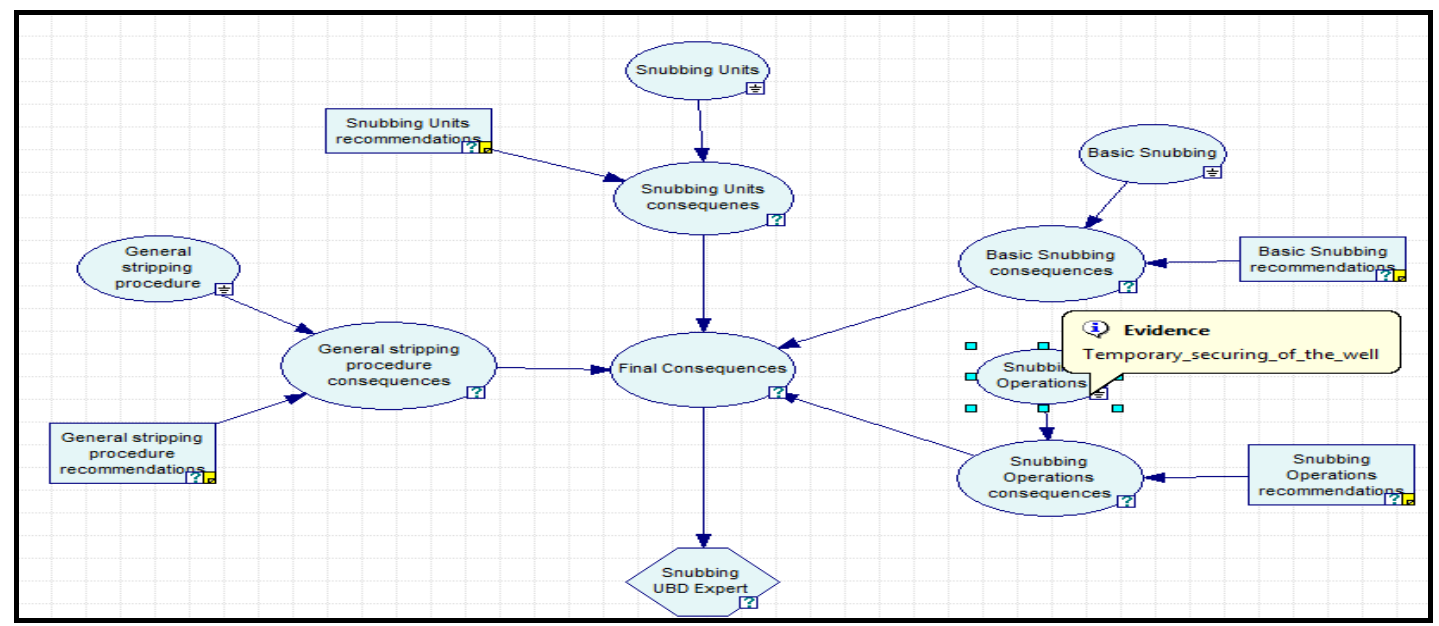

Fig.208: Selection of a snubbing operation (temporary securing of the well)

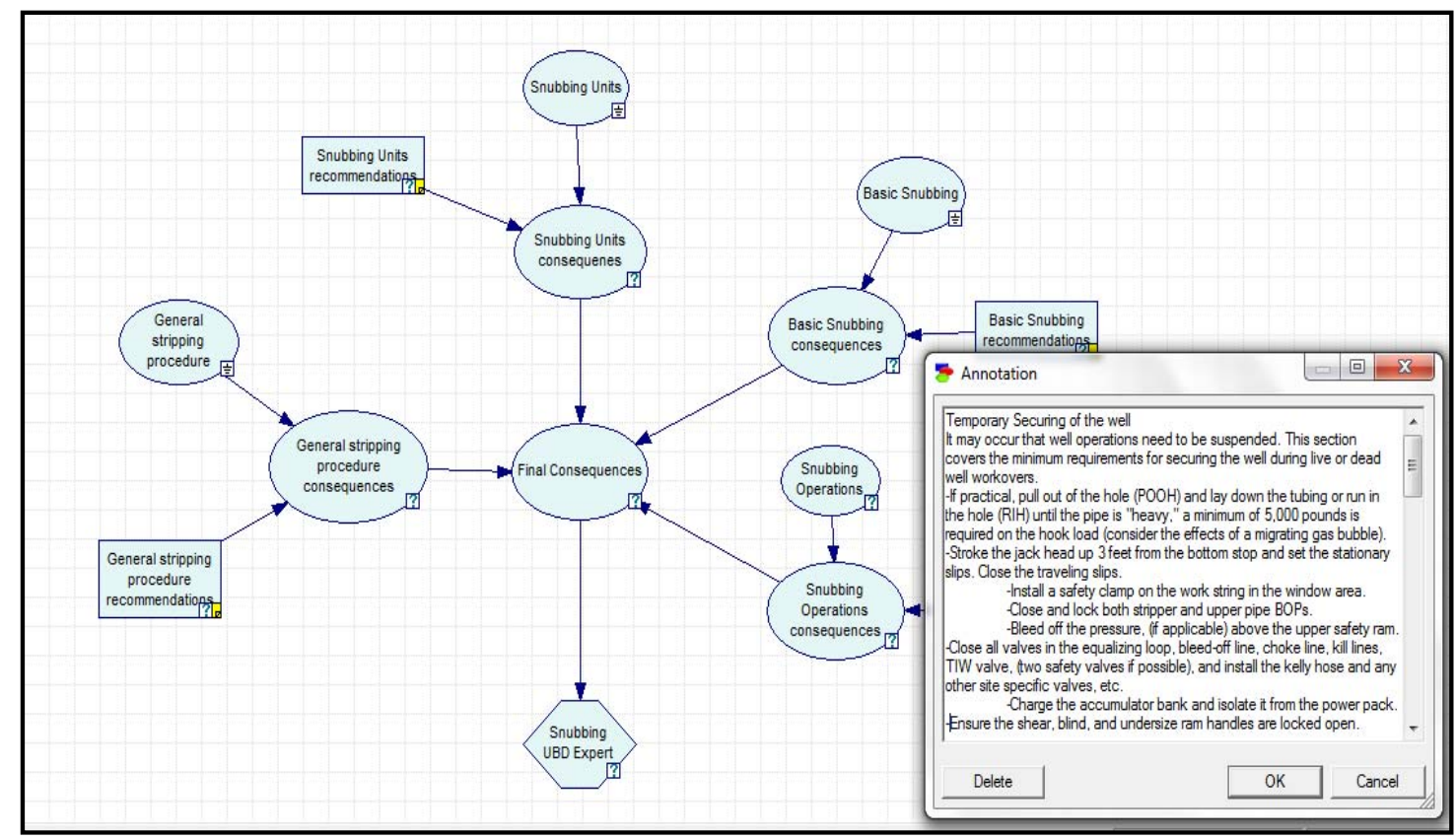

Fig.209: Recommendation for a snubbing operation (temporary securing of the well) 


\section{CHAPTER IX}

\section{CONCLUSIONS AND SUGGESTION FOR FUTURE WORK}

The Bayesian approach was found suitable for designing expert system based on the factors mentioned above. The model can work as a guide to aid drilling engineers and scientists to design and execute optimum drilling fluids. Using this approach to build up expert systems is more flexible than using flow charts. Updating flow charts is time consuming and might require redesigning them again to be used by different experts or in different fields. Using Bayesian Network allows us to update our industry practices by updating the probabilities states mentioned in this research. Bayesian Network was used to design models for well completion, drilling fluids, well control, cementing and underbalanced drilling.

Literature review and completion experts' opinions were used as evidence to build a model using the proposed Bayesian Network. Variable nodes allow the user to input desired well conditions that allows for generating the corresponding best completion practices. Eighteen uncertainty nodes are defined for this model to determine best practices in six decision nodes. The model is divided into six parts or decisions. Each decision has uncertainties and consequences nodes. 
The consequences node combines the uncertainty nodes where completion expert opinions were used to assign and define the conditional probability distribution. The model then calculates the optimum practices decision.

Literature review and drilling fluids experts' opinions were used as evidence to build the drilling fluid model. Variable nodes allow the user to input desired well conditions that allows for generating the corresponding best drilling fluids practices. Three uncertainty nodes are defined for this model to determine best practices in one decision node (recommended drilling fluids). The model has one decision which has uncertainties and one consequence node. The consequence node combines the uncertainty nodes where drilling fluids' expert opinions were used to assign and define the conditional probability distribution. The model then calculates the recommended drilling fluids decision.

The well control model is divided into three parts or decisions. Each decision has uncertainties and consequences nodes. The consequences node combines the uncertainty nodes where well control expert opinions were used to assign and define the conditional probability distribution. The model then calculates the optimum practices decision. The first part or decision provides the proposed circulation method decision based on the kick details provided. The second part provides the user about the optimum recommended practice based on the possible scenarios and operations in well control. The third part provides the user with a quick check list for trouble shooting in case of problems while controlling the well. 
The cementing model has six uncertainty nodes (well type, objectives, bottom hole static temperature, pumping time, drilling fluids, and consequences). This considers three decision criteria (recommended cementing formulations, recommended spacers formulations and recommended operational practices). The model is designed in a way to give the user options to design well cementing and best practices effectively. The user will select options that match his application from well type, bottom hole temperature or required pumping time, objective and drilling fluid. Then the model (cementing expert utility) will suggest optimum cement formulations, spacer formulations and operational practices that fit the given well conditions.

Underbalanced drilling expert system here is combined into nine models as

follow:

o General approach to underbalanced drilling

o Flow underbalanced drilling

o Gaseated underbalanced drilling

o Foam underbalanced drilling

o $\quad$ Air and gas underbalanced drilling

o Mud cap drilling

o Underbalanced Liner Drilling Model

o Underbalanced Coil tube Model

o Snubbing and Stripping Model

Uncertainty nodes are defined for each model to determine best practices decision nodes. The model is divided into several parts or decisions. Each decision has 
uncertainties and consequences nodes. The consequences node combines the uncertainty nodes where underbalanced drilling expert opinions were used to assign and define the conditional probability distribution. The model then calculates the optimum practices decision. Below are descriptions of the models.

The UBD General approach to underbalanced drilling model is divided into four parts of uncertainty and decision nodes. The first part describes the formation to be drilled underbalanced and the considerations required. The second part shows the planning phases' uncertainty and its corresponding recommendations. The third part shows the equipments requirement uncertainty node or options and its corresponding decision (equipment recommendations). The fourth part shows the operations planning probability and its corresponding decisions

The flow UBD model is divided into three parts (tripping, connection and flow drilling uncertainty and decision nodes). The gaseated UBD model is divided into four parts (selection method benefits and challenges, requirements for general limits of gas and fluid volume, operational concerns and challenges recommendations, and well kicks recommendations). The foam model is divided into two parts (challenges and technical limits with foam system and basic designs of foam systems). The air and gas model is divided into four parts. The first part is rotary and hammers drilling probabilities and recommendations. The second part is limits and challenges to gas drilling probabilities and recommendations. The third part is rig requirements and recommendations. The fourth part is gas drilling operations probabilities and recommendations. The mud cap model is divided into three parts. The first part is background to mud cap drilling 
probabilities and recommendations. The second part is drilling problems probabilities and recommendations. The third part is floating mud cap drilling in depleted formation probabilities and recommendations. The UBLD model is divided into three parts. The first part is basic planning probabilities and recommendations. The second part is drilling problems that can be solved and recommendations. The third part is limits and challenges probabilities and recommendations. The underbalanced coil tube model is divided into two parts. The first part is pre-planning probabilities and requirements. The second part is drilling challenges probabilities and solutions. The snubbing and stripping model is divided into four parts. The first part is basic snubbing probabilities and recommendations. The second part is snubbing units' probabilities and recommendations. The third part is general stripping procedure and recommendations. The fourth part is snubbing operations probabilities and its recommendations.

In case new practices or different experts' opinions are presented then all we need to do is simply change the states of probabilities. In case that the above model is missing other factors then we can also update the model and its corresponding states of probabilities. The flexibility of Bayesian Network in terms of updating the structure model and its beliefs makes this method the first systematic approach to build experts systems. This advisory system is intended to be a field guide for the drilling engineer or rig supervisor. 


\subsection{Suggestion for future work}

Future work can include designing a similar model using Bayesian Network for more drilling operations such as managed pressure drilling practices. In addition, it will be of interest to use the developed models in this research in the field for evaluation and updating. For example, the drilling fluids model and the cementing model were constructed using programs from Saudi Arabia. Programs from the USA can be used to expand the practices due to different conditions such as higher temperature or shale gas formation. 


\section{REFERENCES}

Abbaspour, K., Matta, V., Huggenberger, P., and Johnso, C.A. 2000. A Contaminated Site Investigation: Comparison of Information Gained from Geophysical Measurements and Hydro-geological Modeling. Contaminant Hydrology 40: 365380.

Al-Kinani, A., Nunez, G., Stundner, M., Zangi, G., Iskandar, O., Mata, T., Cottone, S., and Cavero, J. 2009. Selection of Infill Drilling Locations Using Customized Type Curves. Paper SPE 122186 presented at the SPE Latin American \& Caribbean Petroleum Engineering Conference, Cartagena, Columbia, 31 May- 3 June. http://dx.doi.org/10.2118/122186-MS.

Al-Yami, A.S., Al-Arfaj, M.K., Nasr-El-Din, H.A., Jennings, S., Khafaji, A., Al-Ariani, M., and Al-Humaidi, A. 2007. Development of New Retarder Systems to Mitigate Differential Cement Setting in Long Deep Liners. Paper SPE/IADC 107538 presented at the Middle East Drilling Technology Conference \& Exhibition, Cairo, Egypt, 22-24 October. http://dx.doi.org/10.2118/107538-MS.

Al-Yami, A.S., Nasr-El-Din, H.A., Al-Saleh, S.H., Al-Humaidi, A.S., Al-Arfaj, M.K., Awang, M.Z., and Al-Mohanna, K.S. 2008. Lab Investigation of Oil Swelling Elastomers for Smart Well. Paper OTC 19403 presented at the Offshore Technology Conference, Houston, Texas, 5-8 May. http://dx.doi.org/10.2118/19403-MS.

Al-Yami, A.S. and Nasr-El-Din, H.A. 2009. Completion Fluids Challenges in Maximum Reservoir Contact Wells. Paper SPE 121638 presented at the International 
Symposium on Oilfield Chemistry, Woodlands, Texas, USA, 20-22 April. http://dx.doi.org/10.2118/121638-MS.

Al-Yami, A.S., Nasr-El-Din, H.A., Al-Humaidi, A.S., Al-Arfaj, M.K., and Al-Saleh,

S.H. 2010a. Effect of $\mathrm{HCl}$ Acid and Brines on Water-Swelling Packers. SPE Drill \& Compl 25 (3): 322-327. SPE-114812-PA. http://dx.doi.org/10.2118/114812-PA.

Al-Yami, A.S., Schubert, J., Medina, C., and Ok-Youn, Y. 2010b. Drilling Expert System for the Optimal Design and Execution of Successful Cementing Practices. Paper IADC/SPE 135183 presented at the Asia Pacific Drilling Technology Conference and Exhibition, Ho Chi Minh City, Vietnam, 1-3 November. http://dx.doi.org/10.2118/135183-MS.

Al-Yami, A.S., Schubert, J., and Beck, G. 2011. Expert System for the Optimal Design and Execution of Successful Completion Practices Using Artificial Bayesian Intelligence. Paper SPE 143826 presented at the Brazil Offshore Conference and Exhibition, Macaé, Brazil, 14-17 June. http://dx.doi.org/10.2118/143826-MS.

Al-Yami, A.S. and Schubert, J. 2012a. Drilling Fluids Consultation System: Development and Field Applications. Paper SPE 152098 presented at the SPE Western North American Regional Meeting, Bakersfield, California, USA, 19-23 March. http://dx.doi.org/10.2118/152098-MS.

Al-Yami, A.S. and Schubert, J. 2012b. Underbalanced Drilling Expert System Development. Paper SPE 152101 presented at the SPE Western North American Regional Meeting, Bakersfield, California, USA, 19-23 March. http://dx.doi.org/10.2118/152101-MS. 
Al-Yami, A.S. and Schubert, J. 2012c. Development of Optimum Well Control Practices Using Artificial Bayesian Intelligence. Paper OTC 22882 presented at the Offshore Technology Conference, Houston, Texas, USA, 30 April-3 May. http://dx.doi.org/10.2118/22882-MS.

Al-Yami, A.S. and Schubert, J. 2012d. Guidelines for Optimum Underbalanced Drilling Practices Using Artificial Bayesian Intelligence. Paper OTC 22883 presented at the Offshore Technology Conference, Houston, Texas, USA, 30 April-3 May. http://dx.doi.org/10.2118/22883-MS.

Brinkhorst, J.W. 1994. Optimization of Drilling Fluid and Clean-Up Operations in Rogan South, Draugen Field, Norway. Presented at the Horizontal Well Technology Forum, Aberdeen, 24-25January.

Carpenter, P., Nicholas, E., and Henrie, M. 2006. Bayesian Belief Networks for Pipeline Leak Detection. Paper PSIG 0604 presented at the PSIG Annual Meeting, Williamsburg, Virginia, 11-13 October. http://dx.doi.org/10.2118/0604-MS.

Dashevskiy, D., Dubinsky, V., and Macpherson, J.D. 1999. Application of Neural Networks for Predictive Control in Drilling Dynamics. Paper SPE 56442 presented at the SPE Annual Technical Conference and Exhibition, Houston, USA, 3-6 October. http://dx.doi.org/10.2118/56442-MS.

Downs, J.D. 1992. Formate Brines: New Solutions to Deep Slim Hole Drilling Fluid Design Problems. Paper SPE 24973 presented at the European Petroleum Conference, Cannes, France, 16-18 November. http://dx.doi.org/10.2118/24973-MS. Ferraresi, M., Todini, E., and Vignoli, R. 1996. A Solution to the Inverse Problem in 
Groundwater Hydrology Based on Kalman Filtering. Journal of Hydrology 175: $567-$ 581. http://dx.doi.org/10.1016/S0022-1694(96)80025-4.

Fjellheim, R., Herbert, M., Arild, O., Bisio, R., and Holo, O. 2010. Collaboration and Decision Support in Geosteering. Paper SPE 128721 presented at the SPE Intelligent Energy Conference and Exhibition, Utrecht, The Netherlands, 23-25 March. http://dx.doi.org/10.2118/128721-MS.

Fink, J.K. 2002. Oil Field Chemicals. USA: Gulf Professional Publishing/Elsevier.

Garrouch, A.A. and Haitham, M.S. 2003. Using Fuzzy Logic for UBD Candidate Selection. Paper IADC/SPE 81644 presented at the IADC/SPE Underbalanced Technology Conference and Exhibition, Houston, Texas, U.S.A., 25-26 March. http://dx.doi.org/10.2118/81644-MS.

Garrouch, A.A., Lababidi, H., and Abdullah, S. 2004. A Fuzzy Expert System for the Completion of Multilateral Wells. Paper IADC/SPE 87963 presented at the IADC/SPE Asia Pacific Drilling Technology Conference and Exhibition, Kuala Lumpur, Malaysia, 13-15 September. http://dx.doi.org/10.2118/87963-MS.

Gelman, A., Carlin, J.B., Stern H.S. et al. 2003. Bayesian Data Analysis, second edition. London. Chapman and Hall.

Ghabayen, S., McKee, M., and Kemblowski, M. 2006. Ionic and Isotopic Ratios for Identification of Salinity Sources and Missing Data in the Gaza Aquifer. Journal of Hydrology 318: 360-373. http://dx.doi.org/10.1016/j.jhydrol.2005.06.041.

Giese, M. and Bratvold, R.B. 2010. Probabilistic Modeling for Decision Support in Integrated Operation. Paper SPE 127761 presented at the SPE Intelligent Energy 
Conference and Exhibition, Utrecht, The Netherlands, 23-25 March. http://dx.doi.org/10.2118/127761-MS.

Giese, M. and Bratvold, R. 2011. Probabilistic Modeling for Decision Support in Integrated Operations. SPE Economics and Management 3 (3): 173-185. SPE127761-PA. http://dx.doi.org/10.2118/127761-PA.

Good, I. J. 1961a. A Causal Calculus (I). The British Journal for the Philosophy of Science 11 (44): 305-318.

Good, I. J. 1961b. A Causal Calculus (II). The British Journal for the Philosophy of Science 12 (45): 43-51.

GRØTTHEIM. O.E. 2005. Development and Assessment of Electronic Manual for Well Control and Blowout Containment. MS Thesis, Texas A\&M University, College Station, Texas (August 2005).

Hayes-Roth, F. 1987. Expert Systems Applied to the Petroleum Industry Upstream Portion. Paper SPE 22411 presented at the 12th World Petroleum Congress, Houston, USA, 26 April - 1 May. http://dx.doi.org/10.2118/22411-MS.

Hill, A.D., Zhu, D., and Economides, M.J. 2008. Multilateral Wells, 35-50. Richardson, Texas, SPE.

Howard, R.A. and Matheson, J.E. 1981. Influence Diagrams. The Principles and Applications 2: 719-762.

Jonathan B. 2009. Well Completion Design. Amsterdam, The Netherlands: Elsevier.

Kim, J.H. and Pearl, J. 1983. A Computational Model for Combined Causal and Diagnostic Reasoning in Inference Systems. IJCAI83: 190-193. 
Korb, K.B. and Nicholson, A.E. 2004. Bayesian Artificial Intelligence. London: Chapman and Hall.

Kravis, S., Irrgang, R., Phatak, A., Martins, A., and Nakagawa, E. 2002. Drilling Parameter Selection for Well Quality Enhancement in Deepwater Environments. Paper SPE 77358 presented at the SPE Annual Technical Conference and Exhibition, San Antonio, Texas, 29 September-2 October. http://dx.doi.org/10.2118/77358-MS.

Kulakofsky, D.S., Wu, F-L., Onan, D.D., and Wohleb, J.B. 1993. Development and Application of a Knowledge-Based Expert System for Cement-Slurry Design. SPE Comp App 5 (1): 21-25. SPE- 24417-PA. http://dx.doi.org/10.2118/24417-PA.

Lauritzen, S. L., and Spiegelhalter, D.J. 1988. Local Computations with Probabilities on Graphical Structure and Their Application to Expert Systems. Journal of the Royal Statistical Society Series B Methodological 50 (2): 157-224. ISBN: 1558601252.

Lee, C.-J. and Lee, K.J. 2005. Application of Bayesian network to the probabilistic risk assessment of nuclear waste disposal. Reliability Engineering \& System Safety 91(5): $515-532$.

Lloyd, G.M., Bode, D.J., Nickens, H.V., and Varnado, S.G. 1990. Practical Applications of Real-Time Expert Systems for Automatic Well Control. Paper SPE 19919 presented at the IADC/SPE Drilling Conference, Houston, Texas, USA, 27 February - 2 March. http://dx.doi.org/10.2118/19919-MS.

McCaskill, J. and Bradford, W. 1972. Drilling Fluid System for Deep Drilling-An Interrelated Approach. Paper SPE 3912 presented at the Deep Drilling Symposium, Amarillo, Texas, 11-12 September. http://dx.doi.org/10.2118/3912-MS. 
Pandey, V.J. and Osisanya, S.O. 2001. Development of an Expert System for Solids Control in Drilling Fluids. J. Cdn. Pet. Tech. 40 (9): 50-59. http://dx.doi.org/10.2118/01-09-05.

Pearl, J. 1988. Probabilistic Reasoning in Intelligent Systems: Networks of Plausible Inference. San Francisco, California: Morgan Kaufmann Publishers.Inc.

Rajaieyamchee, M.A. and Bratvold, R.B. 2009. Real Time Decision Support in Drilling Operations Using Bayesian Decision Networks. Paper SPE 124247 presented at the SPE Annual Technical Conference and Exhibition, New Orleans, Louisiana, USA, 47 October. http://dx.doi.org/10.2118/124247 -MS.

Rajaieyamchee, M.A. and Bratvold, R.B. 2010. A Decision Analytic Framework for Autonomous Geosteering. Paper SPE 135416 presented at the SPE Annual Technical Conference and Exhibition, Florence, Italy, 19-22 September. http://dx.doi.org/10.2118/135416 -MS.

Rasheva, S. and Bratvold, R.B. 2011. A New and Improved Approach for Geological Dependency Evaluation for Multiple-Prospect Exploration. Paper SPE 147062 presented at the Annual Technical Conference and Exhibition, Denver, Colorado, USA, 30 October -2 November. http://dx.doi.org/10.2118/147062 -MS.

Rehm, B., Hebert, R., and Hebert, J. 1975. Practical Pressure Control. Tulsa, Oklahoma: PennWell Publishing Company.

Roland, H., Suvaluck Ratanavani, C., Sevaphol le, M., Jonathan, N., Rossawan, C., Chawiwan, J., Siriwat, V., and Sawatdiwong, S. 2011. Water Production Surveillance Workflow Using Neural Network and Bayesian Network Technology: 
A Case Study for Bangkok North Field, Thailand. Paper IPTC 15015 presented at the International Petroleum Technology Conference, Bangkok, Thailand, 7-9 February. http://dx.doi.org/10.2118/15015 -MS.

Samuel, M., Marcinew, R., Al-Harbi, M., Samuel, E., Xiao, Z., Ezzat, A.M., Khamees, S.A., Jarrett, C., Ginest, N.H., Bartko, K., Hembling, D., and Nasr-El-Din, H.A. 2003. A New Solids-Free Non-Damaging High Temperature Lost-Circulation Pill: Development and First Field Applications. Paper SPE 81494 presented at the Middle East Oil Technical Conference \& Exhibition, Bahrain, 5-8 April. http://dx.doi.org/10.2118/81494 -MS.

Sauer, C.W. and Landrum, W.R. 1985.Cementing-A Systematic Approach. JPT 37 (12): 2184-2196. SPE 11981-PA. http://dx.doi.org/10.2118/11981-PA.

Shadravan, A., Amani, M., Molinari, D., Politecnico, D.T., and Hugall, N.J. 2010. Methods and Benefits of Knowledge Sharing in the Petroleum Industry. Paper SPE 137777 presented at the SPE Latin American \& Caribbean Petroleum Engineering Conference, Lima, Peru, 1-3 December. http://dx.doi.org/10.2118/137777-MS.

Smith, R.C.1984. Successful Primary Cementing Can Be a Reality. JPT 36 (11): 18511858. SPE 13498-PA. http://dx.doi.org/10.2118/13498-PA.

Sousa, R. and Einstein, H.H. 2007. Risk Analysis for Tunneling Projects Using Bayesian Networks. Paper presented at the $11^{\text {th }}$ Congress of the International Society for Rock Mechanics, Lisbon, Portugal. ISBN 979-0-415-45084-3. 
Stoner, M.S. 2003. Fuzzy Logic for Directional Steering. Harts E\&P, http://www.makinhole.com/images/PDF/FuzzyLogic4DirectionalSteering.pdf (downloaded 20 April 2012).

Wright, S. 1921. Correlation and Causation. Journal of Agricultural Research 20: 557585.

Wright, S. 1934. The Method of Path Coefficients. Annals of Mathematical Statistics 5 (3): 161-215.

Zerafat, M.M., Ayatollahi, S., Mehranbod, N., and Barzegari, D. 2011. Bayesian Network Analysis as a Tool for Efficient EOR Screening. Paper SPE 143282 presented at the SPE Enhanced Oil Recovery Conference, Kuala Lumpur, Malaysia, 19-21 July. http://dx.doi.org/10.2118/143282-MS. 


\section{VITA}

Name: $\quad$ Abdullah Saleh H. Alyami

Address: $\quad$ Saudi ARAMCO, 9734 Dhahran, 31311, Saudi Arabia

Email Address: abdullah.yami@aramcoservices.com

Education: $\quad$ B.S., Chemistry, Florida Institute of Technology, Florida, 1998

M.S., Petroleum Engineering, King Fahd University of Petroleum \& Minerals, Dhahran, Saudi Arabia. June, 2007

Ph.D., Petroleum Engineering, Texas A\&M University, College

Station, Texas, August 2012 